\title{
Modelos para a dinâmica da dengue com infecção sequencial e inclusão de estratégias de vacinação por vacina tetravalente
}

\author{
Larissa Marques Sartori
}

TESE APRESENTADA

$\mathrm{AO}$

Instituto DE MATEMÁticA E Estatística

DA

UniversidADE DE SÃo PAUlo

PARA

OBTENÇÃO DO TÍTULO

$\mathrm{DE}$

DOUTOR EM CIÊNCIAS

Programa: Matemática Aplicada

Orientadora: Prof ${ }^{\mathrm{a}}$. Dr ${ }^{\mathrm{a}}$. Joyce da Silva Bevilacqua

O presente trabalho foi realizado com apoio da Coordenação de Aperfeiçoamento de Pessoal de Nível Superior - Brasil (CAPES) - Código de Financiamento 001

São Paulo, Novembro de 2018 


\title{
Modelos para a dinâmica da dengue com infecção sequencial e inclusão de estratégias de vacinação por vacina tetravalente
}

\begin{abstract}
Esta versão da tese contém as correções e alterações sugeridas pela Comissão Julgadora durante a defesa da versão original do trabalho, realizada em 21/09/2018. Uma cópia da versão original está disponível no Instituto de Matemática e Estatística da Universidade de São Paulo.
\end{abstract}

Comissão Julgadora:

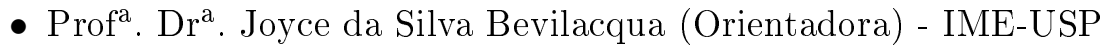

- Prof. Dr. Sergio Muniz Oliva Filho - IME-USP

- Prof. Dr. Eduardo Massad - FGV-RJ

- Prof. Dr. Marcelo Nascimento Burattini - FM-USP

- Prof. Dr. Marcos Amaku - FM-USP 


\section{Agradecimentos}

Esta tese foi elaborada com a ajuda de diversas pessoas que colaboraram de forma direta ou indireta. Agradeço à minha família: Zilda, Paulino, Iuri e Amanda, por terem superado a distância e por sempre me darem força para que eu alcance meus objetivos. E ao Martijn que me fez sorrir até nos momentos mais difíceis, sempre presente mesmo distante.

Os objetivos da tese foram alcançados graças à $\mathrm{Dr}^{\mathrm{a}}$. Joyce $\mathrm{S}$. Bevilacqua, que me orientou e me apoiou ao longo desses anos, que fez o trabalho de extração dos dados necessários para a tese, e que me permitiu divergir e seguir minha intuição em diversas fases da pesquisa; à Dra ${ }^{\mathrm{a}}$. Gabriela Gomes pela orientação no doutorado sanduíche, e que foi de fundamental importância para as direções do trabalho; ao Dr. Sergio M. Oliva que desde o mestrado apoiou minha trajetória acadêmica, e esteve sempre aberto para discutir tópicos da pesquisa, e pela oportunidade do doutorado no exterior.

O grupo de epidemiologia matemática foi de essencial contribuição. Agradeço aos queridos professores Dr. Pedro Peixoto, Dr ${ }^{\mathrm{a}}$. Claudia Peixoto e Dr. Nelson Kuhl que colaboram com a pesquisa de todos mestrandos e doutorandos do grupo, e a esses colegas que estão igualmente apreendendo e trocando conhecimento. E ao Dr. Pedro Peixoto pela administração do Lab-MAP.

Agradeço ao Dr. Ricardo Palácios, pelas discussões e contribuições com informações epidemiológicas, e aos pesquisadores Dr. Eduardo Massad, Dr. Flávio Coelho e Dr. Marcelo Burattini que participaram de algumas reuniões e compartilharam informações importantes sobre a modelagem de doenças infecciosas. Igualmente, agradeço ao Dr. Caetano Souto-Maior, pela ajuda na compreensão de tópicos em epidemiologia, e ao Dr. Duván Cataño e Eduardo Edamatsu pela ajuda com tópicos de estatística e de programação em R.

Em adição, também agradeço ao Dr. Sergio M. Oliva, ao Dr. Marcos Amaku, ao Dr. Eduardo Massad, e ao Dr. Marcelo Burattini, por aceitarem o convite para participar da Comissão Julgadora, pela leitura e pelas sugestões para o trabalho.

Agradeço aos professores: Dr. Saulo Rabello M. de Barros (orientador de mestrado), e ao Dr. Jaime E. A. Rodriguez (orientador de iniciação científica), que foram extremamente importantes no meu desenvolvimento como professora e pesquisadora. E à todos professores da UNESP-Ilha Solteira e do IME-USP que ensinam matemática com entusiasmo.

Meu carinho e obrigada às pessoas que conheci ao longo desses anos e que se tornaram muito importantes em minha vida: à Sra. Irene e Sr. Eurico (in memoriam), que me receberam e foram minha família em São Paulo. À Valéria, André, Diego e Waltraud Boxall que foram minha família em Liverpool. Às amigas que conheci durante o período de estudos na Inglaterra e cuja amizade continua mesmo à distância; Vanessa, Edith, Carina e Stefany. 
Com igual carinho, agradeço aos amigos da minha cidade natal que torceram e se alegraram com minhas vitórias, em especial à Joice, Hannah e Juliana, aos amigos da UNESP, às meninas do MAP e colegas do Lab-MAP, em geral, à todos aqueles que conheci ao longo desses anos em São Paulo e que fizeram parte dos meus momentos de descontração dentro e fora da USP, tornando a caminhada mais leve, alguns nomes: Lilian, Diego C., Ana, Francielle, Patrícia e Fabrício Leal, Patrícia A., Bruna, Laura, Simone, Belmiro, Duván, Marcelo, Jeovanny, Pollyanna, Jerusa, Vanessa, Sandra, Benigno, Arcelino, Leonardo, Luana, Leandro, Clayton, Cristiane A., Vinícius ...

Agradeço à todos funcionários que fazem com que o IME seja um ótimo ambiente de trabalho, funcionando da melhor forma possível: as funcionárias do café, os funcionários das secretarias, da CPG e do MAP, os funcionários da Seção de Informática, funcionários da gráfica, funcionários da segurança e da limpeza. E aos funcionários dos restaurantes universitários.

Em especial sou grata à CAPES, pelo suporte financeiro durante o mestrado e doutorado, assim como ao projeto Ciência sem Fronteiras da CAPES, 88887.117813/2016-00 - CSF-PVE-S, pelo suporte durante o período de Doutorado no exterior. À Universidade de São Paulo por todas as oportunidades, e à Liverpool School of Tropical Medicine - LSTM, Reino Unido, por ter me recebido para o doutorado sanduíche.

São Paulo, Novembro de 2018

Larissa Marques Sartori 


\title{
Resumo
}

\author{
SARTORI, L. M. Modelos para a dinâmica da dengue com infecção sequencial e inclusão \\ de estratégias de vacinação por vacina tetravalente. 2018. 132 f. Tese (Doutorado) - Instituto \\ de Matemática e Estatística, Universidade de São Paulo, São Paulo, 2018.
}

A modelagem epidemiológica é uma importante ferramenta que auxilia os órgãos de saúde no controle de doenças infecciosas, pois permitem analisar e comparar diversas estratégias que facilitam a tomada de decisões e definições de protocolos. A dengue é atualmente a doença viral humana com maior número de casos. Possui índice de mortalidade baixo, entretanto, é endêmica em mais de 100 países e $40 \%$ da população mundial está em risco de contrair a infecção. Através dos dados de notificação de dengue no Brasil, evidenciamos que os surtos são sazonais, que há alternância de sorotipos ao longo dos anos e mostramos que a doença é diferente em cada localização, e que somente com uma normalização adequada é possível sugerir um agrupamento coerente de municípios. Neste trabalho, as informações obtidas a partir dos dados são usadas para a estruturação dos modelos matemáticos e para a estimação de parâmetros que validam estes modelos. Comparamos a dinâmica de transmissão de dengue do modelo com um sorotipo, com modelos que permitem a interação de dois, três e quatro sorotipos simultaneamente, além da possibilidade de até quatro infecções sequenciais. Os modelos com múltiplos sorotipos são expandidos do modelo básico que categoriza hospedeiros dentro de uma população como suscetíveis (S), infectados (I) e recuperados $(\mathrm{R})$ e acoplado à dinâmica dos vetores suscetíveis $(\mathrm{V})$ e infectados $\left(\mathrm{V}_{i}\right)$. Nossos modelos incluem: um período de imunidade cruzada de forma que o indivíduo adquire imunidade permanente para o sorotipo que já foi infectado e imunidade temporária para os demais; uma forçante de sazonalidade na taxa de nascimento dos vetores; uma assimetria com taxas de transmissão diferentes para cada sorotipo; e o compartimento dos vacinados, com uma vacina tetravalente que confere diferentes imunidades para cada sorotipo. Os resultados mostram que para a reprodução de surtos anuais é necessário a inclusão da forçante de sazonalidade na taxa de nascimento dos vetores, e que o modelo com quatro sorotipos é o que melhor reproduz os dados de incidência de dengue, sendo o mais adequado para analisar estratégias de vacinação com uma vacina tetravalente. Comparamos duas estratégias de vacinação: vacinação aleatória na população e vacinação direcionada para faixas etárias. Neste caso, os resultados demonstram a superioridade da estratégia direcionada e que as escolhas das faixas etárias devem ser definidas por município e não por um protocolo nacional.

Palavras-chave: Modelagem epidemiológica, dengue, múltiplos sorotipos, infecção sequencial, vacina tetravalente, estimação de parâmetros. 


\section{Abstract}

SARTORI, L. M. Models for the dynamics of dengue with sequential infection and inclusion of vaccination strategies by tetravalent vaccine. 2018. $132 \mathrm{f}$. Tese (Doutorado) Instituto de Matemática e Estatística, Universidade de São Paulo, São Paulo, 2018.

Epidemiological modelling is an important tool that assists the health agencies in the control of infectious diseases, since it allows analysing and to compare several strategies that facilitate decisionmaking and protocol definitions. Dengue is currently the most important vector-borne disease. The mortality rate of dengue is low, however, it is endemic in more than 100 countries and about $40 \%$ of the world's population is at risk of contracting the infection. Through the dengue notification data in Brazil, we emphasize that the outbreaks are seasonal, there is serotypes alternation over the years and we show that the disease is different in each locality, and that only with a suitable standardization it is possible to propose an appropriate grouping of municipalities. In this work, we use the data information to formulate the mathematical models and for the parameter's estimation in order to validate these models. We compare the dynamics of dengue of the one serotype model with the models that allow interaction of two, three and four serotypes simultaneously, including the possibility of at most four sequential infections. The multi-strain models are expanded from the basic model which categorizes the host population as susceptible (S), infected (I), and recovered $(\mathrm{R})$ and coupled with the dynamics of the susceptible $(\mathrm{V})$ and infected $\left(\mathrm{V}_{i}\right)$ vectors. Our models include: a period of cross-immunity which means permanent immunity to the serotype of the infection and temporary immunity to the other serotypes; a seasonal forcing in the mosquitoes birth rate; different transmissions rates, so that the models are asymmetric; and the compartment of vaccinated individuals with a tetravalent vaccine which confers different immunities for each serotype. The results show that to reproduce yearly outbreaks it is necessary to include the seasonal forcing in the birth rate of the vectors, and that the four serotypes model is the one that best reproduces the dengue incidence data, being the most suitable model to analyse vaccination strategies with a tetravalent vaccine. We compare two vaccination strategies: random vaccination and vaccination targeted at age groups. In this case, the results demonstrate the superiority of the targeted strategy and that the choices of the age groups should be defined by municipality and not by a national protocol.

Keywords: Epidemiological modelling, dengue, multi-strain, sequential infection, tetravalent vaccine, parameter estimation. 


\section{Sumário}

$\begin{array}{ll}\text { Lista de Símbolos } & \text { ix }\end{array}$

Lista de Figuras

Lista de Tabelas $\quad$ xv

Introdução $\quad$ xvii

1 Estudo da dengue no Brasil $\quad 1$

1.1 Materiais . . . . . . . . . . . . . . . . . . . . 1

1.1.1 Dados populacionais . . . . . . . . . . . . . . . . 2

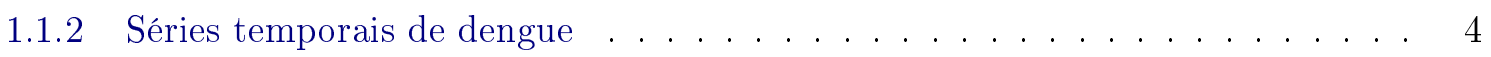

1.1.3 Sazonalidade . . . . . . . . . . . . . . . . . . . . 5

1.1.4 Sorotipos de dengue . . . . . . . . . . . . . . . . . 6

1.1.5 Notificações por faixas etárias . . . . . . . . . . . . . . . . . 7

1.2 Normalizações. . . . . . . . . . . . . . . . . . . . 8

1.3 Correlação . . . . . . . . . . . . . . . . . . . . . . . . . . . 12

1.3.1 Correlação e vacina . . . . . . . . . . . . . . . . . . . . 15

1.3 .2 Correlação e mobilidade . . . . . . . . . . . . . . . . . . . . 18

2 Modelagem da dengue $\quad 19$

2.1 Hipóteses e parâmetros dos modelos . . . . . . . . . . . . . . . . 20

2.1 .1 Modelo básico . . . . . . . . . . . . . . . . . . . . . 22

2.1 .2 Modelos com múltiplos sorotipos . . . . . . . . . . . . . 23

2.2 Modelos com múltiplos sorotipos e vacinação . . . . . . . . . . . . . . . . . . 27

2.2 .1 Vacinação aleatória na população . . . . . . . . . . . . . . . . 28

2.2.2 Vacinação direcionada para faixas etárias . . . . . . . . . . . . . . . . 30

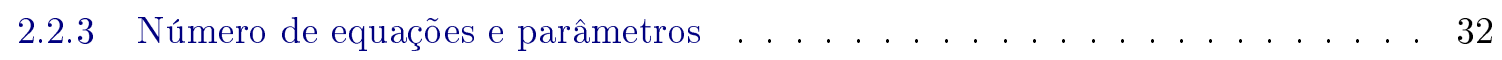

2.3 Estudo qualitativo dos modelos . . . . . . . . . . . . . . . . 33

2.3 .1 Número básico de reprodução $R_{0} \ldots \ldots \ldots \ldots \ldots \ldots \ldots$

2.3 .2 Equilíbrios . . . . . . . . . . . . . . . . . 36

2.3 .3 Estabilidade . . . . . . . . . . . . . . . . . . . . 39

2.4 Estimação de parâmetros . . . . . . . . . . . . . . . . . . 40

2.4 .1 Métodos de estimação . . . . . . . . . . . . . . . . . . . . . . . . . . . . .

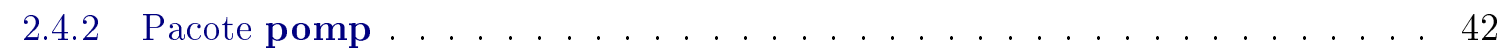

2.4 .3 Aplicação do algoritmo . . . . . . . . . . . . . . . . 42 
3 Resultados numéricos

3.1 Modelos com e sem sazonalidade . . . . . . . . . . . . . . . . . . 45

3.1 .1 Estabilidade numérica . . . . . . . . . . . . . . . . . 47

3.2 Ajuste dos modelos aos dados . . . . . . . . . . . . . . . . . 52

3.2 .1 Modelos com múltiplos sorotipos . . . . . . . . . . . . . . . 54

3.2.2 Modelos com múltiplos sorotipos compartimentados por faixa etária . . . . . 57

3.3 Projeções com os modelos . . . . . . . . . . . . . . . . . . . . . . 60

3.3.1 Modelos com múltiplos sorotipos . . . . . . . . . . . . . . . 61

3.3.2 Modelos com múltiplos sorotipos compartimentados por faixa etária . . . . . 65

3.4 Cenários de vacinação com os modelos . . . . . . . . . . . . . . . . . . 69

3.4.1 Vacinação aleatória na população . . . . . . . . . . . . . . 71

3.4 .2 Vacinação direcionada para faixas etárias . . . . . . . . . . . . 75

3.4.3 Coberturas de vacinação . . . . . . . . . . . . . . . . . . . . . . 79

4 Conclusões $\quad 81$

$\begin{array}{ll}\text { A Teoria epidemiológica elementar } & 83\end{array}$

A.1 Modelagem matemática . . . . . . . . . . . . . . . . . . 83

A.1.1 Modelo sem demografia . . . . . . . . . . . . . . . . . . 84

A.1.2 Modelo com demografia . . . . . . . . . . . . . . . . . . . 84

A.1.3 Modelo com vacinação . . . . . . . . . . . . . . . . . 86

A.2 Número básico de reprodução e equilíbrios do sistema . . . . . . . . . . . . . 88

A.2.1 Cálculo do $R_{0} \ldots \ldots \ldots \ldots \ldots \ldots \ldots$

A.2.2 Estabilidade e equilíbrios do sistema . . . . . . . . . . . . . 91

B Resultados complementares $\quad 93$

B.0.3 Resultados Rio de Janeiro . . . . . . . . . . . . . . . . . . . . . . . . . . . 94

B.0.4 Resultados Salvador . . . . . . . . . . . . . . . . . . . . . 95

B.0.5 Projeções e vacinação para Rio de Janeiro . . . . . . . . . . . . . . . . . . 96

B.0.6 Projeções e vacinação para Salvador . . . . . . . . . . . . . . . . . . 97

$\begin{array}{ll}\text { Referências Bibliográficas } & 99\end{array}$ 


\section{Lista de Símbolos}

$d X / d t \quad$ Derivada de $X$ em relação a $t$ (Derivative of $X$ with respect to $t$ )

$\mathrm{S} \quad$ Humanos suscetíveis soronegativos (Susceptible seronegative humans)

$\mathrm{S}_{i j k} \quad$ Humanos suscetíveis soropositivos com imunidade para os sorotipos $i, j$ e $k$

(Susceptible seropositive humans and immune to the serotypes $i, j$ and $k$ )

I Humanos infectados (Infected humans)

$\mathrm{I}_{i j k l} \quad$ Humanos infectados sequencialmente pelos sorotipos $i, j, k$ e $l$

(Humans sequentially infected by the serotypes $i, j, k$ and $l$ )

$\mathrm{R} \quad$ Humanos recuperados de todas infecções (Humans recovered from all infections)

$\mathrm{R}_{i j k} \quad$ Humanos recuperados da infecção pelos sorotipos $i, j$ e $k$

(Human recovered from infections by the serotypes $i, j$ and $k$ )

$\mathrm{V} \quad$ Vetores suscetíveis (Susceptible vectors)

$\mathrm{V}_{i} \quad$ Vetores infectados com o sorotipo $i$ (Vectors infected by the serotype $i$ )

$\mathrm{S}_{Z} \quad$ Humanos suscetíveis soronegativos no grupo etário $\mathrm{Z}$

(Susceptible seronegative humans in the age group Z)

$\mathrm{I}_{Z} \quad$ Humanos infectados no grupo etário $\mathrm{Z}$ (Infected humans in the age group $Z$ )

$\mathrm{N}_{h} \quad$ População total de humanos (Total human population)

$\mathrm{N}_{m} \quad$ População total de mosquitos (Total mosquitoes population)

$\mu_{h} \quad$ Taxa de mortalidade natural dos humanos (Natural mortality rate of humans)

$\mu_{m} \quad$ Taxa de mortalidade natural dos mosquitos (Natural mortality rate of mosquitoes)

$\gamma \quad$ Taxa de recuperação para humanos (Recovery rate of humans)

$\beta_{i} \quad$ Taxa de transmissão de vetor infectado com sorotipo $i$ para humanos suscetíveis

(Transmission rate from infected vectors with serotype $i$ to susceptible humans)

$\Omega_{i} \quad$ Taxa de transmissão de humano infectado com sorotipo $i$ para vetores suscetíveis

(Transmission rate from infected human with serotype $i$ to susceptible vectors)

$\varphi \quad$ Taxa de imunidade cruzada temporária (Temporary cross-immunity rate)

$\psi_{S} \quad$ Proporção de suscetíveis vacinados (Proportion of susceptible vaccinated)

$\sigma \quad$ Taxa de infeç̧ão em indivíduos vacinados (Infection rate in vaccinated individuals)

a Taxa de transição de faixa etária (Age range transition rate) 


\section{Lista de Figuras}

1.1 Distribuição da população brasileira por faixas etárias no ano de 2010, Censo 2010. . 3

1.2 Incidência de dengue por 100000 habitantes em 12 capitais brasileiras da $1^{\mathrm{a}}$ semana de 2008 à $35^{\mathrm{a}}$ semana de 2014 . . . . . . . . . . . . . . . . . . . . . . 4

1.3 Incidência de dengue em capitais brasileiras nos anos 2011, 2012 e 2013 . . . . . . . . 5

1.4 Incidência de dengue no Brasil por sorotipos, período de 2008 a 2014 . . . . . . . . . 6

1.5 Notificações de casos de dengue registrados no Brasil no ano de 2010, por faixas etárias e por regiões. . . . . . . . . . . . . . . . . . . 7

1.6 Incidência de dengue por faixas etárias com a normalização $N 1$, Brasil todo e regiões, ano de $2010 \ldots \ldots \ldots \ldots \ldots \ldots \ldots$

1.7 Incidência de dengue por faixas etárias com a normalização $N 2$, Brasil todo e regiões, ano de $2010 \ldots \ldots \ldots \ldots$. . . . . . . . . . . . . . . . . 10

1.8 Incidência de dengue por faixas etárias com a normalização $N 3$, Brasil todo e regiões, ano de $2010 \ldots \ldots \ldots \ldots \ldots \ldots \ldots$

1.9 Estados que não puderam ser agrupados segundo correlação $\geq 0.90$ nos dados de incidência de dengue do ano de 2010, separados por faixa etária e calculados com a

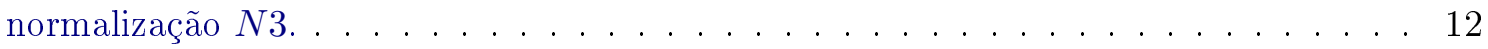

1.10 Agrupamento de estados que apresentam correlação $\geq 0.90$ entre si nos dados de incidência de dengue do ano de 2010, separados por faixa etária e calculados com a normalização $N 3 \ldots \ldots \ldots \ldots \ldots \ldots \ldots \ldots \ldots \ldots$

1.11 Agrupamento das cidades teste da vacina que apresentaram alta correlação nos dados de incidência por faixa etária. . . . . . . . . . . . . . . . . . . . 16

1.12 Incidência de dengue em cidades do estado do Rio de Janeiro, ano de 2008. . . . . 18

2.1 Dinâmica de transmissão de dengue em um modelo com um sorotipo, humanos suscetíveis, infectados e recuperados (SIR), e vetores suscetíveis e infectados $\left(\mathrm{VV}_{i}\right)$. . . 22

2.2 Dinâmica de transmissão de dengue em um modelo com dois sorotipos, $2 \times$ SIR para humanos e $\mathrm{VV}_{i}$ para vetores. . . . . . . . . . . . . . . . . . 23

2.3 Dinâmica de transmissão de dengue em um modelo com quatro sorotipos, $4 \times \mathrm{SIR}$

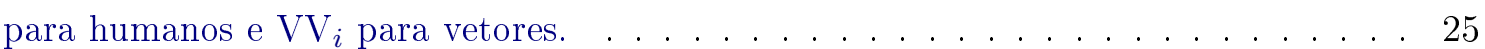

2.4 Dinâmica de transmissão de dengue em um modelo com dois sorotipos, $2 \times$ SIR para humanos e $\mathrm{VV}_{i}$ para vetores, e compartimento dos vacinados $\mathrm{H}_{V} \ldots \ldots \ldots$. . . . 28

2.5 Dinâmica de transmissão de dengue em um modelo com dois sorotipos compartimentado por faixas etárias, $2 \times \mathrm{SIR}_{A, b}$ para humanos e $\mathrm{VV}_{i}$ para vetores, e compartimento

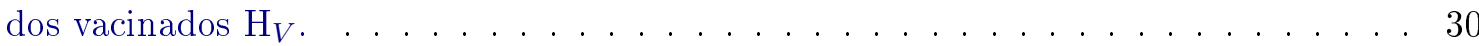


2.6 Esquematização do algoritmo de estimação de parâmetros pomp aplicado para o

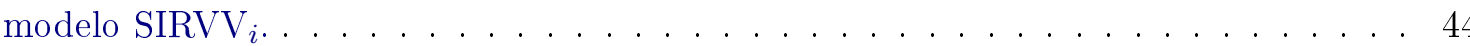

3.1 Comparação do modelo com 1 sorotipo $\left(\operatorname{SIRVV}_{i}\right)$, sem forçante de sazonalidade (figura da esquerda) e com forçante de sazonalidade (figura da direita) na taxa de nascimento dos mosquitos. . . . . . . . . . . . . . . . .

3.2 Comparação do modelo com 2 sorotipos $\left(2 \times \mathrm{SIRVV}_{i}\right)$, sem forçante de sazonalidade (figura da esquerda) e com forçante de sazonalidade (figura da direita) na taxa de nascimento dos mosquitos. . . . . . . . . . . . . . . . . . .

3.3 Comparação do modelo com 3 sorotipos $\left(3 \times \mathrm{SIRVV}_{i}\right)$, sem forçante de sazonalidade (figura da esquerda) e com forçante de sazonalidade (figura da direita) na taxa de nascimento dos mosquitos. . . . . . . . . . . . . . . . . .

3.4 Comparação do modelo com 4 sorotipos $\left(4 \times \mathrm{SIRVV}_{i}\right)$, sem forçante de sazonalidade (figura da esquerda) e com forçante de sazonalidade (figura da direita) na taxa de nascimento dos mosquitos. . . . . . . . . . . . . . . . . .

3.5 Autovalores nos equilíbrios livre de doença de cada modelo. Gráficos da esquerda para o caso $R_{0}<1$ e gráficos da direita para o caso $R_{0}>1 \ldots \ldots$. . . . 47

3.6 Séries temporais do modelo com 1 sorotipo sem sazonalidade (figura esquerda) e com sazonalidade (figura direita) . . . . . . . . . . . . . . . . 48

3.7 Retrato de fase para o modelo com 1 sorotipo sem e com sazonalidade. . . . . . . . . 48

3.8 Autovalores da matriz jacobiana no equilíbrio endêmico do modelo com 1 sorotipo

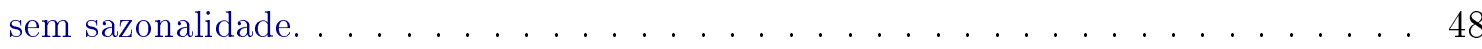

3.9 Séries temporais do modelo com 2 sorotipos sem sazonalidade (figura esquerda) e com sazonalidade (figura direita) . . . . . . . . . . . . . . . . . 49

3.10 Retrato de fase para o modelo com 2 sorotipos sem e com sazonalidade. . . . . . . . 49

3.11 Séries temporais do modelo com 3 sorotipos sem sazonalidade (figura esquerda) e com sazonalidade (figura direita) . . . . . . . . . . . . . . . . 50

3.12 Retrato de fase para o modelo com 3 sorotipos sem e com sazonalidade. . . . . . . . 50

3.13 Séries temporais do modelo com 4 sorotipos sem sazonalidade (figura esquerda) e com sazonalidade (figura direita) . . . . . . . . . . . . . . 51

3.14 Retrato de fase para o modelo com 4 sorotipos sem e com sazonalidade. . . . . . . 51

3.15 Séries temporais de cidades brasileiras em que estão sendo testadas a vacina e que serão usadas para estimação de parâmetros. . . . . . . . . . . . . . . . . 53

3.16 Ajuste dos modelos aos dados de incidência de cidades brasileiras, da $1^{\mathrm{a}}$ semana de 2011 a $35^{\mathrm{a}}$ semana de 2014 . . . . . . . . . . . . . . . . . . . . . 54

3.17 Ajuste dos modelos compartimentados por faixa etária aos dados de incidência de cidades brasileiras, da $1^{\mathrm{a}}$ semana de 2011 a $35^{\mathrm{a}}$ semana de $2014 \ldots$. . . . . . . . . . 57

3.18 Projeção dos modelos com os parâmetros estimados dos dados de incidência de dengue de Aracaju. . . . . . . . . . . . . . . . . . . . . . . . . 61

3.19 Projeção dos modelos com os parâmetros estimados dos dados de incidência de dengue de Brasília. . . . . . . . . . . . . . . . . . . . .

3.20 Projeção dos modelos com os parâmetros estimados dos dados de incidência de dengue de Fortaleza. . . . . . . . . . . . . . . . . . . . . . . . . . . . . 
3.21 Projeção dos modelos com os parâmetros estimados dos dados de incidência de dengue de São Paulo. . . . . . . . . . . . . . . . . . . . . . . . . . . . . . 64

3.22 Projeção dos modelos compartimentados por faixa etária com os parâmetros estimados dos dados de incidência de dengue de Aracaju. . . . . . . . . . . . . . . . . . 65

3.23 Projeção dos modelos compartimentados por faixa etária com os parâmetros estimados dos dados de incidência de dengue de Brasília. . . . . . . . . . . . . . . . . 66

3.24 Projeção dos modelos compartimentados por faixa etária com os parâmetros estimados dos dados de incidência de dengue de Fortaleza. . . . . . . . . . . . . . . . . . . 67

3.25 Projeção dos modelos compartimentados por faixa etária com os parâmetros estimados dos dados de incidência de dengue de São Paulo. . . . . . . . . . . . . . . . . . . . 68

3.26 Vacinação aleatória na população nos modelos com múltiplos sorotipos e dados de Aracaju. ........................... . 71

3.27 Vacinação aleatória na população nos modelos com múltiplos sorotipos e dados de Brasília. . . . . . . . . . . . . . . . . . . . . . . . . 72

3.28 Vacinação aleatória na população nos modelos com múltiplos sorotipos e dados de Fortaleza. ............................ 73

3.29 Vacinação aleatória na população nos modelos com múltiplos sorotipos e dados de São Paulo. . . . . . . . . . . . . . . . . . . . . . . . . . 74

3.30 Vacinação direcionada para faixas etárias nos modelos com múltiplos sorotipos compartimentados e dados de Aracaju. . . . . . . . . . . . . . . . . . . . . . . . . 75

3.31 Vacinação direcionada para faixas etárias nos modelos com múltiplos sorotipos compartimentados e dados de Brasília. . . . . . . . . . . . . . . . . . . . . . 76

3.32 Vacinação direcionada para faixas etárias nos modelos com múltiplos sorotipos compartimentados e dados de Fortaleza. . . . . . . . . . . . . . . . . . . . . . . . . 77

3.33 Vacinação direcionada para faixas etárias nos modelos com múltiplos sorotipos compartimentados e dados de São Paulo. . . . . . . . . . . . . . . . . . . . . . 78

3.34 Comparação diferentes coberturas de vacinação na população aplicada para a cidade de São Paulo. . . . . . . . . . . . . . . . . . . . . . . . . 79

A.1 Esquema do fluxo de indivíduos entre os compartimentos dos suscetíveis S, infectados I e recurados $\mathrm{R}$ no modelo sem demografia. . . . . . . . . . . . . . . . . . . . . . 84

A.2 Esquema do fluxo de indivíduos entre os compartimentos dos suscetíveis S, infectados I e recurados $\mathrm{R}$ no modelo com demografia. . . . . . . . . . . . . . . . . . . . 85

A.3 Esquema do fluxo de indivíduos entre os compartimentos $\mathrm{S}, \mathrm{H}_{V}$, I e R. Vacina em recém-nascidos. . . . . . . . . . . . . . . . . . . . . . . . . 86

A.4 Esquema do fluxo de indivíduos entre os compartimentos $\mathrm{S}, \mathrm{I}, \mathrm{R}$ e $\mathrm{H}_{V}$. Vacinação aleatória da população. . . . . . . . . . . . . . . . . . . . . . . . . . . . 87

A.5 Incidência em função do $R_{0}$ calculada com o modelo SIR com demografia. . . . . . . 89

B.1 Ajuste dos modelos aos dados de dengue da cidade do Rio de Janeiro. . . . . . . . . . 94

B.2 Ajuste dos modelos aos dados de dengue da cidade de Salvador. . . . . . . . . . . . . 95

B.3 Projeção dos modelos e simulação de vacinação aleatória na população com os parâmetros estimados dos dados de incidência de dengue do Rio de Janeiro. . . . . . . . . 96 
B.4 Projeção dos modelos e simulação de vacinação aleatória na população com os parâmetros estimados dos dados de incidência de dengue de Salvador. . . . . . . . . . . 97 


\section{Lista de Tabelas}

1.1 População total do Brasil e por regiões no período de 2008 à 2013, Censo de 2010.

1.2 Expectativa de vida da população brasileira total e por regiões no período de 2008 à 2013, Censo de 2010. . . . . . . . . . . . . . . . . . . . . . . 2

1.3 Resultado de aplicar a Normalização $N 1$ nos dados de notificação de dengue, ano de

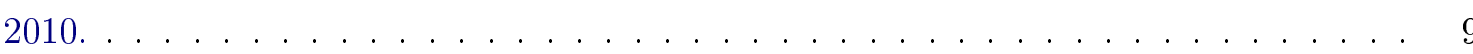

1.4 Resultado de aplicar a Normalização N2 nos dados de notificação de dengue, ano de $2010 \ldots \ldots \ldots \ldots \ldots \ldots \ldots$

1.5 Resultado de aplicar a Normalização N3 nos dados de notificação de dengue, ano de

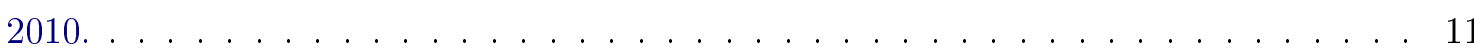

1.6 Correlação entre os dados de incidência de dengue do ano de 2010, de todos estados brasileiros normalizados com $N 3 \ldots \ldots \ldots \ldots \ldots \ldots \ldots$

1.7 Correlação entre as incidências por faixa etária, normalizadas com $N 3$, de 12 cidades em que estão sendo testada a vacina. . . . . . . . . . . . . . . . 17

2.1 Listas de parâmetros conhecidos e parâmetros a serem estimados para cada modelo. $\quad 32$

3.1 Parâmetros globais que são mantidos fixos em todos os modelos. . . . . . . . . . . . 52

3.2 População total e separada em grupos etários para as cidades: Aracaju, Brasília, Fortaleza e São Paulo, Censo de 2010 . . . . . . . . . . . . . . . . . 53

3.3 Parâmetros encontrados para ajustar os modelos aos casos de dengue notificados na cidade de Aracaju, da $1^{\mathrm{a}}$ semana de 2011 à $35^{\mathrm{a}}$ semana 2014 . . . . . . . . . . . 55

3.4 Parâmetros encontrados para ajustar os modelos aos casos de dengue notificados na cidade de Brasília, da $1^{\mathrm{a}}$ semana de 2011 à $35^{\mathrm{a}}$ semana 2014 . . . . . . . . . . . 55

3.5 Parâmetros encontrados para ajustar os modelos aos casos de dengue notificados na cidade de Fortaleza, da $1^{\mathrm{a}}$ semana de 2011 à $35^{\mathrm{a}}$ semana $2014 \ldots$. . . . . . . . . . 56

3.6 Parâmetros encontrados para ajustar os modelos aos casos de dengue notificados na cidade de São Paulo, da $1^{\mathrm{a}}$ semana de 2011 à $35^{\mathrm{a}}$ semana 2014 . . . . . . . . . . . 56

3.7 Parâmetros encontrados para ajustar os modelos compartimentados em duas faixas etárias $A$ e $B$ aos casos de dengue notificados na cidade de Aracaju, da $1^{\text {a }}$ semana

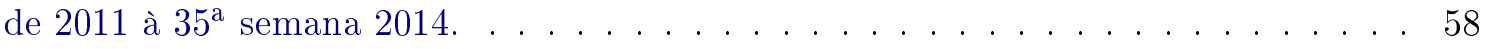

3.8 Parâmetros encontrados para ajustar os modelos compartimentados em duas faixas etárias $A$ e $B$ aos casos de dengue notificados na cidade de Brasília, da $1^{\text {a }}$ semana de 2011 à $35^{\mathrm{a}}$ semana $2014 \ldots \ldots \ldots \ldots \ldots \ldots$ 
3.9 Parâmetros encontrados para ajustar os modelos compartimentados em duas faixas etárias $A$ e $B$ aos casos de dengue notificados na cidade de Fortaleza, da $1^{\mathrm{a}}$ semana de 2011 à $35^{\text {a }}$ semana 2014 . . . . . . . . . . . . . . . . . . . . . . . . . 59

3.10 Parâmetros encontrados para ajustar os modelos compartimentados em duas faixas etárias $A$ e $B$ aos casos de dengue notificados na cidade de São Paulo, da $1^{\text {a }}$ semana de 2011 à $35^{\mathrm{a}}$ semana 2014 . . . . . . . . . . . . . . . . . . . . . . . . . 59

3.11 Proporção $\psi$ a ser vacinada aleatoriamente na população. . . . . . . . . . . . . . . 70

3.12 Proporção $\psi$ a ser vacinada no grupo etário com maior número de casos. . . . . . . . 70

3.13 Proporção $\psi$ a ser vacinada aleatoriamente na população de São Paulo. . . . . . . . . 79

B.1 Parâmetros globais que são mantidos fixos em todos os modelos. . . . . . . . . . . . 93

B.2 População total das cidades: Rio de Janeiro e Salvador, Censo de 2010 . . . . . . . . . 93

B.3 Parâmetros encontrados para ajustar os casos de dengue notificados na cidade do Rio de Janeiro, da $1^{\mathrm{a}}$ semana de 2008 à $35^{\mathrm{a}}$ semana 2014 . . . . . . . . . . . . . . . . 94

B.4 Parâmetros encontrados para ajustar os casos de dengue notificados na cidade de Salvador, da $1^{\mathrm{a}}$ semana de 2008 à $35^{\mathrm{a}}$ semana $2014 \ldots \ldots \ldots$. . . . . . . . . . 95

B.5 Proporção $\psi$ a ser vacinada aleatoriamente na população do Rio de Janeiro. . . . . . 96

B.6 Proporção $\psi$ a ser vacinada aleatoriamente na população de Salvador. . . . . . . . . 97 


\section{Introdução}

A história da humanidade é marcada por doenças que dizimaram populações, como a Peste Negra que no século XIV foi responsável por mais de 20 milhões de mortes, e a Varíola e Sarampo que causaram 2.6 milhões de mortes por ano na década de 1980. O esforço de órgãos de saúde fez com que várias dessas doenças fossem controladas, salvando milhões de vidas e economizando milhões em gastos públicos (Hethcote, 2000; Keeling e Rohani, 2008; Ross, 1911). Os dados da Organização Mundial da Saúde (OMS) mostram que a eliminação da varíola e imunização contra Poliomelite economizam em torno de 3 bilhões de dólares por ano. Apesar disso, doenças infecciosas continuam sendo grande causa de sofrimento e mortalidade. As estatísticas mais recentes da OMS mostram que HIV, Malária, Tuberculose e Hepatite, infectaram em torno de 500 milhões de pessoas em 2015, sendo responsáveis por aproximadamente 4 milhões de mortes (1.1 milhões por HIV, 429 mil por Malária, 1.4 milhões por Tuberculose, e 1.3 milhões de mortes por Hepatite B e C). Outro número alarmante é que em torno de 1.6 bilhões de pessoas precisaram de tratamento, em massa ou individual, contra doenças tropicais em 2015 (World Health Organization, 2017).

Devido a mutação de patógenos que se adaptam e evoluem, novas doenças emergem e doenças já consideradas extintas reemergem também devido à falta de vacinação e saneamento básico, mudanças climáticas, etc (Liu-Helmersson et al., 2016). Como exemplo de doenças novas, ou recentemente identificadas, tem-se a doença de Lyme descoberta em 1975, nos Estados Unidos, diagnosticada pela primeira vez no Brasil em 1992; a doença dos Legionários descoberta em 1976, comum na América do Norte e Europa; o HIV/AIDS, atualmente vigente no mundo todo devido à transmissão sexual, observado clinicamente pela primeira vez nos Estados Unidos em 1981; Hepatite C em 1989, Hepatite E, 1990, o Hantavírus (1993) e a Chikungunya que só havia sido detectada na África, na Ásia Oriental e na Índia, e com casos confirmados no Brasil em 2014 (Nunes et al., 2015). Doenças como Tuberculose, pneumonia e gonorreia continuam evoluindo. Já a Malária, a Febre Amarela, a Zika e a Dengue, entram para o grupo das doenças reemergentes, as quais estão aparecendo em novas regiões e se propagam cada vez mais devido a diversos fatores (Dejnirattisai et al., 2016; Hethcote, 2000; Krämer et al., 2010; Liu-Helmersson et al., 2016; Ma e Xia, 2009; Martcheva, 2015; Teixeira et al., 2013; Villela et al., 2017; Wang et al., 2017).

A dengue é uma doença com poucas mortes registradas, porém é atualmente a doença viral humana com maior número de casos, sendo um arbovírus da família Flaviviridae, gênero Flavivírus, transmitida através da picada de mosquitos fêmeas do gênero Aedes infectadas com o vírus, os quais também são responsáveis pela transmissão do vírus Zika, Chikungunya e Febre Amarela (de Moura Rodrigues et al., 2015; Dejnirattisai et al., 2016; Gubler et al., 2014; Martcheva, 2015; Nunes et al., 2015; Villela et al., 2017; Wang et al., 2017). O vírus está presente em diversas regiões da América do Sul e Central, África, e Ásia, cujo clima favorece a proliferação dos vetores (Bhatt et al., 2013; Gubler et al., 2014; Nagao e Koelle, 2008; Nisalak et al., 2003; 
World Health Organization et al., 2009). Estima-se que a dengue é endêmica em mais de 100 países e que $40 \%$ da população mundial está em risco de contrair a doença (Teixeira et al., 2013). Até 2014, foram reportados mais de 1 milhão de casos nas Américas, aproximadamente 341000 destes foram confirmados laboratorialmente com 684 óbitos registrados por dengue (Fares et al., 2015).

De acordo com o Ministério da Saúde (MS), a recorrência de dengue no Brasil documentada clínica e laboratorialmente foi em 1981-1982 em Roraima e a primeira grande epidemia ocorreu em 1986 no Rio de Janeiro (Fares et al., 2015; Rodriguez-Barraquer et al., 2011; Teixeira et al., 2013). No período de 2000 à 2007 o Brasil foi responsável por mais de $60 \%$ dos casos de dengue reportados no mundo. Atualmente, os quatros sorotipos de dengue circulam no Brasil, denominados DENV-1, DENV-2, DENV-3 e DENV-4, nas cinco regiões: Norte, Nordeste, Sudeste, Centro-Oeste e Sul (Precioso et al., 2015; Teixeira et al., 2013). No ano de 2014, as regiões com maior incidência foram Sudeste (312318 casos reportados) e Centro-Oeste (114814 casos reportados), porém essa distribuição varia com os anos pois depende do sorotipo dominante e da quantidade de indivíduos suscetíveis para o sorotipo em circulação (Fares et al., 2015). Os registros até 2014, mostram que o maior número de casos ocorreu em 2013, contabilizando 1442710 casos, em 2010 foram registrados 984357 casos e em 2011, 686358 casos (Precioso et al., 2015). Valores estes que representam o número de casos registrados por indivíduos que buscaram por auxílio médico.

A dengue pode atingir qualquer idade podendo ser assintomática ou sintomática. Estudos mostraram que a quantidade de assintomáticos é aproximadamente 3 vezes o valor de sintomáticos (Bhatt et al., 2013). Geralmente, a primeira infecção não apresenta sérios riscos para o indivíduo infectado, e quando sintomática, manifesta sintomas como: febre, náuseas e vômitos e em alguns casos, a diarreia. No entanto, alguns casos podem se agravar e resultar em hemorragia, e até levar a óbito (Ministério da Saúde, 2016; World Health Organization et al., 2009). As séries temporais mostram que os surtos são sazonais, ocorrendo em geral no período do verão e após períodos de chuva em que os ovos eclodem (Gubler et al., 2014; Teixeira et al., 2013). Recentes estudos, apontam que a reinfecção pode ser mais grave, causando a Síndrome do choque da dengue (SCD) e febre hemorrágica da dengue (FHD), pois a célula aprimora a segunda infecção, fenômeno conhecido por Antibody-Dependent Enhancement (ADE) (Cummings et al., 2005; Ferguson et al., 1999a; Fried et al., 2010; Gibbons et al., 2007; Nagao e Koelle, 2008; Recker et al., 2009; Schwartz et al., 2005; World Health Organization et al., 2009). Também cada infecção oferece imunidade permanente para o sorotipo que foi infectado e imunidade cruzada temporária para todos os outros sorotipos (Adams et al., 2006; Gjini et al., 2016; Wearing e Rohani, 2006). Assim, a dengue consiste em um grande problema mundial, cujo controle ou eliminação podem salvar vidas e resultar em economia de gastos em saúde pública.

As medidas de controle atuais são em relação ao controle do vetor e seus criadouros em conjunto com campanhas de conscientização da população (Boccia et al., 2014). Uma estratégia sendo testada com os mosquitos é utilizando a bactéria Wolbachia, a qual impede o vetor de transmitir o vírus da dengue (Bliman et al., 2015; King et al., 2018; Souto-Maior et al., 2015; Werren, 1997). Outra abordagem utiliza uma linhagem geneticamente modificada do Aedes Aegypti selvagem para que não cheguem à idade reprodutiva, quando a fêmea precisa se alimentar de sangue para pôr ovos (de Valdez et al., 2011). A vacinação é o meio mais eficaz para controlar ou até mesmo erradicar uma doença, o problema é que não existem vacinas para todas doenças infecciosas. Para a dengue, algumas vacinas já foram testadas e outras estão em fase de testes, porém a grande difi- 
culdade é que a vacina deve ser tetravalente, isto é, ser eficaz contra os 4 sorotipos existentes da doença (Ferguson et al., 2016; Precioso et al., 2015; Torresi et al., 2017; Wilder-Smith e Massad, 2016; World Health Organization et al., 2009).

\section{Epidemiologia matemática}

Para auxiliar os órgãos de saúde no controle de doenças infecciosas, modelos matemáticos são desenvolvidos como ferramentas que auxiliam na definição de protocolos. Os modelos matemáticos nos permitem analisar a propagação e comparar diversas estratégias de controle. Historicamente, considera-se que um dos primeiros modelos epidemiológicos foi formulado e resolvido por Daniel Bernoulli (1760), usado para avaliar o impacto da imunização com varíola bovina para proteger indivíduos da infecção da varíola. O estudo consistiu em calcular o aumento da expectativa de vida considerando que a varíola fosse eliminada (Brauer e Castillo-Chavez, 2001; Krämer et al., 2010). O processo de variolação começou na China Antiga, que mesmo sem completo entendimento, usavam a infecção como proteção. Posteriormente, o inglês Edward Jenner (1796), observando que os fazendeiros em contato com a varíola bovina cowpox, não eram infectados com a varíola humana, começou a aplicar a infecção da varíola bovina nos seres humanos para protegê-los contra a varíola (Keeling e Rohani, 2008), relacionando o nome vacinação para esse procedimento, nome que deriva da palavra vacca que é vaca em Latin. Durante o século 19 esse processo foi usado em muitos países, mas a varíola permaneceu endêmica, com aproximadamente 15 milhões de casos por ano. Somente em 1967 a OMS realizou uma grande campanha de vacinação mundial e então a varíola foi eliminada com o último caso registrado na Somália em 1977 (Krämer et al., 2010).

A epidemiologia matemática continuou se aprimorando com William Farr (1840) que ajustou eficientemente uma curva normal aos dados de morte por varíola, ocorridos no período de 1837 à 1839 na Inglaterra e País de Gales. Esta teoria de ajuste foi melhor desenvolvida por John Brownlee (1906), o qual usava a fundamentos estatísticos para ajustar curvas a grandes séries de dados epidêmicos, enquanto isso Hamer e Ross desenvolviam uma teoria para entender a relação entre o número de mosquitos e a incidência de Malária (Anderson et al., 1992). William Hamer (1906) presumiu que o número de novos casos por unidade de tempo (incidência da doença) estava relacionado com o produto das densidades de indivíduos suscetíveis e infecciosos, conhecido como princípio de ação de massas, que foi utilizado em um modelo para entender epidemias de sarampo, um modelo com tempo discretizado e aplicado para um problema contínuo por Ronald Ross (1908). Neste mesmo período, Ronald Ross celebrava a descoberta da transmissão de Malária por mosquito, justificando que os surtos de malária poderiam ser evitados se a população de mosquitos pudesse ser reduzida abaixo de um nível crítico, no qual ensaios de campo então apoiaram suas conclusões e levaram ao sucesso no controle de malária (Anderson et al., 1992; Anderson, 1982; Brauer e Castillo-Chavez, 2001; Keeling e Rohani, 2008). Assim, Ronald Ross (1911) propôs o primeiro modelo de equações diferenciais para malária, considerando vetor-hospedeiro e produziu uma série de modelos matemáticos sobre a propagação da malária lançando as bases da teoria moderna do controle de doenças infecciosas (Anderson, 1982; Krämer et al., 2010; Ross, 1911; Scherer e McLean, 2002).

O trabalho de Hamer e Ross foi então, consequentemente, explorado em detalhes por Soper (1929) e por Kermack e Mckendrick (1927) que estruturaram o cenário compartimental SIR, categorizando hospedeiros dentro de uma população de suscetíveis (S), infectados (I) e recuperados 
(R), introduzindo a teoria do valor limiar, a qual estabeleceu que a proporção de suscetíveis na população deve exceder um limiar crítico para a infecção invadir a população (Anderson, 1982; Brauer e Castillo-Chavez, 2001; Kermack e McKendrick, 1927; Krämer et al., 2010). Trabalhos e estudos nessa área foram expandidos por Bailey (1975), Becker (1979), Dietz e Schenzle (1985), Dietz (1988). Também a variação aleatória dos elementos ou contágio se mostrou determinante na propagação e persistência da infecção e então se desenvolveram as teorias estocásticas (Anderson et al., 1992). Atualmente existem modelos determinísticos e estocásticos para a maioria das doenças infecciosas, que envolvem todos os tipos de análises: imunidade passiva, estrutura de idade, heterogeneidade, propagação espacial, etc (Águas et al., 2008; Brauer e Castillo-Chavez, 2001; Hethcote, 2000; White et al., 2007; Yang, 2001).

\section{Modelagem da dengue}

Com modelos matemáticos preditivos podemos identificar possíveis surtos a partir do início de uma epidemia, e então simular numericamente os resultados de possíveis intervenções para reduzir a transmissão (Gumel e Lenhart, 2010; Hethcote, 2000; Krämer et al., 2010; Rodrigues et al., 2012). Neste sentido, estudos surgiram, apresentando diferentes simulações relacionadas ao controle dos vetores, simulando efeitos de incluir a Wolbachia nos vetores (Bliman et al., 2015; King et al., 2018; Souto-Maior et al., 2015; Souto-Maior, 2017; Wang et al., 2017; Werren, 1997), e outras interferências de controle, como: controle mecânico (diminuir a taxa de oviposição do vetor) e controle químico (inseticida e larvicida) (Amaku et al., 2014; Burattini et al., 2008; de Valdez et al., 2011; Rodrigues et al., 2013; Thomé et al., 2010). Alguns estudos também foram desenvolvidos para identificar a densidade das populações de mosquitos e concluiu-se que a densidade de fêmeas é proporcional ao número de pessoas em cada residência (de Moura Rodrigues et al., 2015).

A mobilidade humana também é um fator em analise para explicar a propagação da dengue e doenças relacionadas (Amaku et al., 2016; Brauer e Castillo-Chavez, 2001; dos Santos et al., 2018; Krämer et al., 2010; Nunes et al., 2015). Tanto em escala global como em escalas menores, existe um trânsito diário de pessoas que se locomovem para trabalhar, turismo, etc. Os vetores transmissores não viajam grandes distâncias e o período de incubação, da picada ao aparecimento dos sintomas, dura geralmente de 2 a 7 dias, assim, as pessoas podem se locomover infectadas ainda sem sintomas e transportar a doença para outros lugares em que o mosquito Aedes é suscetível, da mesma forma que podem se infectar no ambiente de trabalho ou durante viagens e trazer o vírus para contaminar vetores ao redor do ambiente residencial (Liu-Helmersson et al., 2016; Massad et al., 2008; World Health Organization et al., 2009). Estudos com abordagem de redes fornecem uma maneira de compreender as interações entre indivíduos em diferentes escalas, sendo uma potente ferramenta para entender as características de transmissão em comunidades, regiões e países, explorando a mobilidade humana e em alguns casos a mobilidade do vetor (Barmak et al., 2011; de Castro Medeiros et al., 2011; Keeling e Rohani, 2008).

Evidências de que a incidência de dengue mudou ao longo dos anos, por exemplo, no Brasil, tem atingido mais crianças ultimamente (Rodriguez-Barraquer et al., 2011), fez com que modelos fossem adaptados para considerar os diferentes fatores que influenciam na vacinação como: estrutura de idade, proporção da população a ser vacinada, suscetibilidade da população, eficácia da vacina e melhor idade para aplicá-la (Anderson e May, 1985, 1982; Andraud et al., 2012; d'Onofrio, 2002; 
Ferguson et al., 1999b; Gjini et al., 2016; Gomes et al., 2004, 2014; Liu et al., 2008; Maier et al., 2017; Martcheva, 2015; Massad et al., 1994; Rodrigues et al., 2014). Alguns trabalhos também analisam os impactos dos programas de vacinação, mostrando que dependendo do nível de redução do vetor há um limiar na eficácia da vacina abaixo do qual é melhor não introduzi-la (Boccia et al., 2014; Scherer e McLean, 2002). Modelos atuais estão sendo aperfeiçoados para analisar o resultado de aplicação de vacinas desenvolvidas para a dengue, devido ao fato desta oferecer proteção contra os 4 sorotipos existentes, como as vacinas do Sanofi e do Instituto Butantan (Aguiar et al., 2016; Billings et al., 2008; Ferguson et al., 2016; Maier et al., 2017; Precioso et al., 2015). A vacina do Sanofi foi mostrada ter boa eficácia se aplicada em indivíduos de 9 a 45 anos e que já tiveram infecção previamente (Aguiar et al., 2016; Wilder-Smith e Massad, 2016), aumentando o risco de hospitalização em indivíduos soronegativos, enquanto a vacina do Instituto Butantan está na fase de testes III (Precioso et al., 2015).

\section{Modelos com múltiplos sorotipos}

Os modelos mais complexos incluem os efeitos de ADE e de imunidade cruzada na persistência do vírus, mostrando que o aprimoramento frequentemente pode causar complexos e persistentes ciclos ou comportamento epidêmico caótico, além de agir para permitir a coexistência de todos os sorotipos (Adams et al., 2006; Billings et al., 2007; Cummings et al., 2005; Ferguson et al., 1999a; Nagao e Koelle, 2008; Nisalak et al., 2003; Recker et al., 2009; Reich et al., 2013; Schwartz et al., 2005; Wearing e Rohani, 2006). Modelos com múltiplos sorotipos também foram usados para estudar a interação das doenças transmitidas pelo Aedes, relacionando que a infecção prévia por dengue pode aprimorar a infecção por Zika (Dejnirattisai et al., 2016; Villela et al., 2017). O estudo da coexistência de dois ou mais sorotipos de uma mesma doença, como ocorre com a dengue, mostra que a coexistência é favorecida pois a suscetibilidade é aumentada para a segunda infecção, o que pode explicar porque certas sequência de infecções são associadas com maior número de casos de FHD, como observado em alguns países que uma segunda infecção com os sorotipos II, III e IV, resulta em uma doença mais severa (Esteva e Vargas, 2003; Fried et al., 2010; Kooi et al., 2014).

Um dos maiores desafios é trabalhar com modelos com múltiplos sorotipos, que incluem o compartimento dos vetores e sazonalidade (Aguiar et al., 2011; Hartley et al., 2002; Kao e Eisenberg, 2017). Wearing e Rohani mostraram que somente ADE ou heterogeneidade do vírus não são consistentes com os dados de notificação e que para gerar epidemias com as características observadas nos dados deve-se ter uma combinação de variação sazonal na demografia do vetor e crucialmente um curto período de imunidade cruzada (Wearing e Rohani, 2006). Chikaki e Ishikawa trabalharam com um modelo com estrutura de idade com interação de 4 sorotipos, possibilidade de 4 infecções, também incluindo o efeito de ADE e imunidade cruzada, acoplando o compartimento dos vetores, e analisaram a influência dos casos assintomáticos na dinâmica de transmissão de dengue na Tailândia (Chikaki e Ishikawa, 2009). Coudeville e Garnett exploraram um modelo com 4 sorotipos e possibilidade de 2 infecções. O modelo foi estruturado para grupos etários, de forma que a transmissão depende da idade. Concluíram que sazonalidade e imunidade cruzada são fatores chave para explicar a dinâmica de dengue no sul do Vietnã (Coudeville e Garnett, 2012). Estes modelos consideram os compartimentos dos humanos suscetíveis (S), expostos (E), infectados (I), com imunidade cruzada $(C)$, recuperados $(R)$, e vetores suscetíveis $(V)$, expostos $\left(V_{E}\right)$ e infectados $\left(V_{i}\right)$. 
Wikramaratna et al. investigaram os efeito de infecções terciárias e quaternárias por dengue, apontando que mesmo preservando o comportamento dinâmico geral, terceiras ou mais infecções afetam a força geral de infecção e as taxas de incidência de FHD/SCD dependentes de idade na população (Wikramaratna et al., 2010). Aguiar et al. estudaram modelos com a dinâmica de interação de 2 e 4 sorotipos expandidos a partir de um SIR. Os modelos permitem até duas infecções sequenciais e consideram ADE na segunda infecção. Os modelos não consideram a transmissão vetor-hospedeiro, de forma que a forçante de sazonalidade é incluída na taxa de transmissão entre humanos suscetíveis e infectados. Os modelos são simétricos, o que implica que não há diferença na taxa de transmissão para diferentes sorotipos. Com um estudo teórico comparando os modelos com dois e quatro sorotipos, concluíram que não se tem grandes vantagens em usar o modelo de 4 sorotipos, considerando que o de 2 sorotipos é preferível por ser mais fácil de estimar parâmetros a partir dos dados (Aguiar e Stollenwerk, 2017; Aguiar et al., 2011, 2013). Em adição, testaram o efeito da vacina da dengue do Sanofi no modelo com 2 sorotipos compartimentado em três faixas etárias, aplicado aos dados de dengue da Tailândia (Aguiar et al., 2016) .

Nossa contribuição com este trabalho é fazer uma comparação entre os modelos SIR considerando a dinâmica de 1 sorotipo e interação de 2, 3 e 4 sorotipos coexistindo. Consideramos que a transmissão é entre vetor-hospedeiro (Esteva e Vargas, 1998), e as taxas de transmissão são diferentes para cada sorotipo, de forma que os modelos são assimétricos. Não incluímos o efeito de ADE na segunda infecção, entretanto incorporamos uma forçante de sazonalidade na taxa de nascimentos dos mosquitos e supomos imunidade cruzada temporária após cada infecção que confere um período de imunidade contra todos sorotipos e imunidade permanente contra o sorotipo do qual já foi infectado, sendo possível um indivíduo totalmente suscetível obter até 4 infecções sequencialmente. Por fim, incluímos o compartimento dos vacinados e analisamos dois cenários de vacinação: vacinação aleatória na população e vacinação direcionada para faixas etárias. Baseamo-nos nos trabalhos (Chikaki e Ishikawa, 2009; Coudeville e Garnett, 2012; Souto-Maior, 2017) e principalmente em (Aguiar e Stollenwerk, 2017; Aguiar et al., 2011, 2016). Os parâmetros dos modelos são estimados a partir de dados de incidência de dengue de cidades brasileiras onde estão sendo testadas a vacina do Instituto Butantan (Precioso et al., 2015). Para a estimação de parâmetros, utilizamos o pacote pomp implementado em linguagem $R$ (King et al., 2016, 2017). Para as soluções numéricas dos sistemas de equações diferenciais ordinárias, utilizamos o método de Rosenbrock implementado em Fortran (Sartori, 2014).

\section{Objetivos}

O objetivo do nosso trabalho é comparar a dinâmica de transmissão que ocorre quando se tem um, dois, três ou quatro sorotipos de dengue coexistindo em uma população e possibilidade de até quatro infecções sequenciais. Depois de estruturados os modelos, e estimados parâmetros a partir de dados reais de incidência de dengue, analisamos cenários de vacinação, considerando uma vacina tetravalente aplicada em uma proporção aleatória da população ou direcionada para um grupo etário. Os objetivos específicos são:

- Estudar dos dados de incidência da dengue no Brasil;

- Identificar faixas etárias em maior risco de infecção; 
- Estudar um modelo básico e expandir para a dinâmica de múltiplos sorotipos;

- Desenvolver um modelo que acopla a dinâmica de iteração de até 4 sorotipos com possibilidade de até 4 infecções sequenciais, considerando a transmissão vetor-hospedeiro;

- Incorporar nos modelos uma compartimentalização por faixa etária;

- Estimar parâmetros para os modelos a partir dos dados de incidência de dengue no Brasil;

- Simular estratégias de vacinação com os modelos.

\section{Organização da tese}

O Capítulo 1, contém um estudo da dengue no Brasil. Através dos dados de notificação da doença, mostramos que a dengue é diferente em cada localização, que os surtos são sazonais e que há alternância de sorotipos ao longo dos anos. As informações obtidas a partir dos dados, são usadas para a estruturação dos modelos matemáticos e para a estimação de parâmetros que validam estes modelos. Para complementar, fazemos um estudo de aplicar diferentes normalizações nos dados separados por faixas etárias e identificamos perfis diferentes segundo a quantidade de casos com uma normalização adequada. O coeficiente de correlação, é aplicado então para fazer um agrupamento desses perfis por semelhança. Por fim, a correlação também é usada para estudar mobilidade humana como fator de propagação da dengue.

No segundo capítulo (Capítulo 2), apresentamos a modelagem epidemiológica da dengue comparando modelos que consideram a dinâmica de transmissão por 1, 2, 3 e 4 sorotipos. Nossos modelos com coexistência de múltiplos sorotipos são expandidos a partir da dinâmica de um modelo compartimental básico que considera humanos suscetíveis (S), infectados (I) e recuperados (R) e mosquitos suscetíveis $(\mathrm{V})$ e infectados $\left(\mathrm{V}_{i}\right)$. Fazemos um breve estudo dos pontos de equilíbrios e número básico de reprodução para estes modelos e explicamos a teoria e adaptação do pacote utilizado para a estimação dos parâmetros dos modelos a partir dos dados.

O Capítulo 3, contém os resultados numéricos. Comparamos os resultados dos modelos com um, dois, três e quatro sorotipos com ou sem incluir a forçante de sazonalidade na taxa de nascimento dos vetores. Apresentamos o ajuste dos modelos aos dados de incidência de algumas cidades brasileiras estudadas no Capítulo 1, selecionadas dentre as cidades em que estão sendo feito os testes da fase III da vacina tetravalente da dengue produzida pelo Instituto Butantan. Os ajustes são feitos para os modelos de múltiplos sorotipos com e sem considerar os modelos compartimentados por faixa etária. Para completar, analisamos alguns cenários de vacinação com estes modelos.

Por fim, seguem as conclusões, em que discutimos as vantagens e desvantagens de considerar modelos com múltiplos sorotipos, comentando as contribuições e estudos decorrentes da tese. Apresentamos a lista de referências consultadas, um Apêndice A contendo algumas definições e conceitos epidemiológicos básicos necessários na modelagem de doenças infecciosas, sendo indicado para leitores em um primeiro contato com modelagem epidemiológica. E um Apêndice B, no qual mais alguns resultados numéricos são apresentados. 
xxiv

INTRODUÇÃO 


\section{Capítulo 1}

\section{Estudo da dengue no Brasil}

Dados epidemiológicos são uma fonte da qual se podem obter informações essenciais sobre uma doença infecciosa, tais como, força de infecção, taxa de transmissão, áreas de maior risco, faixas etárias mais suscetíveis, etc (Coelho e Carvalho, 2015; Coelho et al., 2011; Fares et al., 2015; Gibbons et al., 2007; Vynnycky e White, 2010). Neste capítulo estudamos os dados de incidência de dengue no Brasil, e destacamos as características fundamentais da doença que são a base para a construção dos modelos matemáticos. Algumas séries temporais serão exibidas para mostrar como a dengue é uma doença diferente em cada local, o que torna difícil um agrupamento ou padronização, as quais também evidenciam que os surtos são sazonais. Apesar da análise de sorotipo ser feita em uma pequena porcentagem dos infectados, através de uma amostra das séries de dados é possível ver a alternância ao longo dos anos dos quatro diferentes sorotipos de dengue existentes no Brasil DENV-1, DENV-2, DENV-3 e DENV-4. As séries temporais também são usadas para estimação de parâmetros dos modelos matemáticos, questão fundamental para a validação dos modelos (Fares et al., 2015; Vynnycky e White, 2010).

Através de um estudo de aplicar diferentes normalizações nos dados de incidência por faixa etária, identificamos uma normalização adequada que permite um agrupamento de estados ou cidades com características semelhantes em relação as faixas etárias mais afetadas e que pode ser um fator decisivo no protocolo de aplicação de uma vacina (Ferguson et al., 2016; Precioso et al., 2015; World Health Organization et al., 2009). Depois de aplicada a normalização, o agrupamento é feito através de correlação, as quais também são usadas nas séries temporais, pois nos dão um indício de como a mobilidade humana contribui com a propagação do vírus (Amaku et al., 2016; Brauer e Castillo-Chavez, 2001; dos Santos et al., 2018; Krämer et al., 2010).

\subsection{Materiais}

Nesta seção organizamos as informações que serão utilizadas nas simulações numéricas dos modelos matemáticos apresentados na tese. Os dados populacionais, como total populacional de cidades, estados, Brasil todo, também a expectativa de vida, são informações obtidas através de sites de órgãos públicos responsáveis por retratar um população e suas características (IBGE, 2017). O banco de dados de dengue, foi fornecido pelo Dr. Ricardo Palacios, Instituto Butantan, já com uma pré-filtragem dos dados originais em posse da Secretaria de Vigilância Sanitária do Ministério da Saúde do Brasil (Ministério da Saúde, 2016; Ministério da Saúde/SVS, 2017). Um segundo filtro foi aplicado para obter somente as informações pertinentes para a pesquisa; semana, ano, município, idade e número de notificações.

Outras características como heterogeneidade da população, regiões de maior risco, taxa de mortalidade, influência da temperatura, fatores socioeconômicos, saneamento básico, etc, também podem ser obtidas dos dados e incluídas nos modelos, o que torna a modelagem mais complexa, portanto nos focaremos somente nas informações básicas, suficientes para descrever a dengue de forma simples porém realista e que não dificulte a estimação de parâmetros. 


\subsubsection{Dados populacionais}

Os dados da população brasileira são necessários para normalizar os dados de notificação de dengue e para as simulações computacionais em que precisamos saber a quantidade populacional de cada região analisada. O Instituto Brasileiro de Geografia e Estatística (IBGE) é o órgão que desde de 1940 realiza a contagem da população brasileira e extrai informações gerais sobre a população, como: cor, gênero, domicílio, faixa etária, condições socioeconômicas, etc. O último censo foi realizado no ano de 2010 e o próximo está previsto para 2020 (IBGE, 2017).

A Tabela 1.1 contém informações da população brasileira total e separadas por regiões no período de 2008 à 2013, as quais são uma projeção feita a partir do Censo Demográfico de 2010, IBGE (IBGE, 2017). No período apresentado, observa-se um pequeno aumento do tamanho populacional, porém essa variação não é significativa quando separada por estados e municípios, portanto, por questões de simplicidade, usaremos os dados populacionais do ano de 2010 para as normalizações e simulações deste trabalho. Tabelas semelhantes contendo informações da população residente separada por faixas etárias para municípios e estados, também foram necessárias, mas não serão explicitamente apresentadas devido o grande volume de dados. Uma amostra de como a população é distribuída por faixas etárias no ano de 2010 é dada na Figura 1.1.

\begin{tabular}{c|c|c|c|c|c|c}
\hline \multicolumn{7}{c}{ Total populacional } \\
\hline Região/Ano & 2008 & 2009 & 2010 & 2011 & 2012 & 2013 \\
\hline Brasil & 191532439 & 193543969 & 195497797 & 197397018 & 199242462 & 201032714 \\
Norte & 15658112 & 15935514 & 16206409 & 16471131 & 16730156 & 16983484 \\
Nordeste & 53543869 & 54035553 & 54506351 & 54955883 & 55384833 & 55794707 \\
Sudeste & 80904319 & 81660443 & 82392683 & 83103755 & 83795056 & 84465570 \\
Sul & 27611414 & 27858309 & 28099409 & 28336491 & 28569231 & 28795762 \\
Centro-Oeste & 13814725 & 14054150 & 14292945 & 14529758 & 14763186 & 14993191 \\
\hline
\end{tabular}

Tabela 1.1: População total do Brasil e separada para as 5 regiões: Norte, Nordeste, Sudeste, Sul e CentroOeste. Para o ano de 2010 os dados são censitários, e os demais anos 2008, 2009, 2011, 2012 e 2013 são projeções do Censo de 2010, (IBGE, 2017).

Outra informação relevante é a expectativa de vida do brasileiro (Tabela 1.2), que é utilizada para calcular a taxa de mortalidade da população. Apresentamos os valores para o mesmo período de anos dos dados populacionais da Tabela 1.1. Os valores não variam muito de ano para ano na mesma região, e variam de 70 à 77 anos se compararmos todas as regiões. Para cada região usaremos o valor obtido no ano de 2010 que é um ano censitário e cujos valores coincidem com a média desse período de anos de cada região (IBGE, 2017).

\begin{tabular}{c|c|c|c|c|c|c}
\hline \multicolumn{7}{|c}{ Expectativa de vida } \\
\hline Região/Ano & 2008 & 2009 & 2010 & 2011 & 2012 & 2013 \\
\hline Brasil & 73.15 & 73.51 & 73.86 & 74.20 & 74.52 & 74.84 \\
Norte & 70.26 & 70.53 & 70.79 & 71.05 & 71.29 & 71.54 \\
Nordeste & 70.53 & 70.89 & 71.23 & 71.57 & 71.89 & 72.21 \\
Sudeste & 74.78 & 75.17 & 75.55 & 75.90 & 76.25 & 76.58 \\
Sul & 75.15 & 75.52 & 75.87 & 76.22 & 76.55 & 76.87 \\
Centro-Oeste & 73.17 & 73.43 & 73.69 & 73.95 & 74.19 & 74.43 \\
\hline
\end{tabular}

Tabela 1.2: Expectativa de vida da população brasileira total e para cada região no período de 2008 à 2013. Para o ano de 2010 os dados são censitários, e os demais anos 2008, 2009, 2011, 2012 e 2013 são projeções do Censo de 2010, (IBGE, 2017). 
A Figura 1.1 evidencia que a população se distribui de forma semelhante nas regiões brasileiras, sendo que a faixa etária $\geq 20<40$ anos é a que contém maior número de residentes. Porém, essa distribuição pode variar se olharmos por estados e municípios e também separando em faixas etárias menores.
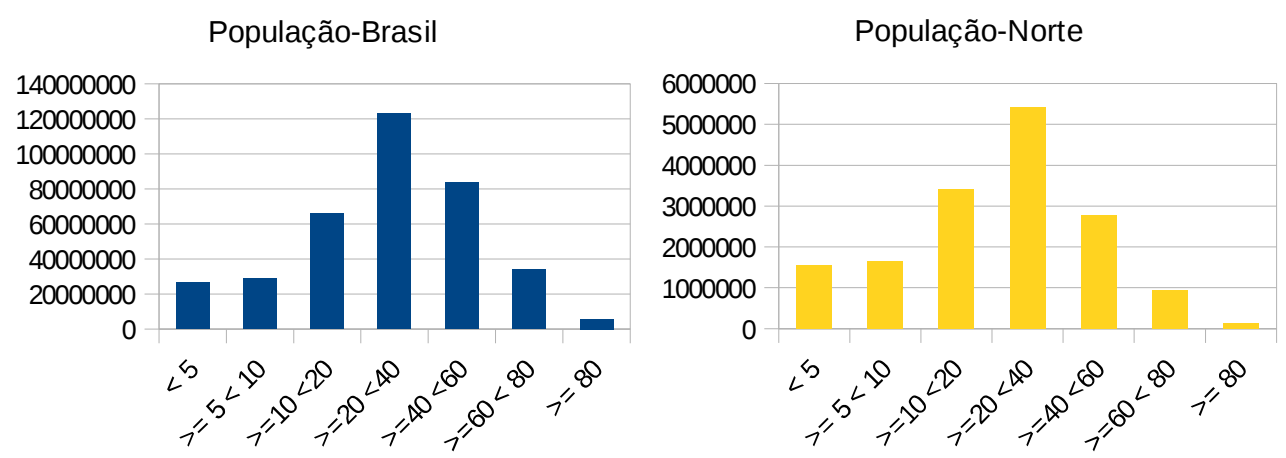

População-Nordeste
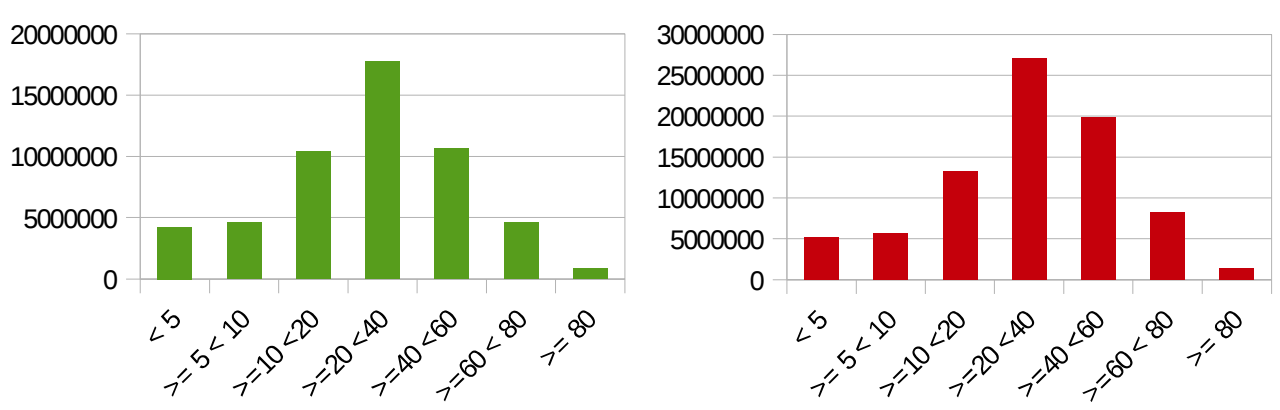

População-Sul

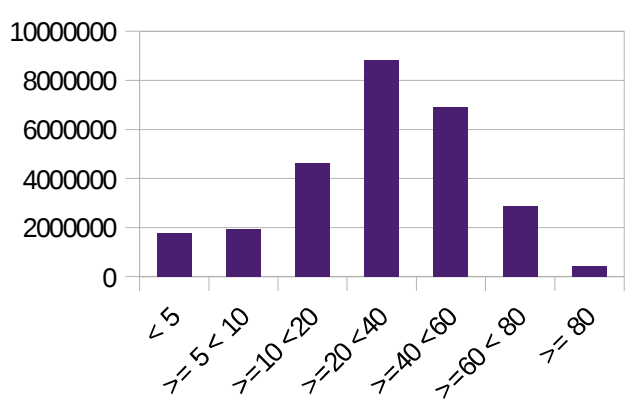

População-Centro-Oeste

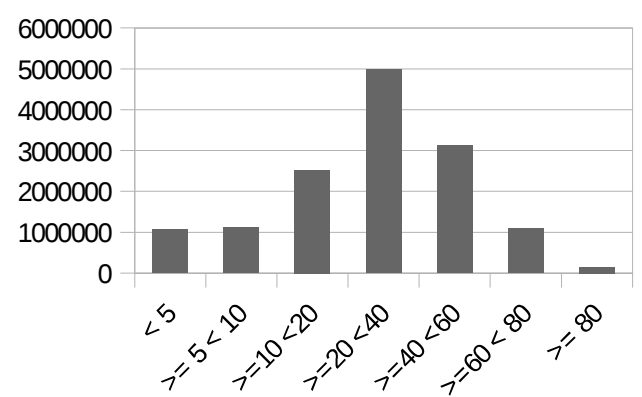

Figura 1.1: Distribuição da população brasileira no ano de 2010, nos grupos etários: $(<5),(\geq 5<10)$, $(\geq 10<20),(\geq 20<40),(\geq 40<60),(\geq 60<80)$ e $(\geq 80)$ anos. A primeira figura apresenta a distribuição para o Brasil todo e as outras são de cada região: Norte, Nordeste, Sudeste, Sul e Centro-Oeste. Os gráficos contêm os totais populacionais sem nenhuma normalização, Censo de 2010 (IBGE, 2017). 


\subsubsection{Séries temporais de dengue}

A Figura 1.2 apresenta as séries temporais de dengue de 12 capitais brasileiras, escolhidas dentro das 5 regiões. Os dados são a incidência dengue por 100000 habitantes (Definição A.3), isto é, as notificações semanais divididas pela população de cada cidade e multiplicadas por 100000 . O período de dados é da $1^{\mathrm{a}}$ semana de 2008 à $35^{\mathrm{a}}$ semana de 2014, e os totais populacionais de cada cidade são obtidos do Censo de 2010 (IBGE, 2017; Ministério da Saúde, 2016; Ministério da Saúde/SVS, 2017).

Os gráficos evidenciam que a dengue tem um padrão diferente em cada localização, não permitindo um agrupamento por semelhança, indicando que a estimação de parâmetros deve ser feita para cada série separadamente.
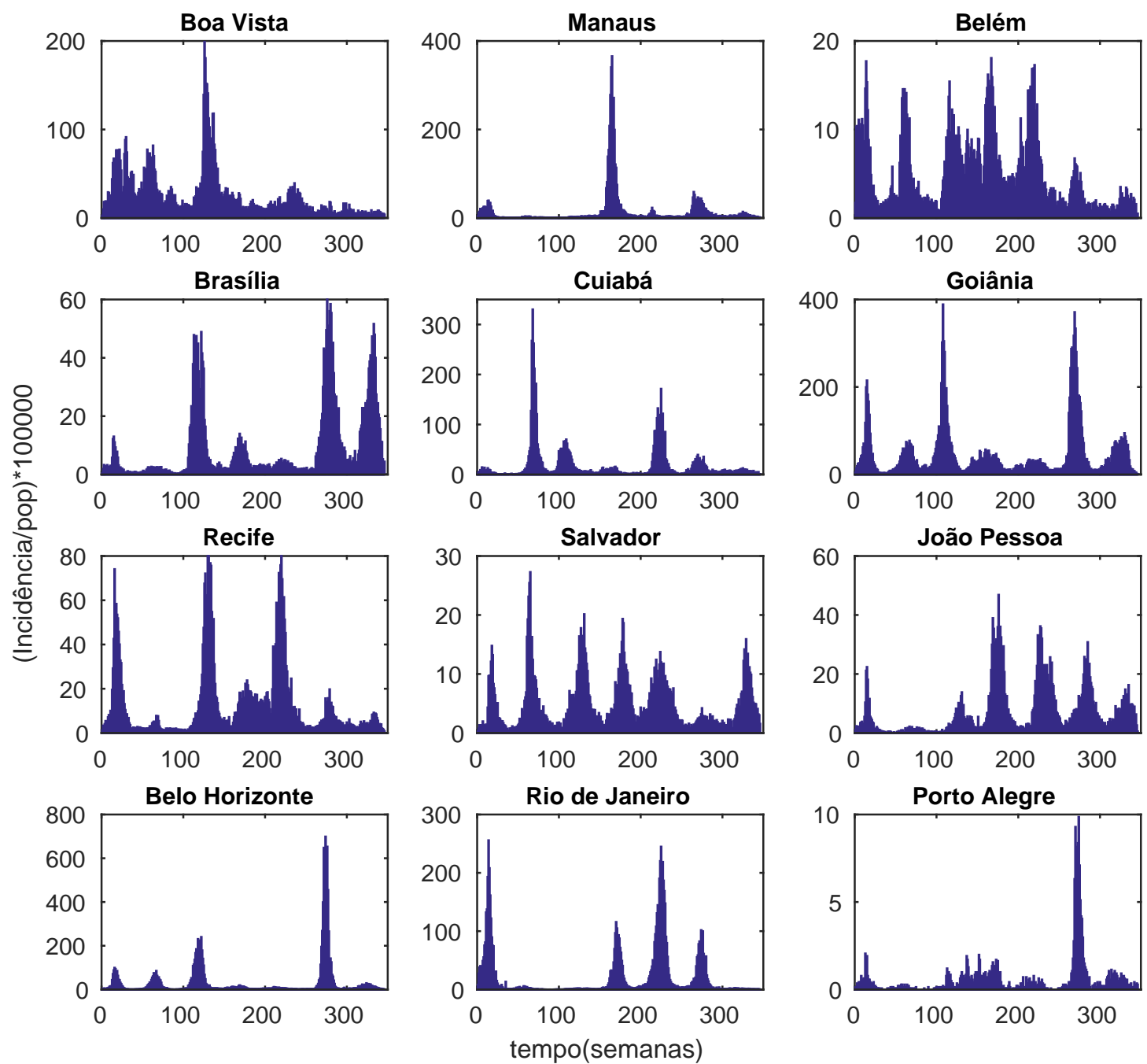

Figura 1.2: Incidência de dengue por 100000 habitantes em 12 capitais brasileiras da $1^{a}$ semana de 2008 à $35^{a}$ semana de 2014, totalizando 346 semanas. Na ordem, as cidades do Norte: Boa Vista, Manaus e Belém; do Centro-Oeste: Brasília, Cuiabá e Goiânia; do Nordeste: Recife, Salvador e João Pessoa; do Sudeste: Belo Horizonte e Rio de Janeiro e do Sul: Porto Alegre. 


\subsubsection{Sazonalidade}

Os gráficos de diferentes anos epidemiológicos nos permite observar que geralmente os surtos ocorrem uma vez por ano em cada cidade, e na mesma época do ano, sendo este o período de chuvas e temperaturas altas, mostrando que os surtos são sazonais. Como pode ser observado na Figura 1.2, vários anos não tiveram surtos de dengue, ou os surtos não foram notificados. Para analisar se este fato indicaria um ciclo da dengue, seria necessário uma série de dados mais completa, com muitos anos de notificações.

Na Figura 1.3 exibimos as séries temporais de dengue de algumas capitais brasileiras que registraram surtos de dengue em três anos consecutivos. Os dados são de incidência por 100000 habitantes, da $1^{\mathrm{a}}$ semana de janeiro à $52^{\mathrm{a}}$ semana de dezembro, nos anos: 2011, 2012 e 2013. É possível notar que em algumas cidades, a incidência já é alta no começo do ano, infectando uma grande quantidade de pessoas, e assim o surto termina mais rápido, como ocorre, por exemplo, em Rio Branco, Goiânia e Curitiba. Por outro lado, em cidades muito populosas, como São Paulo e Salvador, o surto demora mais para acontecer e consequentemente permanece por mais tempo na população. Por esse motivo, uma forçante de sazonalidade pode ser usada na taxa de nascimentos dos vetores no modelo matemático, de forma que obtemos nascimento de vetores em todos anos e assim gera-se picos anuais, devendo ser estimadas a amplitude e a fase da sazonalidade para cada série de dados.

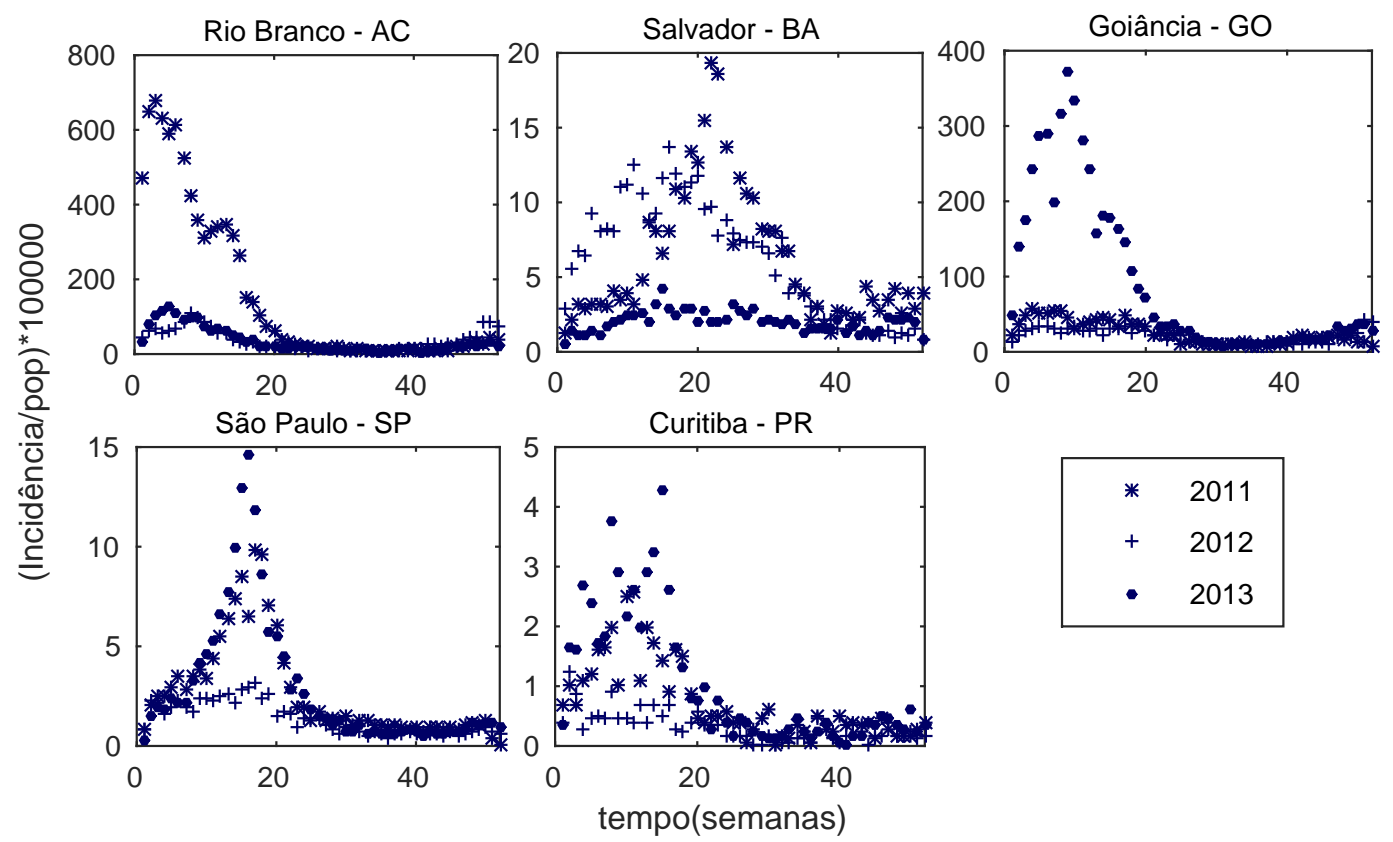

Figura 1.3: Incidência de dengue nas capitais Rio Branco, Salvador, Goiânia, São Paulo e Curitiba, da $1^{a}$ à $52^{a}$ semana de cada ano, para os anos 2011, 2012 e 2013. Os gráficos mostram que os surtos são anuais, com diferentes intensidades e duração. Rio Branco, Goiânia e Curitiba apresentam os picos dos surtos já no começo de cada ano, enquanto para Salvador e São Paulo os picos ocorrem em torno da $15^{a}$ à $20^{a}$ semana dos anos epidemiológicos. 


\subsubsection{Sorotipos de dengue}

De acordo com dados epidemiológicos, os quatro sorotipos existentes de dengue circulam no Brasil (Precioso et al., 2015; Teixeira et al., 2013). A confirmação laboratorial e informação dos sorotipos são feitas somente para uma pequena amostra de infectados e esse procedimento começou somente nos últimos anos, assim assume-se que o sorotipo dominante de cada ano é o que mais apareceu nos poucos testes feitos no início da epidemia, não sendo possível identificar se o indivíduo já foi infectado por dengue previamente (Coelho e Carvalho, 2015). Na maioria das vezes o diagnóstico é feito somente sobre critérios clínicos.

A Figura 1.4 apresenta as notificações que identificam o sorotipo, extraídas do banco de dados de dengue e agrupadas para o Brasil todo no período de 2008 a 2014. É possível observar a coexistência de sorotipos em um mesmo surto e também a intercalação dos sorotipos ao longo dos anos.
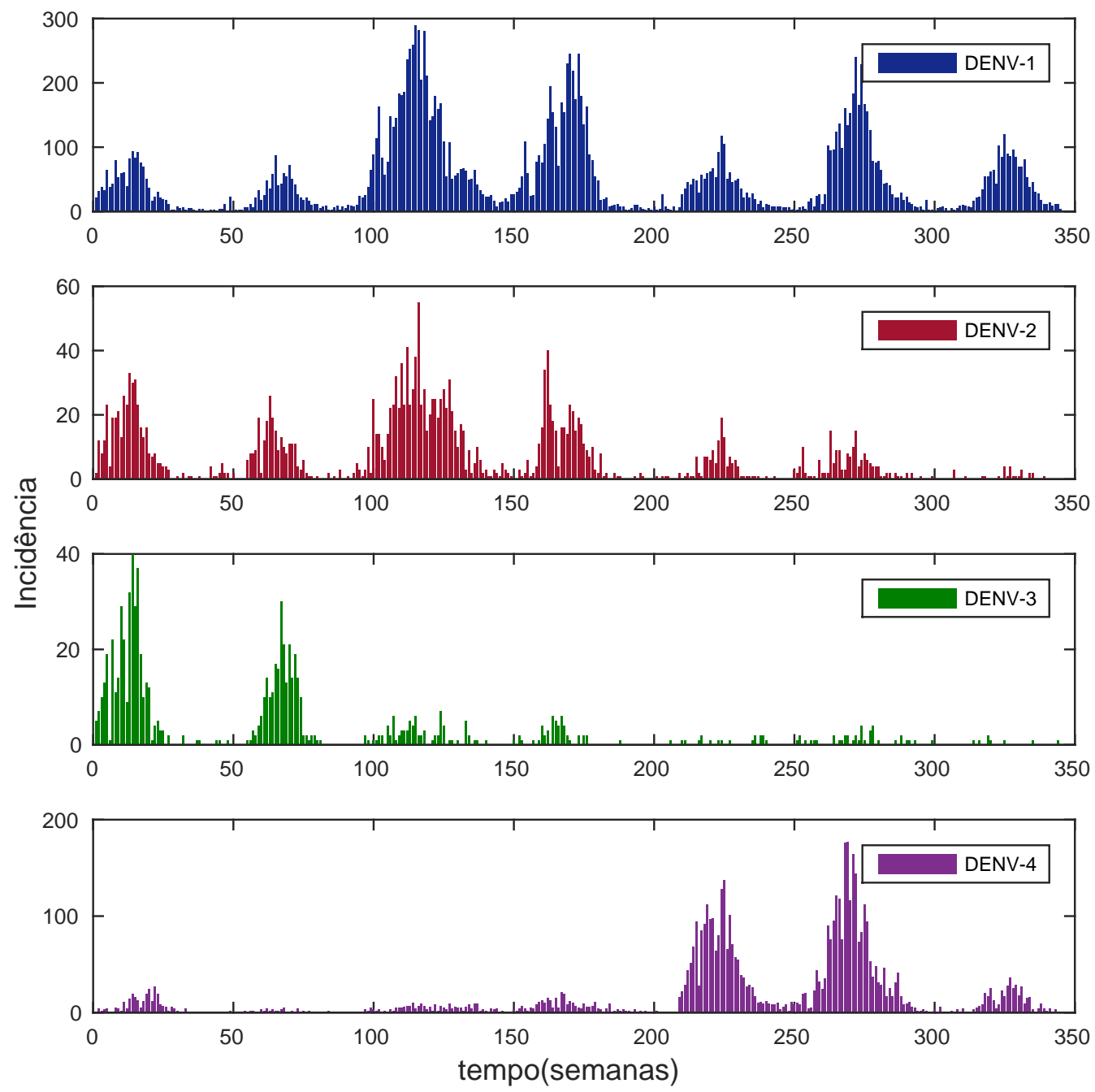

Figura 1.4: Incidência de dengue no Brasil por sorotipos, da $1^{a}$ semana de 2008 à $35^{a}$ semana de 2014, totalizando 346 semanas. A primeira figura contém a série temporal para o sorotipo DENV-1, a segunda para o sorotipo DENV-2, terceira para sorotipo DENV-3 e por último do sorotipo DENV-4. 


\subsubsection{Notificações por faixas etárias}

A partir do banco de dados de dengue, agrupamos as notificações semanais de casos ocorridos no ano de 2010 para o Brasil todo e por regiões, nas mesmas faixas etárias que os dados populacionais da Figura 1.1. A Figura 1.5 ilustra que a distribuição do número de infectados por faixas etárias é semelhante ao total populacional nos grupos etários, isto é, a maior quantidade de casos registrados está no grupo $\geq 20<40$ anos. Porém essa distribuição não fornece informações sobre os grupos etários mais afetados segundo a densidade populacional de cada grupo.
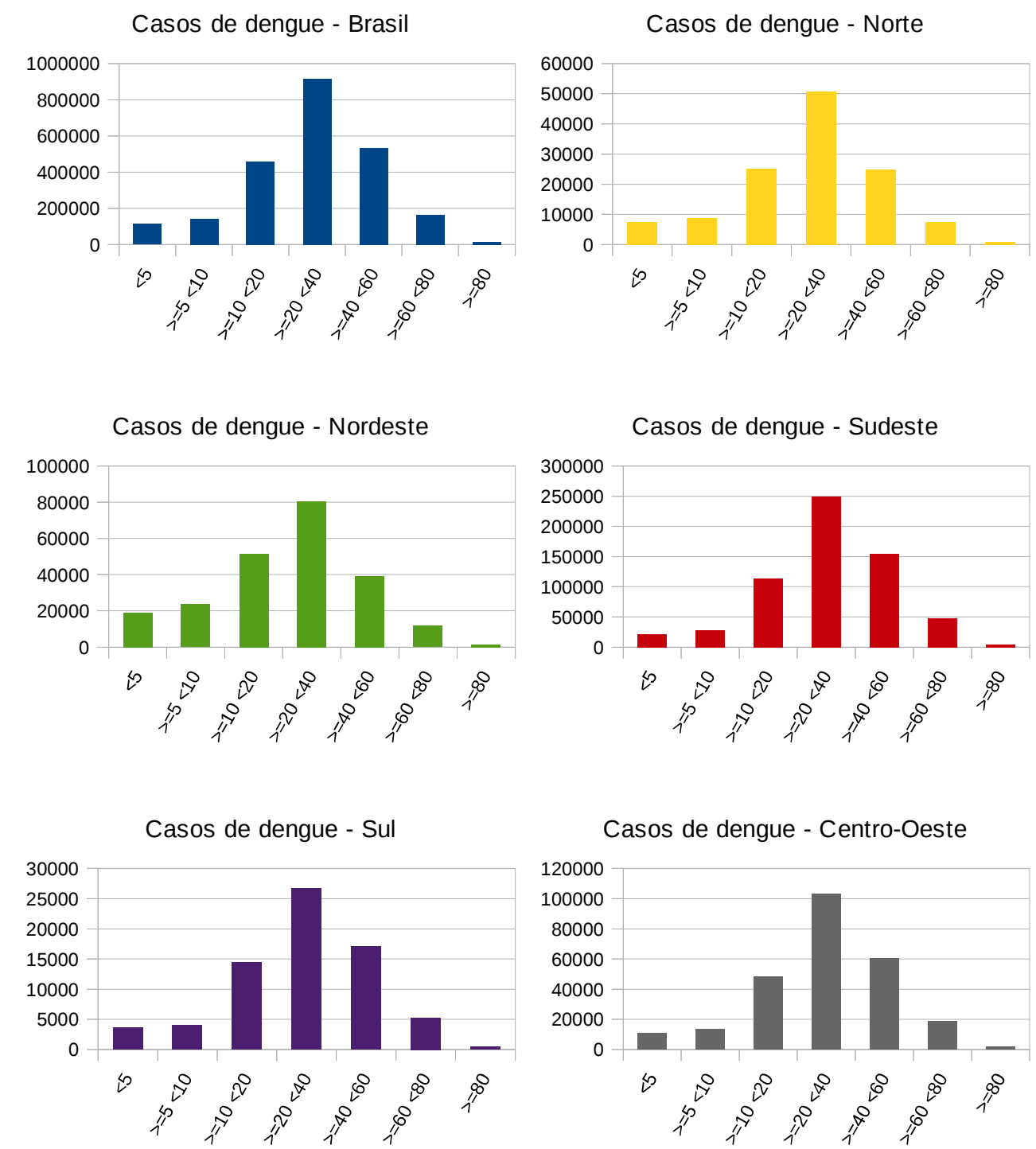

Figura 1.5: Notificações de casos de dengue registrados no Brasil no ano de 2010 e agrupados para as regiões: Norte, Nordeste, Sudeste, Sul e Centro-Oeste, segundo os grupos etários: $(<5),(\geq 5<10),(\geq 10<20)$, $(\geq 20<40),(\geq 40<60),(\geq 60<80)$ e $(\geq 80)$ anos. A primeira figura apresenta a distribuição para $o$ Brasil todo e as outras são de cada região: Norte, Nordeste, Sudeste, Sul e Centro-Oeste. Os gráficos contêm os totais populacionais sem nenhuma normalização. 


\subsection{Normalizações}

Como é razoável esperar e observável das Figuras 1.1 e 1.5, a faixa etária que contém maior número de casos coincide com a faixa etária de maior agrupamento populacional, que é de $\geq 20<40$ anos, porém, isso é diferente de comparar a proporção de infectados em cada faixa etária, o que pode ser feito utilizando-se normalizações.

O Ministério da Saúde (MS) utiliza o número de casos por 100 mil habitantes em cada espaço geográfico para alertar as ações de vigilância epidemiológica do país para o caso de uma possível epidemia da doença (Ministério da Saúde, 2016). A Organização Mundial da Saúde (OMS) considera que há epidemia quando um local registra um número maior ou igual a 300 casos a cada 100 mil habitantes.

A normalização usada pelo Ministério da Saúde para calcular a incidência de dengue a cada 100 mil habitantes, a qual denotaremos por $N_{M S}$, é dada por

$$
N_{M S}=\frac{\text { número de casos de dengue confirmados em residentes }}{\text { população total residente }} \times 100000
$$

Nosso intuito é caracterizar a população brasileira em grupos de acordo com a semelhança na proporção de casos de dengue separados por faixas etárias, para isso vamos analisar três normalizações diferentes. A primeira (N1) (Equação 1.2) é equivalente a normalização $N_{M S}$ (Equação 1.1), porém com as notificações de dengue separadas por faixas etárias. A segunda normalização $(N 2)$ (Equação 1.3) segue a mesma lógica, porém dividimos pelo total de casos na região em vez de dividir pela população total. E na terceira normalização (N3) (Equação 1.4), temos que os casos de dengue por faixa etária são divididos pela população respectiva da faixa etária.

Utilizando os dados de notificação de dengue do Brasil e regiões, apresentados na Figura 1.5 com os dados populacionais da Figura 1.1, temos que os pares de tabelas e figuras: Tabela 1.3 e Figura 1.6, Tabela 1.4 e Figura 1.7, Tabela 1.5 e Figura 1.8, mostram os resultados de se aplicar, respectivamente, as normalizações $N 1, N 2$ e $N 3$.

Os resultados mostram que a incidência é distribuída da mesma forma entre as faixas etárias com $N 1$ e $N 2$, pois essas normalizações são equivalentes diferindo apenas em escala. Porém, não acontece o mesmo comportamento utilizando $N 3$, quando calculamos a incidência de acordo com a população em cada faixa etária.

A Figura 1.8, destaca esses resultados: temos que no gráfico de incidência do Brasil, a faixa etária com maior número de casos está no intervalo $\geq 20<40$ anos, o mesmo segue para as regiões Norte, Sudeste e Centro-Oeste, entretanto o Nordeste têm uma incidência maior entre crianças nos grupos $\geq 5<10$ e $\geq 10<20$ anos e no Sul o grupo dominante é de $\geq 10<20$ anos. Ainda no Norte podemos observar que os casos ocorrem em proporções maiores em adultos e idosos do que em crianças e adolescentes, sendo o oposto do observado no Nordeste. 
Normalização 1 (N1): Quantidade de notificações por faixa etária dividida pela população total de cada região multiplicada por 100000.

$$
N 1=\frac{\text { número de casos de dengue por faixa etária }}{\text { população total residente de cada região }} \times 100000
$$

\begin{tabular}{c|c|c|c|c|c|c|c}
\hline \multicolumn{8}{c}{ Incidência de dengue calculada com a normalização $N 1$} \\
\hline Região/Fx. etária & $<5$ & $\geq 5<10$ & $\geq 10<20$ & $\geq 20<40$ & $\geq 40<60$ & $\geq 60<80$ & $\geq 80$ \\
\hline Brasil & 32.5 & 40.9 & 132.4 & 267.5 & 155.5 & 48.1 & 4.6 \\
Norte & 47.3 & 55.7 & 158.6 & 319.8 & 157.4 & 47.6 & 5.5 \\
Nordeste & 35.5 & 44.6 & 96.9 & 151.7 & 74.2 & 22.1 & 2.3 \\
Sudeste & 26.7 & 35.2 & 141.1 & 310.2 & 192.8 & 60.1 & 5.6 \\
Sul & 13.2 & 14.9 & 52.8 & 97.2 & 62.4 & 19.2 & 1.6 \\
Centro-Oeste & 75.0 & 94.0 & 342.2 & 732.8 & 429.0 & 133.8 & 12.4 \\
\hline
\end{tabular}

Tabela 1.3: Resultado de aplicar a Normalização N1 nos dados de notificação de dengue, ano de 2010. Para os casos de dengue somados no país, a divisão é feita pela população total Brasileira, e para as regiões, divide-se pela população respectiva da região, segundo a Tabela 1.1.
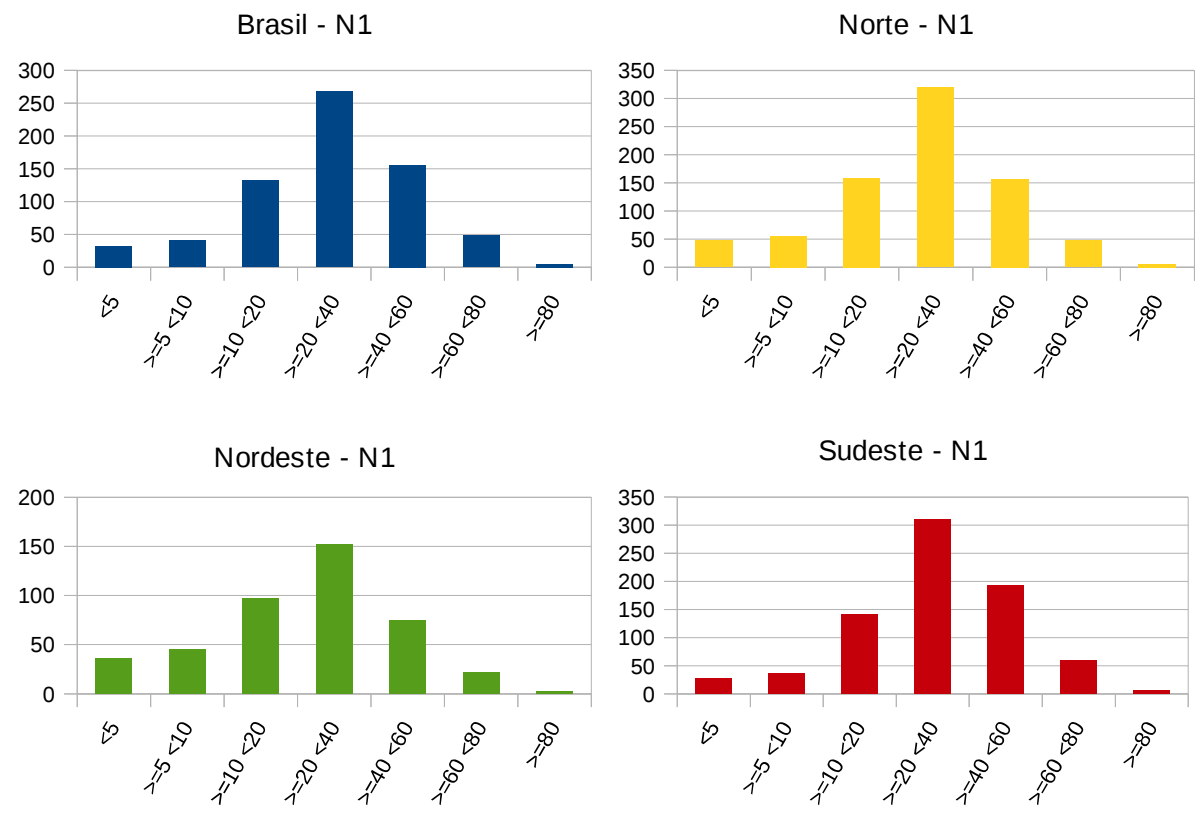

Sul - N1

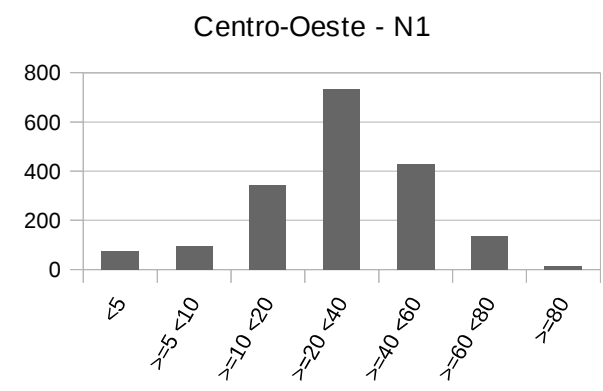

Figura 1.6: Incidência de dengue por faixas etárias com a normalização $N 1$, Brasil todo e regiões, ano de 2010, para os grupos de idade: $(<5),(\geq 5<10),(\geq 10<20),(\geq 20<40),(\geq 40<60),(\geq 60<80) e$ $(\geq 80)$ anos. 
Normalização 2 (N2): Quantidade de notificações por faixa etária dividida pelo total de notificações de cada região multiplicada por 100000 .

$$
N 2=\frac{\text { número de casos de dengue por faixa etária }}{\text { total de notificações de cada região }} \times 100000
$$

\begin{tabular}{c|c|c|c|c|c|c|c}
\hline \multicolumn{1}{c}{ Incidência de dengue calculada com a normalização $N 2$} \\
\hline Região/Fx. etária & $<5$ & $\geq 5<10$ & $\geq 10<20$ & $\geq 20<40$ & $\geq 40<60$ & $\geq 60<80$ & $\geq 80$ \\
\hline Brasil & 4767.0 & 6004.7 & 19431.7 & 39252.1 & 22824.7 & 7049.6 & 670.1 \\
Norte & 5967.2 & 7033.9 & 20028.5 & 40392.9 & 19874.1 & 6012.5 & 691.0 \\
Nordeste & 8315.9 & 10440.5 & 22678.9 & 35501.9 & 17359.5 & 5180.1 & 523.2 \\
Sudeste & 3458.2 & 4555.3 & 18287.7 & 40204.0 & 24988.8 & 7783.4 & 722.6 \\
Sul & 5052.6 & 5688.7 & 20224.2 & 37217.6 & 23877.4 & 7342.6 & 597.0 \\
Centro-Oeste & 4122.8 & 5167.2 & 18810.6 & 40279.6 & 23580.1 & 7356.4 & 683.5 \\
\hline
\end{tabular}

Tabela 1.4: Resultado de aplicar a Normalização N2 nos dados de notificação de dengue, ano de 2010. Para os casos de dengue somados no país, a divisão é feita pelo total de casos ocorridos no país, e para as regiões, divide-se pelo total de casos de cada região.
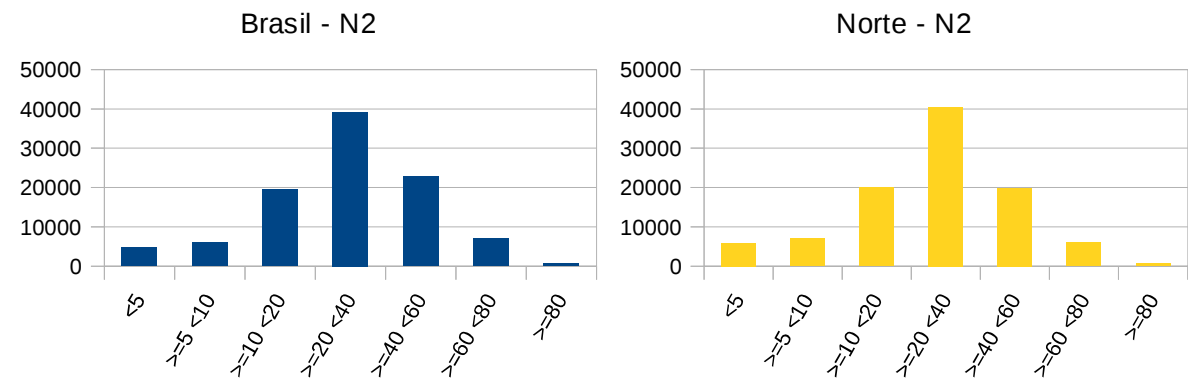

Nordeste - N2

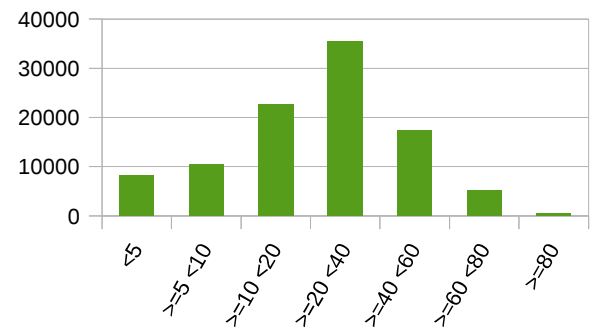

Sudeste - N2

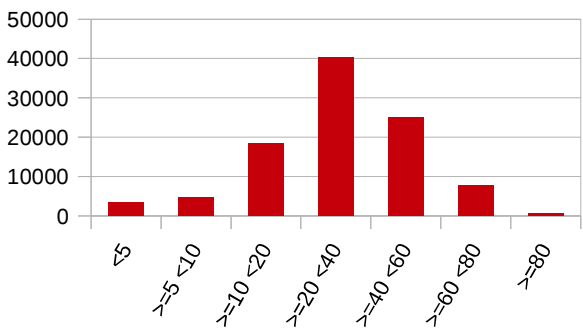

Sul - N2

Centro-Oeste - N2
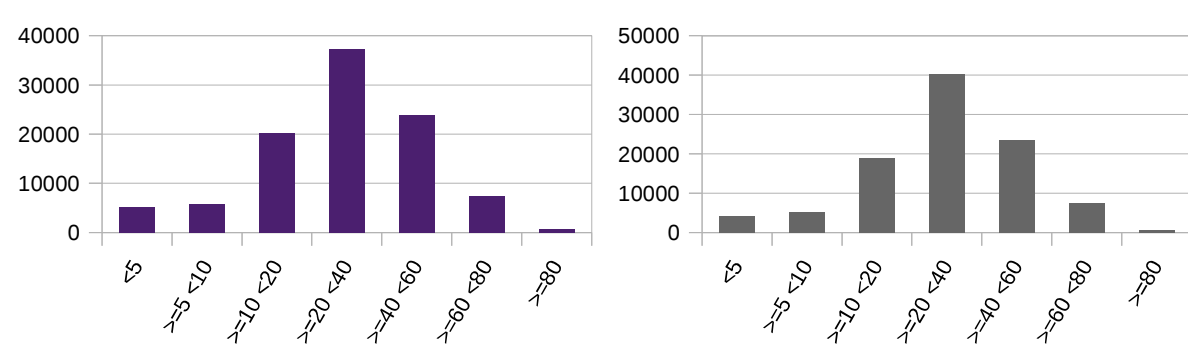

Figura 1.7: Incidência de dengue por faixas etárias com a normalização $N 2$, Brasil todo e regiões, ano de 2010, para os grupos de idade: $(<5),(\geq 5<10),(\geq 10<20),(\geq 20<40),(\geq 40<60),(\geq 60<80) e$ $(\geq 80)$ anos. 
Normalização 3 (N3): Quantidade de notificações por faixa etária dividida pela população total em cada faixa etária multiplicada por 100000 .

$N 3=\frac{\text { número de casos de dengue por faixa etária }}{\text { população total residente de cada região em cada faixa etária }} \times 100000$

\begin{tabular}{c|c|c|c|c|c|c|c}
\hline \multicolumn{2}{c}{ Incidência de dengue calculada com a normalização $N 3$} \\
\hline Região/Fx. etária & $<5$ & $\geq 5<10$ & $\geq 10<20$ & $\geq 20<40$ & $\geq 40<60$ & $\geq 60<80$ & $\geq 80$ \\
\hline Brasil & 449.1 & 521.4 & 739.5 & 797.5 & 685.8 & 519.0 & 296.7 \\
Norte & 482.5 & 538.5 & 739.8 & 936.9 & 900.8 & 800.1 & 631.2 \\
Nordeste & 445.8 & 511.9 & 495.5 & 454.1 & 370.0 & 256.2 & 136.7 \\
Sudeste & 413.7 & 500.2 & 858.1 & 923.3 & 783.1 & 590.6 & 330.7 \\
Sul & 204.9 & 210.9 & 311.8 & 301.2 & 246.5 & 183.7 & 99.7 \\
Centro-Oeste & 992.2 & 1174.3 & 1910.5 & 2065.7 & 1928.6 & 1723.2 & 1194.7 \\
\hline
\end{tabular}

Tabela 1.5: Resultado de aplicar a Normalização N3 nos dados de notificação de dengue, ano de 2010. Para os casos de dengue somados no país, a divisão é feita pelo total populacional em cada faixa etária, e para as regiões, divide-se pelo total populacional de cada região em cada faixa etária.
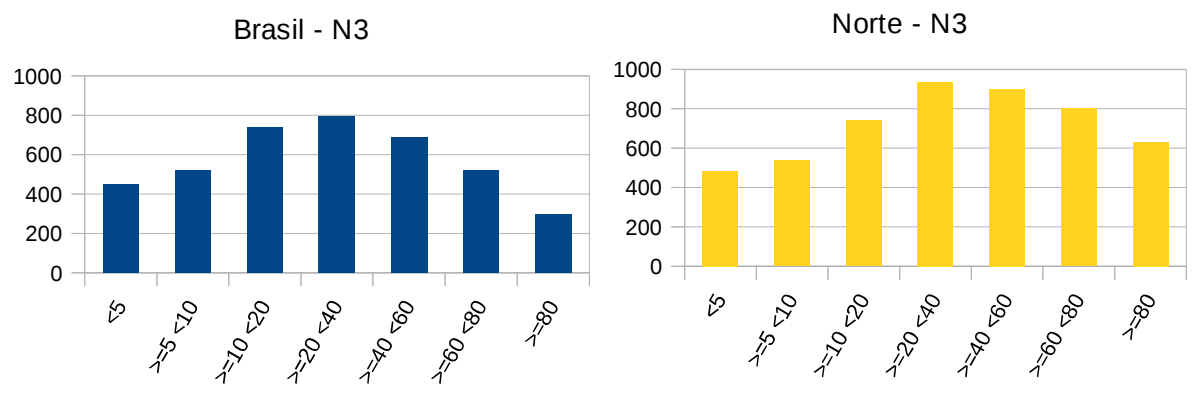

Nordeste - N3

Sudeste - N3
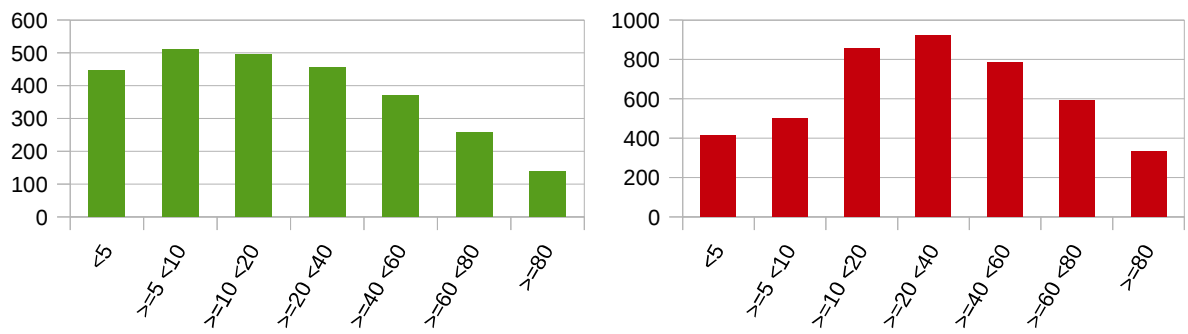

Sul - N3

Centro-Oeste - N3
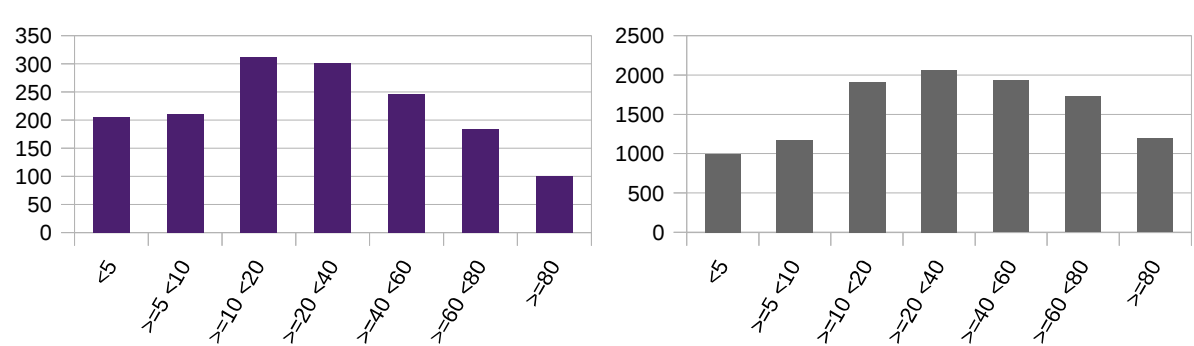

Figura 1.8: Incidência de dengue por faixas etárias com a normalização N3, Brasil todo e regiões, ano de 2010, para os grupos de idade: $(<5),(\geq 5<10),(\geq 10<20),(\geq 20<40),(\geq 40<60),(\geq 60<80) e$ $(\geq 80)$ anos. 


\subsection{Correlação}

Para fazer uma comparação entre dados de incidência de diferentes estados, ou mais detalhadamente, comparar a distribuição de dengue por faixa etária entre os municípios do Brasil, usaremos o coeficiente de correlação de Pearson que fornece uma medida de relação entre duas variáveis aleatórias ou dois conjuntos de dados, cujo cálculo é dado em função das médias e das variâncias dos dados, obtendo valores entre -1 e 1 . Se o resultado for igual a -1, tem-se uma correlação negativa perfeita entre as duas variáveis, ou seja, quando uma aumenta, a outra diminui. Se for igual a 0, as variáveis não dependem linearmente uma da outra, e se o resultado for igual a 1, a correlação é perfeita positiva, as duas crescem ao mesmo tempo. Assim, esse coeficiente mede a intensidade da associação linear existente entre as variáveis (Casella e Berger, 2002).

Nesse sentido, podemos agrupar regiões de acordo com grupos etários de maior risco e ter um indicativo de quais regiões possuem características semelhantes. De acordo com a seção anterior, mostramos que a Normalização $N 3$ é a que fornece uma melhor distinção sobre os perfis etários de distribuição de dengue. Assim, aplicamos a metodologia de calcular a correlação entre todos os estados brasileiros com as notificações de dengue do ano de 2010 separadas por faixa etária e normalizados com N3 (Equação (1.4)). O critério aplicado foi agrupar os estados que possuem correlação $\geq 0.90$ para ter uma maior confiança de que os padrões etários são os mesmos. Os resultados são apresentados na Tabela 1.6, em que cada número é o código de identificação do estado, definidos nas Figuras 1.9 e 1.10.

Na Figura 1.9 temos os estados: 13 Amazonas, 15 Pará, 16 Amapá e 51 Mato Grosso que não puderam ser agrupados segundo o critério da correlação $\geq 0.90$ com nenhum outro estado. A Figura 1.10 apresenta os agrupamentos dos estados que obtiveram correlação $\geq 0.90$ comparados dois a dois de acordo com a Tabela 1.6.

No primeiro gráfico da Figura 1.10 temos o grupo dos estados em que a incidência de dengue foi maior nos grupos de pessoas com idade a partir de 20 anos, o segundo apresenta alta incidência no grupo com idades de 10 à 59 anos e o terceiro gráfico agrupa estados em que a incidência foi alta no grupo de 0 à 39 anos de idade.

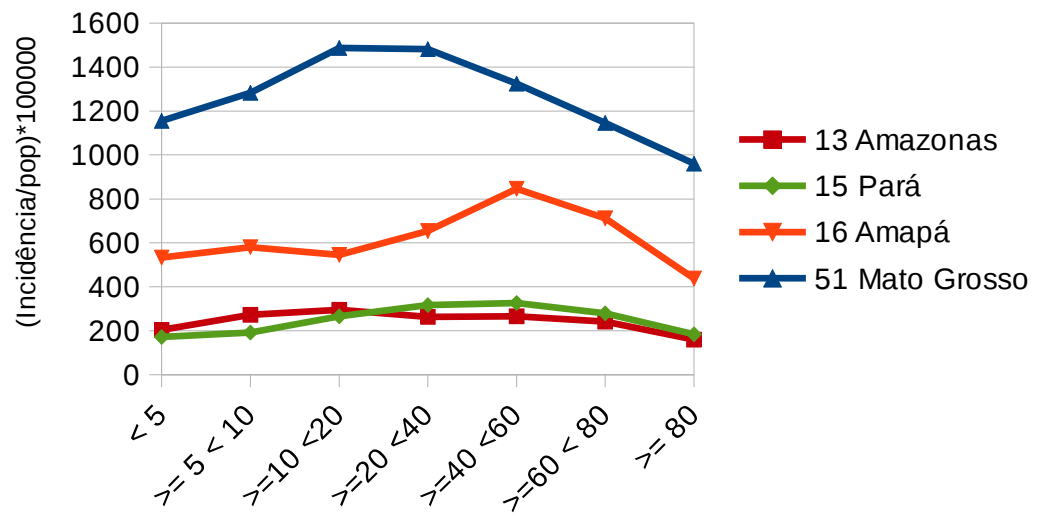

Figura 1.9: Estados que não puderam ser agrupados segundo correlação $\geq 0.90$ com os outros estado nos dados de incidência de dengue do ano de 2010, separados por faixa etária e calculados com a normalização N3, para os grupos de idade: $(<5),(\geq 5<10),(\geq 10<20),(\geq 20<40),(\geq 40<60),(\geq 60<80) e$ ( $\geq 80$ ) anos. Os estados 13-Amazonas, 15-Pará e 16-Amapá não obtiveram correlação $\geq 0.90$ com nenhum outro estado, já 51-Mato Grosso do Sul apresentou correlação alta com alguns estados do segundo grupo da Figura 1.10, porém não foi agrupado por não estar correlacionados com todos do grupo. 

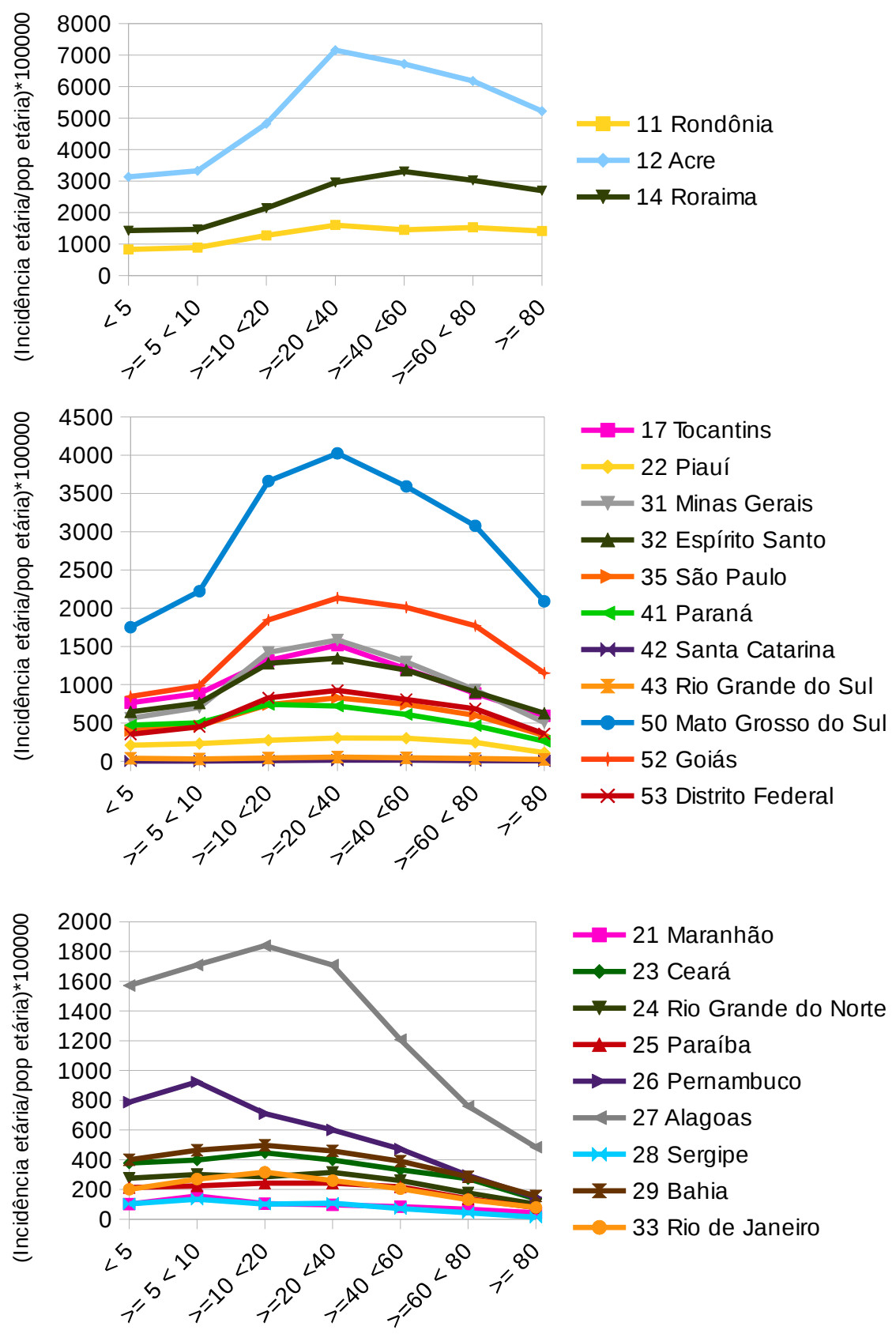

Figura 1.10: Agrupamento de estados que apresentam correlação $\geq 0.90$ nos dados de incidência de dengue no ano de 2010, separados por faixa etária e calculados com a normalização N3. Cada gráfico apresenta um grupo em que os estados estão correlacionados entre si. No primeiro gráfico, o grupo dos estados em que a incidência de dengue foi maior em pessoas com idade $\geq 20$ anos, o segundo apresenta alta incidência no grupo com idades $\geq 10<60$ anos e o terceiro gráfico mostra estados em que a incidência foi alta no grupo de 0 à 39 anos de idade. 


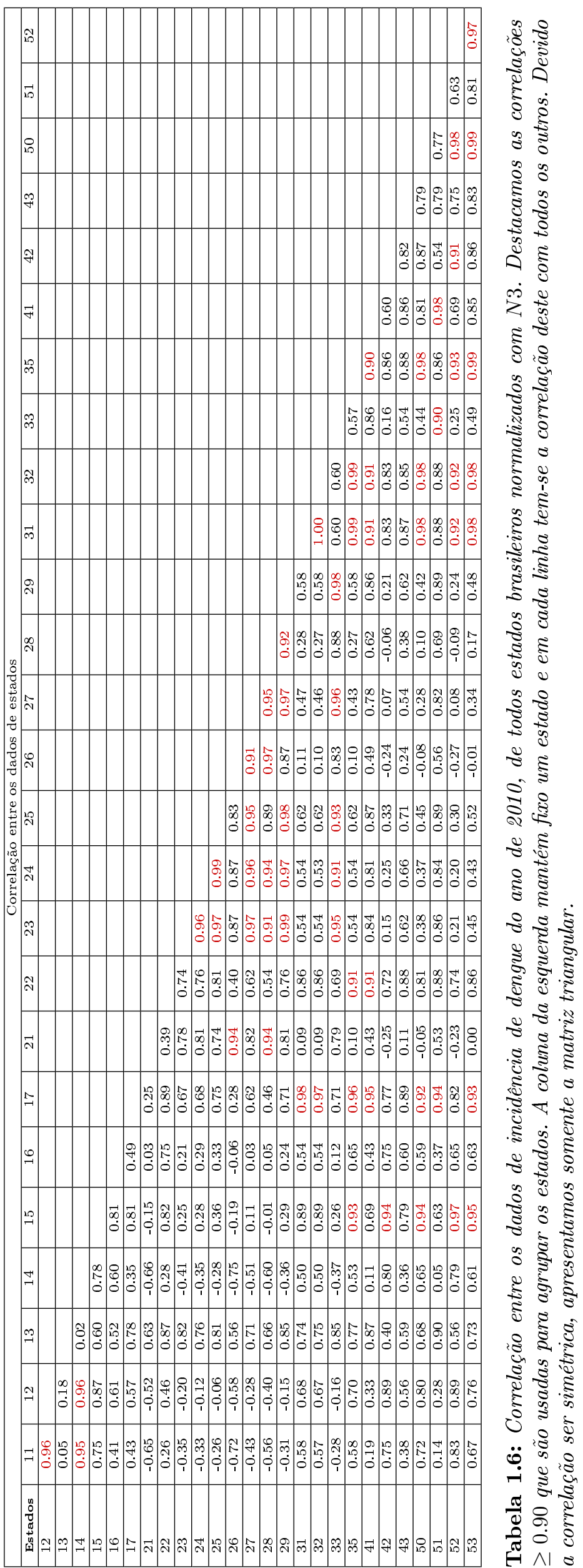




\subsubsection{Correlação e vacina}

Ao aplicar o coeficiente de correlação nos dados de notificação de dengue dos estados dois a dois, normalizados com $N 3$, mostramos que há estados dentro de uma mesma região que possuem características diferentes para a dengue em relação a grupos etários em maior risco, por exemplo, temos da Figura 1.10 que Tocantins, São Paulo, Goiás e Santa Catarina possuem o mesmo perfil etário de maior risco nas faixas etárias de $\geq 10<60$ anos, enquanto Rio Grande do Norte, Bahia e Rio de Janeiro figuram no grupo de risco de 0 à 39 anos. Assim, para critérios de protocolos de vacinação, o adequado é agrupar locais com perfis etários semelhantes. Dentre as vacinas disponíveis para a dengue, a vacina do Sanofi Pasteur, única disponível até o momento, foi mostrada ter eficácia diferente para os sorotipos e também eficácia que varia dependendo da faixa etária do indivíduo. Alguns trabalhos mostraram que ela é eficaz se aplicada em indivíduos soropositivos e indicada para a faixa de 9 à 45 anos (Ferguson et al., 2016; Torresi et al., 2017).

A vacina desenvolvida pelo Instituto Butantan (Butantan-DV) está atualmente na fase III de testes, fase em que é testada em indivíduos de diferentes localizações e com diferentes suscetibilidades. As fases anteriores mostram que a vacina Butantan-DV é recomendada para crianças e adultos de 2 a 59 anos e o esperado é que confira pelo menos $80 \%$ de proteção contra todos os sorotipos prevenindo os sintomas da dengue com uma única dose. Para a fase III, foram escolhidas cidades de todas as regiões brasileiras, sendo 3 cidades no Norte, 4 no Sudeste, 3 no Nordeste, 3 no CentroOeste, e 1 cidade do Sul. O intuito é mostrar a eficácia da vacina sob a exposição dos 4 sorotipos em regiões com diferentes níveis de força de infecção. As cidades escolhidas, apresentam incidência maior ou igual a 200 casos por 100000 habitantes, suporte para a pesquisa clínica através de rede hospitalar estabelecida principalmente em universidades públicas e certificada pelo Ministério da Saúde, e a viabilidade em termos de logística experimental, entre outros critérios (Precioso et al., 2015; Torresi et al., 2017).

Selecionamos 12 cidades, dentre as que estão sendo aplicada a vacina, e calculamos a correlação entre todas cidades duas a duas nos dados normalizados com $N 3$, agrupados nas faixas etárias $<5$, $\geq 5<10, \geq 10<20, \geq 20<40, \geq 40<60, \geq 60<80$ e $\geq 80$. Os valores das correlações são apresentados na Tabela 1.7. Os resultados dos agrupamentos são destacados na Figura 1.11. Concluímos que os perfis epidemiológicos etários da dengue nas cidades testes são diferentes e que cidades distantes podem ter características semelhantes relacionadas com as faixas etárias de maior risco, o que confirma que um agrupamento por estados não é adequado (Figura 1.9 e Figura 1.10). Usaremos esses resultados para simular cenários de aplicação da vacina de acordo com os grupos etários mais atingidos de cada cidade. 

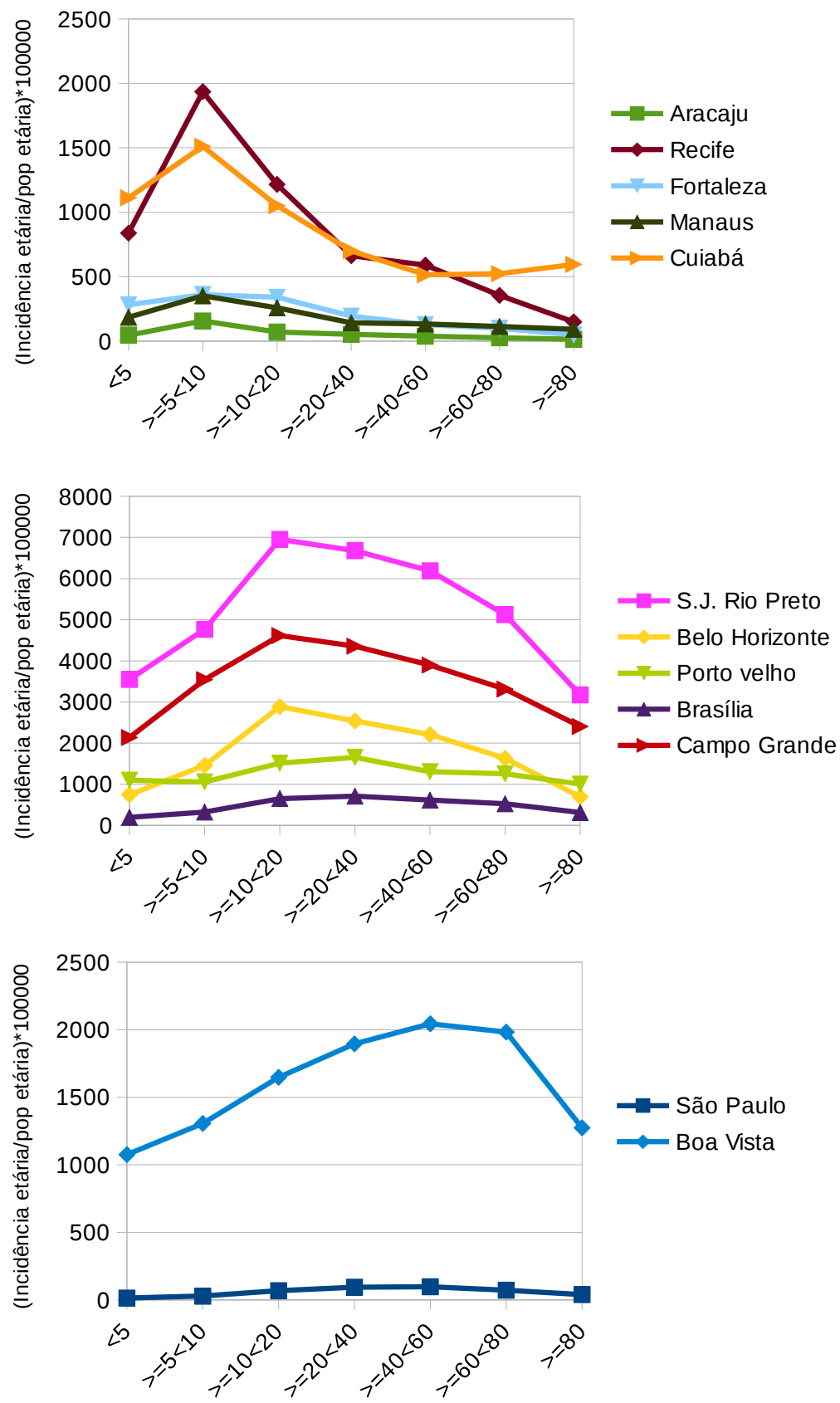

Figura 1.11: Agrupamento das cidades teste da vacina que apresentaram alta correlação nos dados de incidência por faixa etária. Na primeira figura temos que o grupo etário com maior número de casos é de 0 a 19 anos. A segunda figura apresenta as cidades em que os mais afetados possuem idade $\geq 10<60$ anos e por último as cidades em que os mais afetados são $\geq 20<80$ anos de idade. 

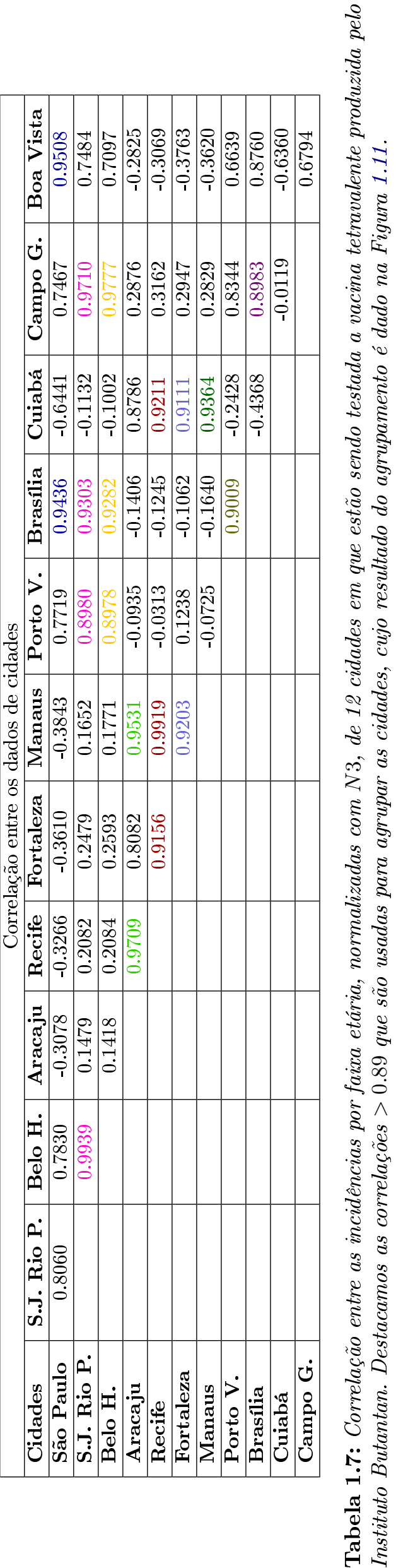


\subsubsection{Correlação e mobilidade}

Para finalizar o capítulo de análise de dados, aplicamos correlação para obter evidências de que a mobilidade humana atua como fator de propagação da dengue. Através das séries temporais é possível observar que um surto não começa ao mesmo tempo em cidades dentro de um mesmo estado, de forma que tem-se um indício de que a epidemia está se alastrando, mostrado na Figura 1.3. É fato que o mosquito não tem a capacidade de viajar longas distâncias, assim, o espalhamento do vírus ocorre quando os humanos infectados viajam de um lugar para outro e são picados por mosquitos suscetíveis de outras regiões que por sua vez se tornam infectados e capazes de transmitir a dengue (Amaku et al., 2016; Barmak et al., 2011; Brauer e Castillo-Chavez, 2001; de Castro Medeiros et al., 2011; Krämer et al., 2010; Liu-Helmersson et al., 2016; Massad et al., 2008; World Health Organization et al., 2009).

A aplicação foi feita para todas as cidades do estado do Rio de Janeiro nas séries temporais de dengue no período de um ano. Apresentamos o estudo de mobilidade através de correlação mais detalhadamente em (dos Santos et al., 2018). Foram selecionadas cidades com uma população maior do que 50 mil habitantes. A metodologia identifica as cidades que tiveram surtos, isto é, acima de 300 casos por 100000 habitantes. Identifica-se a cidade que atingiu primeiro a incidência de 300 casos e esta é definida como o foco da infecção. Após isso seguem-se as etapas: $(i)$ a correlação é aplicada entre todos os pares de cidades para o mesmo período de 52 semanas, (ii) exceto pelo foco, o período das cidades é definido com delay de $n=1,2$ ou 3 semanas.

Uma alta correlação com delay entre duas cidades $\left(C_{j}, C_{k}\right), j, k=1, \cdots, m$, em que $m$ é o número total de cidades analisadas, sugere que o surto tem uma defasagem de $n$-semanas no qual pode indicar que a doença migrou da cidade $C_{j}$ para a $C_{k}$. Definimos que a correlação é significante se seu valor é maior do que 0.8 e a significância $p$-valor é menor do que 0.05 . Nossa hipótese de que a dengue se espalha de uma cidade para a outra pode ser verificada pela evolução da sequência correlações calculadas com defasagem de tempo $n$.

Na Figura 1.12 apresentamos a série temporal das cidades do Estado do Rio de Janeiro que obtiveram alta correlação. Nova Iguaçu foi identificada como foco pois é a primeira cidade a alcançar 300 casos (na décima semana epidemiológica). Nova Iguaçu e Niterói tiveram alta correlação sem delay, indicando que o surto começou na mesma semana; Itaboraí teve correlação com Niterói com deslocamento de 1 semana, e também, Cachoeiras de Macacu teve correlação com Itaboraí com deslocamento de 2 semanas.

Incidência 2008

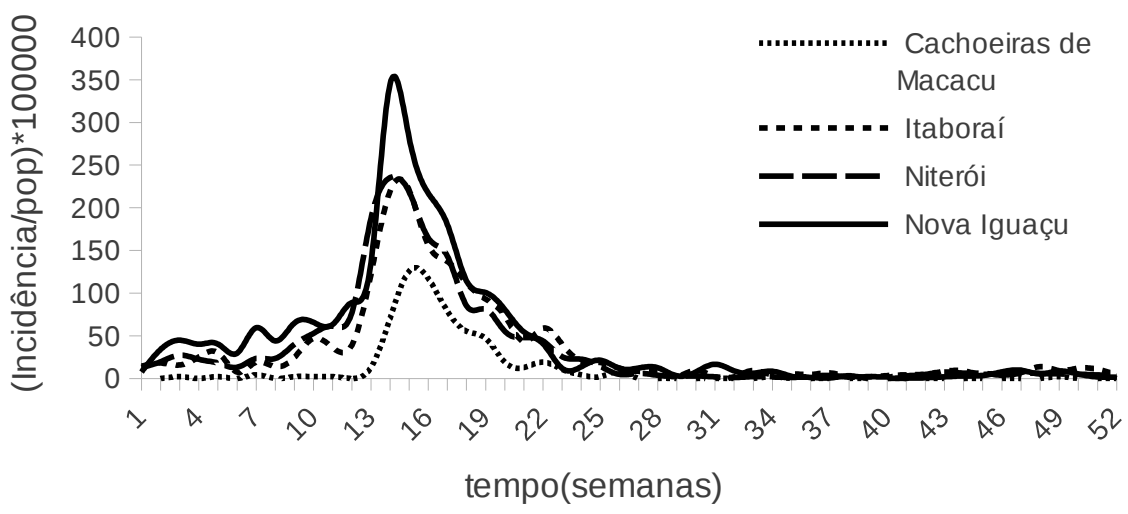

Figura 1.12: Incidência de dengue em cidades do estado do Rio de Janeiro que apresentaram alta correlação entre si, com ou sem deslocamento da série temporal de 52 semanas, ano de 2008. 


\section{Capítulo 2}

\section{Modelagem da dengue}

Entender as características e dinâmica da infecção por dengue é fundamental pois deve-se considerar que a doença pode ser transmitida por diferentes sorotipos e que cada infecção fornece imunidade cruzada temporária para todos os sorotipos e imunidade permanente para o sorotipo da infecção (Reich et al., 2013). Geralmente um sorotipo domina em um ano como mostrado na Figura 1.4, Capítulo 1, mas nos anos seguintes pode mudar se tiver esgotado a quantidade de suscetíveis a ele. Assim, um modelo que considera coexistência de vários sorotipos é necessário para estudar a transmissão de dengue. Porém, é preciso ter em mente que os modelos são uma aproximação da doença, possuem limitações, e que tendem a capturar as características principais (Vynnycky e White, 2010; Wikramaratna et al., 2010). Um modelo será considerado adequado quando considerar muitos detalhes biológicos da doença, sendo transparente no sentido de deixar claro as hipóteses usadas, e também for capaz de reproduzir os dados de incidência.

Nosso modelo básico para humanos é o SIR estruturado por Kermack e Mckendrick (1927), no qual consideramos que a transmissão do vírus se dá através de mosquitos, o que se torna um modelo Ross-MacDonald, porém com somente os compartimentos de mosquitos suscetíveis e infectados (Amaku et al., 2016). Consideramos os modelos com populações constantes e incluímos uma forçante de sazonalidade na taxa de nascimento dos vetores. O modelo com dois sorotipos é baseado nos trabalhos (Aguiar et al., 2011, 2016; Esteva e Vargas, 2003; Kooi et al., 2014; Souto-Maior, 2017), a partir dos quais estendemos para 3 e 4 sorotipos. Aos modelos serão acrescentados o compartimento de vacinação, abordando duas possibilidades: vacinação aleatória na população, que pode ser aplicada em uma proporção de suscetíveis soronegativos ou soropositivos; ou direcionando a vacina para a faixa etária mais afetada de acordo com o estudo feito na Seção 1.3.1, Capítulo 1. Para este fim, os modelos são compartimentados em duas faixas etárias. Na sequência discutimos um método de estimação de parâmetros que será aplicado em todos os modelos para ajustar aos dados de incidência de dengue de algumas séries temporais selecionadas.

Nossa contribuição em relação aos trabalhos existentes (Aguiar e Stollenwerk, 2017; Aguiar et al., 2013; Chikaki e Ishikawa, 2009; Coudeville e Garnett, 2012; Wikramaratna et al., 2010), consiste em comparar os modelos com múltiplos sorotipos, e discutir a importância do nosso modelo com quatro sorotipos, de forma que a transmissão é entre vetor-hospedeiro, e o período de imunidade cruzada é incluído na dinâmica como uma taxa. Consideramos que a imunidade permanente contra todos sorotipos se dá somente após quatro infecções sequenciais, fato que na maioria dos modelos da literatura, é considerado imunidade permanente após a segunda infecção. Não incluímos o efeito de ADE na segunda infecção, e nosso modelo é assimétrico, assim temos uma taxa de transmissão diferente para cada sorotipo. A estimação de parâmetros é feita a partir de dados de incidência de dengue do Brasil, incluindo a estimação dos parâmetros para os compartimentos dos vetores. Os parâmetros serão ajustados por meio do pacote pomp disponível em linguagem $R$ (King et al., $2016,2017)$. Os cenários de vacinação com esses modelos serão aplicados em dados de cidades brasileiras onde estão sendo testadas a vacina do Instituto Butantan (Precioso et al., 2015). Os conceitos epidemiológicos básicos, assim como algumas definições foram incluídos no Apêndice A. 


\subsection{Hipóteses e parâmetros dos modelos}

Os modelos com múltiplos sorotipos consistem na dinâmica do SIR se repetindo $\mathrm{n}$ vezes $(n=$ $1,2,3,4)$, e considera a existência de mosquitos suscetíveis e infectados com um dos sorotipos existentes DENV-1, DENV-2, DENV-3, DENV-4. O modelo com vacinação, considera uma cobertura de vacinação anual aplicada em suscetíveis seronegativos ou soropositivos que após receber a vacina serão movidos para um novo compartimento $\mathrm{H}_{V}$. O adequado é atribuir que a vacina é imperfeita e portanto incluímos uma taxa de infecção em indivíduos vacinados, também sendo possível diferenciar a eficácia para cada sorotipo. Vamos considerar somente dois grupos etários, que consistem em um agrupamento de várias faixas etárias. Todos os modelos apresentados neste trabalho, foram estruturados considerando-se as seguintes hipóteses:

- Todos os indivíduos são inicialmente igualmente suscetíveis à doença, isto é, a população é homogênea, assim a probabilidade de que dois indivíduos contraiam a infecção é a mesma independente da idade, grupo social, ou outras caraterísticas;

- As taxas de nascimentos e mortes são iguais, de forma que as populações permanecem constante;

- Para os modelos com mais de um sorotipo, não há diferença entre os sorotipos em termos de duração da infecção;

- Após cada infecção, o indivíduo estará permanentemente imune para o sorotipo que já foi infectado e com imunidade cruzada temporária para todos sorotipos;

- O período de imunidade cruzada é o mesmo após cada infecção independente do sorotipo;

- Os vetores não podem ser infectados mais de uma vez e não se recuperam após uma infecção.

Com essas considerações, estruturamos os compartimentos que representam as populações de humanos e vetores transmissões.

- $S=$ Humanos suscetíveis soronegativos;

- $I=$ Humanos infectados;

- $I_{i j k l}=$ Humanos infectados sequencialmente pelos sorotipos $i, j, k$ e $l$;

- $R_{i j k}=$ Humanos recuperados da infecção pelos sorotipos $i, j$ e $k$;

- $S_{i j k}=$ Humanos suscetíveis soropositivos com imunidade para os sorotipos $i, j$ e $k$;

- $R=$ Humanos recuperados de todas infecções;

- $V=$ Vetores suscetíveis;

- $V_{i}=$ Vetores infectados com o sorotipo $i$;

- $S_{Z}=$ Humanos do grupo etário Z suscetíveis soronegativos;

- $I_{Z_{i j k l}}=$ Humanos do grupo etário Z infectados com os sorotipos $i, j, k$ e $l$;

- $R_{Z_{i j k}}=$ Humanos do grupo etário Z recuperados da infecção pelos sorotipos $i, j$ e $k$;

- $S_{Z_{i j k}}=$ Humanos do grupo etário Z suscetíveis soropositivos com imunidade para os sorotipos $i, j$ e $k$;

- $H_{V}=$ Humanos vacinados; 
Os índices $i, j, k$ e $l$ em $I$ representam a ordem em que as infecções ocorreram por cada sorotipo, sendo que o último índice é o sorotipo pelo qual o indivíduo está infectado no momento, ou seja, no compartimento $I_{i j k l}$, a primeira infecção foi pelo sorotipo $i$, a segunda com $j$, a terceira com $k$ e a última com o sorotipo $l$, com $i \neq j \neq k \neq l$. No caso dos suscetíveis $S_{i j k}$, os índices representam por quais sorotipos o indivíduo já foi infectado, se tornando imune para estes sorotipos. Usaremos a nomenclatura recuperados para $R$, ao invés de removidos, devido ao fato do indivíduo poder se recuperar e ter mais infecções por diferentes sorotipos.

Os parâmetros epidemiológicos necessários nos modelos de 1 a 4 sorotipos, são descritos abaixo. O parâmetro de imunidade cruzada temporária só é necessário nos modelos com dois ou mais sorotipos.

$* \mathrm{~N}_{h}=$ População total de humanos;

* $\mathrm{N}_{m}=$ População total de mosquitos;

$* \mu_{h}=$ Taxa de nascimento/mortalidade natural dos humanos;

$* \mu_{m}=$ Taxa de nascimento/mortalidade natural dos mosquitos;

* $\gamma=$ Taxa de recuperação dos humanos;

* $\varphi=$ Taxa de imunidade cruzada temporária;

* $\beta=$ Taxa de transmissão entre mosquito infectado e humano suscetível;

$* \beta_{i}=$ Taxa de transmissão entre mosquito infectado com sorotipo $i$ e humano suscetível;

* $\Omega=$ Taxa de transmissão entre humano infectado e mosquito suscetível;

* $\Omega_{i}=$ Taxa de transmissão entre humano infectado com sorotipo $i$ e mosquito suscetível;

* $\alpha_{s}=$ Parâmetro de escala de amplitude na sazonalidade;

$* \delta=$ Fase da sazonalidade;

Parâmetros necessários nos modelos após acrescentar o compartimento dos vacinados.

* $\psi_{S}=$ Proporção de suscetíveis soronegativos vacinados;

$* \psi_{S_{i}}=$ Proporção de suscetíveis soropositivos vacinados;

$* \sigma_{i}^{-}=$Taxa de infecção em soronegativos vacinados;

* $\sigma_{i}^{+}=$Taxa de infecção em soropositivos vacinados;

$* \psi_{S_{Z}}=$ Proporção de suscetíveis soronegativos vacinados no grupo etário $Z$;

* $\psi_{S_{Z_{i}}}=$ Proporção de suscetíveis soropositivos vacinados no grupo etário $Z$;

* $\sigma_{Z_{i}}^{-}=$Taxa de infecção em soronegativos vacinados do grupo etário $Z$;

$* \sigma_{Z_{i}}^{+}=$Taxa de infecção em soropositivos vacinados do grupo etário $Z$;

$* a=$ Taxa de transição de faixa etária. 


\subsubsection{Modelo básico}

Apresentamos aqui o modelo SIR básico, com humanos suscetíveis S, infectados I e recuperados $\mathrm{R}$ da infecção, e somente vetores suscetíveis $\mathrm{V}$ e infectados $\mathrm{V}_{i}$, o qual denominaremos por $\mathrm{SIRVV}_{i}$ (Allen et al., 2008; Amaku et al., 2016; Anderson et al., 1992; Andraud et al., 2012; Brauer e Castillo-Chavez, 2001; Derouich et al., 2003; Esteva e Vargas, 1998, 1999; Keeling e Rohani, 2008; Kermack e McKendrick, 1927; Krämer et al., 2010; Martcheva, 2015; Vynnycky e White, 2010). A dinâmica de transmissão entre os compartimentos é descrita no esquema da Figura 2.1. A equação I dos humanos infectados, pode ser por um dos sorotipos existentes DENV-1, DENV-2, DENV-3 e DENV-4, sendo o sorotipo que dominou no surto ou a soma de todos os infectados, sem diferenciar os sorotipos. Da mesma forma que os mosquitos podem ser infectados com somente um sorotipo, ou $\mathrm{V}_{i}$ pode ser a soma de todos mosquitos infectados.

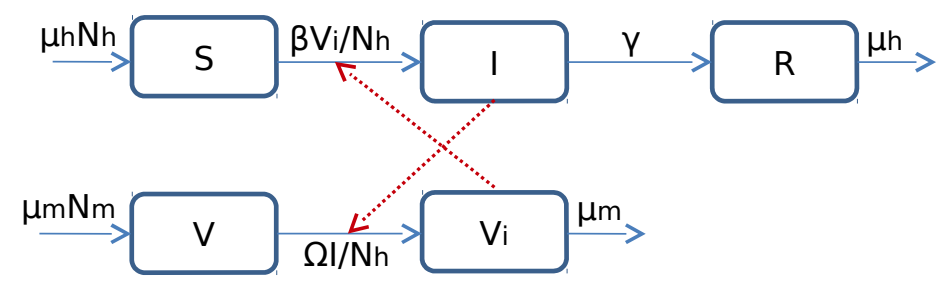

Figura 2.1: Dinâmica de transmissão de dengue em um modelo com um sorotipo, humanos suscetiveis, infectados e recuperados (SIR), e vetores suscetiveis e infectados ( $\left.V V_{i}\right)$. Cada compartimento representa uma população, e as flechas consideram a entrada e saída dos compartimentos de acordo a uma certa taxa. A transmissão do vírus é feita através do contato efetivo de humanos suscetiveis com mosquitos infectados, reciprocamente de mosquito suscetível com humano infectado. A taxa de mortalidade natural está presente em todos compartimentos.

No modelo $\operatorname{SIRVV}_{i}$ com demografia, as populações permanecem constantes, isto é, $S(t)+I(t)+$ $R(t)=N_{h}$ e $V(t)+V_{i}(t)=N_{m}$ (Esteva e Vargas, 1998). A infecção ocorre quando humanos suscetíveis $\mathrm{S}$ entram em contato efetivo com um mosquitos infectados $\mathrm{V}_{i}$ a uma taxa de transmissão $\beta$, então se tornam infectados I e se recuperam a uma taxa $\gamma$, passando a pertencer a classe dos recuperados $\mathrm{R}$. Como a dengue não é uma doença com alta taxa de mortalidade, consideramos somente a taxa de mortalidade natural dos humanos que está presente em todos compartimentos $\mu_{h}$, correspondendo ao inverso da expectativa de vida. De forma análoga, mosquitos suscetíveis $\mathrm{V}$ se tornam infectados $\mathrm{V}_{i}$ quando em contato efetivo com humanos infectados I a uma taxa de transmissão $\Omega$ e são removidos da dinâmica a uma taxa de mortalidade $\mu_{m}$. A transferência dos indivíduos entre os compartimentos de acordo com essas considerações, é descrita pelo sistema de equações diferenciais ordinárias (EDOs) (Sotomayor, 1979):

$$
\begin{aligned}
& \frac{d S}{d t}=\mu_{h} N_{h}-\beta V_{i} S / N_{h}-\mu_{h} S \\
& \frac{d I}{d t}=\beta V_{i} S / N_{h}-\left(\gamma+\mu_{h}\right) I \\
& \frac{d R}{d t}=\gamma I-\mu_{h} R \\
& \frac{d V}{d t}=\mu_{m} N_{m}-\Omega I V / N_{h}-\mu_{m} V \\
& \frac{d V_{i}}{d t}=\Omega I V / N_{h}-\mu_{m} V_{i}
\end{aligned}
$$


Os valores iniciais desse sistema são tais que $S(0) \geq 0, I(0) \geq 0, R(0) \geq 0, V(0) \geq 0$ e $V_{i}(0) \geq 0$, pois em epidemiologia somente interessa as soluções não-negativas desse problema de valor inicial, que são estudadas no conjunto

$$
\Omega=\left\{\left(S, I, R, V, V_{i}\right) \in \mathbb{R}_{+}^{5}: S+I+R \leq N_{h}, V+V_{i} \leq N_{m}\right\}
$$

o qual é positivamente invariante em $\Omega$ com solução única para todo $t$ positivo, que significa que qualquer trajetória do sistema com condição inicial em $\Omega$, permanece em $\Omega$ (Keeling e Rohani, 2008; Krämer et al., 2010; Rodrigues et al., 2012; Sotomayor, 1979).

\subsubsection{Modelos com múltiplos sorotipos}

Para modelar a coexistência de dois sorotipos de dengue em uma população, a dinâmica de transmissão da doença é expandida do modelo básico SIR para humanos (Figura 2.1, Equação (2.1)), sendo necessário um período de imunidade cruzada para os humanos se tornarem suscetíveis novamente e terem a possibilidade de se infectarem com o segundo sorotipo (Adams et al., 2006; Reich et al., 2013). Assim, o modelo diferencia entre infecção primária e secundária e também a ordem em que as infecções ocorreram, isto é, um humano suscetível pode ser infectado primeiro com o sorotipo $i$ e segundo com o sorotipo $j(i \neq j)$, ou vice e versa. Este modelo é denominado $2 \times \mathrm{SIRVV}_{i}$, (Aguiar e Stollenwerk, 2017; Aguiar et al., 2011, 2016; Billings et al., 2007; Kooi et al., 2014; Souto-Maior, 2017). Abaixo temos a representação desse esquema considerando os índices $i=1,2$ que compreendem quaisquer dois sorotipos entre DENV-1, DENV-2, DENV-3 e DENV-4, ou um agrupamento dos sorotipos.
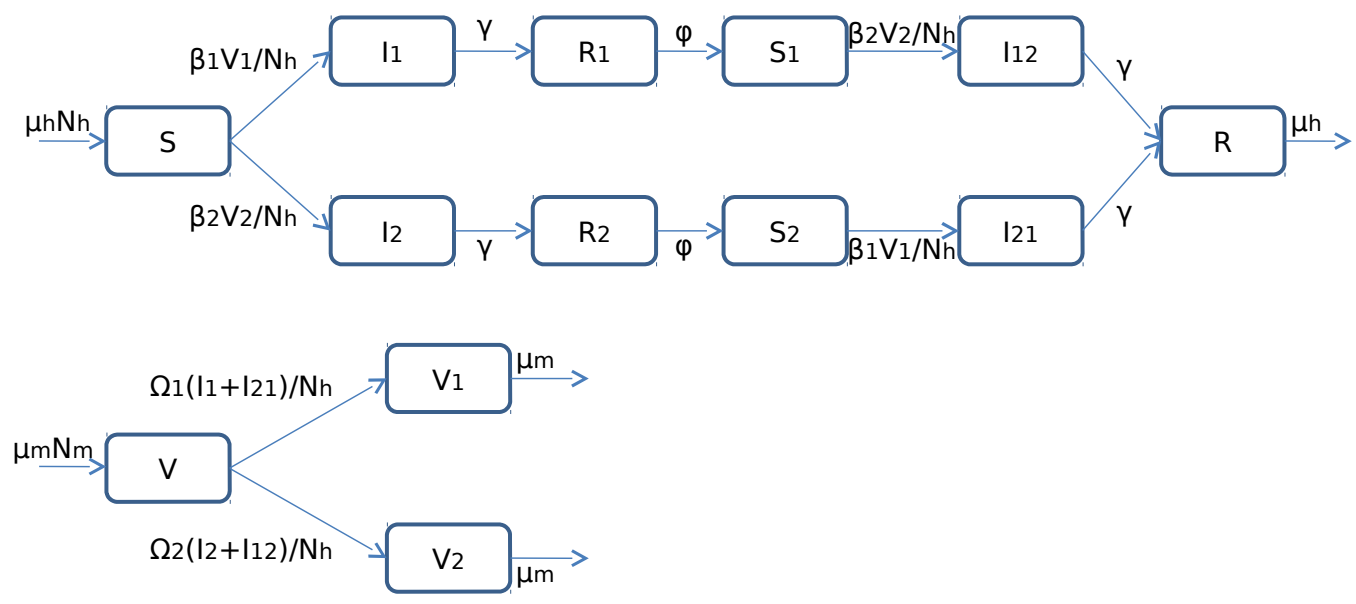

Figura 2.2: Dinâmica de transmissão de dengue em um modelo com dois sorotipos, $2 \times S I R$ para humanos e VV $V_{i}$ para vetores, com a possibilidade de até duas infecções sequenciais. Cada compartimento representa uma população, e as flechas consideram a entrada e saída dos compartimentos de acordo a uma certa taxa. A transmissão do vírus é feita através do contato efetivo de humanos suscetiveis com mosquitos infectados, reciprocamente de mosquitos suscetiveis com humanos infectados.

Neste modelo, após um indivíduo suscetível $(\mathrm{S})$ se tornar infectado $\left(\mathrm{I}_{i}\right)$ a uma taxa de transmissão $\beta_{i}$ por um dos sorotipos, este se recupera a uma taxa $\gamma$ e então passa a ser do compartimento dos recuperados $\left(\mathrm{R}_{i}\right)$, o qual vai ter imunidade permanente ao sorotipo que foi infectado, imunidade cruzada temporária contra todos sorotipos, e após esse período $1 / \varphi$, volta a ser suscetível $\mathrm{S}_{j}$, a uma taxa $\varphi$, a um sorotipo diferente do sorotipo da primeira infecção, podendo assim, ser infectado uma segunda vez $\mathrm{I}_{i j}, i \neq j$ e então se recuperar da segunda infecção $\mathrm{R}$ e ficar permanentemente imune. Novamente, em todos compartimentos consideramos a taxa de mortalidade natural dos humanos $\mu_{h}$ e dos mosquitos $\mu_{m}$. As flechas que indicam transmissão são ocultadas para dar mais clareza nos modelos com dois ou mais sorotipos. As equações que descrevem a dinâmica de transmissão de 
dengue do modelo $2 \times \operatorname{SIRVV}_{i}$ apresentado na Figura 2.2, são dadas por:

Primeira infecção:

$$
\begin{aligned}
& \frac{d S}{d t}=\mu_{h} N_{h}-\left(\beta_{1} V_{1}+\beta_{2} V_{2}\right) S / N_{h}-\mu_{h} S \\
& \frac{d I_{1}}{d t}=\beta_{1} V_{1} S / N_{h}-\left(\gamma+\mu_{h}\right) I_{1} \\
& \frac{d I_{2}}{d t}=\beta_{2} V_{2} S / N_{h}-\left(\gamma+\mu_{h}\right) I_{2} \\
& \frac{d R_{1}}{d t}=\gamma I_{1}-\left(\varphi+\mu_{h}\right) R_{1} \\
& \frac{d R_{2}}{d t}=\gamma I_{2}-\left(\varphi+\mu_{h}\right) R_{2}
\end{aligned}
$$

Segunda infecção:

$$
\begin{aligned}
& \frac{d S_{1}}{d t}=\varphi R_{1}-\beta_{2} V_{2} S_{1} / N_{h}-\mu_{h} S_{1} \\
& \frac{d S_{2}}{d t}=\varphi R_{2}-\beta_{1} V_{1} S_{2} / N_{h}-\mu_{h} S_{2} \\
& \frac{d I_{12}}{d t}=\beta_{2} V_{2} S_{1} / N_{h}-\left(\gamma+\mu_{h}\right) I_{12} \\
& \frac{d I_{21}}{d t}=\beta_{1} V_{1} S_{2} / N_{h}-\left(\gamma+\mu_{h}\right) I_{21} \\
& \frac{d R}{d t}=\gamma\left(I_{12}+I_{21}\right)-\mu_{h} R
\end{aligned}
$$

Vetores:

$$
\begin{aligned}
\frac{d V}{d t} & =\mu_{m} N_{m}-\Omega_{1}\left(I_{1}+I_{21}\right) V / N_{h}-\Omega_{2}\left(I_{2}+I_{12}\right) V / N_{h}-\mu_{m} V \\
\frac{d V_{1}}{d t} & =\Omega_{1}\left(I_{1}+I_{21}\right) V / N_{h}-\mu_{m} V_{1} \\
\frac{d V_{2}}{d t} & =\Omega_{2}\left(I_{2}+I_{12}\right) V / N_{h}-\mu_{m} V_{2}
\end{aligned}
$$

Nesta tese temos por objetivo comparar os modelos de 1, 2, 3 e 4 sorotipos. Assim, considerando que $n=1,2,3,4$ representa a quantidade de sorotipos existentes para a dengue, e que o número máximo de infecções é $m=4$, podemos expandir as equações do modelo com dois sorotipos dado acima, para um sistema que descreve a dinâmica de transmissão de dengue em uma situação de coexistência de 3 e 4 sorotipos distintos, de forma que um humano suscetível pode ser infectado sequencialmente uma vez por cada sorotipo, atribuindo um período de imunidade cruzada após cada infecção. No nosso modelo como 4 sorotipos, o esquema SIR se repete 4 vezes, o qual denominaremos por $4 \times \mathrm{SIRVV}_{i} ; 4 \times \mathrm{SIR}$ para humanos e $\mathrm{VV}_{i}$ para vetores $i=1,2,3,4$, esquematizado na Figura 2.3. 


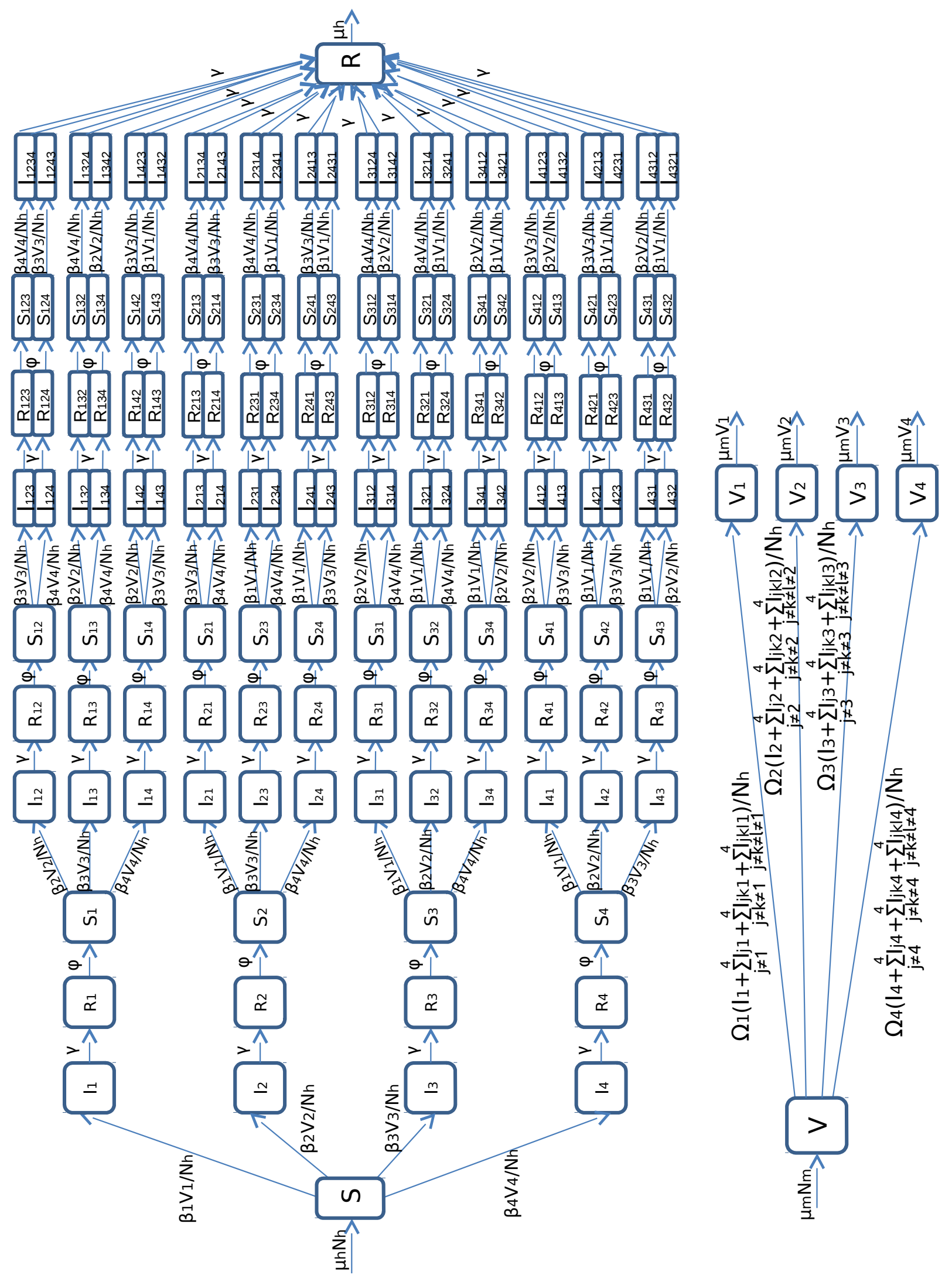

Figura 2.3: Dinâmica de transmissão de dengue em um modelo com quatro sorotipos, $4 \times$ SIR para humanos e $V V_{i}$ para vetores, com a possibilidade de até quatro infecções sequenciais. Cada compartimento representa uma população, e as flechas consideram a entrada e saída dos compartimentos de acordo a uma certa taxa. A transmissão do vírus é feita através do contato efetivo de humanos suscetiveis com mosquitos infectados com um dos sorotipos $1,2,3$, ou 4, reciprocamente de mosquitos suscetiveis com humanos infectados com um dos sorotipos $1,2,3$, ou 4 . 
O sistema de equações que descreve a dinâmica de transmissão de dengue com o modelo $4 \times \operatorname{SIRVV}_{i}$ apresentado na Figura 2.3, é dado por:

Primeira infecção:

$$
\begin{aligned}
& \frac{d S}{d t}=\mu_{h} N_{h}-\left(\sum_{i=1}^{n} \beta_{i} V_{i}\right) S / N_{h}-\mu_{h} S \\
& \frac{d I_{i}}{d t}=\beta_{i} V_{i} S / N_{h}-\left(\gamma+\mu_{h}\right) I_{i}, \quad i=1, n \\
& \frac{d R_{i}}{d t}=\gamma I_{i}-\left(\varphi+\mu_{h}\right) R_{i}, \quad i=1, n
\end{aligned}
$$

Segunda infecção:

$$
\begin{aligned}
& \frac{d S_{i}}{d t}=\varphi R_{i}-\left(\sum_{\substack{j=1 \\
j \neq i}}^{n} \beta_{j} V_{j}\right) S_{i} / N_{h}-\mu_{h} S_{i}, \quad i=1, n \\
& \frac{d I_{i j}}{d t}=\beta_{j} V_{j} S_{i} / N_{h}-\left(\gamma+\mu_{h}\right) I_{i j}, \quad i, j=1, n, \quad j \neq i \\
& \frac{d R_{i j}}{d t}=\gamma I_{i j}-\left(\varphi+\mu_{h}\right) R_{i j}, \quad i, j=1, n, \quad j \neq i
\end{aligned}
$$

Terceira infecção:

$$
\begin{aligned}
& \frac{d S_{i j}}{d t}=\varphi R_{i j}-\left(\sum_{\substack{k=1 \\
k \neq j \neq i}}^{n} \beta_{k} V_{k}\right) S_{i j} / N_{h}-\mu_{h} S_{i j}, \quad i, j=1, n, \quad j \neq i \\
& \frac{d I_{i j k}}{d t}=\beta_{k} V_{k} S_{i j} / N_{h}-\left(\gamma+\mu_{h}\right) I_{i j k}, \quad i, j, k=1, n, \quad k \neq j \neq i \\
& \frac{d R_{i j k}}{d t}=\gamma I_{i j k}-\left(\varphi+\mu_{h}\right) R_{i j k}, \quad i, j, k=1, n, \quad k \neq j \neq i
\end{aligned}
$$

Quarta infecção:

$$
\begin{aligned}
& \frac{d S_{i j k}}{d t}=\varphi R_{i j k}-\beta_{l} V_{l} S_{i j k} / N_{h}-\mu_{h} S_{i j k}, \quad i, j, k, l=1, n, \quad l \neq k \neq j \neq i \\
& \frac{d I_{i j k l}}{d t}=\beta_{l} V_{l} S_{i j k} / N_{h}-\left(\gamma+\mu_{h}\right) I_{i j k l}, \quad i, j, k, l=1, n, \quad l \neq k \neq j \neq i \\
& \frac{d R}{d t}=\gamma\left(\sum_{\substack{i, j, k, l=1 \\
l \neq k \neq j \neq i}}^{n} I_{i j k l}\right)-\mu_{h} R
\end{aligned}
$$


Vetores:
$\frac{d V}{d t}=\mu_{m} N_{m}-\sum_{i=1}^{n} \Omega_{i}\left(I_{i}+\sum_{\substack{j=1 \\ j \neq i}}^{n} I_{j i}+\sum_{\substack{j, k=1 \\ k \neq j \neq i}}^{n} I_{j k i}+\sum_{\substack{j, k, l=1 \\ l \neq k \neq j \neq i}}^{n} I_{j k l i}\right) V / N_{h}-\mu_{m} V$
$\frac{d V_{i}}{d t}=\Omega_{i}\left(I_{i}+\sum_{\substack{j=1 \\ j \neq i}}^{n} I_{j i}+\sum_{\substack{j, k=1 \\ k \neq j \neq i}}^{n} I_{j k i}+\sum_{\substack{j, k, l=1 \\ l \neq k \neq j \neq i}}^{n} I_{j k l i}\right) V / N_{h}-\mu_{m} V_{i}, \quad i=1, n$

Este sistema de equações diferenciais ordinárias possui condições iniciais $\geq 0$ e com solução positiva para todo $t$ positivo na região de interesse biológico. (Esteva e Vargas, 1998, 2003; Keeling e Rohani, 2008; Krämer et al., 2010; Rodrigues et al., 2012; Sotomayor, 1979). Novamente teremos uma taxa de transmissão diferente para cada sorotipo $\beta_{i}$ e $\Omega_{i}$, mutuamente entre mosquitos e humanos, e população constante ao longo do tempo. Em todos os modelos, pode se incluir sazonalidade na taxa de nascimento dos vetores acrescentando-se o fator $\left(1+\alpha_{s} \cos (2 \pi t+\delta)\right)$ na equação para a variação de $V$, em que $\alpha_{s}$ é o fator que determina a amplitude da sazonalidade e $\delta$ a fase (Aguiar et al., 2011; Hartley et al., 2002). Com esse fator teremos que o nascimento dos vetores será grande no período que acontece o maior número de casos, que no Brasil ocorre no verão quando temos altas temperaturas e grande volume de chuvas (Gubler et al., 2014; Hartley et al., 2002; Teixeira et al., 2013).

\subsection{Modelos com múltiplos sorotipos e vacinação}

O principal motivo para se estudar e modelar uma doença infecciosa é para buscar soluções de controle afim de evitar que a doença se propague na população. O processo de vacinação tem a finalidade de reduzir o número de suscetíveis na população. Embora esse seja um processo muito eficaz, têm-se muitas dificuldades com relação a vacinação, como por exemplo, estabelecer a proporção da população a ser vacinada afim de erradicar a doença e usufruir da herd imunidade/imunidade de rebanho, definir qual a melhor faixa etária da população deve ser aplicada a doença e lidar com o fato de que a vacina não fornece 100\% de eficácia (Anderson e May, 1985, 1982; Billings et al., 2008; Gomes et al., 2004, 2014; Liu et al., 2008; Massad et al., 1994; Rodrigues et al., 2013, 2014). Para a dengue ainda se tem a dificuldade de que a vacina sendo tetravalente, oferece proteção desigual contra os sorotipos (Ferguson et al., 2016; Maier et al., 2017; Precioso et al., 2015; Torresi et al., 2017; Wilder-Smith e Massad, 2016; World Health Organization et al., 2009).

Aguiar et al. considera o modelo com dois sorotipos compartimentado para três faixas etárias de forma que a vacina é aplicada na faixa etária de 9 à 45 anos, segundo as análises da vacina do Sanofi (Aguiar et al., 2016; Wilder-Smith e Massad, 2016). Para nossos modelos, vamos considerar duas formas de incluir a vacinação; na primeira consideramos uma cobertura de vacinação anual dada por $\psi$, em que vacina-se suscetíveis forma aleatória, podendo ser vacinados indivíduos soronegativos $\mathrm{S}$ e/ou soropositivos $\mathrm{S}_{i}$. Na segunda, os modelos $\mathrm{n} \times \mathrm{SIR}(n=1,2,3,4)$ são compartimentados para duas faixas etárias $A$ e $B$, que podem ser um agrupamento de faixas etárias menores, e então escolhese em qual grupo etário a vacina será aplicada, novamente, vacinando-se soronegativos $\mathrm{S}_{A}$ ou $\mathrm{S}_{B}$ e/ou soropositivo $\mathrm{S}_{A_{i}}$ ou $\mathrm{S}_{B_{i}}$, de forma que $A$ e $B$ são definidas conforme estudo da Seção 1.3.1.

A seguir discutimos a inclusão do compartimento de vacinados $\mathrm{H}_{V}$ nos nossos modelos com 1, 2, 3 e 4 sorotipos apresentados nas seções anteriores, primeiro para uma vacinação aleatória na população e na sequência considerando a vacina direcionada para faixas etárias. Utilizamos como exemplo o modelo com dois sorotipos para mais clareza, porém o mesmo foi feito para os demais modelos. 


\subsubsection{Vacinação aleatória na população}

Na Figura 2.4 apresentamos como a vacinação é incluída no modelo com dois sorotipos e possibilidade de duas infecções. O parâmetro $\psi_{S}$ representa a proporção dos suscetíveis soronegativos que serão vacinados aleatoriamente na população, considerando essa cobertura anual. A possibilidade de vacinar indivíduos soropositivos também é incluída com o parâmetro $\psi_{S_{i}}, i=1,2$. Assim, os indivíduos vacinados são removidos do compartimento dos suscetíveis para o compartimento dos vacinados $\mathrm{H}_{V}$. Além disso, como é muito difícil se ter uma vacina $100 \%$ eficaz, incluímos as taxas $\sigma_{i}^{-}$e $\sigma_{i}^{+}, i=1,2$, que representam, respectivamente, as taxas de infecção em soronegativos e soropositivos vacinados. $\mathrm{O}$ valor $1-\sigma_{i}^{\mp}$ é entendido como o nível de eficácia da vacina para o sorotipo $i$, que pode ser diferente para cada sorotipo. O mesmo foi feito para os modelos com 1, 3 e 4 sorotipos.

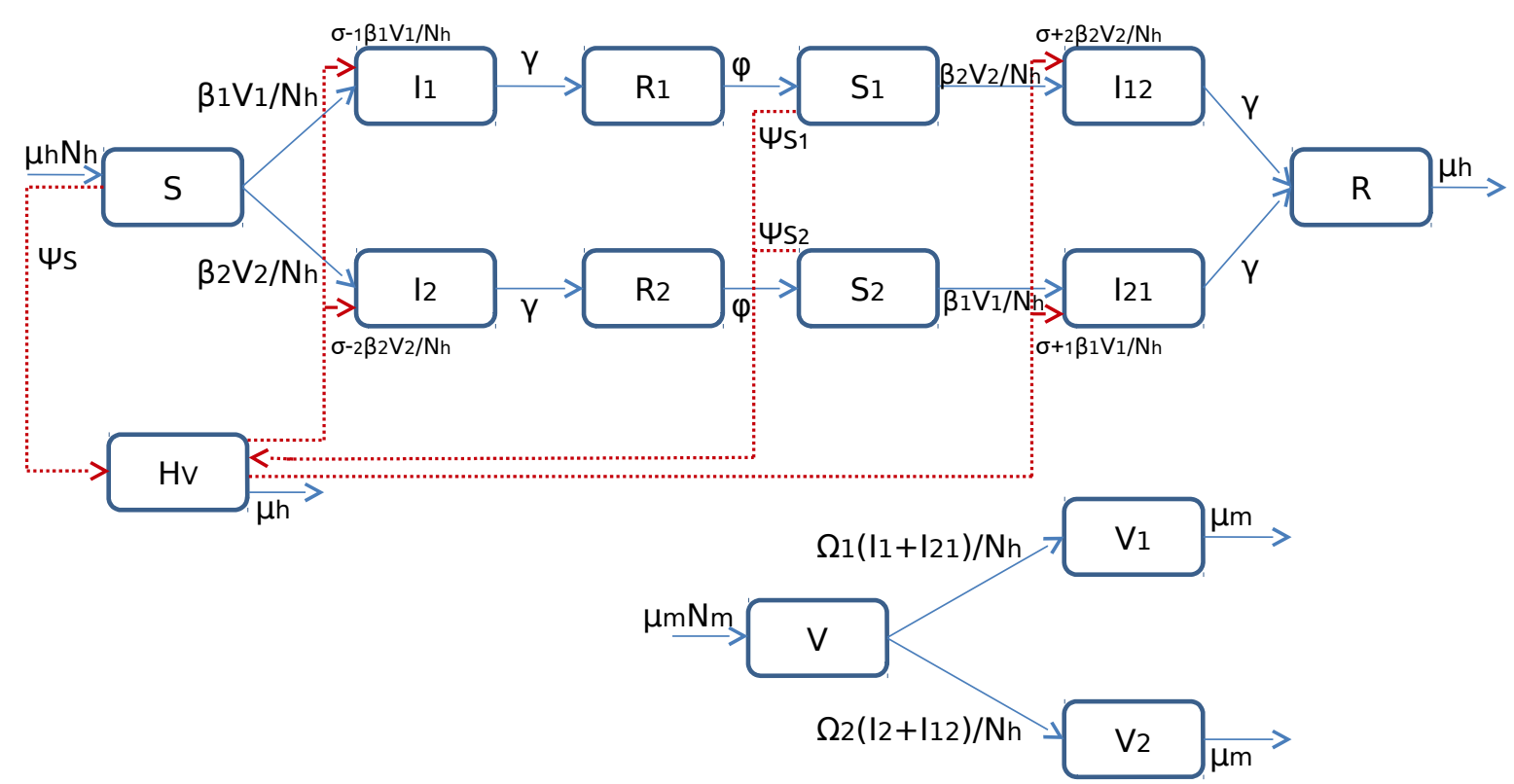

Figura 2.4: Dinâmica de transmissão de dengue em um modelo com dois sorotipos, $2 \times$ SIR para humanos e $V V_{i}$ para vetores. O modelo considera a possibilidade de vacinar uma proporção $\psi_{S}$ de suscetiveis soronegativos e/ou $\psi_{S_{i}}$ de suscetiveis soropositivos que já foram infectados com um dos sorotipos $i=1,2$. Os vacinados serão então movidos para o compartimento $H_{V}$. A vacina pode considerar eficácia diferente para cada sorotipo, de forma que o valor $1-\sigma_{i}^{\mp}$ representa a eficácia da vacina em soronegativos/soropositivos, e então soronegativos e soropositivos, podem contrair a infecção após receberem a vacina, respectivamente, a uma taxa $\sigma_{i}^{-}$e $\sigma_{i}^{+}, i=1,2$. A dinâmica de transmissão e transferência de classes segue a mesma dinâmica do modelo $2 \times S_{\text {SIRV }}$ dado na Figura 2.2.

Da mesma forma que para os modelos $\mathrm{n} \times \mathrm{SIRVV}_{i}$ apresentados na seção anterior, nos modelos com vacinação, a população total permanece constante, de forma que agora tem-se parte dos suscetíveis imunizados, implicando que apenas estarão em um novo compartimento. Para o $2 \times \mathrm{SIRVV}_{i} \mathrm{H}_{V}$, tem-se $S(t)+I_{1}(t)+I_{2}(t)+R_{1}(t)+R_{2}(t)+S_{1}(t)+S_{2}(t)+I_{12}(t)+I_{21}(t)+R(t)+H_{V}=N_{h}$ e $V(t)+V_{1}(t)+V_{2}(t)=N_{m}$. O mesmo segue para os modelos com coexistência de até quatro sorotipos. 
O sistema de EDOs que descreve a inclusão do compartimento dos vacinados $\mathrm{H}_{V}$ na dinâmica de transmissão de dengue com interação de dois sorotipos e duas infecções sequenciais $\left(2 \times \mathrm{SIRVV}_{i}\right)$, é dado por:

Primeira infecção:

$$
\begin{aligned}
& \frac{d S}{d t}=\mu_{h} N_{h}-\left(\sum_{i=1}^{2} \beta_{i} V_{i}\right) S / N_{h}-\psi_{S} S-\mu_{h} S \\
& \frac{d I_{i}}{d t}=\beta_{i} V_{i} S / N_{h}+\sigma_{i}^{-} \beta_{i} V_{i} H_{V} / N_{h}-\left(\gamma+\mu_{h}\right) I_{i} \\
& \frac{d R_{i}}{d t}=\gamma I_{i}-\left(\varphi+\mu_{h}\right) R_{i}
\end{aligned}
$$

Segunda infeç̧ão:

$$
\begin{aligned}
& \frac{d S_{i}}{d t}=\varphi R_{i}-\beta_{j} V_{j} S_{i} / N_{h}-\psi_{S_{i}} S_{i}-\mu_{h} S_{i}, \quad i, j=1,2, \quad j \neq i \\
& \frac{d I_{i j}}{d t}=\beta_{j} V_{j} S_{i} / N_{h}+\sigma_{j}^{+} \beta_{j} V_{j} H_{V} / N_{h}-\left(\gamma+\mu_{h}\right) I_{i j}, \quad i, j=1,2, \quad j \neq i
\end{aligned}
$$

Recuperados:

$$
\frac{d R}{d t}=\gamma\left(I_{12}+I_{21}\right)-\mu_{h} R
$$

Vetores:

$$
\begin{aligned}
& \frac{d V}{d t}=\mu_{m} N_{m}-\sum_{i=1}^{2} \Omega_{i}\left(I_{i}+\sum_{j=1, j \neq i}^{2} I_{j i}\right) V / N_{h}-\mu_{m} V \\
& \frac{d V_{i}}{d t}=\Omega_{i}\left(I_{i}+I_{j i}\right) V / N_{h}-\mu_{m} V_{i}, \quad i, j=1,2, \quad j \neq i
\end{aligned}
$$

Indivíduos Vacinados:

$$
\frac{d H_{V}}{d t}=\psi_{S} S+\psi_{S_{1}} S_{1}+\psi_{S_{2}} S_{2}-\sum_{i=1}^{2} \beta_{i} V_{i}\left(\sigma_{i}^{-}+\sigma_{i}^{+}\right) H_{V} / N_{h}-\mu_{h} H_{V}
$$

o qual possui condições iniciais $S(0) \geq 0, I_{i}(0) \geq 0, R_{i}(0) \geq 0, S_{i}(0) \geq 0, I_{i j}(0) \geq 0, R(0) \geq 0$, $V(0) \geq 0, V_{i}(0) \geq 0$ e $H_{V}(0) \geq 0, i, j=1,2, i \neq j$, e com solução positiva para todo $t \geq 0$. 


\subsubsection{Vacinação direcionada para faixas etárias}

Nesta seção esquematizamos como a vacinação é incluída no modelo com dois sorotipos e possibilidade de duas infecções $2 \times \mathrm{SIRVV}_{i}$, em que os indivíduos estão separados em dois grupos etários $A$ e $B$, Figura 2.5. Importante destacar que estes modelos implicam em apenas dividir a população segundo faixa etária, e que os parâmetros de transmissão continuam sendo em função dos sorotipos.

O parâmetro $\psi_{S_{Z}}(Z=A$ ou $B)$ representa a proporção dos suscetíveis soronegativos da faixa etária $Z$, que serão vacinados anualmente no grupo. Novamente, considera-se a possibilidade de aplicar a vacina em soropositivos dos compartimentos $\mathrm{S}_{Z_{i}}$ com o parâmetro $\psi_{S_{Z_{i}}}, Z=A$ ou $B$, $i=1,2$, semelhante ao da Figura 2.4, em que as flechas são aqui ocultadas para não dificultar a compreensão da figura. Os indivíduos vacinados em qualquer grupo, são transferidos para o compartimento dos vacinados $\mathrm{H}_{V}$. Considerando-se que a vacina não é $100 \%$ eficaz, temos as taxas de infecção $\sigma_{Z_{i}}^{-}$e $\sigma_{Z_{i}}^{+}, i=1,2$, respectivamente, em soronegativos e soropositivos vacinados do grupo etário $Z$, e assim temos a possibilidade de eficácia diferente para soronegativos e soropositivos, diferente para cada sorotipo e também para cada grupo etário. A taxa a representa a transição de faixa etária, implicando que ao atingir a idade 1/a, o indivíduo muda de faixa etária (Aguiar et al., 2016). Analogamente analisa-se a vacinação nos modelos com 1, 3 e 4 sorotipos compartimentados em grupos etários.

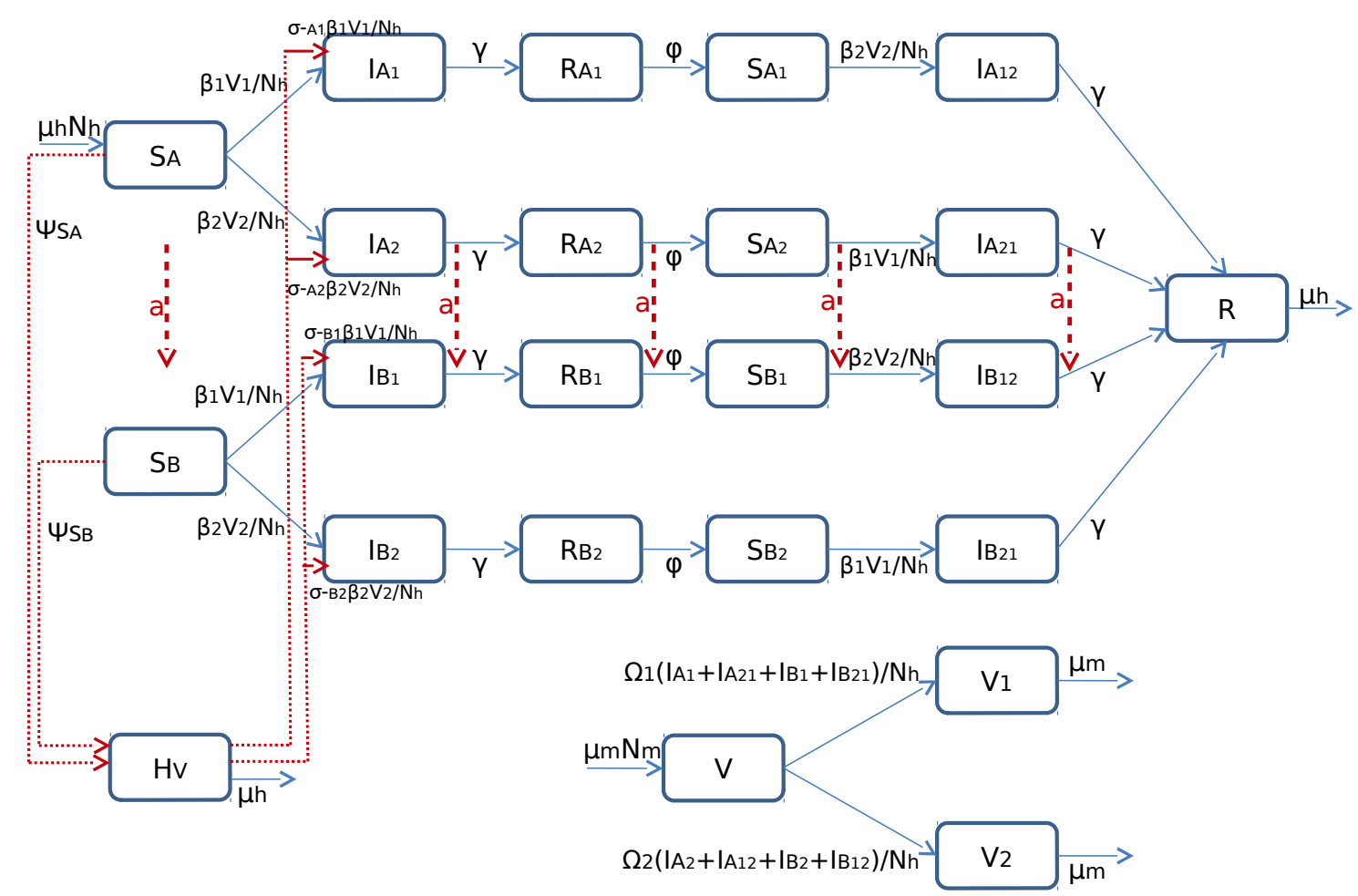

Figura 2.5: Dinâmica de transmissão de dengue em um modelo com dois sorotipos compartimentado por faixas etárias, $2 \times S I R_{A, b}$ para humanos e $V V_{i}$ para vetores, e compartimento dos vacinados $H_{V}$. Considerase que a cobertura de vacinação anual no grupo $Z=A$ ou $B$ de suscetiveis soronegativos, é dada por $\psi_{S_{Z}}$, e equivalentemente a proporção $\psi_{S_{Z_{i}}}$ de suscetiveis soropositivos que já foram infectados com os sorotipos $i=1$ ou 2 . A vacina pode considerar eficácia diferente para cada sorotipo, de forma que $1-\sigma_{Z_{i}}^{\mp}$ representa a eficácia da vacina em soronegativos/soropositivos, e então soronegativos e soropositivos, no grupo etário $Z$ podem contrair a infecção, respectivamente, a uma taxa $\sigma_{Z_{i}}^{-}$e $\sigma_{Z_{i}}^{+}$.

O sistema de EDOs que descreve a inclusão do compartimento dos vacinados $\mathrm{H}_{V}$ na dinâmica de transmissão de dengue com dois sorotipos, e com a população compartimentada para duas faixas etárias, $A$ e $B$, é dado por: 
Primeira infecção no grupo A:

$$
\begin{aligned}
& \frac{d S_{A}}{d t}=\mu_{h} N_{h}-a S_{A}-\left(\sum_{i=1}^{2} \beta_{i} V_{i}\right) S_{A} / N_{h}-\psi_{S_{A}} S_{A}-\mu_{h} S_{A} \\
& \frac{d I_{A i}}{d t}=-a I_{A i}+\beta_{i} V_{i} S_{A} / N_{h}+\sigma_{A i}^{-} \beta_{i} V_{i} H_{V} / N_{h}-\left(\gamma+\mu_{h}\right) I_{A i}, \quad i=1,2 \\
& \frac{d R_{A i}}{d t}=-a R_{A i}+\gamma I_{A i}-\left(\varphi+\mu_{h}\right) R_{A i}, \quad i=1,2
\end{aligned}
$$

Segunda infecção no grupo A:

$$
\begin{aligned}
& \frac{d S_{A i}}{d t}=-a S_{A i}+\varphi R_{A i}-\beta_{j} V_{j} S_{A i} / N_{h}-\psi_{S_{A i}} S_{A i}-\mu_{h} S_{A i}, \quad i, j=1,2, \quad j \neq i \\
& \frac{d I_{A i j}}{d t}=-a I_{A i j}+\beta_{j} V_{j} S_{A i} / N_{h}+\sigma_{A j}^{+} \beta_{j} V_{j} H_{V} / N_{h}-\left(\gamma+\mu_{h}\right) I_{A i j}, \quad i, j=1,2, \quad j \neq i
\end{aligned}
$$

Primeira infecção no grupo B:

$$
\begin{aligned}
& \frac{d S_{B}}{d t}=a S_{A}-\left(\sum_{i=1}^{2} \beta_{i} V_{i}\right) S_{B} / N_{h}-\psi_{S_{B}} S_{B}-\mu_{h} S_{B} \\
& \frac{d I_{B i}}{d t}=a I_{A i}+\beta_{i} V_{i} S_{B} / N_{h}+\sigma_{B i}^{-} \beta_{i} V_{i} H_{V} / N_{h}-\left(\gamma+\mu_{h}\right) I_{B i}, \quad i=1,2 \\
& \frac{d R_{B i}}{d t}=a R_{A i}+\gamma I_{B i}-\left(\varphi+\mu_{h}\right) R_{B i}, \quad i=1,2
\end{aligned}
$$

Segunda infecção no grupo B:

$$
\begin{gathered}
\frac{d S_{B i}}{d t}=a S_{A i}+\varphi R_{B i}-\beta_{j} V_{j} S_{B i} / N_{h}-\psi_{S_{B i}} S_{B i}-\mu_{h} S_{B i}, \quad i, j=1,2, \quad j \neq i \\
\frac{d I_{B i j}}{d t}=a I_{A i j}+\beta_{j} V_{j} S_{B i} / N_{h}+\sigma_{B j}^{+} \beta_{j} V_{j} H_{V} / N_{h}-\left(\gamma+\mu_{h}\right) I_{B i j}, \quad i, j=1,2, \quad j \neq i \\
\frac{d R}{d t}=\gamma\left(I_{A 12}+I_{A 21}+I_{B 12}+I_{B 21}\right)-\mu_{h} R
\end{gathered}
$$

Vetores:

$$
\begin{aligned}
& \frac{d V}{d t}=\mu_{m} N_{m}-\sum_{i=1}^{2} \Omega_{i}\left(I_{A i}+I_{B i}+\sum_{j=1, j \neq i}^{2}\left(I_{A j i}+I_{B j i}\right)\right) V / N_{h}-\mu_{m} V \\
& \frac{d V_{i}}{d t}=\Omega_{i}\left(I_{A i}+I_{B i}+\sum_{j=1, j \neq i}^{2}\left(I_{A j i}+I_{B j i}\right)\right) V / N_{h}-\mu_{m} V_{i}, \quad i=1,2
\end{aligned}
$$

Indivíduos Vacinados:

$$
\begin{aligned}
& \frac{d H_{V}}{d t}=\psi_{S_{A}} S_{A}+\psi_{S_{B}} S_{B}+\sum_{i=1}^{2}\left(\psi_{S_{A i}} S_{A i}+\psi_{S_{B i}} S_{B i}\right)- \\
& \sum_{i=1}^{2} \beta_{i} V_{i}\left(\sigma_{A i}^{-}+\sigma_{B i}^{-}+\sigma_{A i}^{+}+\sigma_{B i}^{+}\right) H_{V} / N_{h}-\mu_{h} H_{V}
\end{aligned}
$$




\subsubsection{Número de equações e parâmetros}

Nos modelos SIR repetidos, com $n=1,2,3$, 4 sorotipos e possibilidade de $m=1,2,3,4$ infecções (Figura 2.3), o número de equações nos compartimentos dos humanos é dado por:

$$
T_{e q H}=2+n !+3 \sum_{m=1}^{n-1} \frac{n !}{(n-m) !}
$$

O número total de equações no sistema de EDOs é então $T_{e q H}$ adicionado à quantidade de equações que compõe os compartimentos dos vetores. Assim, no modelo com $n=4$ e $m=4$ o número total de equações é $T_{e q H}+5=151$ equações. Nos modelos com vacinação, além dos compartimentos dos vetores, acrescenta-se o compartimento dos indivíduos vacinados $\mathrm{H}_{V}$. $\mathrm{E}$ no modelo com duas faixas etárias e vacinação, temos que a quantidade de equações no compartimento dos humanos é dada por $2 \times T_{e q H}$ mais os compartimentos dos vetores.

A Tabela 2.1 contém os parâmetros presentes em cada modelo, de forma que separamos entre parâmetros que são considerados globais e fixos em todos modelos e parâmetros que precisam ser estimados a partir dos dados. Os parâmetros relativos à vacinação, como proporção de vacinados e eficácia, ainda não estão disponíveis, então serão escolhidos de forma apropriada segundo referências.

\begin{tabular}{|c|c|c|c|c|}
\hline Parâmetros & \multicolumn{4}{|c|}{ Modelos } \\
\hline & 1 Sorotipo & 2 Sorotipos & 3 Sorotipos & 4 Sorotipos \\
\hline \multirow{7}{*}{ Conhecidos } & $N_{h}, \mu_{h}$ & $N_{h}, \mu_{h}$ & $N_{h}, \mu_{h}$ & $N_{h}, \mu_{h}$ \\
\hline & $\gamma$ & $\gamma, \varphi$ & $\gamma, \varphi$ & $\gamma, \varphi$ \\
\hline & $\mu_{m}$ & $\mu_{m}$ & $\mu_{m}$ & $\mu_{m}$ \\
\hline & $\psi_{S}$ & $\psi_{S_{1}}, \psi_{S_{2}}$ & $\psi_{S_{1}}, \psi_{S_{2}}, \psi_{S_{3}}$ & $\psi_{S_{1}}, \psi_{S_{2}}, \psi_{S_{3}}, \psi_{S_{4}}$ \\
\hline & $\psi_{S_{A}}, \psi_{S_{B}}$ & $\begin{array}{l}\psi_{S_{A_{1}}}, \psi_{S_{A_{2}}} \\
\psi_{S_{B_{1}}}, \psi_{S_{B_{2}}}\end{array}$ & $\begin{array}{l}\psi_{S_{A_{1}}}, \psi_{S_{A_{2}}}, \psi_{S_{A_{3}}} \\
\psi_{S_{B_{1}}}, \psi_{S_{B_{2}}}, \psi_{S_{B_{3}}}\end{array}$ & $\begin{array}{l}\psi_{S_{A_{1}}}, \psi_{S_{A_{2}}}, \psi_{S_{A_{3}}}, \psi_{S_{A_{4}}} \\
\psi_{S_{B_{1}}}, \psi_{S_{B_{2}}}, \psi_{S_{B_{3}}}, \psi_{S_{B_{4}}}\end{array}$ \\
\hline & $\sigma$ & $\begin{array}{l}\sigma_{1}^{-}, \sigma_{2}^{-} \\
\sigma_{1}^{+}, \sigma_{2}^{+} \\
\end{array}$ & $\begin{array}{l}\sigma_{1}^{-}, \sigma_{2}^{-}, \sigma_{3}^{-} \\
\sigma_{1}^{+}, \sigma_{2}^{+}, \sigma_{3}^{+} \\
\end{array}$ & $\begin{array}{l}\sigma_{1}^{-}, \sigma_{2}^{-}, \sigma_{3}^{-}, \sigma_{4}^{-} \\
\sigma_{1}^{+}, \sigma_{2}^{+}, \sigma_{3}^{+}, \sigma_{4}^{+} \\
\end{array}$ \\
\hline & $\sigma_{A}, \sigma_{B}$ & $\begin{array}{l}\sigma_{A_{1}}^{-}, \sigma_{A_{2}}^{-} \\
\sigma_{B_{1}}^{-}, \sigma_{B_{2}}^{-} \\
\sigma_{A_{1}}^{+}, \sigma_{A_{2}}^{+} \\
\sigma_{B_{1}}^{+}, \sigma_{B_{2}}^{+}\end{array}$ & $\begin{array}{l}\sigma_{A_{1}}^{-}, \sigma_{A_{2}}^{-}, \sigma_{A_{3}}^{-} \\
\sigma_{B_{1}}^{-}, \sigma_{B_{2}}^{-}, \sigma_{B_{3}}^{-} \\
\sigma_{A_{1}}^{+}, \sigma_{A_{2}}^{+}, \sigma_{A_{3}}^{+} \\
\sigma_{B_{1}}^{+}, \sigma_{B_{2}}^{+}, \sigma_{B_{3}}^{+}\end{array}$ & $\begin{array}{l}\sigma_{A_{1}}^{-}, \sigma_{A_{2}}^{-}, \sigma_{A_{3}}^{-}, \sigma_{A_{4}}^{-} \\
\sigma_{B_{1}}^{-}, \sigma_{B_{2}}^{-}, \sigma_{B_{3}}^{-}, \sigma_{B_{4}}^{-} \\
\sigma_{A_{1}}^{+}, \sigma_{A_{2}}^{+}, \sigma_{A_{3}}^{+}, \sigma_{A_{4}}^{+} \\
\sigma_{B_{1}}^{+}, \sigma_{B_{2}}^{+}, \sigma_{B_{3}}^{+}, \sigma_{B_{4}}^{+}\end{array}$ \\
\hline Estimados & & & & \\
\hline & $\beta_{1}$ & $\beta_{1}, \beta_{2}$ & $\beta_{1}, \beta_{2}, \beta_{3}$ & $\beta_{1}, \beta_{2}, \beta_{3}, \beta_{4}$ \\
\hline Em todos & $\Omega_{1}$ & $\Omega_{1}, \Omega_{2}$ & $\Omega_{1}, \Omega_{2}, \Omega_{3}$ & $\Omega_{1}, \Omega_{2}, \Omega_{3}, \Omega_{4}$ \\
\hline modelos & $\alpha, \delta$ & $\alpha, \delta$ & $\alpha, \delta$ & $\alpha, \delta$ \\
\hline & $V(0), V_{1}(0)$ & $V(0), V_{1}(0), V_{2}(0)$ & $V(0), V_{1}(0), V_{2}(0), V_{3}(0)$ & $V(0), V_{1}(0), V_{2}(0), V_{3}(0), V_{4}(0)$ \\
\hline $\mathbf{n} \times \mathbf{S I R V V}_{i}$ & $S(0)$ & $S(0)$ & $S(0)$ & $S(0)$ \\
\hline pop. total & $I(0)$ & $I_{1}(0), I_{2}(0)$ & $I_{1}(0), I_{2}(0), I_{3}(0)$ & $I_{1}(0), I_{2}(0), I_{3}(0), I_{4}(0)$ \\
\hline $\mathbf{n} \times \mathbf{S I R V V}_{i}$ & $S_{A}(0), S_{B}(0)$ & $S_{A}(0), S_{B}(0)$ & $S_{A}(0), S_{B}(0)$ & $S_{A}(0), S_{B}(0)$ \\
\hline pop. etária & $I_{A}(0), I_{B}(0)$ & $\begin{array}{l}I_{A_{1}}(0), I_{A_{2}}(0) \\
I_{B_{1}}(0), I_{B_{2}}(0) \\
\end{array}$ & $\begin{array}{l}I_{A_{1}}(0), I_{A_{2}}(0), I_{A_{3}}(0) \\
I_{B_{1}}(0), I_{B_{2}}(0), I_{B_{3}}(0)\end{array}$ & $\begin{array}{l}I_{A_{1}}(0), I_{A_{2}}(0), I_{A_{3}}(0), I_{A_{4}}(0) \\
I_{B_{1}}(0), I_{B_{2}}(0), I_{B_{3}}(0), I_{B_{4}}(0) \\
\end{array}$ \\
\hline
\end{tabular}

Tabela 2.1: Listas de parâmetros conhecidos e parâmetros a serem estimados para cada modelo. Os parâmetros conhecidos são considerados globais e possuem o mesmo valor em todos os modelos, sendo eles, a taxa de recuperação $\gamma$, a taxa de imunidade cruzada temporária $\varphi$, a taxa de mortalidade dos mosquitos $\mu_{m}$, e as proporções de vacinados soropositivos e soronegativos, assim como a eficácia da vacina para cada sorotipo. A população total de humanos e a taxa de mortalidade variam conforme a região. Os parâmetros estimados em todos os modelos são as taxas de transmissão entre humanos e vetores, os parâmetros da forçante de sazonalidade $(\alpha$ e $\delta)$, e a população de mosquitos suscetiveis e infectados no tempo $t=0$. Nos modelos $n \times S I R V V_{i}$ com população total, estimamos a quantidade inicial de humanos suscetiveis (S(0)) e infectados com cada sorotipo $\left(I_{i}(0)\right)$. Nos modelos $n \times S I R V V_{i}$ com população compartimentada por faixas etárias, são as estimadas as populações iniciais de suscetiveis e infectados em cada faixa etária. 


\subsection{Estudo qualitativo dos modelos}

Nesta seção vamos fazer uma breve discussão sobre pontos de equilíbrio dos sistemas de equações diferenciais ordinárias e da estabilidade destes pontos (Li et al., 2011; Sotomayor, 1979). Para isso, precisamos primeiro definir o conceito de número básico de reprodução para modelos epidemiológicos (Anderson e May, 1982; Diekmann et al., 1990; Heesterbeek e Dietz, 1996; Sanches e Massad, 2016; van den Driessche e Watmough, 2002).

\subsubsection{Número básico de reprodução $\mathbf{R}_{0}$}

O número básico de reprodução $R_{0}$ é o conceito mais importante em epidemiologia, pois fornece uma quantidade limiar que determina se a doença vai persistir na população, quando $R_{0}>1$, ou se a doença não vai se propagar, no caso de $R_{0}<1$, isto é, existe um "equilíbrio endêmico" para o modelo ou o "equilíbrio livre de doença" é estável? (Anderson e May, 1985; Ferguson et al., 1999b; Gumel e Lenhart, 2010; Krämer et al., 2010; van den Driessche, 2017).

Matematicamente, calculamos $R_{0}$ como a taxa na qual novos casos são produzidos por um indivíduo durante seu período médio infeccioso, quando inserido em uma população toda suscetível. Porém deve-se levar em conta que o $R_{0}$ sempre depende da estrutura do modelo. Em um cenário endêmico, $R_{0}$ fornece uma compreensão/ideia da prevalência do equilíbrio endêmico e a idade média de infecção. O desenvolvimento do $R_{0}$ foi apresentado por Kermack e Mckendrick (1927), porém foi Macdonald que atribuiu o nome "taxa básica de reprodução" e o símbolo para esse conceito limiar, relacionado a persistência de Malária, que então se popularizou com Dietz (1975) e Anderson e May (Anderson e May, 1982; Heesterbeek e Dietz, 1996; Sanches e Massad, 2016).

Existem várias formas de calcular o $R_{0}$ : com a função de sobrevivência, com a matriz de próxima geração, através dos autovalores da matriz jacobiana, através de dados epidemiológicos, e outras (Heffernan et al., 2005; Li et al., 2011; van den Driessche, 2017; Villela et al., 2017). O método da função de sobrevivência é o que melhor fornece o verdadeiro número médio de infecções secundárias, porém é necessário obter uma expressão para a probabilidade de que um indivíduo recentemente infectado permaneça infeccioso por um certo tempo (probabilidade de sobrevivência) e a infectividade em função do tempo, o que se torna muito complicado para ser usado em modelos mais complexos (Heesterbeek e Dietz, 1996; Heffernan et al., 2005). O método de próxima geração foi desenvolvido por Diekmann et al. e popularizado por van den Driessche e Watmough (Diekmann et al., 1990; van den Driessche e Watmough, 2002), e consiste de uma generalização do método da Jacobiana, o qual por sua vez consiste em linearizar os sistema de equações diferenciais em torno do equilíbrio livre de doença e calcular seus autovalores, assim, o sistema linearizado terá as mesmas propriedades que o sistema não linear se for hiperbólico (Li et al., 2011; Sotomayor, 1979). Heffernan et al. mostraram que o $R_{0}$ obtido com a matriz de próxima geração ao quadrado é igual ao valor obtido com o método de sobrevivência (Heffernan et al., 2005).

Usaremos o método que calcula $R_{0}$ fazendo uso da matriz matriz de próxima geração, melhor explicado no Apêndice A. Esse método não é indicado em casos de modelos que possuem vários compartimentos com produção de infectados e muitos parâmetros, como é o caso dos modelos que incluem o compartimento dos expostos E, pois não se pode garantir a unicidade das matrizes de transmissão e transição, as quais dependem da compreensão do modelador, podendo resultar em diferentes valores de $R_{0}$. Além disso, como os modelos aqui estudados abordam a transmissão vetor-hospedeiro, o método de próxima geração não produz o número de humanos infectados por um outro humano infectado, mas sim a média geométrica do número de infecções por geração, por esse motivo usaremos o valor $R_{0}^{2}$ (Heffernan et al., 2005; Li et al., 2011; Sanches e Massad, 2016). 


\section{$R_{0}$ para o modelo SIRVV $_{i}$}

De acordo com o método explicado no Apêndice A, para o sistema (2.1), temos as seguintes equações com produção de infectados, uma para os humanos e outra para os vetores transmissores (Diekmann et al., 1990; van den Driessche e Watmough, 2002),

$$
\begin{aligned}
& \frac{d I}{d t}=\beta V_{i} S / N_{h}-\left(\gamma+\mu_{h}\right) I \\
& \frac{d V_{i}}{d t}=\Omega I V / N_{h}-\mu_{m} V_{i}
\end{aligned}
$$

A matriz Jacobiana calculada no ponto em que não existem infectados, conhecido como equilíbrio livre de doença, $\left(S^{*}, I^{*}, R^{*}, V^{*}, V_{i}^{*}\right)=\left(N_{h}, 0,0, N_{m}, 0\right)$, que denotaremos por $E^{*}$, é dada por

$$
J\left(E^{*}\right)=\left[\begin{array}{cc}
-\left(\gamma+\mu_{h}\right) & \beta \\
\frac{\Omega N_{m}}{N_{h}} & -\mu_{m}
\end{array}\right]
$$

da qual segue a decomposição em termos de transmissão $T$ e transição $\Sigma$ :

$$
x=\left(I, V_{i}\right), \quad T=\left[\begin{array}{cc}
0 & \beta \\
\frac{\Omega N_{m}}{N_{h}} & 0
\end{array}\right], \quad \Sigma=\left[\begin{array}{cc}
-\left(\gamma+\mu_{h}\right) & 0 \\
0 & -\mu_{m}
\end{array}\right] .
$$

Assim, a matriz de próxima geração $K$, é dada por:

$$
K=-T \Sigma^{-1}=\left[\begin{array}{cc}
0 & \frac{\beta}{\mu_{m}} \\
\Omega N_{m} & 0
\end{array}\right] .
$$

da qual calculamos os autovalores:

$$
\lambda= \pm \sqrt{\frac{\beta \Omega N_{m}}{\mu_{m}\left(\gamma+\mu_{h}\right) N_{h}}} .
$$

Portanto, número básico de reprodução para o sistema $\operatorname{SIRVV}_{i}$, calculado com a matriz de próxima geração, é definido como o raio espectral da matriz $\mathrm{K}(\rho(K))$, o qual usaremos o valor ao quadrado:

$$
\overline{R_{0}}=R_{0}^{2}=\frac{\beta \Omega N_{m}}{\mu_{m}\left(\gamma+\mu_{h}\right) N_{h}} .
$$

Esse valor implica que um humano infeccioso introduzido em uma população de suscetíveis é picado durante seu período infeccioso por $N_{m} / N_{h}\left(\gamma+\mu_{h}\right)$ mosquitos, o qual uma proporção $\Omega N_{m} / N_{h}\left(\gamma+\mu_{h}\right)$ destes mosquitos se tornaram infectados. Semelhantemente tem-se que um mosquito infeccioso distribui $N_{h} / N_{h} \mu_{m}$ picadas nos humanos durante sua vida infectado e então a proporção $\beta N_{h} / N_{h} \mu_{m}$ destas picadas vão causar novas infecções na população de humanos, assim a média geométrica dessas quantidade de infectados é o valor de infeções secundárias $R_{0}$.

\section{$R_{0}$ para o modelo $2 \times \operatorname{SIRVV}_{i}$}

Em modelos com múltiplos sorotipos, considera-se um $R_{0}$ para cada sorotipo, pois cada sorotipo tem taxas de transmissão $\beta_{i}$ e $\Omega_{i}$ diferentes (Allen et al., 2008; Billings et al., 2007, 2008; Keeling e Rohani, 2008). Para o modelo $2 \times \mathrm{SIRVV}_{i}$ (Figura 2.2) temos que o ponto em que não existem infectados é dado por

$$
E^{*}=\left(S^{*}, I_{1}^{*}, I_{2}^{*}, R_{1}^{*}, R_{2}^{*}, S_{1}^{*}, S_{2}^{*}, I_{12}^{*}, I_{21}^{*}, R^{*}, V^{*}, V_{1}^{*}, V_{2}^{*}\right)=\left(N_{h}, 0,0,0,0,0,0,0,0,0, N_{m}, 0,0\right) .
$$

Dentre as equações que descrevem o modelo $2 \times \operatorname{SIRVV}_{i}$, Equações (2.3), (2.4) e (2.5), temos as 
seguintes equações com produção de infectados, quatro para humanos e duas para mosquitos:

$$
\begin{aligned}
\frac{d I_{1}}{d t} & =\beta_{1} V_{1} S / N_{h}-\left(\gamma+\mu_{h}\right) I_{1} \\
\frac{d I_{2}}{d t} & =\beta_{2} V_{2} S / N_{h}-\left(\gamma+\mu_{h}\right) I_{2} \\
\frac{d I_{12}}{d t} & =\beta_{2} V_{2} S_{1} / N_{h}-\left(\gamma+\mu_{h}\right) I_{12} \\
\frac{d I_{21}}{d t} & =\beta_{1} V_{1} S_{2} / N_{h}-\left(\gamma+\mu_{h}\right) I_{21} \\
\frac{d V_{1}}{d t} & =\Omega_{1}\left(I_{1}+I_{21}\right) V / N_{h}-\mu_{m} V_{1} \\
\frac{d V_{2}}{d t} & =\Omega_{2}\left(I_{2}+I_{12}\right) V / N_{h}-\mu_{m} V_{2}
\end{aligned}
$$

Dessa forma, a matriz jacobiana do Sistema (2.24) calculada em $E^{*}$, é dada por

$$
J\left(E^{*}\right)=\left[\begin{array}{cccccc}
-\left(\gamma+\mu_{h}\right) & 0 & 0 & 0 & \beta_{1} & 0 \\
0 & -\left(\gamma+\mu_{h}\right) & 0 & 0 & 0 & \beta_{2} \\
0 & 0 & -\left(\gamma+\mu_{h}\right) & 0 & 0 & 0 \\
0 & 0 & 0 & -\left(\gamma+\mu_{h}\right) & 0 & 0 \\
\frac{\Omega_{1} N_{m}}{N_{h}} & 0 & 0 & \frac{\Omega_{1} N_{m}}{N_{h}} & -\mu_{m} & 0 \\
0 & \frac{\Omega_{2} N_{m}}{N_{h}} & \frac{\Omega_{2} N_{m}}{N_{h}} & 0 & 0 & -\mu_{m}
\end{array}\right]
$$

e temos a seguinte decomposição em termos de transmissão $T$ e transição $\Sigma$

$$
\begin{aligned}
& x=\left(I_{1}, I_{2}, I_{12}, I_{21}, V_{1}, V_{2}\right) \\
& T=\left[\begin{array}{cccccc}
0 & 0 & 0 & 0 & \beta_{1} & 0 \\
0 & 0 & 0 & 0 & 0 & \beta_{2} \\
0 & 0 & 0 & 0 & 0 & 0 \\
0 & 0 & 0 & 0 & 0 & 0 \\
\frac{\Omega_{1} N_{m}}{N_{h}} & 0 & 0 & \frac{\Omega_{1} N_{m}}{N_{h}} & 0 & 0 \\
0 & \frac{\Omega_{2} N_{m}}{N_{h}} & \frac{\Omega_{2} N_{m}}{N_{h}} 0 & 0 & 0 &
\end{array}\right] \\
& \Sigma=\left[\begin{array}{cccccc}
-\left(\gamma+\mu_{h}\right) & 0 & 0 & 0 & 0 & 0 \\
0 & -\left(\gamma+\mu_{h}\right) & 0 & 0 & 0 & 0 \\
0 & 0 & -\left(\gamma+\mu_{h}\right) & 0 & 0 & 0 \\
0 & 0 & 0 & -\left(\gamma+\mu_{h}\right) & 0 & 0 \\
0 & 0 & 0 & 0 & -\mu_{m} & 0 \\
0 & 0 & 0 & 0 & 0 & -\mu_{m}
\end{array}\right]
\end{aligned}
$$


Assim,

$$
K=-T \Sigma^{-1}=\left[\begin{array}{cccccc}
0 & 0 & 0 & 0 & \frac{\beta_{1}}{\mu_{m}} & 0 \\
0 & 0 & 0 & 0 & 0 & \frac{\beta_{2}}{\mu_{m}} \\
0 & 0 & 0 & 0 & 0 & 0 \\
0 & 0 & 0 & 0 & 0 & 0 \\
\frac{\Omega_{1} N_{m}}{\left(\gamma+\mu_{h}\right) N_{h}} & 0 & 0 & \frac{\Omega_{1} N_{m}}{\left(\gamma+\mu_{h}\right) N_{h}} & 0 & 0 \\
0 & \frac{\Omega_{2} N_{m}}{\left(\gamma+\mu_{h}\right) N_{h}} & \frac{\Omega_{2} N_{m}}{\left(\gamma+\mu_{h}\right) N_{h}} & 0 & 0 & 0
\end{array}\right] .
$$

E temos que K possui 6 autovalores:

$$
\lambda_{1}=\sqrt{\frac{\beta_{1} \Omega_{1} N_{m}}{\mu_{m}\left(\gamma+\mu_{h}\right) N_{h}}}, \quad \lambda_{2}=\sqrt{\frac{\beta_{2} \Omega_{2} N_{m}}{\mu_{m}\left(\gamma+\mu_{h}\right) N_{h}}}, \quad \lambda_{3}=-\lambda_{1}, \quad \lambda_{4}=-\lambda_{2}, \quad \lambda_{5}=\lambda_{6}=0 .
$$

Assim, definimos um número básico de reprodução para cada sorotipo (Esteva e Vargas, 2003) (Apêndice A):

$$
\overline{R_{0 i}}=\overline{R_{0 i}}=R_{0 i}^{2}=\frac{\beta_{i} \Omega_{i} N_{m}}{\mu_{m}\left(\gamma+\mu_{h}\right) N_{h}}, \quad i=1,2 .
$$

\section{$R_{0}$ para o modelo $\mathbf{n} \times \mathbf{S I R V V}_{i}$}

Como mostrado para o modelo com dois sorotipos, no modelo com interação de quatro sorotipos teremos um $R_{0}$ para cada (Allen et al., 2008; Esteva e Vargas, 2003):

$$
\overline{R_{0 i}}=R_{0 i}^{2}=\frac{\beta_{i} \Omega_{i} N_{m}}{\mu_{m}\left(\gamma+\mu_{h}\right) N_{h}}, \quad i=1,4 .
$$

De forma que o número básico de reprodução para o sistema todo será definido como o máximo entre eles $R_{0}^{2}=\max \left\{R_{0 i}^{2}\right\}$.

Esta abordagem leva a situação em que a coexistência exige que a fração de suscetíveis seja $>1 / R_{0 i}^{2}$. A quantidade de mosquitos é vital para determinar $R_{0}$ e a dinâmica da infecção. Quando há muito mais humanos comparados a mosquitos, sustentar a transmissão pode ser impossível, pois $R_{0}$ aumenta quando aumenta o número de mosquitos e diminui quando aumenta a população de humanos, isto é, para a infecção se propagar e invadir, a razão de mosquito para humanos $N_{m} / N_{h}$ tem que ser maior do que $\mu_{m}\left(\gamma+\mu_{h}\right) /\left(\beta_{i} \Omega_{i}\right)$.

Com este método obtemos que o valor do $R_{0}$ no modelo em que uma proporção $\psi$ é vacinada com uma vacina de eficácia $1-\sigma$, é dado por:

$$
\overline{R_{0 V}}=\overline{R_{0}}(1-\psi+\sigma \psi) .
$$

\subsubsection{Equilíbrios}

Um equilíbrio $x^{*}$ de $y^{\prime}=F(y)$, é uma solução de $F\left(x^{*}\right)=0$ (Ver Apêndice A, Seção A.2.2. Vamos nos basear nos trabalhos (Derouich et al., 2003) e (Esteva e Vargas, 1998, 1999).

Teorema 2.1 O sistema de Equações (2.1) que descrevem o modelo SIRVV $V_{i}$ possui dois pontos de equilibrio, $E_{0}=(1,0,0)$ e $E_{1}=\left(S^{*}, I^{*}, V_{i}^{*}\right)$.

Dem: Das hipóteses do modelo (2.1), temos que as populações são constantes, isto é, $N_{h}=S+I+R$ e $N_{m}=V+V_{i}$, assim podemos fazer substituições de forma a simplificar as equaçôes do modelo. Considera-se as seguintes normalizações:

$$
S^{*}=\frac{S}{N_{h}}, \quad I^{*}=\frac{I}{N_{h}}, \quad R^{*}=\frac{R}{N_{h}}, \quad V^{*}=\frac{V}{N_{m}}, \quad V_{i}^{*}=\frac{V_{i}}{N_{m}} .
$$


As equações de $R^{*}$ e $V^{*}$ são obtidas facilmente, pois $R^{*}=1-S^{*}-I^{*}, V^{*}=1-V_{i}^{*}$. Assim, o Sistema (2.1) pode ser reescrito de forma equivalente como um sistema não-linear tri-dimensional:

$$
\begin{aligned}
& \frac{d S^{*}}{d t}=\mu_{h}\left(1-S^{*}\right)-\beta N_{m} V_{i}^{*} S^{*} / N_{h} \\
& \frac{d I^{*}}{d t}=\beta N_{m} V_{i}^{*} S^{*} / N_{h}-\left(\gamma+\mu_{h}\right) I^{*} \\
& \frac{d V_{i}^{*}}{d t}=\Omega I^{*}\left(1-V_{i}^{*}\right)-\mu_{m} V_{i}^{*}
\end{aligned}
$$

Para encontrar os pontos de equilíbrio, igualamos a zero esse novo Sistema (2.32) e calculamos as soluções da forma $E_{i}=\left(S^{*}, I^{*}, V_{i}^{*}\right)$. Da terceira equação de (2.32) igualada a zero, temos que

$$
V_{i}^{*}=\frac{\Omega I^{*}}{\Omega I^{*}+\mu_{m}}
$$

Igualando a zero a primeira equação de (2.32) e usando (2.33), tem-se

$$
\begin{gathered}
\mu_{h}\left(1-S^{*}\right)-\frac{\beta}{N_{h}} N_{m}\left(\frac{\Omega I^{*}}{\Omega I^{*}+\mu_{m}}\right) S^{*}=0 \Longrightarrow \\
\Longrightarrow \mu_{h} S^{*}+\frac{\beta}{N_{h}} N_{m}\left(\frac{\Omega I^{*}}{\Omega I^{*}+\mu_{m}}\right) S^{*}=\mu_{h} \Longrightarrow \\
\Longrightarrow \frac{\mu_{h} N_{h}\left(\Omega I^{*}+\mu_{m}\right)}{\mu_{h} N_{h}\left(\Omega I^{*}+\mu_{m}\right)+\beta N_{m} \Omega I^{*}}=S^{*} .
\end{gathered}
$$

Assim,

$$
S^{*}=\frac{\left(\Omega I^{*}+\mu_{m}\right)}{\left(\frac{\beta}{\mu_{h} N_{h}} N_{m} \Omega+\Omega\right) I^{*}+\mu_{m}} .
$$

Substituindo (2.33) e (2.34) na segunda equação do Sistema (2.32) igualada a zero, segue que:

$$
\begin{aligned}
\Longrightarrow \frac{\beta N_{m}}{N_{h}}\left(\frac{\Omega I^{*}}{\Omega I^{*}+\mu_{m}}\right) \frac{\left(\Omega I^{*}+\mu_{m}\right)}{\left(\frac{\beta}{\mu_{h} N_{h}} N_{m} \Omega+\Omega\right) I^{*}+\mu_{m}} & =\left(\gamma+\mu_{h}\right) I^{*} .
\end{aligned}
$$

Dividindo ambos os lados da última equação por $\left(\gamma+\mu_{h}\right)$, definindo $M=\frac{\gamma+\mu_{h}}{\mu_{h}}$ e usando

$$
\overline{R_{0}}=R_{0}^{2}=\frac{\beta \Omega N_{m}}{N_{h} \mu_{m}\left(\gamma+\mu_{h}\right)}
$$

obtemos:

$$
\begin{aligned}
\overline{R_{0}} \mu_{m}\left[\frac{I^{*}}{\left(\frac{\overline{R_{0}} \mu_{m}\left(\gamma+\mu_{h}\right)}{\mu_{h}}+\Omega\right) I^{*}+\mu_{m}}\right] & =I^{*} \Longrightarrow \\
\Longrightarrow \overline{R_{0}} \mu_{m} I^{*} & =I^{*}\left[\left(\frac{\overline{R_{0}} \mu_{m}\left(\gamma+\mu_{h}\right)}{\mu_{h}}+\Omega\right) I^{*}+\mu_{m}\right] \Longrightarrow \\
\Longrightarrow \overline{R_{0}} I^{*} & =I^{*}\left[\left(\overline{R_{0}} M+\frac{\Omega}{\mu_{m}}\right) I^{*}+1\right] \Longrightarrow
\end{aligned}
$$




$$
\Longrightarrow \overline{R_{0}} I^{*}-I^{*}=I^{* 2} \overline{R_{0}} M+I^{* 2} \frac{\Omega}{\mu_{m}}
$$

Do qual segue que $I^{*}$ é a solução da equação de segundo grau:

$$
-\left(\overline{R_{0}} M+\frac{\Omega}{\mu_{m}}\right) I^{* 2}+\left(\overline{R_{0}}-1\right) I^{*}=0,
$$

possuindo duas soluçôes:

- $I^{*}=0$ que resulta no equilíbrio livre de doença, implicando que a população é toda suscetível: $E_{0}=(1,0,0)$ ou equivalentemente no sistema não normalizado $E_{0}=\left(N_{h}, 0,0\right)$;

- E a solução não nula

$$
I^{*}=\frac{\overline{R_{0}}-1}{\overline{R_{0}} M+\frac{\Omega}{\mu_{m}}} .
$$

Substituindo o valor de $I^{*}$ da Equação (2.36) nas equações (2.34) e (2.33), obtemos os valores de $S^{*}$ e $V_{i}^{*}$ em função de $\overline{R_{0}}$, e assim temos o equilibrio em que a doença persiste na população, denominado equilíbrio endêmico do sistema (2.32), dado por:

$$
E_{1}=\left(\frac{\frac{\Omega}{\mu_{m}}+M}{\left(\frac{\Omega}{\mu_{m}}+\overline{R_{0}} M\right)}, \frac{\overline{R_{0}}-1}{\left(\frac{\Omega}{\mu_{m}}+\overline{R_{0}} M\right)}, \frac{\frac{\Omega}{\mu_{m}}\left(\overline{R_{0}}-1\right)}{\overline{R_{0}}\left(\frac{\Omega}{\mu_{m}}+M\right)}\right)
$$

Se $\overline{R_{0}} \leq 1$, então $E_{0}$ é o único equilíbrio em $\Lambda^{*}$, se $\overline{R_{0}}>1$ então o equilíbrio endêmico $E_{1}$ também estará em $\Lambda^{*}$, em que $\Lambda^{*}$ é a região de interesse do ponto de visto biológico (Esteva e Vargas, 1998, 1999):

$$
\Lambda^{*}=\left\{\left(S^{*}, I^{*}, V_{i}^{*}\right): 0 \leq V_{i}^{*} \leq 1,0 \leq S^{*}, 0 \leq I^{*}, S^{*}+I^{*} \leq 1\right\}
$$

\section{Equilíbrios para o modelo $2 \times \operatorname{SIRVV}_{i}$}

Os modelos com coexistência de dois sorotipos já foram estudados qualitativamente em diversos trabalhos (Billings et al., 2007, 2008; Esteva e Vargas, 2003; Kooi et al., 2014), os quais mostraram a existência do equilíbrio livre de doença que para o caso do $2 \times \operatorname{SIRVV}_{i}$, Equações (2.3), (2.4) e (2.5), é dado por:

$$
E_{0}^{*}=\left(N_{h}, 0,0,0,0,0,0,0,0,0, N_{m}, 0,0\right),
$$

existência dos equilíbrios de borda que representam a dominância de somente um sorotipo:

$$
E_{01}^{*}=\left(N_{h}, I_{1}^{*}, 0, R_{1}^{*}, 0, S_{1}^{*}, 0,0,0,0, N_{m}, V_{1}^{*}, 0\right)
$$

e

$$
E_{02}^{*}=\left(N_{h}, 0, I_{2}^{*}, 0, R_{2}^{*}, 0, S_{2}^{*}, 0,0,0, N_{m}, 0, V_{2}^{*}\right) .
$$

E do equilíbrio de coexistência dos dois

$$
E_{1}^{*}=\left(S^{*}, I_{1}^{*}, I_{2}^{*}, R_{1}^{*}, R_{2}^{*}, S_{1}^{*}, S_{2}^{*}, I_{12}^{*}, I_{21}^{*}, R^{*}, V^{*}, V_{1}^{*}, V_{2}^{*}\right) .
$$

Para os modelos com 3 e 4 sorotipos a dificuldade consiste em saber a quantidade exata de equilíbrios, pois além do equilíbrio livre de doença e dos equilíbrios de borda, podem-se ter os equilíbrios de coexistência com combinações 2 a 2 e 3 a 3 sorotipos. 


\subsubsection{Estabilidade}

Considerando o sistema de equações diferenciais ordinárias autônomo, isto é, em que as funções $y_{i}$ são independentes do tempo $t$,

$$
y^{\prime}=F(y), \quad y \in R^{n} .
$$

Tem-se que cada $y_{i}$ são funções continuamente diferenciáveis de $t$. No estudo de dinâmica das populações e epidemiologia matemática, cada $y_{i}$ denota a densidade da população de uma espécie, ou estado, e a funções $F_{i}$ exprimem a lei de interação entre as espécies ou indivíduos das populações (Brauer e Castillo-Chavez, 2001; Sotomayor, 1979).

Quando temos sistemas não lineares, é muito difícil encontrar as soluções de forma explícita, então o que se faz é o estudo do retrato de fase que indica a forma global da família das soluções máximas. O iniciador do estudo de retrato de fase para um sistema de equações foi H. Poincaré trabalhando com mecânica Celeste para estudar a estabilidade do sistema solar (Hethcote, 1976; Sotomayor, 1979).

Se para o tempo $t \longrightarrow \infty$, as soluções $y_{i}$ tendem para um ponto de equilíbrio $x=\left(x_{1}, x_{2}, \ldots, x_{n}\right)$, $x_{i}>0, i=1, \ldots, n$, interpreta-se que as populações evoluem para uma situação de coexistência. Um equilíbrio $x^{*}=\left(x_{1}^{*}, x_{2}^{*}, \ldots, x_{n}^{*}\right)$ é uma solução de $F\left(x^{*}\right)=0$, isto é, é uma solução constante do sistema de equações diferenciais. Geometricamente o equilíbrio é um ponto no plano de fase que é a órbita de uma solução constante. Se por outro lado as soluções tendem para uma órbita periódica $\Upsilon(t)=\left(x_{1}(t), x_{2}(t), \ldots, x_{n}(t)\right), x_{i}(t)>0, i=1, \ldots, n$, implica que as populações flutuam em um ciclo contínuo.

Definição 2.1 Um equilíbrio $x^{*}$ é estável se cada solução com valores iniciais próximas do equilíbrio está definida para todo $t \geq 0 \mathrm{e}$ em adição, permanecem próximas suficientemente do equilíbrio quando $t \longrightarrow \infty$.

Definição 2.2 Um sistema linear chama-se hiperbólico se todos os autovalores têm parte real diferente de zero. Em particular se todos os autovalores tiverem parte real negativa, então o equilíbrio é estável, enquanto que se existir um autovalor com parte real positiva, implicará que o equilíbrio é instável.

Para analisar a estabilidade local dos pontos de equilíbrio, calculamos a matriz Jacobiana (J) do sistema nesses pontos e analisamos os autovalores. Assim, para o sistema $\mathrm{SIRVV}_{i}$ temos a matriz equivalente normalizada (2.32) e os pontos de equilíbrio $E_{0}=(1,0,0)$ e $E_{1}=\left(S^{*}, I^{*}, V_{i}^{*}\right)$ (Equação $(2.37))$. A estabilidade local do equilíbrio livre de doença $E_{0}$ é governada pela matriz Jacobiana (Esteva e Vargas, 1998):

$$
J\left(E_{0}\right)=\left[\begin{array}{ccc}
-\mu_{h} & 0 & -\frac{\beta}{N_{h}} N_{m} \\
0 & -\left(\gamma+\mu_{h}\right) & \frac{\beta}{N_{h}} N_{m} \\
0 & \Omega & -\mu_{m}
\end{array}\right],
$$

O polinômio característico de (2.42) é dado por:

$$
\begin{aligned}
p(\lambda) & =\left(-\mu_{h}-\lambda\right)\left(\left(\left(\gamma+\mu_{h}\right)+\lambda\right)\left(\mu_{m}+\lambda\right)-\Omega \frac{\beta}{N_{h}} N_{m}\right) \\
& =\left(-\mu_{h}-\lambda\right)\left(\left(\left(\gamma+\mu_{h}\right) \mu_{m}-\Omega \frac{\beta}{N_{h}} N_{m}\right)+\left(\gamma+\mu_{h}+\mu_{m}\right) \lambda+\lambda^{2}\right),
\end{aligned}
$$


tal que seus autovalores são (usando $\overline{R_{0}}$ definido em $(2.35)$ ):

$$
\lambda_{1}=-\mu_{h} \quad e \quad \lambda_{2}=\frac{-\left(\gamma+\mu_{h}+\mu_{m}\right) \pm \sqrt{\left(\gamma+\mu_{h}+\mu_{m}\right)^{2}-4 \mu_{m}\left(\gamma+\mu_{h}\right)\left(1-\overline{R_{0}}\right)}}{2}
$$

Assim, a parte real dos autovalores são negativas, então $E_{0}$ é localmente assintoticamente estável se $\overline{R_{0}}<1$, e é possível mostrar que é globalmente assintoticamente estável em $\Lambda^{*}$ (Equação (2.38)) para $\overline{R_{0}} \leq 1$, usando a função de Lyapunov (ver (Esteva e Vargas, 1998)).

Para $\overline{R_{0}}>1$ o equilíbrio $E_{0}$ se torna um ponto hiperbólico instável e então surge o equilíbrio $E_{1}$. Para se analisar a estabilidade do equilíbrio endêmico, calcula-se os autovalores da matriz jacobiana em $E_{1}$ (Esteva e Vargas, 1998; Keeling e Rohani, 2008; Sotomayor, 1979).

Devido a complexidade de calcular os autovalores dos equilíbrios para os modelos com múltiplos sorotipos, assim como o retrato de fase e as soluções aproximadas do sistema, apresentaremos no próximo capítulo, um estudo com resultados obtidos a partir de métodos numéricos (Kooi et al., 2014; Sartori, 2014).

\subsection{Estimação de parâmetros}

Para que um modelo descreva uma doença infecciosa de forma realista, o ideal é que os parâmetros do modelo sejam estimados através dos dados de incidência da doença (Casella e Berger, 2002; Clayton et al., 1993; He et al., 2009). Geralmente, os dados são notificações semanais, portanto são somente parte da informação sobre o progresso da doença, de forma que a modelagem destas exige modelos matemáticos complexos que descrevam características da doença em grandes e pequenas populações. Portanto, além da construção do modelo, tem-se o problema de estimação dos parâmetros.

Vários pacotes foram desenvolvidos para este propósito (Coelho et al., 2011; King et al., 2016, 2017; Stocks et al., 2017) e diversos trabalhos aplicam técnicas de inferência para estimar parâmetros para descrever as mais diversas doenças. Águas et al. aplicam a estimação de parâmetros para um modelo matemático aplicado aos dados clínicos de Malária de oito regiões endêmicas na África Subsariana (Águas et al., 2008). White et al. também fazem inferência para um modelo que analisa a dinâmica da transmissão do vírus sincicial respiratório (White et al., 2007). Cauchemez e Fergunson estimam parâmetros para um modelo Sarampo aplicado nos dados de Londres (Cauchemez e Ferguson, 2008). Recentemente, têm-se aumentado a quantidade de trabalhos que utilizam inferência para estimar parâmetros em modelos para doenças que podem ser transmitidas por mais de um patógeno, como dengue, Malária, rotavírus e influenza (Coelho et al., 2011; Shrestha et al., 2011; Stocks et al., 2017). Coelho e Carvalho estimam parâmetros para um modelo de dengue aplicado aos dados de incidência do Rio de Janeiro (Coelho e Carvalho, 2015). Kao e Eisenberg estimam parâmetros para um modelo transmissão de dengue que considera transmissão vetor-hospedeiro (Kao e Eisenberg, 2017), e vários outros que trabalham tanto com abordagem determinística ou estocástica (Clayton et al., 1993; Gjini et al., 2016; Shrestha et al., 2011).

Nesta seção estudamos a estimação de parâmetros para os nossos modelos de transmissão de dengue com múltiplos sorotipos com população total e com população compartimentada por faixas etárias, apresentados neste capítulo. Começamos com uma breve explicação de métodos utilizados e destacamos que; como os ajustes são feitos para modelos determinísticos, a estimação de parâmetros implica encontrar a curva do modelo que melhor reproduz os dados. Os resultados são apresentados para algumas cidades as quais estão sendo testadas a vacina do Instituto Butantan. No Apêndice B mais alguns resultados são apresentados. 


\subsubsection{Métodos de estimação}

A estimação de parâmetros é uma tarefa complexa, especialmente quando o modelo inclui compartimentos em que parte dos parâmetros são desconhecidos e não observáveis, como é o caso de modelos que incluem o compartimento dos vetores na dinâmica de transmissão da doença em que não são conhecidos, por exemplo, o tamanho da população de mosquitos suscetíveis, e a quantidade de novos mosquitos infectados semanalmente.

O métodos dos mínimos quadrados é uma opção simples para ajustar modelos a dados. O ajuste é feito através do cálculo do erro quadrático, que consiste da soma do quadrado das diferenças entre o resultado obtido com o modelo e os dados. O objetivo então é encontrar, sobre todos os possíveis valores dos parâmetros do modelo, quais parâmetros minimizam a discrepância entre os dados e a predição do modelo, ou seja, o conjunto de parâmetros que resultam em um menor erro quadrático. Porém com esse método, não temos o controle do erro sobre cada ponto do ajuste e somente do valor final da soma dos erros ao quadrado.

A estimação por verossimilhança é uma ótima opção pois fornece um meio de controlar o erro em cada ponto da aproximação. A verossimilhança significa uma medida do suporte fornecido por um conjunto de dados para um valor particular do parâmetro de um modelo de probabilidade. Em outras palavras, verossimilhança $\mathcal{L}$ é a probabilidade de um conjunto de dados ocorrer sobre uma determinada hipótese particular, ou seja, uma função da probabilidade condicional (Casella e Berger, 2002; Clayton et al., 1993).

Definição 2.3 Seja $f(x \mid \theta)$ a função densidade de probabilidade de uma amostra $X$. Assim, se $X=x$ é observado, a função de $\theta$ definida por

$$
\mathcal{L}(\theta \mid x)=f(x \mid \theta)
$$

é denominada de função de verossimilhança.

Se $X$ é um vetor, então $\mathcal{L}(\theta \mid x)=\mathbb{P}_{\theta}(X=x)$. Podemos comparar a função de verossimilhança de dois parâmetros e obtemos que se

$$
\mathbb{P}_{\theta_{1}}(X=x)=\mathcal{L}\left(\theta_{1} \mid x\right)>\mathcal{L}\left(\theta_{2} \mid x\right)=\mathbb{P}_{\theta_{2}}(X=x),
$$

então a amostra que observamos é mais provável de ocorrer se $\theta=\theta_{1}$ do que se $\theta=\theta_{2}$, isto é, $\theta_{1}$ é um valor mais plausível de ser o verdadeiro valor de $\theta$ do que $\theta_{2}$ (Casella e Berger, 2002).

Definição 2.4 Considerando que $X_{1}, \ldots, X_{n}$ são amostras com função densidade de probabilidade $f\left(x \mid \theta_{1}, \ldots, \theta_{k}\right)$, temos que a função de verossimilhança é dada por

$$
\mathcal{L}(\theta \mid x)=\mathcal{L}\left(\theta_{1}, \ldots, \theta_{k} \mid x_{1}, \ldots, x_{n}\right)=\prod_{i=1}^{n} f\left(x_{i} \mid \theta_{1}, \ldots, \theta_{k}\right) .
$$

Quando encontramos um conjunto ou intervalo de valores que um parâmetro pode assumir, podemos determinar qual é o valor mais provável para o parâmetro calculando a máxima verossimilhança. Os problemas então, associados a encontrar o valor de máxima verossimilhança se reduzem a encontrar o máximo global de uma função e lidar com a questão da sensibilidade numérica relacionada à pequenas mudanças nos dados (Clayton et al., 1993).

Definição 2.5 Seja $\hat{\theta}(x)$ o valor dos parâmetros para o qual $\mathcal{L}(\theta \mid x)$ atinge seu máximo como uma função de $\theta$ para cada ponto da amostra $x$ mantido fixo. Uma estimativa de máxima verossimilhança (MLE) do parâmetro $\theta$ baseado em uma amostra $X$ é $\hat{\theta}(X)$. 
O log-verossimilhança é aplicado para o caso em que o valor de um parâmetro é muito pequeno e tem a propriedade importante de que a diferença no log da verossimilhança têm uma escala natural que não depende do modelo ou dos dados (em uma primeira aproximação), e tal que as diferenças na ordem de 1 unidade são estatisticamente significativas. Denotamos por

$$
l(\theta)=\log \mathcal{L}(\theta) .
$$

Ao empregar verossimilhança no ajuste de modelos aos dados surge a necessidade de considerar uma distribuição de probabilidade para o erro. Há diversas distribuições que podem ser usadas, por exemplo, quando os casos de notificação são registrados manualmente, o erro cometido é normalmente distribuído, então a verossimilhança pode ser feita usando a distribuição normal para os erros. O resultado de aplicar a verossimilhança com erros normalmente distribuídos é muito semelhante ao de aplicar mínimos quadrados (King et al., 2017). Se os dados são resultados de um processo amostral, então eles podem ser descritos como uma amostra binomial ou como uma amostra de Poisson, entre outras (Stocks et al., 2017). Porém, a escolha do melhor modelo para os erros, sempre depende da natureza dos dados que serão analisados.

A distribuição de Poisson foi escolhida pois é uma distribuição de probabilidade para variáveis aleatórias discretas, expressando a probabilidade de um número de eventos ocorrer durante um intervalo fixo de tempo se esses eventos ocorrem a uma taxa constante conhecida e independentemente de quando ocorreu o último evento (Casella e Berger, 2002). Poisson é apropriada para os dados de incidência dengue que são número de novos casos registrados semanalmente.

Definição 2.6 Uma variável aleatória $X$ tomando valores inteiros não-negativos tem uma distribuição de Poisson com parâmetro ( $\lambda$ ) se

$$
\mathbb{P}(X=x \mid \lambda)=\frac{e^{-\lambda} \lambda^{x}}{x !}, x=0,1, \ldots,
$$

em que $\lambda$ é o número médio de eventos por intervalo.

\subsubsection{Pacote pomp}

Para facilitar essa tarefa, muitos pacotes foram criados para fazer a estimativa de parâmetros tanto por mínimos quadrados como por máxima verossimilhança; pomp, Berkeley Madonna ( software, BIP (Flávio Coelho). Usaremos o pacote pomp implementado em linguagem $R$.

O pacote pomp fornece uma estrutura flexível para investigações estatísticas de processos de Markov parcialmente observados (Partially observed Markov process, (POMP)), também conhecidos como modelos oculto de Markov ou sistemas dinâmicos estocásticos. No pomp está implementado o ajuste de parâmetros pelo método dos mínimos quadrados e principalmente um conjunto de métodos estatísticos modernos como: cadeias de Markov, Monte Carlo sequencial, filtragem, computação Bayesiana aproximada, estimativa de máxima verossimilhança sintética, e outros (King et al., 2016, 2017; Stocks et al., 2017).

\subsubsection{Aplicação do algoritmo}

Nessa seção discutimos os passos essenciais de como aplicar o pomp para estimar os parâmetros dos nossos modelos. A primeira etapa necessária é um objeto que codifique o modelo e os dados (King et al., 2016, 2017). Primeiro codifica-se o sistema de equações diferenciais ordinárias com a função (skeleton), juntamente com os dados que são notificações semanais de dengue (data), as condições iniciais do sistema (initializer), as variáveis (statenames) e também os parâmetros do modelo (paramnames), sendo que os parâmetros fixos, são definidos em param_fixos e os demais precisam ser estimados (params), para cada modelo teremos um conjunto diferente de parâmetros, mostrado na Tabela 2.1 . 
Na sequência define-se uma função $f 1$, que calcula um primeiro ajuste com mínimos quadrados, sse, cujo erro, é dado pelo quadrado da diferença entre o número de infectados obtido com a solução do sistema de EDOs e os dados de incidência observados. A função optim é então aplicada para encontrar, dentre o espaço de valores possíveis dos parâmetros, o conjunto de parâmetros que fornecem o menor erro quadrático, sendo necessário informar qual a função que se quer otimizar e valores iniciais para os parâmetros. Nesse momento é fundamental se ter um bom valor inicial para os parâmetros para que o método convirja e estime valores que façam sentido no contexto sendo aplicado.

Depois de estimado com o método dos mínimos quadrados, os valores dos parâmetros são usados como valor inicial para uma segunda estimativa por meio de verossimilhança, função $f 2$, em que vamos considerar que o erro no ajuste de cada dado satisfaz uma distribuição de Poisson. A equação $I$ no sistema de EDOs modela a dinâmica da população de infectados, então modelamos o erro de medição supondo que os dados $X_{t}$ resultantes de um processo de amostragem, são Poisson com média $p I_{t}$, isto é:

$$
X_{t} \sim \operatorname{Poisson}\left(p I_{t}\right)
$$

em que $I_{t}$ é a verdadeira intensidade de infectados no modelo no tempo $t, X_{t}$ é o número de indivíduos infectados segundo a amostra no tempo $t$ e $p$ representa a combinação da eficiência da amostragem e detectabilidade de infecções. Como o modelo é determinístico, supomos que o resultado do modelo é correto e então o erro está aplicado em cima dos dados. O parâmetro $p$ deve ser estimado variando entre 0 e 1 , e indica que quando o resultado é um valor menor do que 1 , o ajuste não usou $100 \%$ do valor de $I$ segundo os parâmetros estimados, o que pode ser um indício de que a epidemia pode ser maior do que as séries temporais de dados observadas/registradas, também podendo ser interpretado como a proporção de assintomáticos (Bhatt et al., 2013). Utiliza-se escala $\log$ e depois o resultado é recalculado na escala original mle2.

Em cada modelo, as funções estimadoras, tanto f1 como f2 são aplicadas para dois conjuntos de parâmetros, pois não são estimados todos ao mesmo tempo. Primeiro obtêm-se as taxas de transmissão $\beta_{i}$ e $\Omega_{i}$, e o parâmetro $p$, e depois estes valores obtidos são usados para estimar os parâmetros da forçante de sazonalidade $\alpha$ e $\delta$ e os valores iniciais $S(0), I_{i}(0), V(0)$ e $V_{i}(0)$. Para cada conjunto de parâmetros estimados temos um valor de log verossimilhança, o qual apresentaremos o negativo deste valor.

Depois de obtidos todos os parâmetros necessários, aplica-se a função trajectory que simula o sistema de EDOs com estes parâmetros e devolve a curva de solução $I$, contendo o total de infectados, que é então comparada com os dados. Por fim, analisa-se a parte de aleatoriedade dos dados e um intervalo de confiança para o erro. Aplicamos a raply que replica 2000 vezes rpois, que por sua vez, aplica Poisson $n$ vezes (= quantidade de dados) com média $\lambda=p * I$ e armazena os resultados em um arquivo simdat. Então aaply pega os dados em simdat aplica a função quantile e armazena os resultados em quantiles. A função genérica quantile produz quantiles de amostras correspondentes às probabilidades dadas. Aplicamos para as probabilidades 0.025, 0.5 e 0.975 , construindo assim, um intervalo de $95 \%$ de confiança. Por fim esses valores quantiles são plotados juntamente com um valor aleatório typ dentre os 2000 calculados. O esquema abaixo mostra como codificar o modelo básico $\mathrm{SIRVV}_{i}$ e aplicar o algoritmo de estimação de parâmetros. 


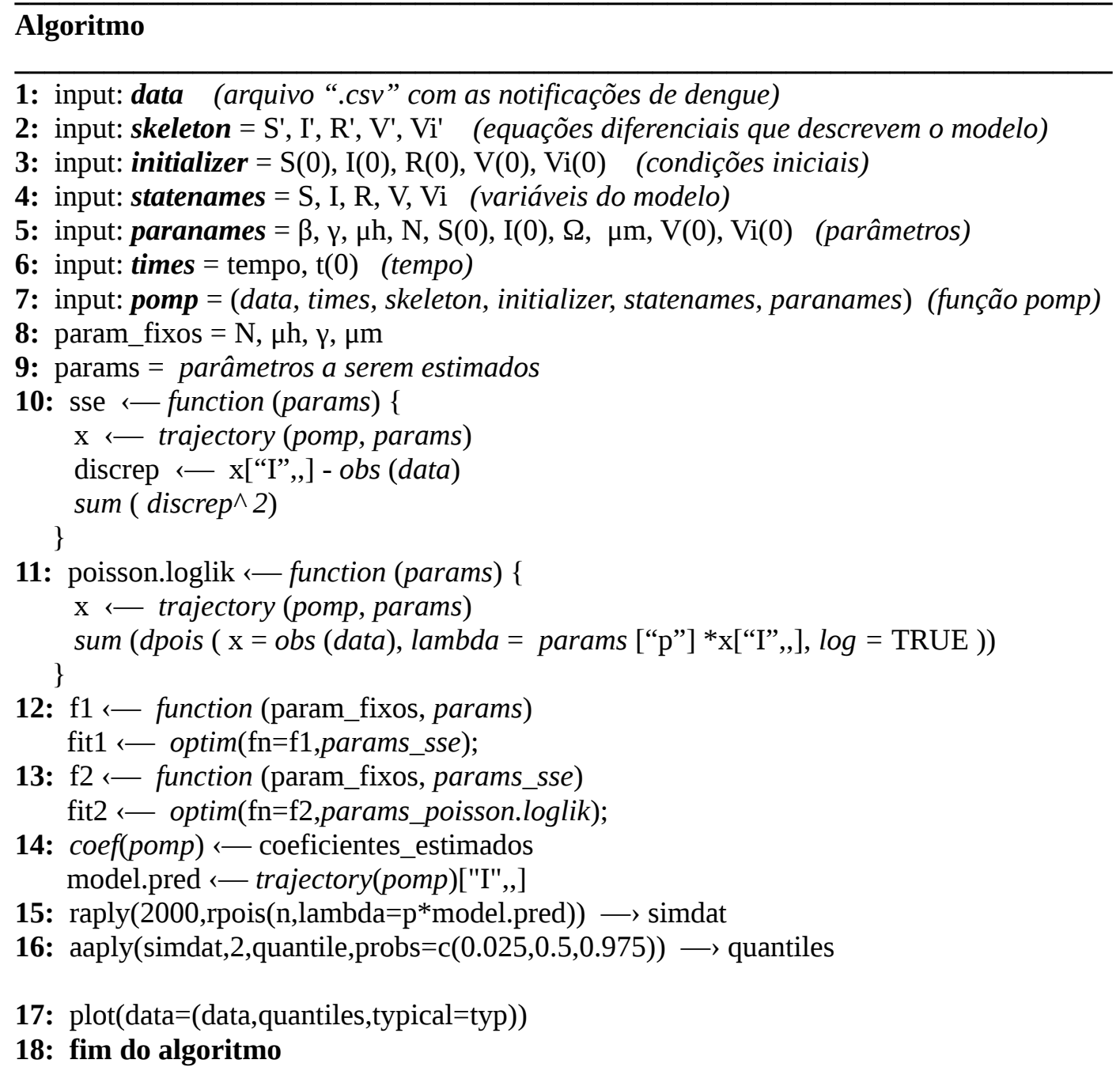

Figura 2.6: Esquematização do algoritmo de estimaçãa de parâmetros pomp aplicado para o modelo $\operatorname{SIRVV} V_{i}$. 


\section{Capítulo 3}

\section{Resultados numéricos}

Neste capítulo apresentaremos soluções numéricas para os modelos do Capítulo 2 e a estimação de parâmetros para esses modelos. Também, analisamos os efeitos de aplicar uma vacina tetravalente na população. Todas os resultados numéricos foram gerados com o método de Rosenbrock o qual é um aprimoramento de um Runge-Kutta, implementado em Fortran, apresentado em detalhes em (Sartori, 2014). As estimações de parâmetros foram feitas com o pacote pomp implementado em R (King et al., 2016, 2017) e os gráficos plotados com MATLAB ou R.

\subsection{Modelos com e sem sazonalidade}

Uma importante diferença entre considerar modelos com um ou vários sorotipos, é que no primeiro a infecção depende de mais de um surto para que o indivíduo seja infectado mais de uma vez, ou para que pessoas sejam infectadas por diferentes sorotipos, e após um período de imunidade cruzada espera-se que o indivíduo volte a ser suscetível para poder ser infectado por um sorotipo diferente, enquanto no modelo com vários sorotipos, os vírus competem entre si pelos suscetíveis, e então podemos ter mais de um sorotipo agindo em um surto até que um deles domine (Seção 1.1.4). Matematicamente isso faz com que o modelo tenha oscilações por causar alternação de qual sorotipo domina em cada surto e devido a infecção por um sorotipo gerar imunidade para o sorotipo já infectado, fazendo com que se tenha alternância no vírus dominante.

As figuras a seguir mostram os resultados de considerar a forçante de sazonalidade na taxa de nascimento dos vetores (Aguiar et al., 2011; Hartley et al., 2002). Nas simulações dos modelos sem a forçante de sazonalidade, é possível ver que oscilações ocorrem e que há alternância dos sorotipos, porém os surtos não são anuais, não sendo possível ajustar os modelos aos dados de incidência em que já evidenciamos que os surtos geralmente ocorrem anualmente (Seção 1.1.3).

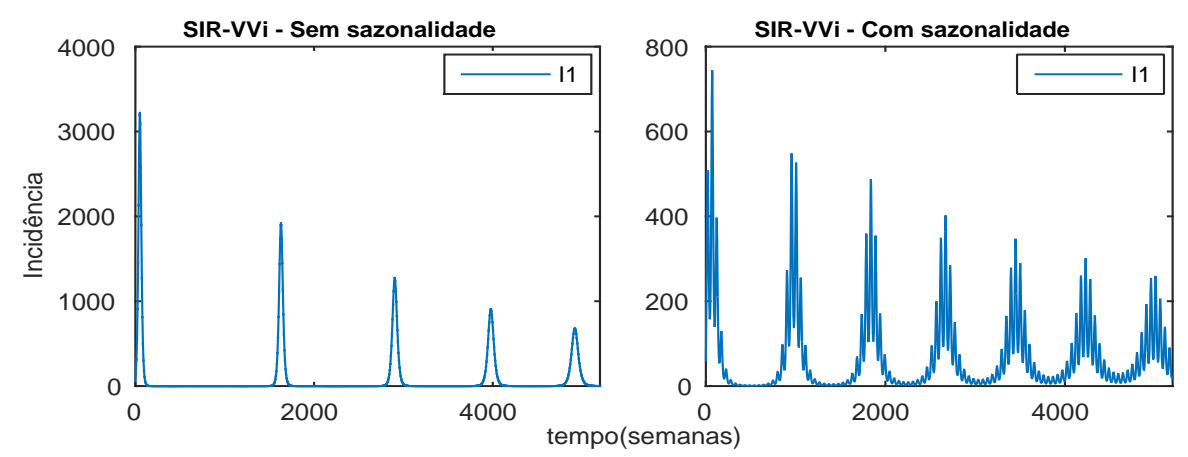

Figura 3.1: Comparação do modelo com 1 sorotipo $\left(S I R V V_{i}\right.$ ), sem forçante de sazonalidade (figura da esquerda) e com forçante de sazonalidade (figura da direita) na taxa de nascimento dos mosquitos, em um periodo de 100 anos $=5200$ semanas. Parâmetros (em semanas): $N_{h}=571149, N_{m}=604675, \mu_{m}=0.7$, $\mu_{h}=0.00027, \gamma=1.0, \beta=3.8, \Omega=0.34, \overline{R_{01}}=1.9535$. 


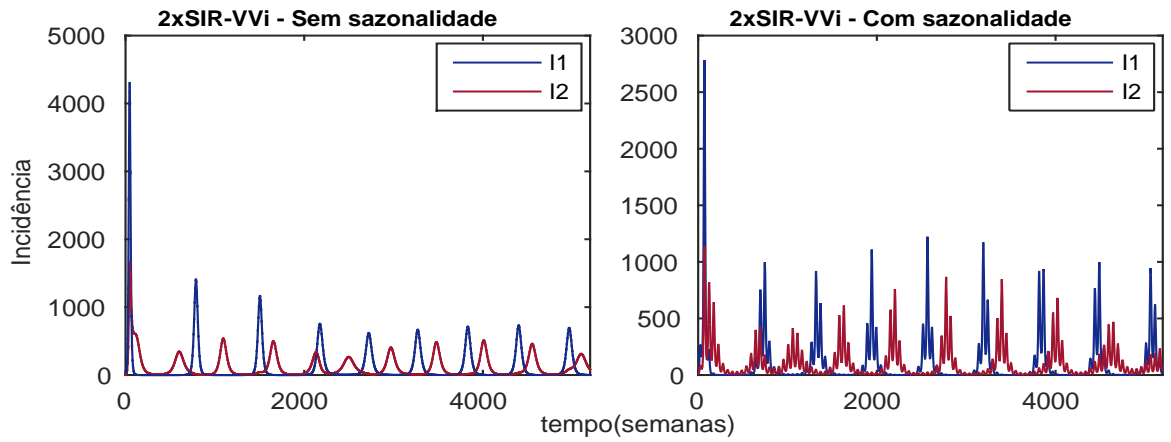

Figura 3.2: Comparação do modelo com 2 sorotipos (2×SIRVV $V_{i}$ ), sem forçante de sazonalidade (figura da esquerda) e com forçante de sazonalidade (figura da direita) na taxa de nascimento dos mosquitos, em um período de 100 anos $=5200$ semanas. Parâmetros (em semanas): $N_{h}=571149, N_{m}=831486, \mu_{m}=0.7$, $\mu_{h}=0.00027, \gamma=1.0, \varphi=0.038, \beta_{1}=4.28, \beta_{2}=0.33, \Omega_{1}=0.33, \Omega_{2}=4.28, \overline{R_{01}}=2.9366, \overline{R_{02}}=$ 2.9360 .
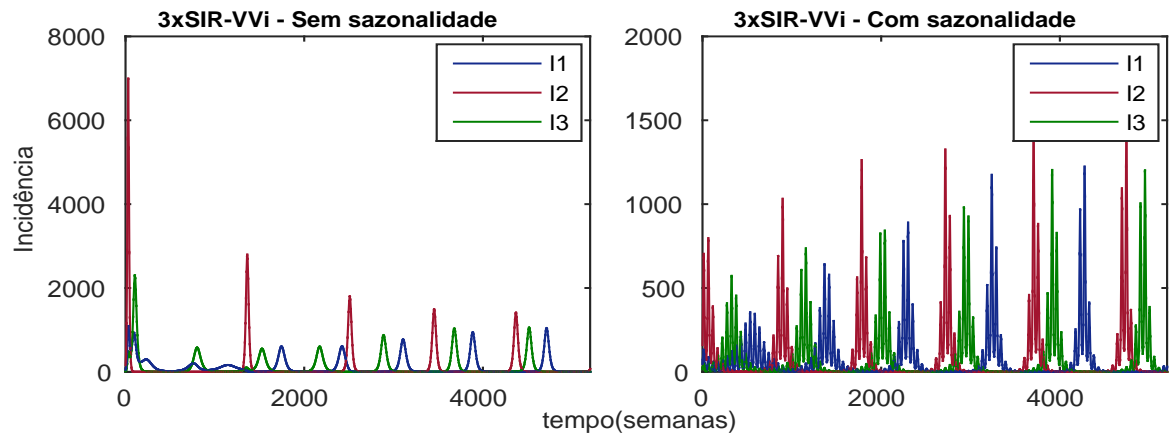

Figura 3.3: Comparação do modelo com 3 sorotipos $\left(3 \times S I R V V_{i}\right)$, sem forçante de sazonalidade (figura da esquerda) e com forçante de sazonalidade (figura da direita) na taxa de nascimento dos mosquitos, em um periodo de 100 anos $=5200$ semanas. Parâmetros (em semanas): $N_{h}=571149, N_{m}=773628, \mu_{m}=0.7$, $\mu_{h}=0.00027, \gamma=1.0, \varphi=0.038, \beta_{1}=0.88, \beta_{2}=14.45, \beta_{3}=2.92, \Omega_{1}=1.39, \Omega_{2}=0.089, \Omega_{3}=0.43$, $\overline{R_{01}}=2.3662, \overline{R_{02}}=2.4878, \overline{R_{03}}=2.4289$.
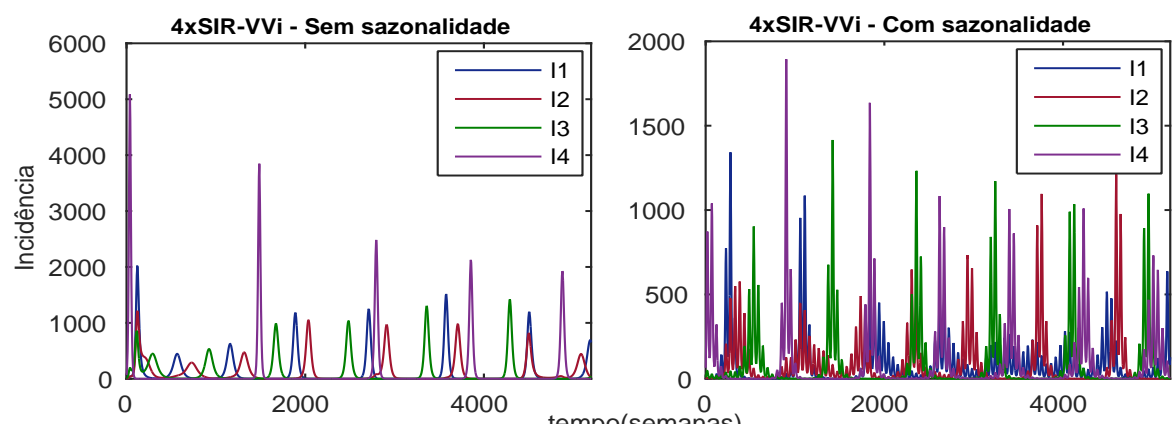

Figura 3.4: Comparação do modelo com 4 sorotipos $\left(4 \times S I R V V_{i}\right)$, sem forçante de sazonalidade (figura da esquerda) e com forçante de sazonalidade (figura da direita) na taxa de nascimento dos mosquitos, em um período de 100 anos $=5200$ semanas. Parâmetros (em semanas): $N_{h}=571149, N_{m}=813735, \mu_{m}=0.7$, $\mu_{h}=0.00027, \gamma=1.0, \varphi=0.038, \beta_{1}=10.6, \beta_{2}=3.05, \beta_{3}=0.53, \beta_{4}=12.7, \Omega_{1}=0.11, \Omega_{2}=0.40$, $\Omega_{3}=2.23, \Omega_{4}=0.10, \overline{R_{01}}=2.3725, \overline{R_{02}}=2.4824, \overline{R_{03}}=2.4049, \overline{R_{04}}=2.5841$. 


\subsubsection{Estabilidade numérica}

Devido a dificuldade de se obter expressões analíticas para as soluções dos sistemas de equações diferenciais ordinárias não lineares, vamos estudar os retratos de fase para nossos modelos, calculados segundo os parâmetros dos gráficos da seção anterior, considerando os modelos com e sem a forçante de sazonalidade na taxa de nascimento dos vetores, de forma que simulamos para um período de 10000 anos e usamos somente os últimos 50 anos.

\section{Estabilidade no equilíbrio livre de doença}

Nesta seção mostramos o resultado dos autovalores das matrizes jacobianas no equilíbrio livre de doença $E_{0}$ para cada modelo $\mathrm{n} \times \mathrm{SIRVV}_{i}, n=1,2,3,4$. Os autovalores estão normalizados pelo de valor máximo entre eles, e foram calculados com o pacote LAPACK (Anderson et al., 1999). Os resultados confirmam a teoria de que para $R_{0}<1$ o equilíbrio $E_{0}$ é estável e instável para $R_{0}>1$.
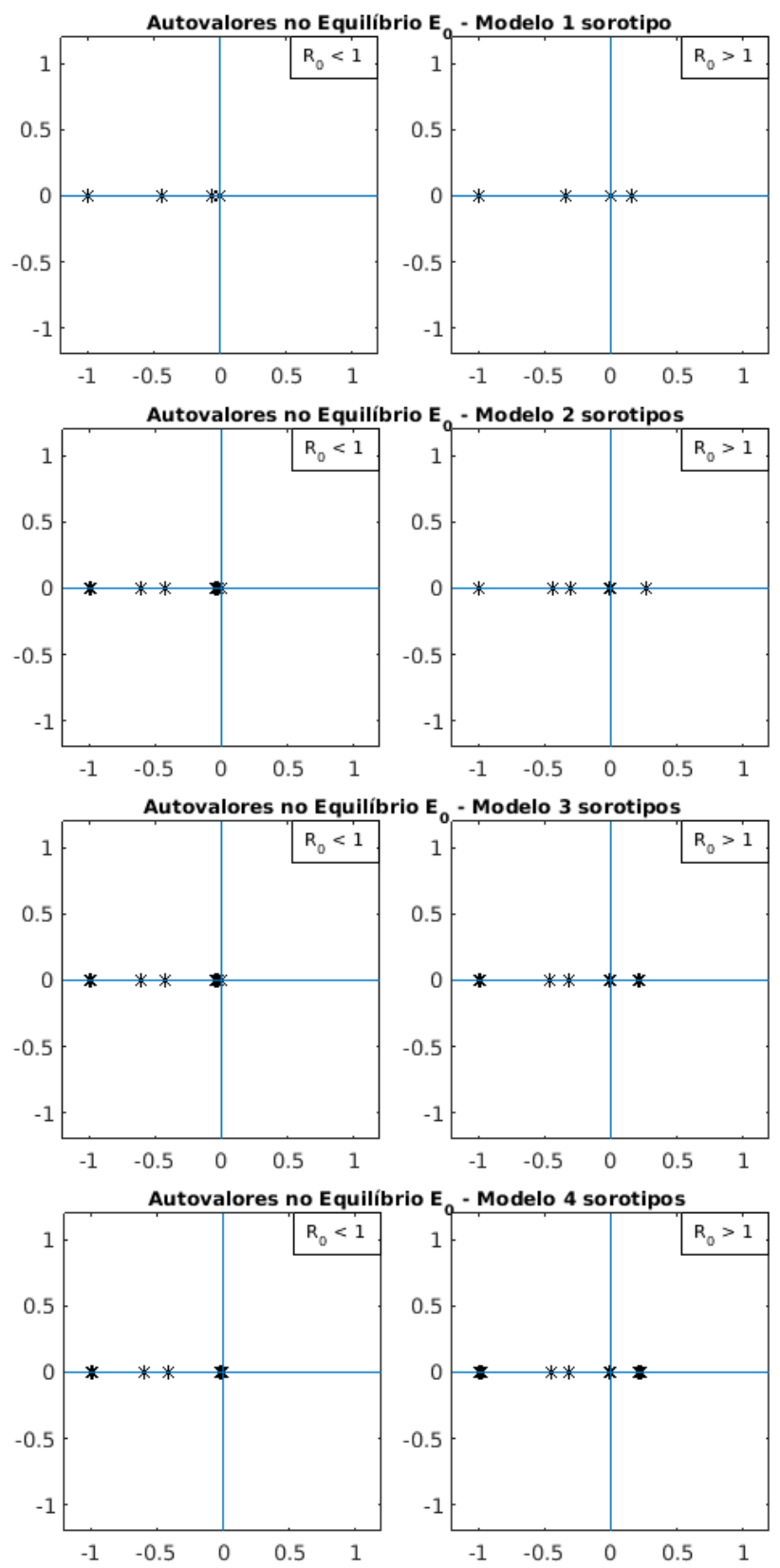

Figura 3.5: Autovalores nos equilíbrios livre de doença de cada modelo. Gráficos da esquerda para o caso $R_{0}<1$ e gráficos da direita para o caso $R_{0}>1$. 


\section{Modelo SIRVV}

O modelo $\mathrm{SIRVV}_{i}$ sem sazonalidade converge para um ponto de equilíbrio denominado equilíbrio endêmico, em que não se tem mais surtos e a quantidade de infectados permanece constante ao longo do tempo (Figura 3.6). Para esse caso, como o equilíbrio é um ponto, podemos calcular os autovalores da matriz jacobiana neste ponto e então como estes possuem parte real negativa (Figura 3.8), mostramos que o equilíbrio endêmico do modelo com 1 sorotipo sem sazonalidade, é estável. No caso de incluir a sazonalidade, a solução converge para uma órbita periódica Figura 3.7.
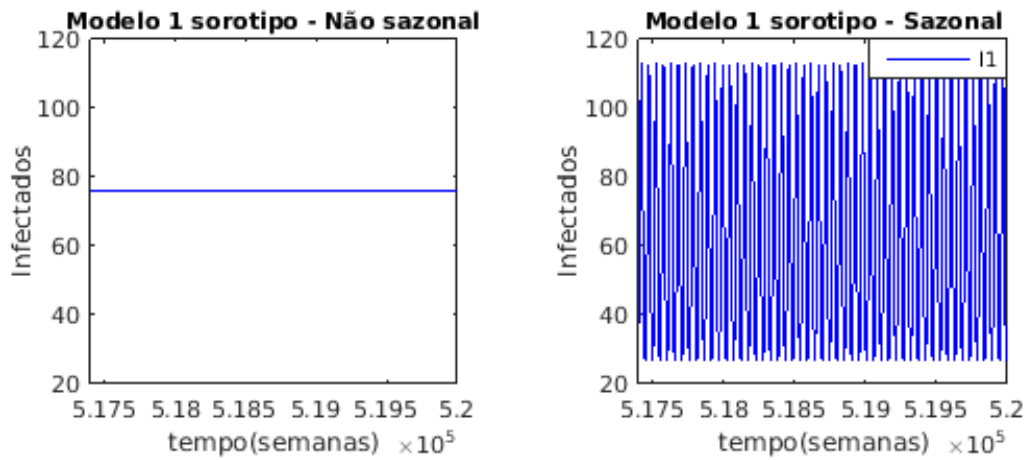

Figura 3.6: Séries temporais do modelo com 1 sorotipo sem sazonalidade (figura esquerda) e com sazonalidade (figura direita). Simulações com os mesmos parâmetros da Figura 3.1 para um período de 10000 anos, em que apresentamos somente os últimos 50 anos.
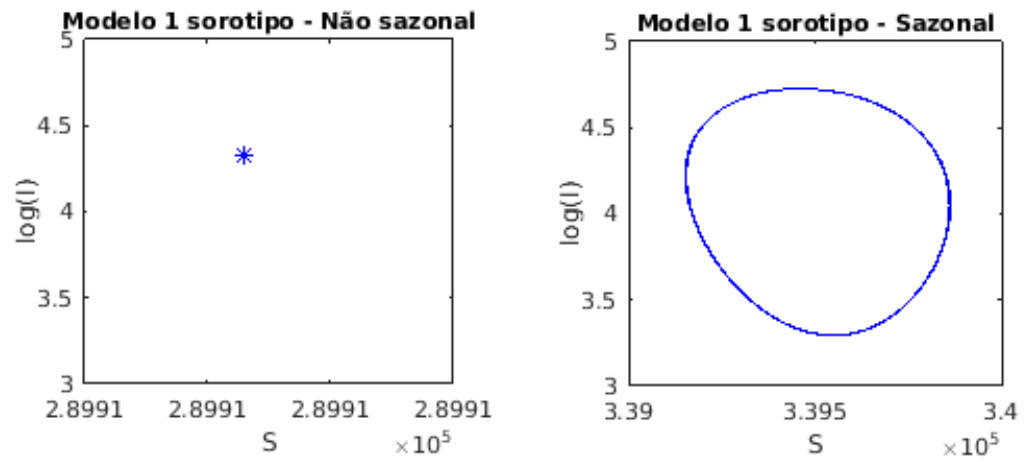

Figura 3.7: Retrato de fase $S \times I$ para o modelo com 1 sorotipo sem sazonalidade (figura esquerda) e com sazonalidade (figura direita) de acordo com as séries da Figura 3.6.

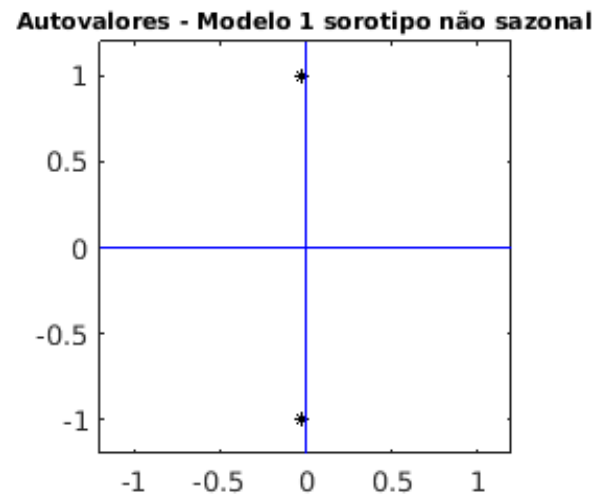

Figura 3.8: Autovalores da matriz jacobiana no equilíbrio endêmico do modelo com 1 sorotipo sem sazonalidade, mostrando que o equilíbrio endêmico neste caso é estável. 


\section{Modelo $2 \times \operatorname{SIRVV}_{i}$}

No caso do modelo com 2 sorotipos, as séries temporais (Figura 3.9) mostram que a coexistência de sorotipos fazem com que o modelo não tenha um equilíbrio endêmico, no sentido do equilíbrio ser um ponto, e sim temos que as soluções convergem para órbitas periódicas Figura 3.10.
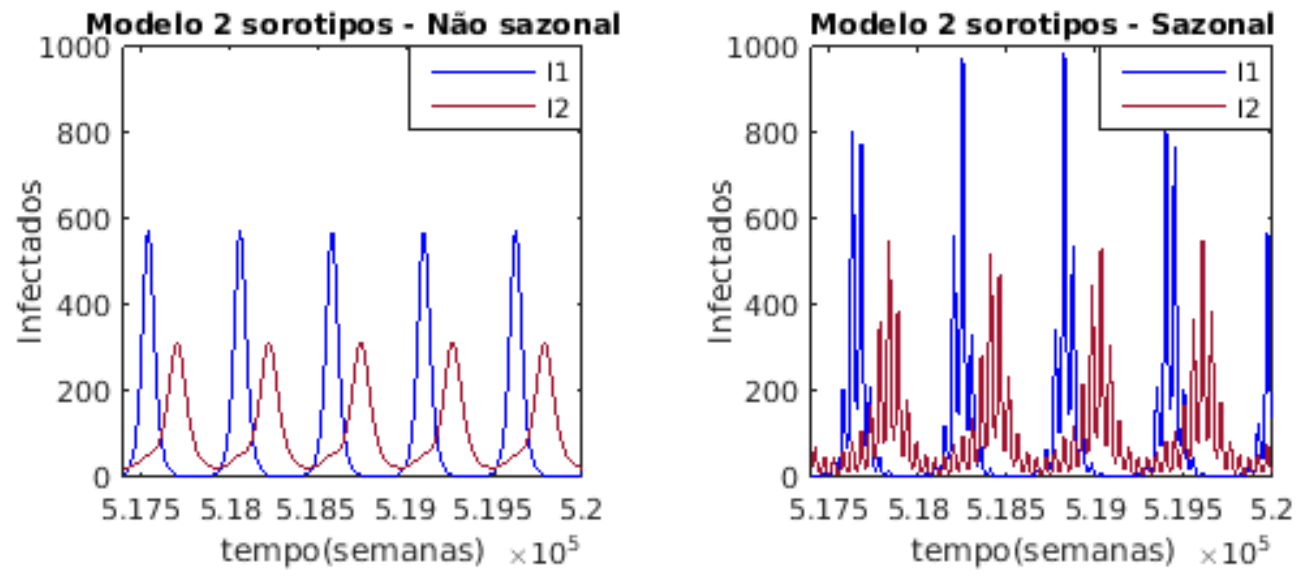

Figura 3.9: Séries temporais do modelo com 2 sorotipos sem sazonalidade (figura esquerda) e com sazonalidade (figura direita). Simulações com os mesmos parâmetros da Figura 3.2 para um período de 10000 anos, em que apresentamos somente os últimos 50 anos.
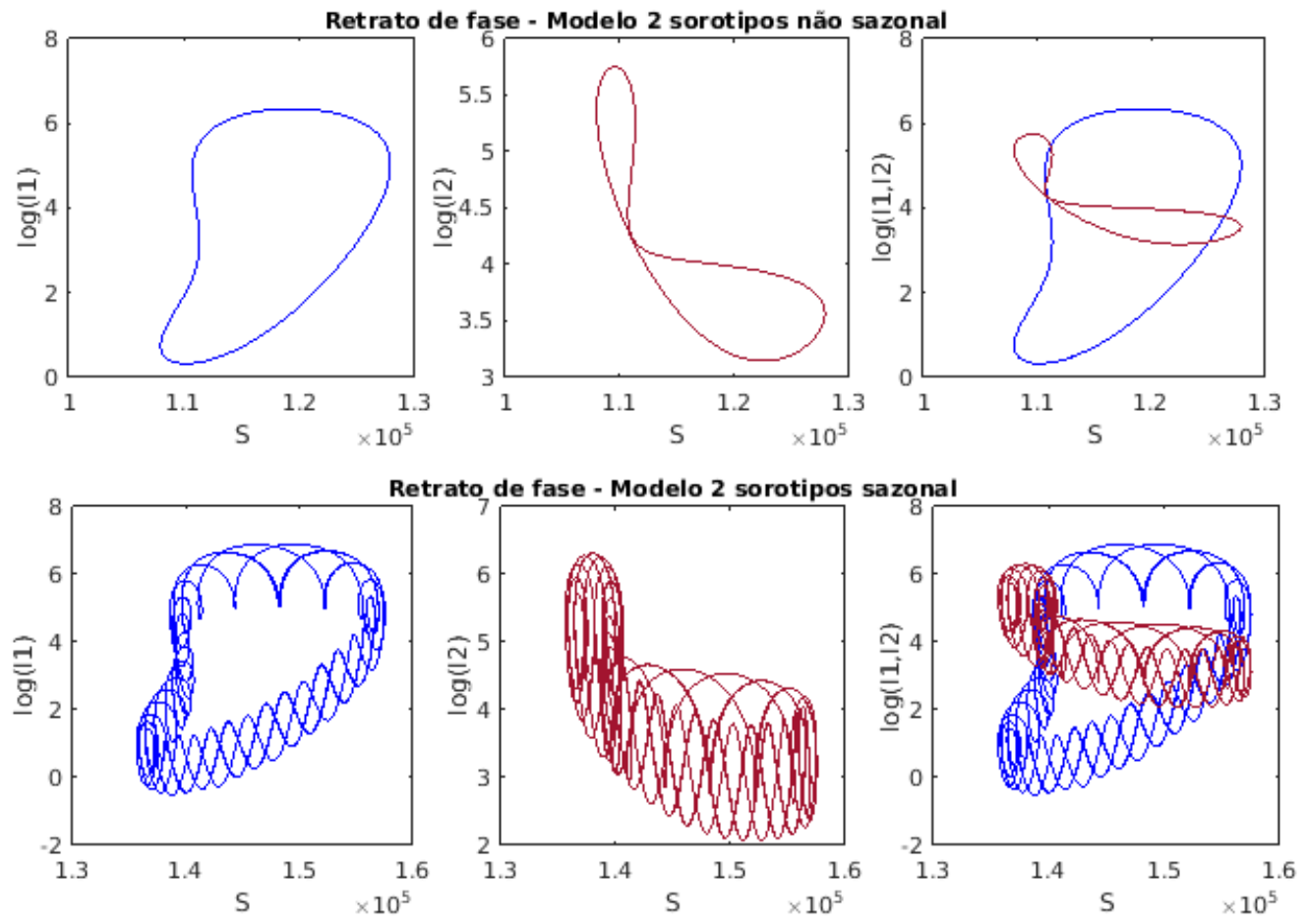

Figura 3.10: Retrato de fase $S \times I_{i}$ para o modelo com 2 sorotipos sem e com sazonalidade de acordo com as séries da Figura 3.9. Apresentamos o retrato de fase dos infectados com cada sorotipo separadamente $e$ depois juntos no mesmo gráfico. 


\section{Modelo $3 \times$ SIRVV $_{i}$}

Semelhantemente ao caso do modelo com 2 sorotipos, as séries temporais (Figura 3.11) do modelo com 3 sorotipos, mostram que a coexistência de sorotipos fazem com que o modelo não tenha um equilíbrio endêmico, no sentido do equilíbrio ser um ponto, e sim temos que as soluções convergem para órbitas, em que nem é possível dizer se são periódicas Figura 3.12.
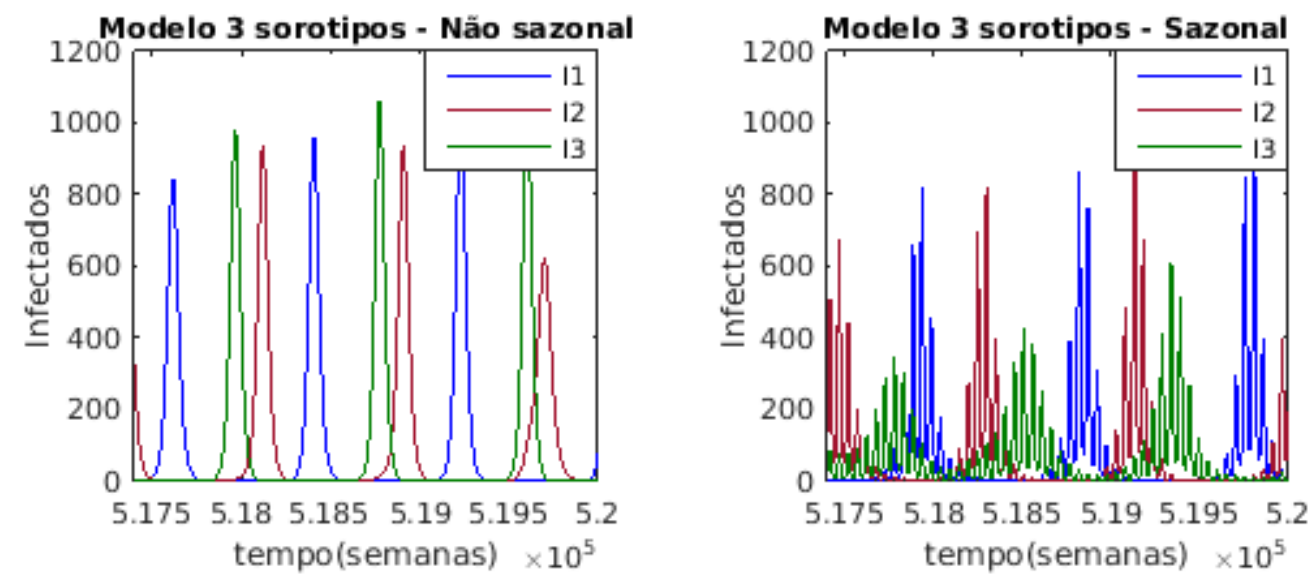

Figura 3.11: Séries temporais do modelo com 3 sorotipos sem sazonalidade (figura esquerda) e com sazonalidade (figura direita). Simulações com os mesmos parâmetros da Figura 3.3 para um período de 10000 anos, em que apresentamos somente os últimos 50 anos.
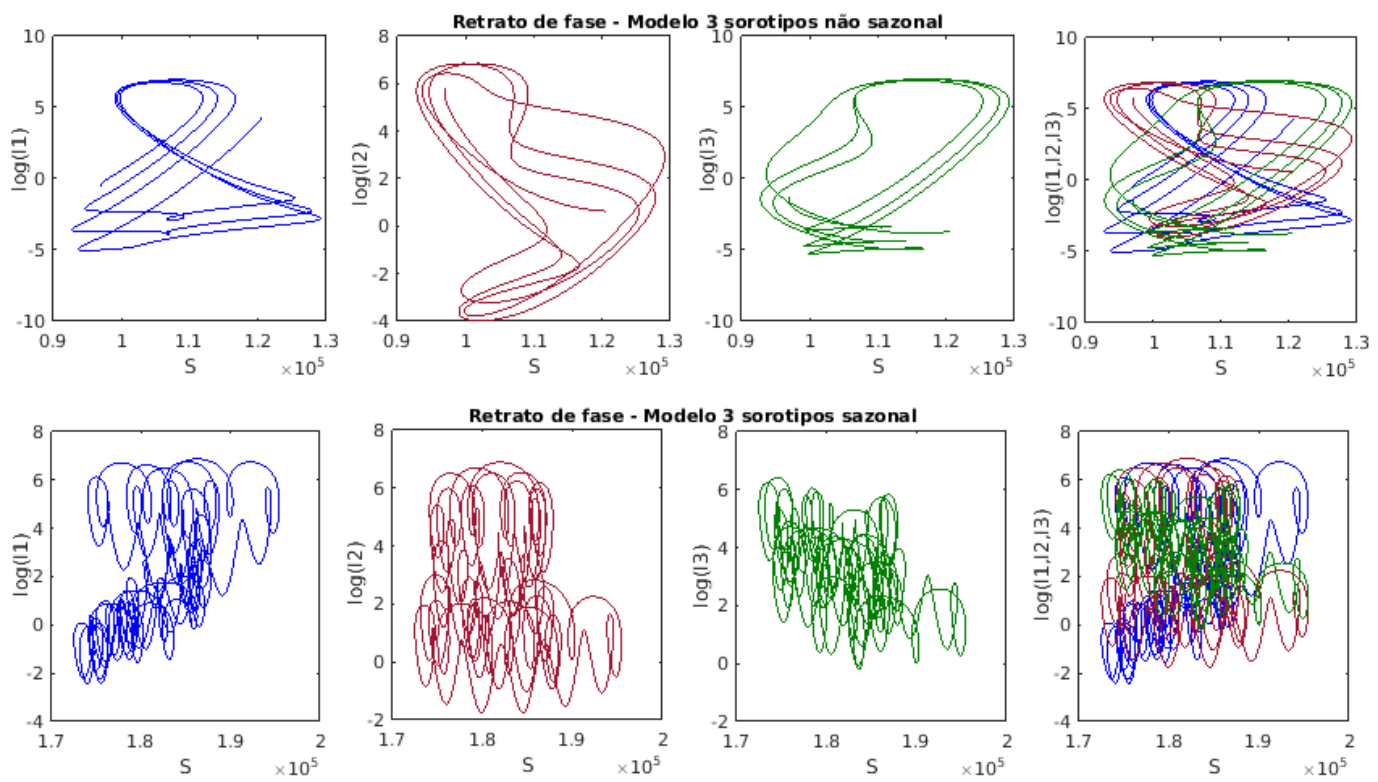

Figura 3.12: Retrato de fase $S \times I_{i}$ para o modelo com 3 sorotipos sem e com sazonalidade de acordo com as séries da Figura 3.11. Apresentamos o retrato de fase dos infectados com cada sorotipo separadamente $e$ depois juntos no mesmo gráfico. 


\section{Modelo $4 \times \operatorname{SIRVV}_{i}$}

As séries temporais (Figura 3.13) mostram que a coexistência no modelo com 4 sorotipos, fazem com que o modelo não tenha um equilíbrio endêmico como um ponto, e sim temos que as soluções convergem para órbitas que não são periódicas Figura 3.14.
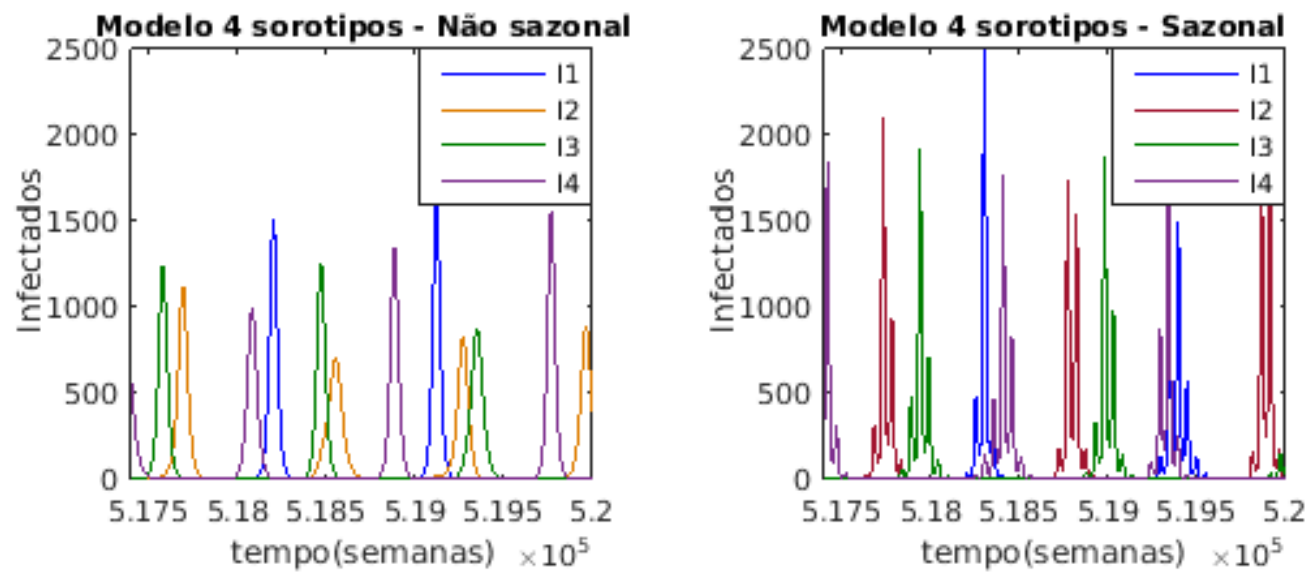

Figura 3.13: Séries temporais do modelo com 4 sorotipos sem sazonalidade (figura esquerda) e com sazonalidade (figura direita). Simulações com os mesmos parâmetros da Figura 3.4 para um período de 10000 anos, em que apresentamos somente os últimos 50 anos.
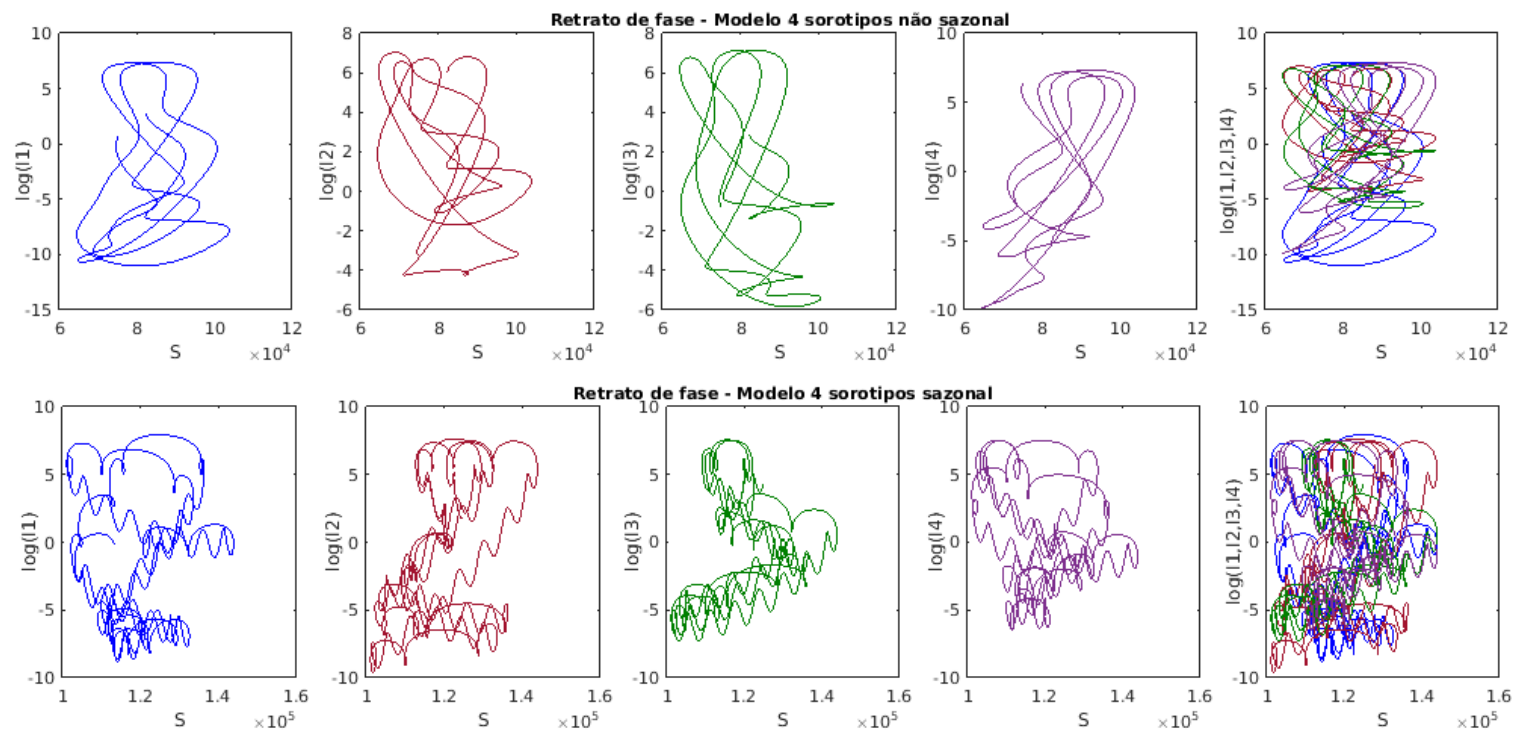

Figura 3.14: Retrato de fase $S \times I_{i}$ para o modelo com 4 sorotipos sem e com sazonalidade de acordo com as séries da Figura 3.13. Apresentamos o retrato de fase dos infectados com cada sorotipo separadamente e depois juntos no mesmo gráfico. 


\subsection{Ajuste dos modelos aos dados}

Na estimação de parâmetros o ideal é que se tenha a máxima quantidade de parâmetros possíveis fixados, para que poucos deles sejam estimados de forma mais consistente com as condições epidemiológicas. Os valores dos parâmetros $N_{h}$, respectivo ao tamanho populacional de cada cidade, e $\mu_{h}$, taxas de nascimento e de mortalidade dos humanos, são obtidos de estatísticas demográficas feitas por órgãos públicos como IBGE (IBGE, 2017), mostrado no Capítulo 1. Outros parâmetros são considerados globais, isto é, são mantidos fixos no ajuste das séries temporais aos modelos para estimação dos outros parâmetros (Tabela 2.1, Capítulo 2).

O período de recuperação dos humanos $\gamma$ é definido como 1 semana, devido os dados a serem ajustados representarem o número de novos casos a cada semana de forma que estamos ajustando dados de incidência, e o período de imunidade cruzada é fixado em 6 meses (=180 dias) (Aguiar et al., 2011). O período de vida do mosquito é definido como 10 dias, pois estamos somente considerando mosquitos fêmeas adultos capazes de transmitir a doença, geralmente o período de vida total dos mosquitos é considerado em torno de 40 dias, desde ovos até a morte (Andraud et al., 2012; Boccia et al., 2014; Rodrigues et al., 2013). Os valores desses parâmetros globais são dados na Tabela 3.1. Os parâmetros restantes são os que precisam ser estimados, pois dependem de particularidades de cada localização, e cuja estimação deve ser feita a partir dos dados de notificação da doença (Anderson, 1982; Keeling e Rohani, 2008).

\begin{tabular}{c|c}
\hline Parâmetros & Valor(semanas) \\
\hline$\mu_{h}$ Nordeste & $7 /\left(71^{*} 365\right)$ \\
$\mu_{h}$ Centro-Oeste & $7 /\left(73^{*} 365\right)$ \\
$\mu_{h}$ Sudeste & $7 /\left(75^{*} 365\right)$ \\
$\gamma$ & 1 \\
$\varphi$ & $7 / 180$ \\
$\mu_{m}$ & $7 / 10$ \\
\hline
\end{tabular}

Tabela 3.1: Parâmetros globais que são mantidos fixos em todos os modelos. Consideramos que as taxas de nascimento/mortalidade $\left(\mu_{h}\right)$, de recuperação $(\gamma)$ e de imunidade cruzada temporária $(\varphi)$ para os humanos e também a taxa de mortalidade dos vetores $\left(\mu_{m}\right)$ não são estimadas, mas sim consideradas fixas em todas séries temporais ajustadas aos modelos.

O algoritmo de estimação de parâmetros do pomp foi aplicado para ajustar os modelos aos dados de incidência de dengue de 4 cidades brasileiras que estão recebendo os testes da Fase III da vacina da dengue do Instituto Butantan. As cidades foram escolhidas de forma a serem uma de cada grupo etário estudados por meio de correlação, apresentados na Figura 1.11 da Seção 1.3.1.

Da Figura 1.2 podemos observar que a maioria das cidades não tiveram surtos em todos os anos consecutivos no período de 7 anos de dados. Como temos modelos com até 4 sorotipos e assimétricos, queremos que a metodologia seja capaz de estimar uma taxa de transmissão para cada sorotipo e portanto trabalhamos com os dados do período de 2011 a 2014 que são os anos que apresentaram maior número de casos e contêm 4 surtos.

A Figura 3.15 mostra as séries temporais das 4 cidades escolhidas, que apresentam perfis diferentes, com variados níveis de incidência e risco etários diferentes, segundo a normalização por faixa etária, e também com diferentes totais populacionais (Tabela 3.2). 


\begin{tabular}{c|c|c|c|c|c}
\hline \multicolumn{6}{c}{ Populações } \\
\hline Cidades & População Total & Fx. et. A & Fx. et. B & Pop. Grupo A & Pop. Grupo B \\
\hline Aracaju & 571149 & 0 a 19 & $\geq 20$ & 176945 & 394204 \\
Brasília & 2570160 & 0 a 19 & $\geq 20$ & 829238 & 1740922 \\
Fortaleza & 2452185 & 0 a 19 & $\geq 20$ & 777835 & 1674350 \\
São Paulo & 11253503 & 0 a 39 & $\geq 40$ & 7143895 & 4109608 \\
\hline
\end{tabular}

Tabela 3.2: População total e separada em grupos etários para as cidades: Aracaju, Brasilia, Fortaleza e São Paulo, segundo o Censo demográfico de 2010, IBGE (IBGE, 2017).
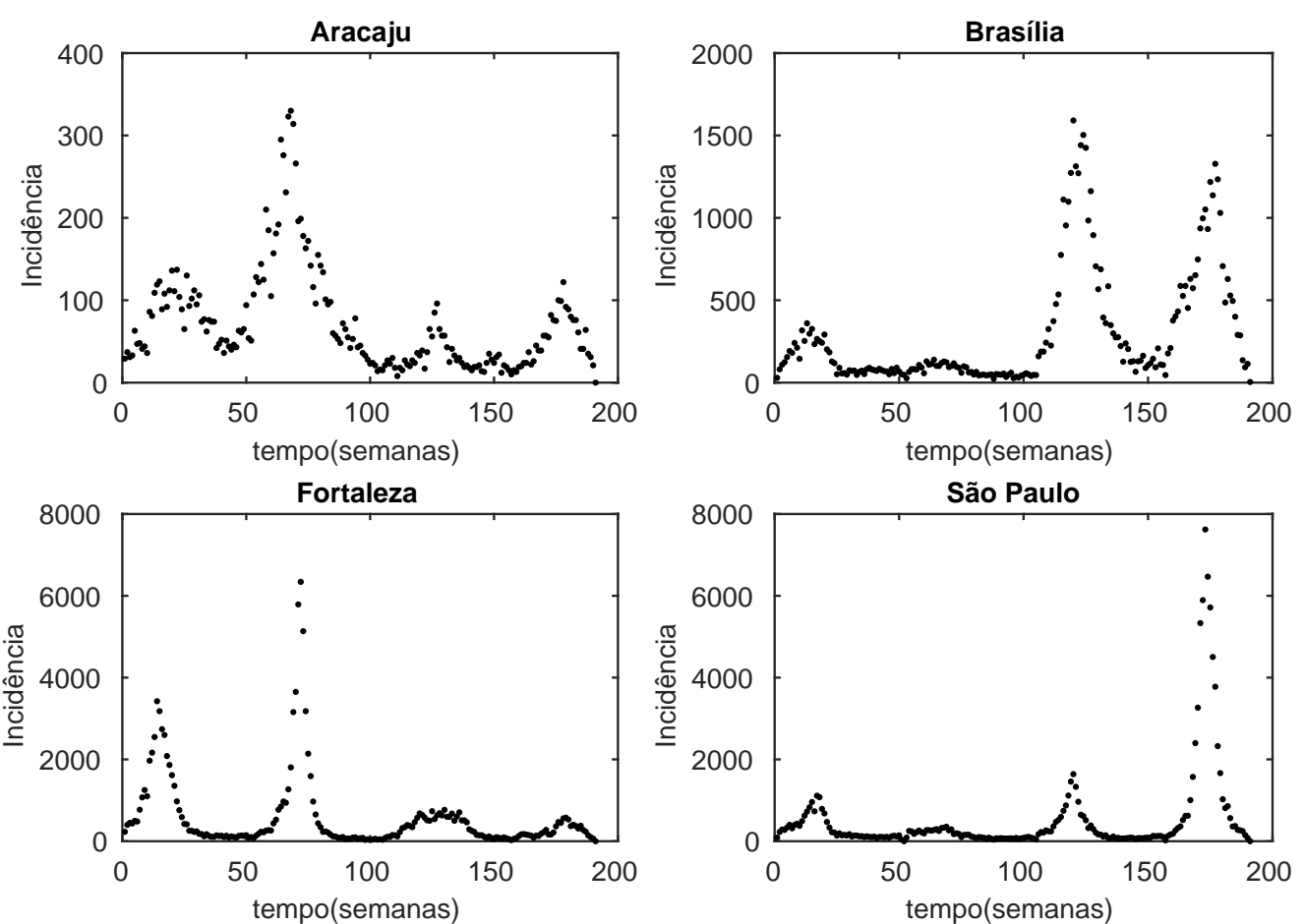

Figura 3.15: Séries temporais de cidades brasileiras em que estão sendo testadas a vacina do Instituto Butantan e que serão usadas para estimação de parâmetros; Aracaju, Brasília, Fortaleza e São Paulo. O periodo de dados é da $1^{a}$ semana de 2011 a 35 semana de 2014, totalizando 191 semanas.

\section{Observações}

Importante destacar que os dados de dengue disponíveis são o número de novos casos registrados semanalmente de cada cidade. As notificações são feitas em unidades básicas de saúde e são registradas manualmente, portanto podem haver erros no momento de gravar os dados computacionalmente, outra discrepância pode ser causada por notificações que são acumuladas em semanas com feriados e somente registradas na semana posterior, e por último, a dengue também tem a particularidade de que muitos casos são assintomáticos, o que pode ocasionar em uma sub notificação do número real de infectados.

Os ajustes de parâmetros foram feitos com os dados brutos das séries temporais da Figura 3.15 e são discutidos na próxima seção. Os parâmetros que variam com sorotipo, como taxas de transmissão e quantidade inicial de infectados, recebem todos os mesmos valores iniciais no algoritmo de estimação, para que o resultado não favoreça nenhum dos sorotipos. 


\subsubsection{Modelos com múltiplos sorotipos}

Os gráficos da Figura 3.16 exibem o resultado do ajuste dos modelos de 1 a 4 sorotipos aos dados de incidência de dengue das cidades da Figura 3.15. O ajuste é feito entre os dados e a curva I solução do compartimento dos infectados, sendo que nos modelos com mais de um sorotipo, a curva I representa a soma de todos infectados. O ajuste é feito primeiro com mínimos quadrados e novamente com verossimilhança, como descrito na Seção 2.4. A região sombreada, representa o intervalo de $95 \%$ de confiança para os valores estimados, que em alguns resultados quase não é possível observar pois a região é muito restrita.
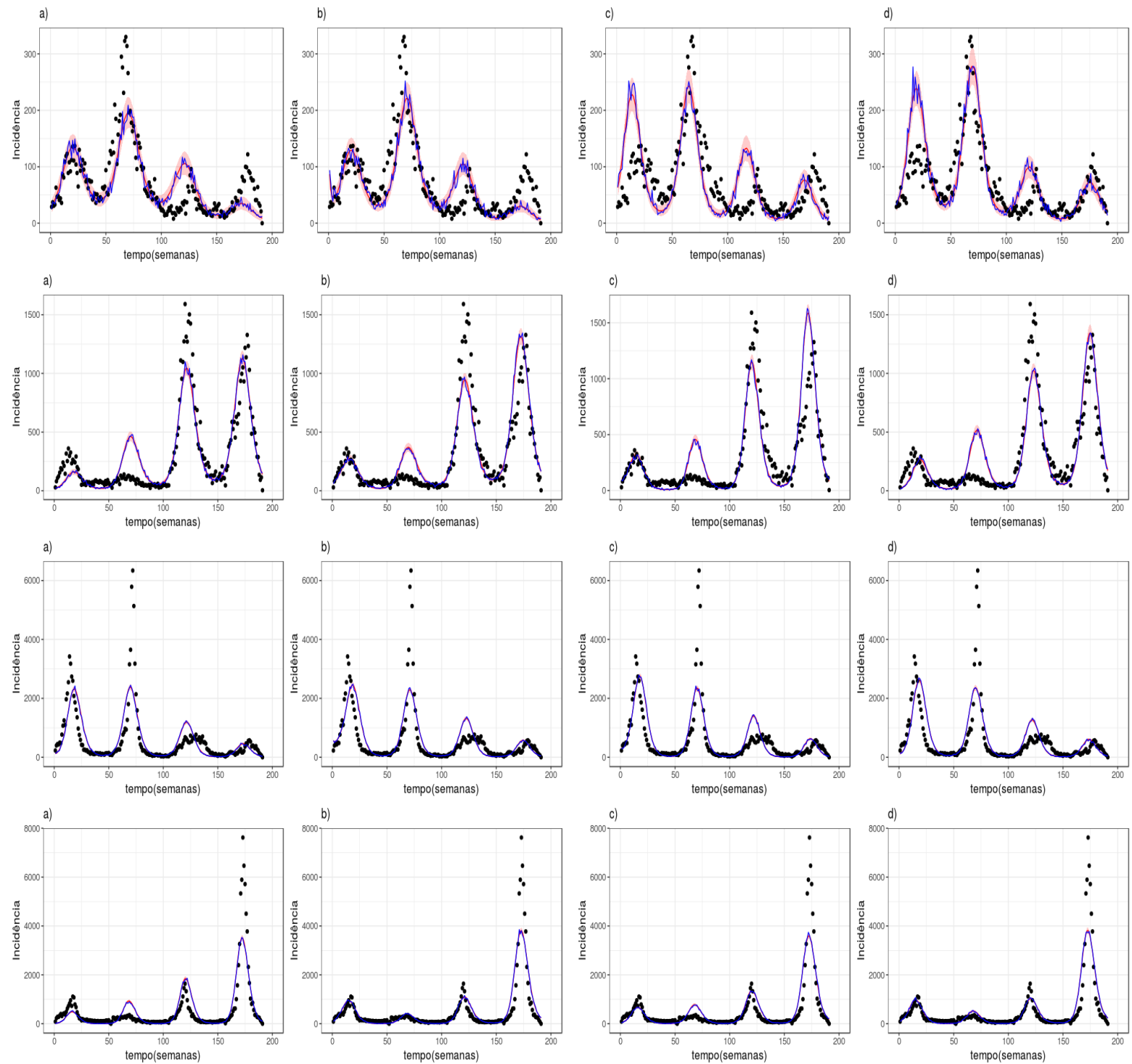

Figura 3.16: Ajuste dos modelos aos dados de incidência de cidades brasileiras, da $1^{a}$ semana de 2011 a $35^{a}$ semana de 2014. As cidades apresentadas foram selecionadas dentre as estudadas na Seção 1.3.1 que estão participando da Fase III de testes da vacina tetravalente contra a dengue produzida pelo Instituto Butantan. Na primeira fileira temos os gráficos dos ajustes para Aracaju, seguindo dos ajustes para Brasília, $2^{a}$ fileira de gráficos, na $3^{a}$ fileira o ajuste para Fortaleza, e por fim para a cidade de São Paulo. Cada coluna mostra o resultado do ajuste com os diferentes modelos: a) $S I R V V_{i}$ (1 Sorotipo), b) $2 \times S I R V V_{i}$ (2 Sorotipos), c) $3 \times S I R V V_{i}$ (3 Sorotipos), d) $4 \times S I R V V_{i}$ (4 Sorotipos). Os pontos em preto são a quantidade de casos registrados semanalmente no periodo analisado. A curva continua em azul representa uma amostra da solução da curva I calculada com os parâmetros estimados por verossimilhança dentro do intervalo de $95 \%$ de confiança, de forma que nos modelos com mais de um sorotipo, I contém a soma de todos os infectados. 
Os valores dos parâmetros estimados são dados em: Tabela 3.3, Tabela 3.4, Tabela 3.5 e Tabela 3.6, para as séries de dados de Aracaju, Brasília, Fortaleza e São Paulo, respectivamente. O valor de $p$ é estimado com o modelo de 1 sorotipo $\left(\mathrm{SIRVV}_{i}\right)$ e o valor encontrado é mantido fixo para a estimação com os outros modelos.

\begin{tabular}{c|c|c|c|c}
\hline Aracaju & \multicolumn{4}{|c}{ Modelos } \\
\hline Parâmetros(semanas) & 1 Sorotipo & 2 Sorotipos & 3 Sorotipos & 4 Sorotipos \\
\hline$\beta_{1}, \Omega_{1}$ & $3.8063,0.3423$ & $8.2875,0.1574$ & $0.8839,1.3999$ & $10.6044,0.1194$ \\
$\beta_{2}, \Omega_{2}$ & - & $0.3351,1.1702$ & $14.4545,0.0896$ & $3.0554,0.4065$ \\
$\beta_{3}, \Omega_{3}$ & - & - & $2.9271,0.4308$ & $0.5343,2.2377$ \\
$\beta_{4}, \Omega_{4}$ & - & - & - & $12.7093,0.1008$ \\
$p$ & 0.2678 & 0.26 & 0.26 & 0.26 \\
$-\log$ Verossimilhança & 5935 & 5933 & 6013 & 6268 \\
\hline$R_{01}$ & 1.97 & 2.7121 & 2.3937 & 2.5764 \\
$R_{02}$ & - & 0.8153 & 2.5054 & 2.5272 \\
$R_{03}$ & - & - & 2.4394 & 2.4327 \\
$R_{04}$ & - & - & - & 2.6068 \\
\hline$\alpha$ & 0.0362 & 0.0437 & 0.0610 & 0.0542 \\
$\delta$ & 0.9370 & 0.8867 & 1.5466 & 0.9791 \\
$S_{(0)}$ & 359508.7 & 269883.9 & 334842.1 & 299892.0 \\
$I_{1}(0)$ & 58.655 & 131.34 & 72.45 & 1.2869 \\
$I_{2}(0)$ & - & 583.51 & 159.33 & 2.2382 \\
$I_{3}(0)$ & - & - & 28.09 & 10.5818 \\
$I_{4}(0)$ & - & - & - & 65.1970 \\
$V(0)$ & 604613.1 & 831465.8 & 773586.2 & 813685.0 \\
$V_{1}(0)$ & 61.903 & 7.13 & 23.19 & 0.003 \\
$V_{2}(0)$ & - & 4.06 & 19.44 & 0.061 \\
$V_{3}(0)$ & - & - & 0.003 & - \\
$V_{4}(0)$ & 2400 & 2630 & 4027 & 19.10 \\
\hline $\log$ Verossimilhança & & & & 2274
\end{tabular}

Tabela 3.3: Parâmetros encontrados para ajustar os modelos aos casos de dengue notificados na cidade de Aracaju, da $1^{a}$ semana de 2011 à $35^{a}$ semana 2014, nos modelos de 1 a 4 sorotipos. Estimativa utilizando Minimos quadrados e verossimilhança.

\begin{tabular}{c|c|c|c|c}
\hline Brasília & \multicolumn{4}{|c}{ Modelos } \\
\hline Parâmetros(semanas) & 1 Sorotipo & 2 Sorotipos & 3 Sorotipos & 4 Sorotipos \\
\hline$\beta_{1}, \Omega_{1}$ & $2.4444,0.5363$ & $5.9933,0.2191$ & $6.0482,0.2171$ & $4.3682,0.3012$ \\
$\beta_{2}, \Omega_{2}$ & - & $7.7423,0.1463$ & $23.469,0.04344$ & $1.3197,0.9435$ \\
$\beta_{3}, \Omega_{3}$ & - & - & $3.4679,0.3438$ & $1.8517,0.6621$ \\
$\beta_{4}, \Omega_{4}$ & - & - & - & $2.2564,0.5539$ \\
$p$ & 0.3393 & 0.33 & 0.33 & 0.33 \\
$-\log$ Verossimilhança & 11398 & 10589 & 10254 & 11134 \\
\hline$\overline{R_{01}}$ & 2.5884 & 2.4210 & 2.3577 & 1.9766 \\
$\overline{R_{02}}$ & - & 2.0883 & 1.8306 & 1.8706 \\
$R_{03}$ & - & - & 2.1408 & 1.8419 \\
$\overline{R_{04}}$ & - & - & - & 1.8776 \\
\hline$\alpha$ & 0.0637 & 0.0632 & 0.0898 & 0.0773 \\
$\delta$ & 1.1099 & 1.1594 & 1.2364 & 0.8859 \\
$S(0)$ & 1423523 & 1536496 & 1811982 & 1881722 \\
$I_{1}(0)$ & 38.48 & 86.80 & 48.03 & 0.0471 \\
$I_{2}(0)$ & - & $7.39 \mathrm{e}-15$ & 417.72 & 23.17 \\
$I_{3}(0)$ & - & - & $2.82 \mathrm{e}-18$ & 0.00215 \\
$I_{4}(0)$ & - & - & - & 16.26 \\
$V(0)$ & 3553126 & 3317786 & 3231332 & 2703518 \\
$V_{1}(0)$ & 46.37 & 0.005 & 2.68 & 13.78 \\
$V_{2}(0)$ & - & 66.11 & 0.1565 & 0.4808 \\
$V_{3}(0)$ & - & - & 0.6374 & $7.64 \mathrm{e}-11$ \\
$V_{4}(0)$ & - & - & - & 13.33 \\
\hline $\log$ Verossimilhança & 7810 & 6403 & 9268 & 9000
\end{tabular}

Tabela 3.4: Parâmetros encontrados para ajustar os modelos aos casos de dengue notificados na cidade de Brasilia, da $1^{a}$ semana de 2011 à $35^{a}$ semana 2014, nos modelos de 1 a 4 sorotipos. Estimativa utilizando Minimos quadrados e verossimilhança. 


\begin{tabular}{c|c|c|c|c}
\hline Fortaleza & \multicolumn{4}{|c}{ Modelos } \\
\hline Parâmetros(semanas) & 1 Sorotipo & 2 Sorotipos & 3 Sorotipos & 4 Sorotipos \\
\hline$\beta_{1}, \Omega_{1}$ & $1.7248,0.7444$ & $4.2357,0.3032$ & $7.4887,0.1714$ & $4.1171,0.2966$ \\
$\beta_{2}, \Omega_{2}$ & - & $8.0463,0.0993$ & $1.3245,0.7306$ & $2.4689,0.5053$ \\
$\beta_{3}, \Omega_{3}$ & - & - & $0.6414,1.4392$ & $1.2078,1.0254$ \\
$\beta_{4}, \Omega_{4}$ & - & - & - & $5.0720,0.2492$ \\
$p$ & 0.6225 & 0.62 & 0.62 & 0.62 \\
$-\log$ Verossimilhança & 26504 & 25965 & 26115 & 28698 \\
\hline$\overline{R_{01}}$ & 2.5536 & 2.4139 & 2.4657 & 1.8397 \\
$\overline{R_{02}}$ & - & 1.5018 & 1.8589 & 1.8795 \\
$R_{03}$ & - & - & 1.7732 & 1.8659 \\
$R_{04}$ & - & - & - & 1.9042 \\
\hline$\alpha$ & 0.09155 & 0.09658 & 0.1076 & 0.09518 \\
$\delta$ & 0.96360 & 0.8333 & 0.9197 & 0.9330 \\
$S(0)$ & 1486221 & 1530460 & 1607089 & 1981827 \\
$I_{1}(0)$ & 332.97 & 204.83 & 84.08 & 0.495 \\
$I_{2}(0)$ & - & 1206.79 & 0.41 & 3.90 \\
$I_{3}(0)$ & - & - & 694.16 & 4.27 \\
$I_{4}(0)$ & - & - & - & 141.07 \\
$V(0)$ & 3414882 & 3227233 & 3298307 & 2586747 \\
$V_{1}(0)$ & 1.11 & 7.36 & 19.68 & 1.50 \\
$V_{2}(0)$ & - & 63.87 & $6.54 \mathrm{e}-15$ & 2.62 \\
$V_{3}(0)$ & - & - & 0.0457 & 2.34 \\
$V_{4}(0)$ & - & - & - & 42.44 \\
\hline $\log$ Verossimilhança & 24295 & 22236 & 23356 & 24342 \\
\hline
\end{tabular}

Tabela 3.5: Parâmetros encontrados para ajustar os modelos aos casos de dengue notificados na cidade de Fortaleza, da $1^{a}$ semana de 2011 à $35^{a}$ semana 2014, nos modelos de 1 a 4 sorotipos. Estimativa utilizando Minimos quadrados e verossimilhança.

\begin{tabular}{c|c|c|c|c}
\hline São Paulo & \multicolumn{4}{|c}{ Modelos } \\
\hline Parâmetros(semanas) & 1 Sorotipo & 2 Sorotipos & 3 Sorotipos & 4 Sorotipos \\
\hline$\beta_{1}, \Omega_{1}$ & $0.1286,10.017$ & $0.08127,16.1842$ & $1.4583,0.8952$ & $8.6233,0.1432$ \\
$\beta_{2}, \Omega_{2}$ & - & $18.5288,0.06128$ & $0.6623,1.8503$ & $1.8406,0.7160$ \\
$\beta_{3}, \Omega_{3}$ & - & - & $1.0013,1.2255$ & $9.2800,0.1342$ \\
$\beta_{4}, \Omega_{4}$ & - & - & - & $115.1505,0.0101$ \\
$p$ & 0.4446 & 0.44 & 0.44 & 0.44 \\
$-\log$ Verossimilhança & 26759 & 17269 & 22929 & 18011 \\
\hline$\overline{R_{01}}$ & 2.9325 & 2.5987 & 2.2747 & 2.2694 \\
$\overline{R_{02}}$ & - & 2.2434 & 2.1353 & 2.4219 \\
$\overline{R_{03}}$ & - & - & 2.1381 & 2.2887 \\
$R_{04}$ & - & - & - & 2.1374 \\
\hline$\alpha$ & 0.1228 & 0.1001 & 0.1052 & 0.1016 \\
$\delta$ & 1.1730 & 1.1805 & 1.2277 & 1.2254 \\
$S_{(0)}$ & 7103603 & 7457847 & 8866072 & 8198602 \\
$I_{1}(0)$ & 43.80 & 7.60 & 7.33 & 12.69 \\
$I_{2}(0)$ & - & $4.55 \mathrm{e}-5$ & 74.74 & 5.74 \\
$I_{3}(0)$ & - & - & 58.74 & 13.63 \\
$I_{4}(0)$ & - & - & - & 330.09 \\
$V(0)$ & 17936940 & 15568060 & 13729370 & 14480670 \\
$V_{1}(0)$ & 197.14 & 180.47 & 2.91 & 0.10 \\
$V_{2}(0)$ & - & 39.18 & 58.89 & 3.43 \\
$V_{3}(0)$ & - & - & 20.32 & $2.83 \mathrm{e}-4$ \\
$V_{4}(0)$ & 24790 & - & 18134 & 0.99 \\
\hline $\log$ Verossimilhança & & & & 15702 \\
\hline
\end{tabular}

Tabela 3.6: Parâmetros encontrados para ajustar os modelos aos casos de dengue notificados na cidade de São Paulo, da $1^{a}$ semana de 2011 à $35^{a}$ semana 2014, nos modelos de 1 a 4 sorotipos. Estimativa utilizando Minimos quadrados e verossimilhança. 


\subsubsection{Modelos com múltiplos sorotipos compartimentados por faixa etária}

Os gráficos da Figura 3.17, apresentam os ajustes dos modelos aos dados. Os modelos são os $\mathrm{n} \times \operatorname{SIRVV}_{i}, n=1,2,3,4$ compartimentados para as faixas etárias A e B, segundo a Tabela 3.2. Neste caso, a curva de infectados I contém a soma de todos infectados em ambos grupos etários e pelos diferentes sorotipos.
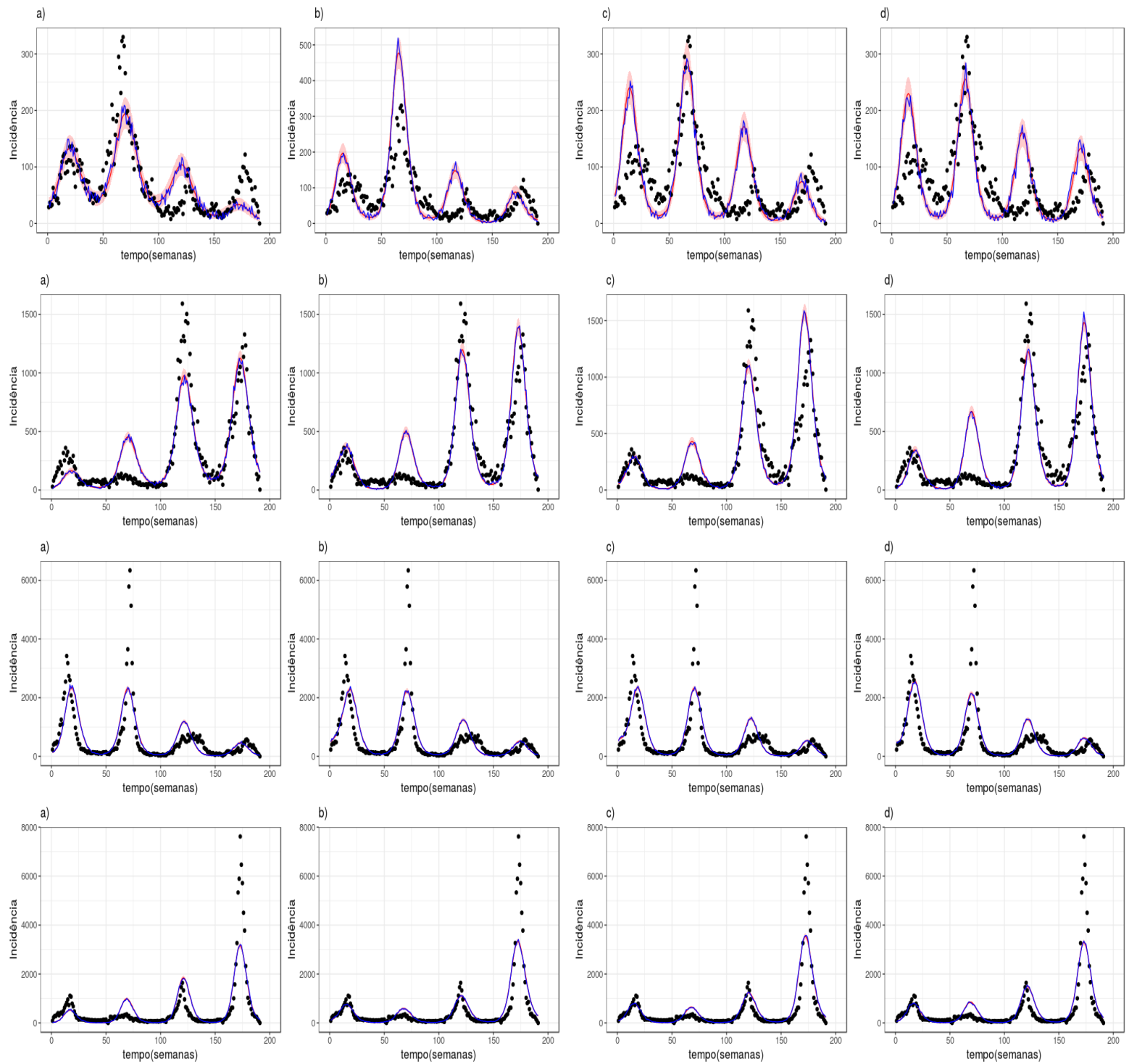

Figura 3.17: Ajuste dos modelos compartimentados por faixa etária aos dados de incidência de cidades brasileiras, da $1^{a}$ semana de 2011 a $35^{a}$ semana de 2014. As cidades apresentadas foram selecionadas dentre as estudadas na Seção 1.3 .1 que estão participando da Fase III de testes da vacina tetravalente contra a dengue produzida pelo Instituto Butantan. Na primeira fileira temos os gráficos dos ajustes para Aracaju, seguindo dos ajustes para Brasília, $2^{a}$ fileira de gráficos, na $3^{a}$ fileira o ajuste para Fortaleza, e por fim para a cidade de São Paulo. Cada coluna mostra o resultado do ajuste com os diferentes modelos: a) SIRVV $V_{i}(1$ Sorotipo), b) $2 \times S I R V V_{i}$ (2 Sorotipos), c) $3 \times S I R V V_{i}$ (3 Sorotipos), d) $4 \times S I R V V_{i}$ (4 Sorotipos). Os pontos em preto são a quantidade de casos registrados semanalmente no periodo analisado. A curva contínua em azul representa uma amostra da solução da curva I calculada com os parâmetros estimados por verossimilhança dentro do intervalo de $95 \%$ de confiança, de forma que nos modelos com mais de um sorotipo, I contém a soma de todos os infectados em ambos grupos. 
Os valores dos parâmetros estimados são dados em: Tabela 3.7, Tabela 3.8, Tabela 3.9 e Tabela 3.10, para as séries de dados de Aracaju, Brasília, Fortaleza e São Paulo, respectivamente. O valor de $p$ é estimado com o modelo de 1 sorotipo $\left(\mathrm{SIRVV}_{i}\right)$ e o valor encontrado é mantido fixo para a estimação com os outros modelos.

\begin{tabular}{|c|c|c|c|c|}
\hline Aracaju & \multicolumn{4}{|c|}{ Modelos compartimentados por faixas etárias } \\
\hline Parâmetros(semanas) & 1 Sorotipo & 2 Sorotipos & 3 Sorotipos & 4 Sorotipos \\
\hline$\beta_{1}, \Omega_{1}$ & $4.3884,0.2969$ & $16.2146,0.08002$ & $17.5920,0.07421$ & $17.7481,0.0721$ \\
\hline$\beta_{2}, \Omega_{2}$ & - & $0.1503,8.5235$ & $2.1675,0.5809$ & $3.2552,0.3926$ \\
\hline$\beta_{3}, \Omega_{3}$ & - & - & $3.8812,0.2859$ & $0.2152,6.0556$ \\
\hline$\beta_{4}, \Omega_{4}$ & - & - & - & $5.6391,0.2218$ \\
\hline$p$ & 0.2678 & 0.26 & 0.26 & 0.26 \\
\hline - log Verossimilhança & 5935 & 5868 & 6077 & 6640 \\
\hline$\overline{R_{01}}$ & 2.1798 & 3.1764 & 2.1343 & 2.3388 \\
\hline$\overline{R_{02}}$ & - & 3.1398 & 2.0585 & 2.3358 \\
\hline$\overline{R_{03}}$ & - & - & 1.8141 & 2.3818 \\
\hline$\overline{R_{04}}$ & - & - & - & 2.2860 \\
\hline$\alpha$ & 0.03488 & 0.07446 & 0.07382 & 0.07592 \\
\hline$\delta$ & 0.93673 & 1.4645 & 1.4283 & 1.3848 \\
\hline$S_{A}(0), S_{B}(0)$ & 150960,205314 & $102046.2,191684$ & $142461.3,276711$ & $107627.5,274193.8$ \\
\hline$I_{A_{1}}(0), I_{B_{1}}(0)$ & $132.36,53.80$ & $19.47,0.019$ & $101.17,35.90$ & $57.20,2.50$ \\
\hline$I_{A_{2}}(0), I_{B_{2}}(0)$ & - & $0.93,0.024$ & $7.58,20.77$ & $4.93,1.21$ \\
\hline$I_{A_{3}}(0), I_{B_{3}}(0)$ & - & - & $42.17,43.99$ & $0.079,0.0095$ \\
\hline$I_{A_{4}}(0), I_{B_{4}}(0)$ & - & - & - & $6.63,3.13 \mathrm{e}-04$ \\
\hline$V(0)$ & 606805.2 & 979007.5 & 653794.3 & 730915 \\
\hline$V_{1}(0)$ & 19.31 & 17.82 & 6.25 & 12.67 \\
\hline$V_{2}(0)$ & - & 0.0027 & $9.84 \mathrm{e}-04$ & 3.10 \\
\hline$V_{3}(0)$ & - & - & 0.169 & 0.75 \\
\hline$V_{4}(0)$ & - & - & - & 1.47 \\
\hline - log Verossimilhança & 2402 & 4250 & 4737 & 4588 \\
\hline
\end{tabular}

Tabela 3.7: Parâmetros encontrados para ajustar os modelos compartimentados em duas faixas etárias $A$ e $B$ aos casos de dengue notificados na cidade de Aracaju, da $1^{a}$ semana de 2011 à $35^{a}$ semana 2014, nos modelos de 1 a 4 sorotipos. Estimativa utilizando Minimos quadrados e verossimilhança.

\begin{tabular}{c|c|c|c|c}
\hline Brasília & \multicolumn{4}{|c}{ Modelos compartimentados por faixas etárias } \\
\hline Parâmetros $($ semanas $)$ & 1 Sorotipo & 2 Sorotipos & 3 Sorotipos & 4 Sorotipos \\
\hline$\beta_{1}, \Omega_{1}$ & $4.6087,0.2844$ & $29.2350,0.03338$ & $0.2390,5.0376$ & $0.5262,2.4552$ \\
$\beta_{2}, \Omega_{2}$ & - & $3.0094,0.4369$ & $3.4215,0.3332$ & $6.6197,0.1977$ \\
$\beta_{3}, \Omega_{3}$ & - & - & $6.0351,0.2173$ & $2.3935,0.5269$ \\
$\beta_{4}, \Omega_{4}$ & - & - & - & $3.9248,0.3227$ \\
$p$ & 0.3391 & 0.33 & 0.33 & 0.33 \\
$-\log$ Verossimilhança & 11392 & 10041 & 10791 & 11529 \\
\hline$\overline{R_{01}}$ & 2.1034 & 2.0278 & 2.5117 & 1.9558 \\
$R_{02}$ & - & 2.7321 & 2.3783 & 1.9812 \\
$R_{03}$ & - & - & 2.7358 & 1.9092 \\
$R_{04}$ & - & - & - & 1.9173 \\
\hline$\alpha$ & 0.06234 & 0.08419 & 0.08167 & 0.09188 \\
$\delta$ & 1.0833 & 1.0834 & 1.2546 & 1.0378 \\
$S_{A}(0), S_{B}(0)$ & $517788.2,1216126$ & $221510.2,1252757$ & $407835.3,1098141$ & $709603.7,1360407$ \\
$I_{A_{1}}(0), I_{B_{1}}(0)$ & $29.71,2.03 \mathrm{e}-06$ & $1.11,404.72$ & $45.69,2.28 \mathrm{e}-08$ & $0.012,2.66$ \\
$I_{A_{2}}(0), I_{B_{2}}(0)$ & - & $2.91,18.14$ & $122.97,20.38$ & $7.97,6.0$ \\
$I_{A_{3}}(0), I_{B_{3}}(0)$ & - & - & $4.15 \mathrm{e}-10,44.25$ & $11.25,12.79$ \\
$I_{A_{4}}(0), I_{B_{4}}(0)$ & - & - & - & $0.60,4.267$ \\
$V(0)$ & 2887840 & 3739433 & 3754123 & 2724282 \\
$V_{1}(0)$ & 23.61 & 14.68 & 9.39 & 2.11 \\
$V_{2}(0)$ & - & 22.66 & 17.94 & 7.19 \\
$V_{3}(0)$ & - & - & 5.07 & 3.89 \\
$V_{4}(0)$ & - & - & - & 2.54 \\
$\log$ Verossimilhança & 7873 & 7576 & 8444 & 10384 \\
\hline
\end{tabular}

Tabela 3.8: Parâmetros encontrados para ajustar os modelos compartimentados em duas faixas etárias A e $B$ aos casos de dengue notificados na cidade de Brasília, da $1^{a}$ semana de 2011 à $35^{a}$ semana 2014, nos modelos de 1 a 4 sorotipos. Estimativa utilizando Minimos quadrados e verossimilhança. 


\begin{tabular}{c|c|c|c|c}
\hline Fortaleza & \multicolumn{4}{|c}{ Modelos compartimentados por faixas etárias } \\
\hline Parâmetros(semanas) & 1 Sorotipo & 2 Sorotipos & 3 Sorotipos & 4 Sorotipos \\
\hline$\beta_{1}, \Omega_{1}$ & $1.8281,0.7023$ & $4.1656,0.3083$ & $5.6157,0.2286$ & $0.9710,0.7905$ \\
$\beta_{2}, \Omega_{2}$ & - & $8.0534,0.0989$ & $2.6109,0.4476$ & $2.0500,0.6052$ \\
$\beta_{3}, \Omega_{3}$ & - & - & $9.4374,0.07347$ & $5.6953,0.2236$ \\
$\beta_{4}, \Omega_{4}$ & - & - & - & $0.2523,4.7763$ \\
$p$ & 0.6212 & 0.62 & 0.62 & 0.62 \\
$-\log$ Verossimilhança & 26502 & 25965 & 26718 & 27388 \\
\hline$\overline{R_{01}}$ & 2.1375 & 2.0245 & 2.4835 & 1.2310 \\
$\overline{R_{02}}$ & - & 1.4948 & 2.2608 & 1.9896 \\
$\overline{R_{03}}$ & - & - & 1.3414 & 2.0423 \\
$\overline{R_{04}}$ & - & - & - & 1.9325 \\
\hline$\alpha$ & 0.08894 & 0.08718 & 0.09328 & 0.09717 \\
$\delta$ & 0.94063 & 0.8507 & 0.8659 & 0.9736 \\
$S_{A}(0), S_{B}(0)$ & $626363.4,1111189$ & $409490,954636.2$ & $393731.7,1096782$ & $519323.2,1364974$ \\
$I_{A_{1}}(0), I_{B_{1}}(0)$ & $194.33,99.07$ & $41.81,47.22$ & $168.79,84.31$ & $765.97,339.25$ \\
$I_{A_{2}}(0), I_{B_{2}}(0)$ & - & $111.12,56.68$ & $0.0014,0.427$ & $6.29,12.81$ \\
$I_{A_{3}}(0), I_{B_{3}}(0)$ & - & - & $0.0043,24.91$ & $172.69,74.18$ \\
$I_{A_{4}}(0), I_{B_{4}}(0)$ & - & - & - & $10.88,9.72$ \\
$V(0)$ & 2858599 & 3539889 & 3321376 & 2753414 \\
$V_{1}(0)$ & 53.65 & 78.18 & 2.31 & 69.83 \\
$V_{2}(0)$ & - & 259.99 & 6.17 & 2.19 \\
$V_{3}(0)$ & - & - & 257.76 & 10.67 \\
$V_{4}(0)$ & - & - & - & 31.47 \\
$\log$ Verossimilhança & 24179 & 22159 & 22421 & 23729 \\
\hline
\end{tabular}

Tabela 3.9: Parâmetros encontrados para ajustar os modelos compartimentados em duas faixas etárias $A$ e $B$ aos casos de dengue notificados na cidade de Fortaleza, da $1^{a}$ semana de 2011 à $35^{a}$ semana 2014, nos modelos de 1 a 4 sorotipos. Estimativa utilizando Minimos quadrados e verossimilhança.

\begin{tabular}{c|c|c|c|c}
\hline São Paulo & \multicolumn{4}{|c}{ Modelos compartimentados por faixas etárias } \\
\hline Parâmetros(semanas) & 1 Sorotipo & 2 Sorotipos & 3 Sorotipos & 4 Sorotipos \\
\hline$\beta_{1}, \Omega_{1}$ & $0.1293,9.9662$ & $5.1310,0.2520$ & $2.7323,0.4412$ & $1.4164,0.9045$ \\
$\beta_{2}, \Omega_{2}$ & - & $5.2897,0.2242$ & $5.7315,0.2076$ & $1.2894,0.9358$ \\
$\beta_{3}, \Omega_{3}$ & - & - & $4.9572,0.2621$ & $0.4710,2.7950$ \\
$\beta_{4}, \Omega_{4}$ & - & - & - & $21.3335,0.0601$ \\
$p$ & 0.4431 & 0.44 & 0.44 & 0.44 \\
$-\log$ Verossimilhança & 26763 & 23388 & 21913 & 23823 \\
\hline$\overline{R_{01}}$ & 2.3806 & 1.8080 & 2.0478 & 1.8384 \\
$\overline{R_{02}}$ & - & 1.6960 & 2.0213 & 1.7315 \\
$R_{03}$ & - & - & 2.2071 & 1.8891 \\
$R_{04}$ & - & - & - & 1.8399 \\
\hline$\alpha$ & 0.1128 & 0.08726 & 0.09528 & 0.09898 \\
$\delta$ & 1.1189 & 1.2568 & 1.2557 & 1.1377 \\
$S_{A}(0), S_{B}(0)$ & 4845246,3434967 & 5377300,2805044 & 5429045,3285644 & 6422524,3701649 \\
$I_{A_{1}}(0), I_{B_{1}}(0)$ & $34.53,40.33$ & $5.13,1.34$ & $2.33,0.412$ & $3.97,4.21$ \\
$I_{A_{2}}(0), I_{B_{2}}(0)$ & - & $188.93,127.90$ & $0.633,74.18$ & $2.54,2.99$ \\
$I_{A_{3}}(0), I_{B_{3}}(0)$ & - & - & $0.645,4.62$ & $0.501,9.14$ \\
$I_{A_{4}}(0), I_{B_{4}}(0)$ & - & - & - & $1.94,3.10$ \\
$V(0)$ & 14556390 & 13790940 & 13385280 & 11306980 \\
$V_{1}(0)$ & $1.53 \mathrm{e}-08$ & 5.63 & 9.13 & 1.53 \\
$V_{2}(0)$ & - & 26.94 & 52.55 & 143.73 \\
$V_{3}(0)$ & - & - & 5.55 & 6.90 \\
$V_{4}(0)$ & - & - & - & 1.89 \\
$\log$ Verossimilhança & 25422 & 17261 & 17065 & 19734 \\
\hline
\end{tabular}

Tabela 3.10: Parâmetros encontrados para ajustar os modelos compartimentados em duas faixas etárias A e $B$ aos casos de dengue notificados na cidade de São Paulo, da $1^{a}$ semana de 2011 à $35^{a}$ semana 2014 , nos modelos de 1 a 4 sorotipos. Estimativa utilizando Minimos quadrados e verossimilhança. 


\subsection{Projeções com os modelos}

Nesta seção vamos apresentar a projeção dos modelos com os parâmetros estimados e apresentados na seção anterior. O objetivo é comparar a projeção que se obtém com cada um dos modelos. Primeiro apresentamos para os modelos com população total e na sequência para os modelos compartimentados por faixas etárias.

As curvas representam as projeções para um período de 25 anos $=1300$ semanas, em que somente as primeiras 191 semanas contém os dados, os quais foram feitos os ajustes. As figuras mostram que em algumas estimações não houve coexistência de sorotipos, porém salientamos que a estimação de parâmetros é um problema mal posto, pois temos 151 equações no modelo mais completo para fazer o ajuste de 191 dados, o que faz com que tenhamos quase tantas equações como dados, criando um problema de indeterminação. Também o ajuste de parâmetros se torna muito sensível às condições iniciais, portanto, podemos obter várias combinações diferentes para os valores dos parâmetros. Os resultados poderiam ser melhorados se o ajuste fosse feito para um período maior de notificações, porém como amostrado na Seção 1.1.2, o período de dados obtidos é de apenas 7 anos e na maioria das cidades não se tem surtos anuais, o que prejudica o ajuste.

Destacamos que para os resultados de Aracaju e Brasília, como os valores obtidos para $p$ foram muito baixos, indicando que só foram usados $26 \%$ e $33 \%$, respectivamente, dos valores de I com os parâmetros estimados, e o ajuste ficou bem próximo dos picos de cada surto, então para os gráficos de projeções destas duas cidades, os dados são multiplicados por $1 / p$, o que pode ser interpretado como a quantidade de assintomáticos para cada caso notificado. No caso de Fortaleza e São Paulo em que o ajuste não alcançou os picos, mesmo obtendo valores de $p$ relativamente altos, $62 \% \mathrm{e}$ $44 \%$, respectivamente, então não multiplicamos os dados por nenhum fator e assim usamos $100 \%$ do valor estimado para I, fazendo com que o ajuste alcance mais os picos.

As figuras com as projeções são apresentadas nas próximas seções, em que são diferenciadas as curvas de infectados com cada sorotipo. No Apêndice B, apresentamos mais alguns resultados complementares para o ajustes de parâmetros em dois casos em que usamos um período de 7 anos de dados. No primeiro caso a série não apresenta surtos em todos anos consecutivos e no segundo caso tem-se um surto por ano com diferentes intensidades.

\section{Discussão}

Em todos resultados dos modelos com população total, obtemos que o modelo de 1 sorotipo tem um ciclo que aparentemente se repete, fazendo com que não ocorra surtos durante alguns anos. O modelo com 2 sorotipos, apesar de se ajustar bem aos dados, não foi bem sucedido em estimar taxas de transmissão diferentes para que houvesse coexistência dos sorotipos. Já os modelos com 3 e 4 sorotipos conseguiram captar melhor a coexistência, sendo que os resultados com o modelo de 4 sorotipos foram melhores em todos os casos, no sentido de estimar intercalação de sorotipos ao longo dos anos e coexistência de diferentes sorotipos em um mesmo surto.

Da mesma forma para os modelos compartimentados em duas faixas etárias, Seção 3.3.2. Nestes ajustes, os modelos com 2 sorotipos obtiveram desempenho melhor ao estimar a coexistência de sorotipos em alguns casos. Os resultados evidenciam que em geral o modelo com 4 sorotipos é o que apresenta melhor dinâmica de intercalação de sorotipos e surtos a cada ano. Porém evidenciamos que com somente duas faixas etárias, tem-se uma aproximação muito grosseira da realidade, e que o ideal seria um modelo compartimentado em três ou mais faixas etárias, separando pelo menos em crianças, adultos e idosos, o que aumenta a complexidade das soluções numéricas e ajustes. 


\subsubsection{Modelos com múltiplos sorotipos}

A Figura 3.18 apresenta os resultados da projeção com os parâmetros estimados a partir dos dados de Aracaju, descritos na Tabela 3.3. Neste caso os dados de dengue foram multiplicados por $1 / 0.26$, de acordo com o valor de $p$ estimado. Essa fração pode ser um indício da quantidade de assintomáticos.
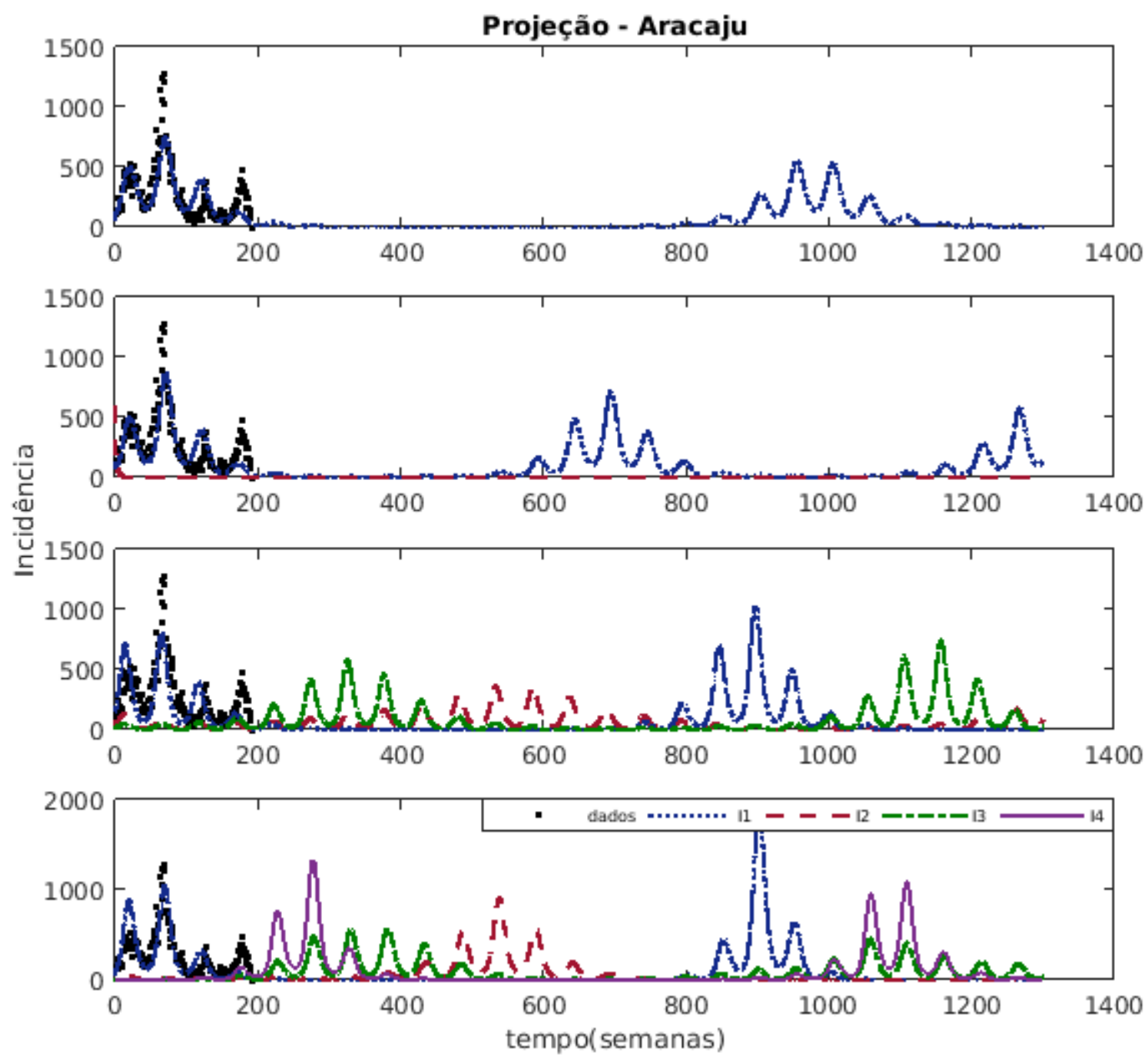

Figura 3.18: Projeção dos modelos com os parâmetros estimados dos dados de incidência de dengue de Aracaju. As curvas foram plotadas com os parâmetros dados na Tabela 3.3 para um período de 25 anos $=1300$ semanas, em que somente as primeiras 191 semanas contém os dados. A primeira figura mostra o ajuste com o modelo de 1 sorotipo $\left(S I R V V_{i}\right)$, a segunda contém o ajuste com o modelo de 2 sorotipos $\left(2 \times S I R V V_{i}\right)$, a terceira com o modelo de 3 sorotipos $\left(3 \times S I R V V_{i}\right)$ e por fim, o ajuste para o modelo com 4 sorotipos $\left(4 \times S I R V V_{i}\right)$. 
A Figura 3.19 apresenta os resultados da projeção com os parâmetros estimados a partir dos dados de Brasília, descritos na Tabela 3.4. Neste caso os dados de dengue foram multiplicados por $1 / 0.33$, de acordo com o valor obtido para $p$. Essa fração pode ser um indício da quantidade de assintomáticos.

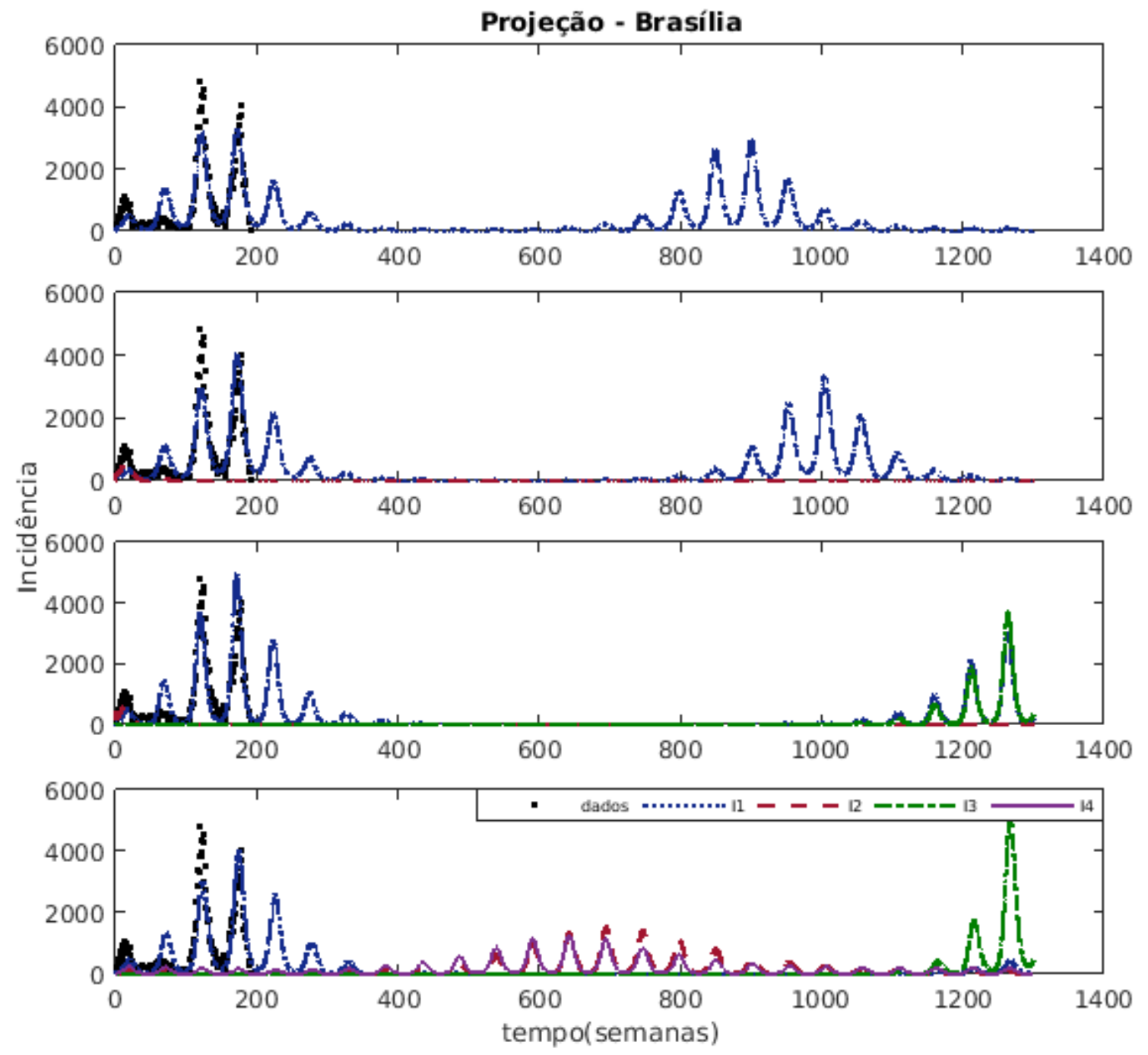

Figura 3.19: Projeção dos modelos com os parâmetros estimados dos dados de incidência de dengue de Brasilia. As curvas foram plotadas com os parâmetros dados na Tabela 3.4 para um período de 25 anos $=1300$ semanas, em que somente as primeiras 191 semanas contém os dados. A primeira figura mostra o ajuste com o modelo de 1 sorotipo $\left(S I R V V_{i}\right)$, a segunda contém o ajuste com o modelo de 2 sorotipos $\left(2 \times S I R V V_{i}\right)$, a terceira com o modelo de 3 sorotipos $\left(3 \times S I R V V_{i}\right)$ e por fim, o ajuste para o modelo com 4 sorotipos $\left(4 \times S I R V V_{i}\right)$. 
A Figura 3.20 apresenta os resultados da projeção com os parâmetros estimados a partir dos dados de Fortaleza, descritos na Tabela 3.5. Neste caso, como o ajuste não atingiu os picos, devido ter surtos com diferentes intensidades no período, e com um valor de $p$ relativamente alto, os dados não foram multiplicados por nenhum fator e assim usamos $100 \%$ do valor de I estimado.
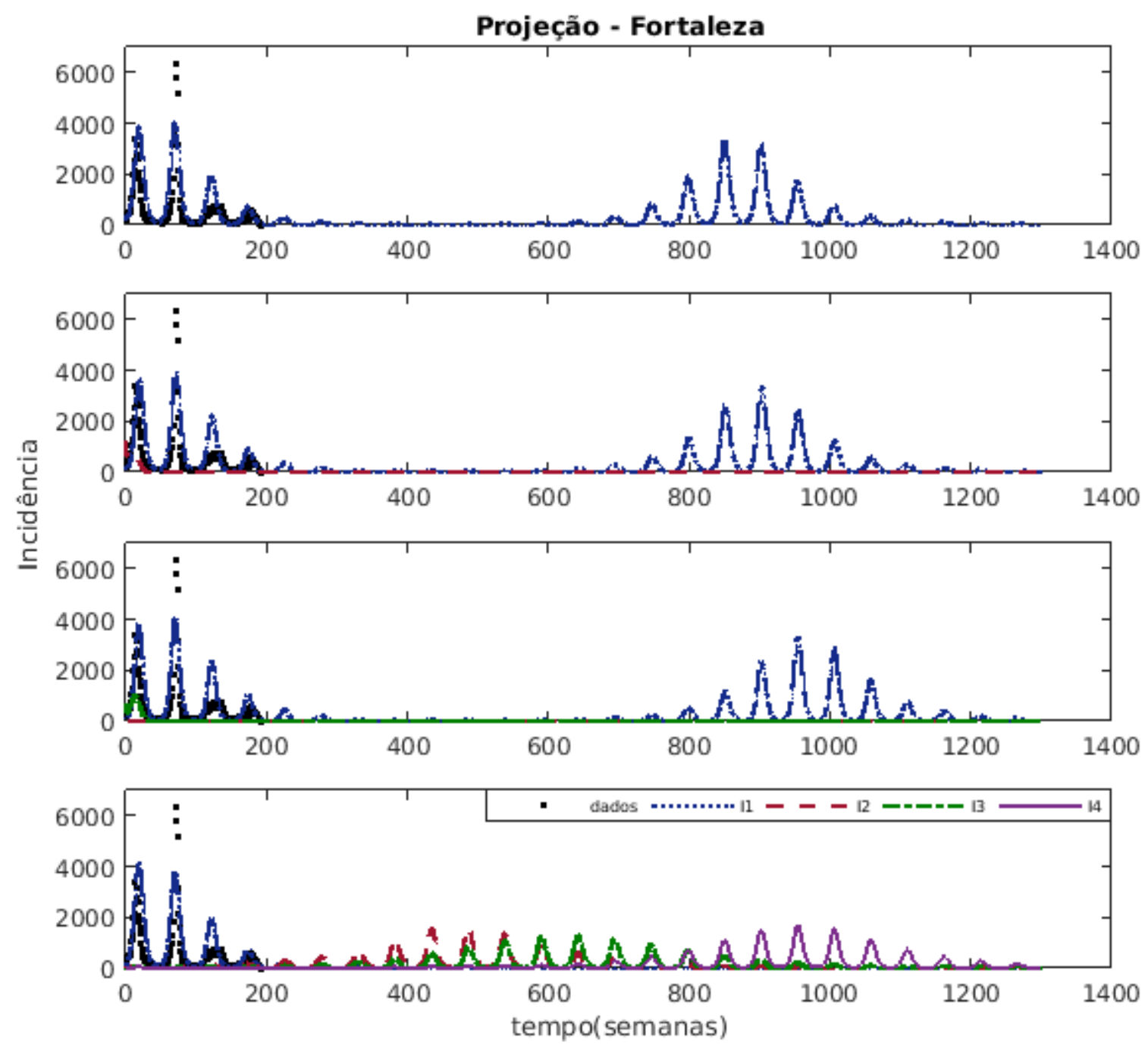

Figura 3.20: Projeção dos modelos com os parâmetros estimados dos dados de incidência de dengue de Fortaleza. As curvas foram plotadas com os parâmetros dados na Tabela 3.5 para um periodo de 25 anos $=1300$ semanas, em que somente as primeiras 191 semanas contém os dados. A primeira figura mostra o ajuste com o modelo de 1 sorotipo $\left(S I R V V_{i}\right)$, a segunda contém o ajuste com o modelo de 2 sorotipos $\left(2 \times S I R V V_{i}\right)$, a terceira com o modelo de 3 sorotipos $\left(3 \times S I R V V_{i}\right)$ e por fim, o ajuste para o modelo com 4 sorotipos $\left(4 \times S I R V V_{i}\right)$. 
A Figura 3.21 apresenta os resultados da projeção com os parâmetros estimados a partir dos dados de São Paulo, descritos na Tabela 3.6. Neste caso como o ajuste não atingiu os picos, devido ter surtos muito menores no período, os dados não foram multiplicados por nenhum fator e assim usamos $100 \%$ do valor de I estimado.
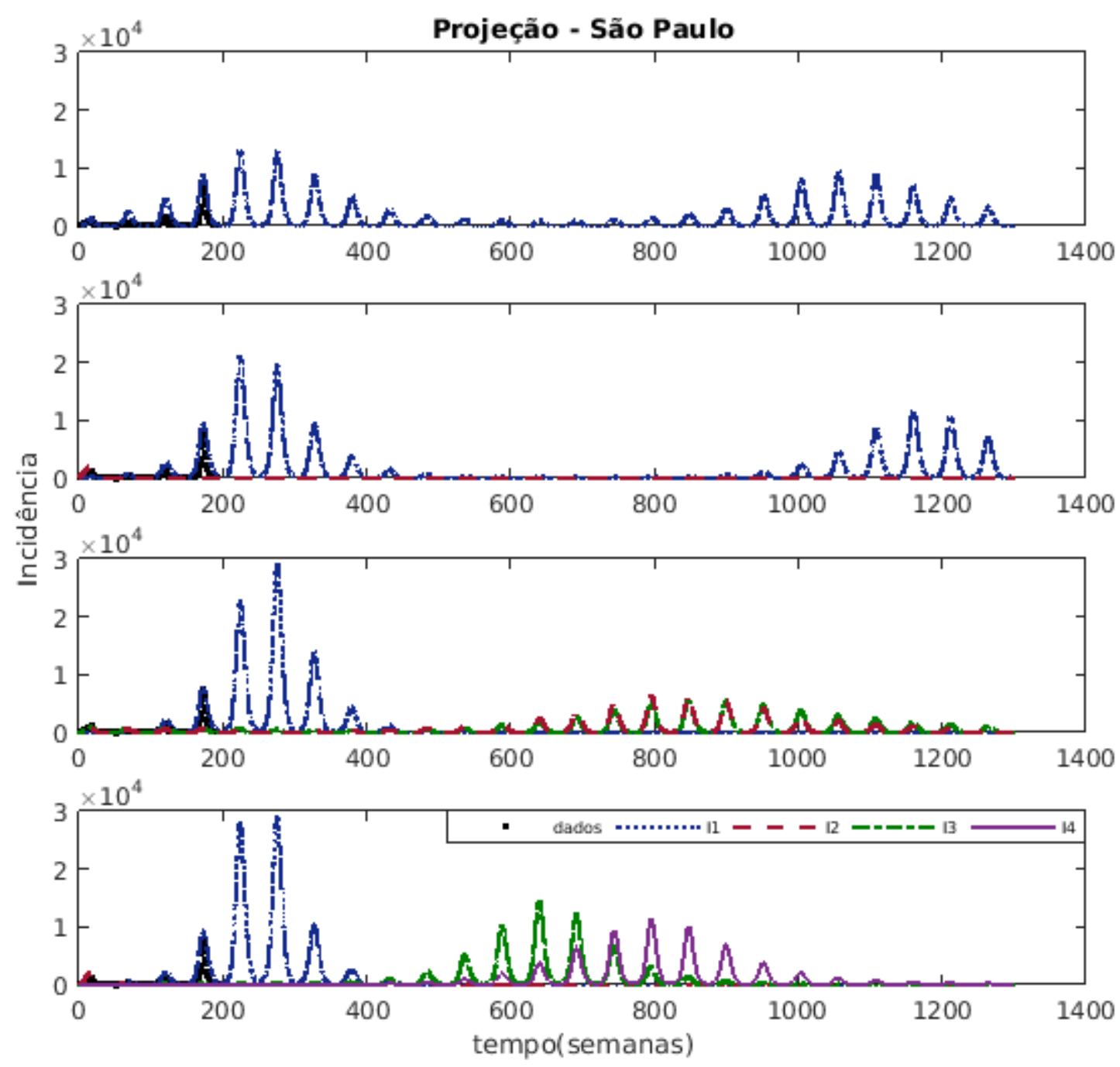

Figura 3.21: Projeção dos modelos com os parâmetros estimados dos dados de incidência de dengue de São Paulo. As curvas foram plotadas com os parâmetros dados na Tabela 3.6 para um período de 25 anos = 1300 semanas, em que somente as primeiras 191 semanas contém os dados. A primeira figura mostra o ajuste com o modelo de 1 sorotipo $\left(S I R V V_{i}\right)$, a segunda contém o ajuste com o modelo de 2 sorotipos $\left(2 \times S I R V V_{i}\right)$, a terceira com o modelo de 3 sorotipos $\left(3 \times S I R V V_{i}\right)$ e por fim, o ajuste para o modelo com 4 sorotipos $\left(4 \times S I R V V_{i}\right)$. 


\subsubsection{Modelos com múltiplos sorotipos compartimentados por faixa etária}

As figuras nesta seção mostram a comparação da projeções para os modelos $\operatorname{SIRVV}_{i}$ compartimentados por faixas etárias, diferenciando as curvas de infectados com cada sorotipo, e com os parâmetros obtidos nos ajustes apresentados na Seção 3.2.2. Nestes modelos as curvas de infectados são a soma dos infectados nos dois grupos etários.

A Figura 3.22 apresenta os resultados da projeção com os parâmetros estimados a partir dos dados de Aracaju. Novamente os dados de dengue foram multiplicados por 1/0.26. Neste caso, diferente do modelo não compartimentado, o modelo com 2 sorotipos foi capaz de estimar parâmetros de coexistência de sorotipos.
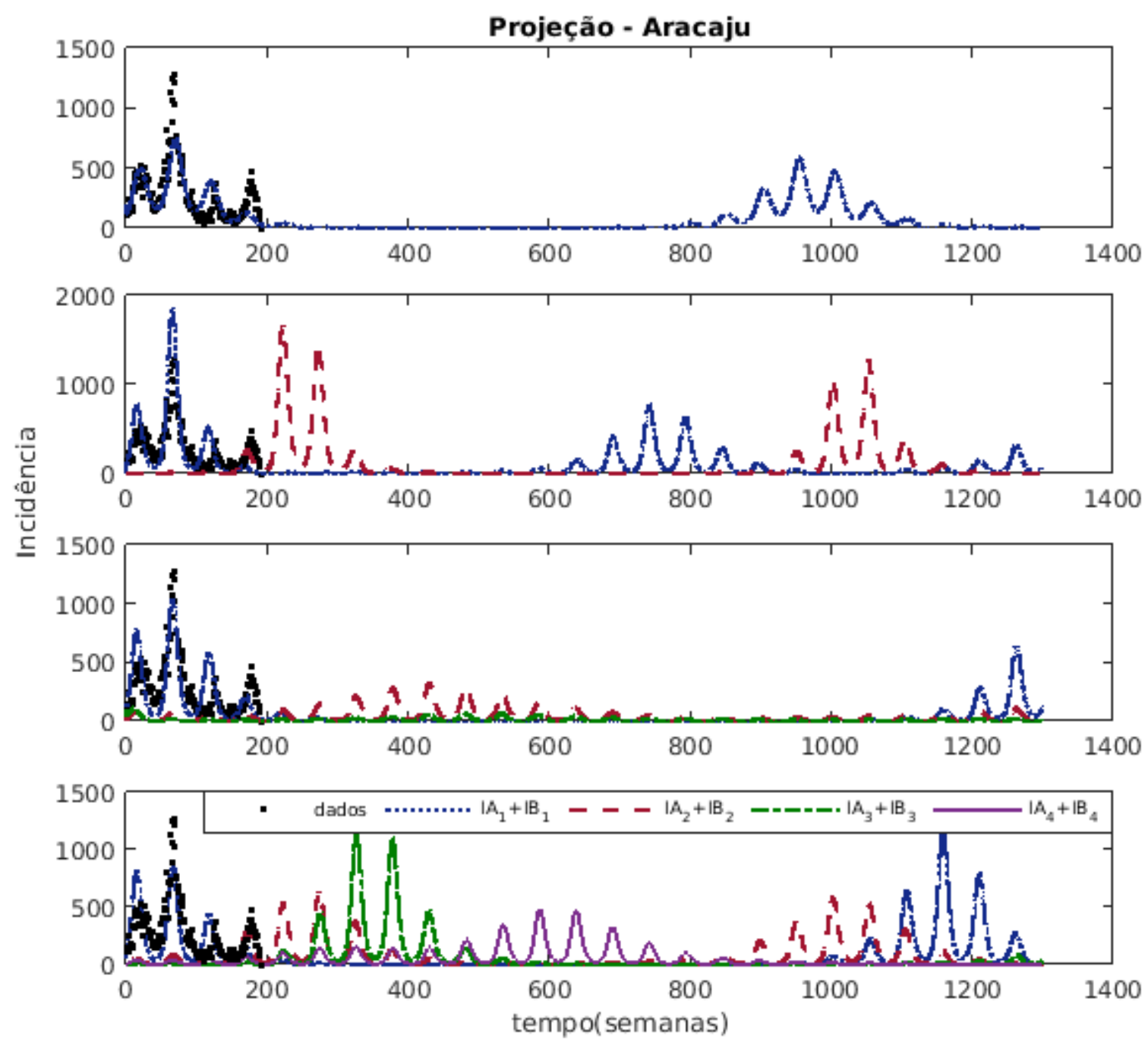

Figura 3.22: Projeção dos modelos compartimentados por faixa etária com os parâmetros estimados dos dados de incidência de dengue de Aracaju. As curvas foram plotadas com os parâmetros dados na Tabela 3.7 para um periodo de 25 anos $=1300$ semanas, em que somente as primeiras 191 semanas contém os dados. A primeira figura mostra o ajuste para o modelo com 1 sorotipo $\left(S I R V V_{i}\right)$, a segunda mostra o ajuste para o modelo com 2 sorotipos $\left(2 \times S I R V V_{i}\right)$, o terceiro contém o ajuste do modelo com 3 sorotipos $\left(3 \times S I R V V_{i}\right)$ e por fim, o ajuste para o modelo com 4 sorotipos $\left(4 \times S I R V V_{i}\right)$. 
A Figura 3.23 apresenta os resultados da projeção com os parâmetros estimados a partir dos dados de Brasília com os modelos compartimentados para duas faixas etárias. Novamente os dados de dengue foram multiplicados por $1 / 0.33$.
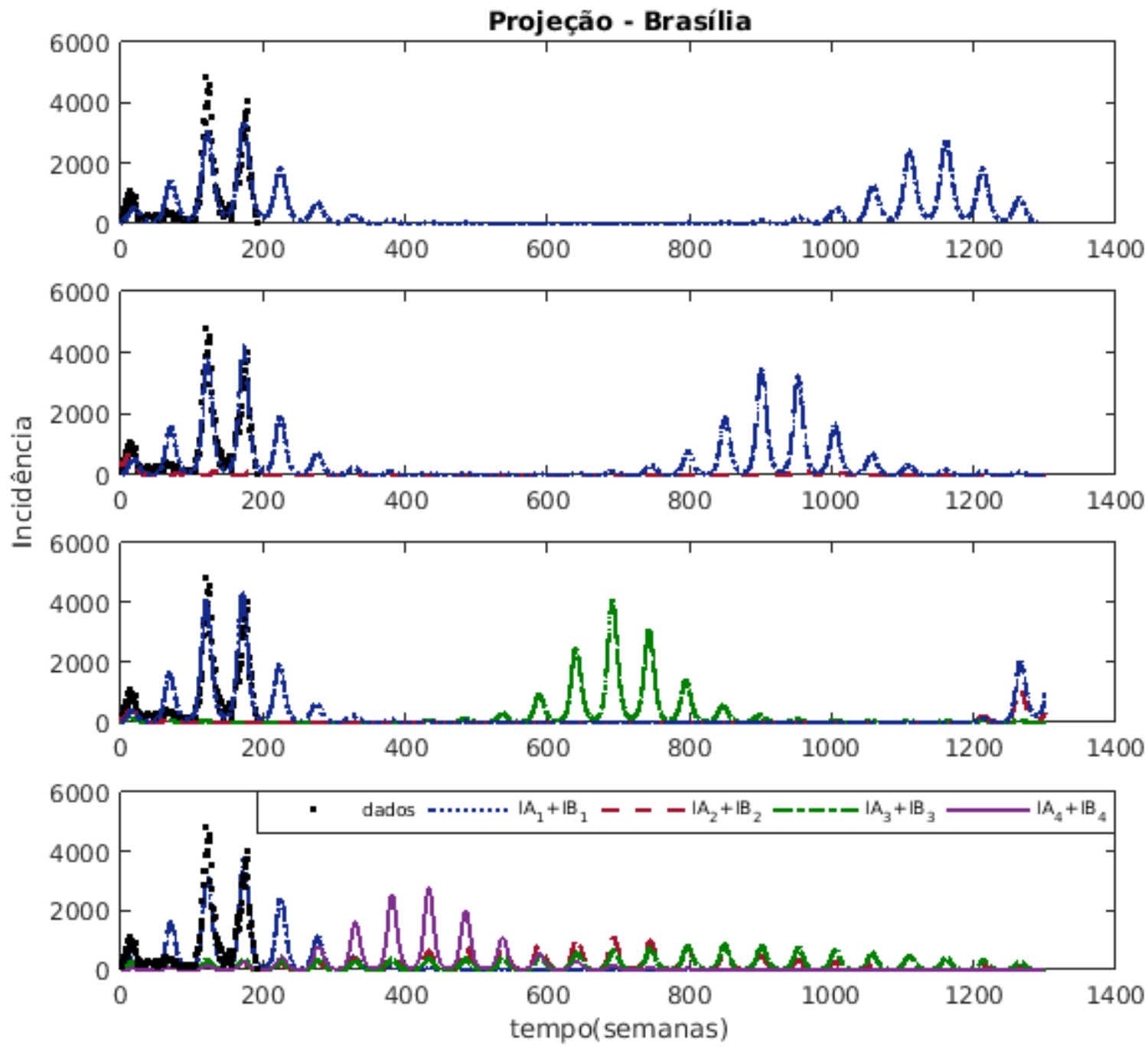

Figura 3.23: Projeção dos modelos compartimentados por faixa etária com os parâmetros estimados dos dados de incidência de dengue de Brasilia. As curvas foram plotadas com os parâmetros dados na Tabela 3.8 para um periodo de 25 anos $=1300$ semanas, em que somente as primeiras 191 semanas contém os dados. A primeira figura mostra o ajuste para o modelo com 1 sorotipo (SIRVV ${ }_{i}$ ), a segunda mostra o ajuste para o modelo com 2 sorotipos $\left(2 \times S I R V V_{i}\right)$, o terceiro contém o ajuste do modelo com 3 sorotipos $\left(3 \times S I R V V_{i}\right)$ e por fim, o ajuste para o modelo com 4 sorotipos $\left(4 \times S I R V V_{i}\right)$. 
A Figura 3.24 apresenta os resultados da projeção com os parâmetros estimados a partir dos dados de Fortaleza com os modelos compartimentados para duas faixas etárias. Os dados não foram multiplicados por nenhum fator e assim usamos $100 \%$ do valor de I estimado.

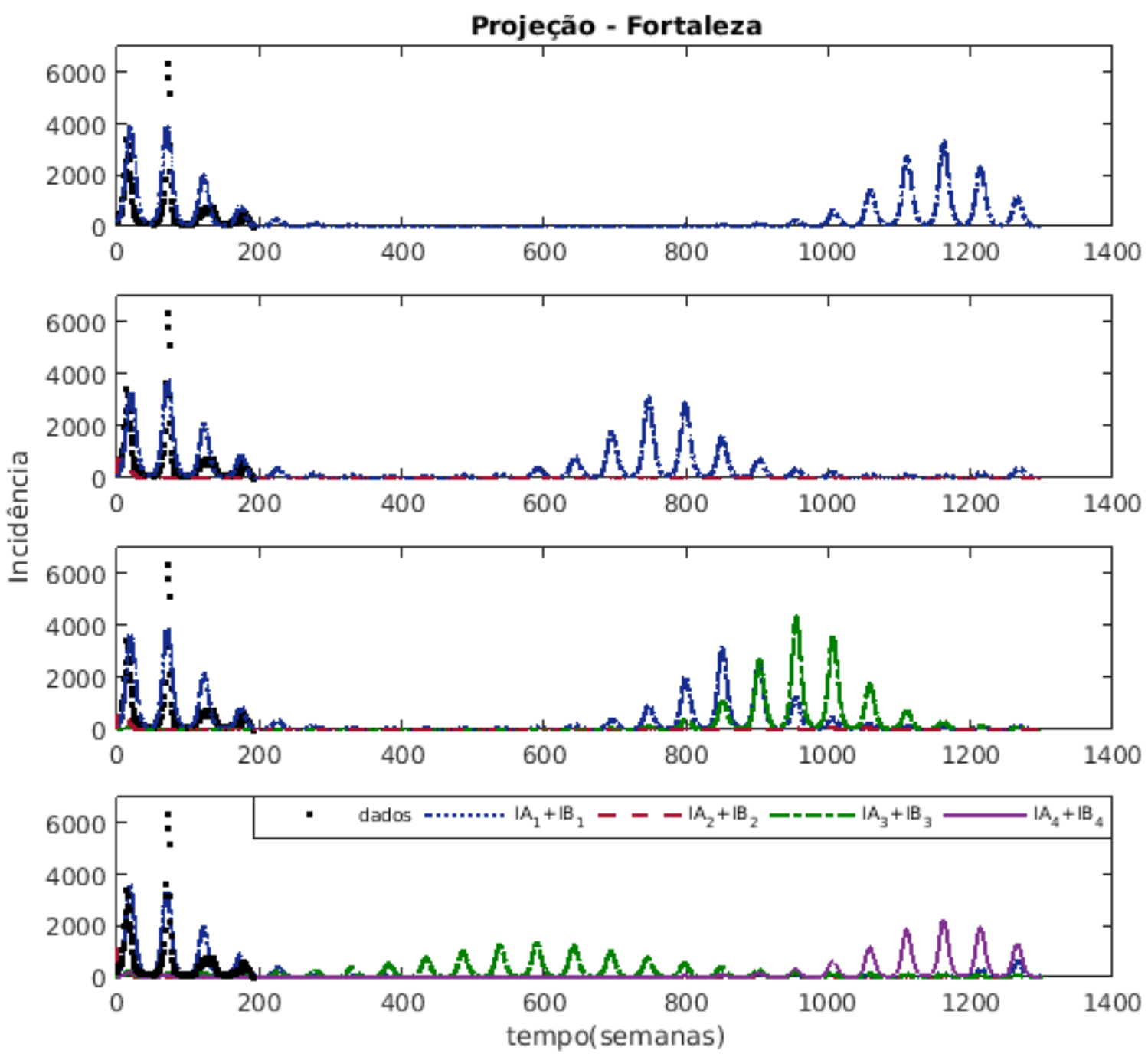

Figura 3.24: Projeção dos modelos compartimentados por faixa etária com os parâmetros estimados dos dados de incidência de dengue de Fortaleza. As curvas foram plotadas com os parâmetros dados na Tabela 3.9 para um período de 25 anos $=1300$ semanas, em que somente as primeiras 191 semanas contém os dados. A primeira figura mostra o ajuste para o modelo com 1 sorotipo ( $S I R V V_{i}$ ), a segunda mostra o ajuste para o modelo com 2 sorotipos $\left(2 \times S I R V V_{i}\right)$, o terceiro contém o ajuste do modelo com 3 sorotipos $\left(3 \times S I R V V_{i}\right)$ e por fim, o ajuste para o modelo com 4 sorotipos $\left(4 \times S I R V V_{i}\right)$. 
A Figura 3.25 apresenta os resultados da projeção com os parâmetros estimados a partir dos dados de São Paulo com os modelos compartimentados para duas faixas etárias. Os dados não foram multiplicados por nenhum fator e assim usamos $100 \%$ do valor de I estimado.
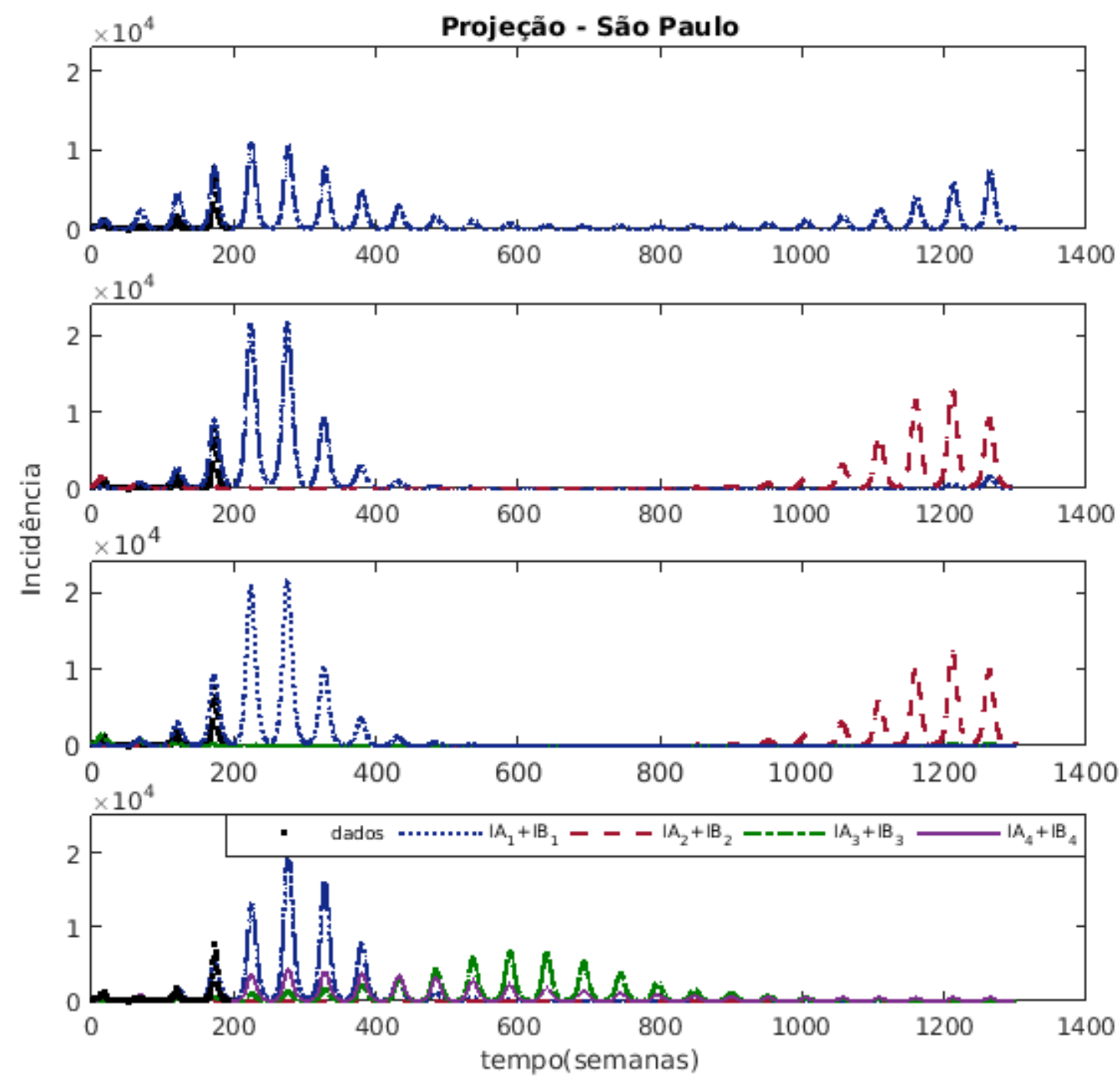

Figura 3.25: Projeção dos modelos compartimentados por faixa etária com os parâmetros estimados dos dados de incidência de dengue de São Paulo. As curvas foram plotadas com os parâmetros dados na Tabela 3.10 para um período de 25 anos $=1300$ semanas, em que somente as primeiras 191 semanas contém os dados. A primeira figura mostra o ajuste para o modelo com 1 sorotipo $\left(S I R V V_{i}\right)$, a segunda mostra o ajuste para o modelo com 2 sorotipos $\left(2 \times S I R V V_{i}\right)$, o terceiro contém o ajuste do modelo com 3 sorotipos $\left(3 \times S I R V V_{i}\right)$ e por fim, o ajuste para o modelo com 4 sorotipos $\left(4 \times S I R V V_{i}\right)$. 


\subsection{Cenários de vacinação com os modelos}

Aqui apresentamos os resultados de simular duas estratégias de vacinação: $1^{\mathrm{a}}$ ) a vacina é aplicada em uma proporção aleatória da população, $2^{\mathrm{a}}$ ) a vacina é direcionada para as faixas etárias mais afetadas de acordo com o estudo apresentado na Seção 1.3.1. Cabe ressaltar que sob o ponto de vista realístico, uma vacina não é aplicada aleatoriamente em um população, geralmente se seleciona um ou mais grupos etários para receber a vacina afim de que a proporção necessária de vacinados seja mais facilmente atingida, o que também depende da doença, por exemplo, algumas enfermidades apresentam sintomas mais graves em crianças, outras em idosos, etc. Ainda, a idade ótima de vacinação não está necessariamente na faixa etária que se tem mais casos, geralmente é um pouco antes de atingir certa idade, o que depende totalmente do histórico da infecção. Portanto, enfatizamos que as estratégias apresentadas, são no intuito de comparar resultados de direcionar a vacina para um grupo etário, ou selecionar uma proporção da população sem diferenciar idade.

Como apresentado na Seção 1.3.1, para cada cidade selecionamos os grupos etários com maior quantidade de casos de acordo com os agrupamentos apresentados na Figura 1.11. O mais adequado seria separar em pelo menos 3 grupos; crianças, adultos e idosos, porém devido a complexidade dos modelos e da quantidade de equações, optamos por inicialmente estruturar a população em dois grupos etários. Os nossos modelos permitem simular cenários com diferentes eficácias para os sorotipos tão como, vacinar soronegativos e soropositivos. A informação sobre a eficácia da vacina do Instituto Butantan só estará disponível após a conclusão da Fase III. Por esse motivo, consideramos o cenário de uma vacina que confere $80 \%$ de eficácia contra cada sorotipo, e que fornece imunidade imediata após aplicação (Precioso et al., 2015).

Para definir qual proporção deve ser vacinada na população, fazemos um estudo em função do valor do $R_{0 V}$ definido na Equação 2.30, e da eficácia da vacina, em que vamos supor eficácia igual contra cada sorotipo da dengue, isto é, $1-\sigma=0.80$. Temos que o valor de $R_{0 V}$, é dado em função do $R_{0}$ sem vacinação, por

$$
\overline{R_{0 V}}=\overline{R_{0}}(1-\psi+\sigma \psi) .
$$

Este valor é calculado na situação em que a população de humanos é totalmente suscetível, fato que não ocorre na realidade com a dengue no Brasil, pois temos epidemias quase todos os anos. Assim, de acordo com os valores obtidos na Seção 3.2, temos que a quantidade inicial estimada para suscetíveis varia em média de $60 \%$ à $70 \%$ da população $N_{h}$. Considerando que temos 191 semanas de dados, e a vacina será aplicada na semana 192, então obtemos das soluções numéricas, a quantidade de suscetíveis na semana 192 e portanto o valor $R_{0 V}$ deve então ser calculado utilizando o $R_{0}$ efetivo, definido na Seção A.2.1, Equação (A.7), o qual é calculado em função da quantidade de suscetíveis no momento da aplicação da vacina:

$$
\overline{R_{0_{\text {efetivo }}}}=\overline{R_{0}} \frac{S(192)}{N_{h}}
$$

Portanto, se queremos controlar a doença, devemos determinar a proporção $\psi$ a ser vacinada afim de que satisfaça:

$$
\overline{R_{0 V}}=\overline{R_{0_{\text {efetivo }}}}(1-\psi+\sigma \psi)<1
$$

o que resulta em:

$$
\psi>\left(1-\frac{1}{R_{0_{\text {efetivo }}}}\right) \times \frac{1}{1-\sigma}
$$

As Tabelas 3.11 e 3.12 contêm o valor de $\psi$ para cada cidade estudada. Calculamos os $R_{0_{\text {efetivo }}}$ 's relacionados aos menores e maiores $R_{0}$ 's obtidos para cada série ajustada em função da quantidade de suscetíveis na semana $192(S(192))$. Assim, obtemos para cada cidade, um $\psi$ menor e maior, 
indicando uma cobertura adequada para vacinação em cada local.

\begin{tabular}{|c|c|c|c|c|}
\hline \multicolumn{5}{|c|}{$\psi$ calculado para população total } \\
\hline Cidades & Aracaju & Brasília & Fortaleza & São Paulo \\
\hline pop. Total & 571149 & 2570160 & 2452185 & 11253503 \\
\hline$R_{0}$ menor & 1.97 & 1.8306 & 1.5018 & 2.1353 \\
\hline Pop S(192) - $R_{0}$ menor & 322580.337 & 1665646.922 & 1395599.95 & 8738996.836 \\
\hline$R_{0}$ maior & 2.7121 & 2.5884 & 2.5536 & 2.9325 \\
\hline pop S(192) $-R_{0}$ maior & 238919.4 & 1309000.508 & 1363900.907 & 7067403.175 \\
\hline$R_{0_{\text {efetivo }}}$ menor & 1.112640071 & 1.1863593144 & 0.8547120241 & 1.6581841178 \\
\hline$R_{0_{\text {efetivo }}}$ maior & 1.1345083415 & 1.3182902679 & 1.4203077484 & 1.8416629747 \\
\hline$\psi$ menor & 0.1265459445 & 0.1963563148 & - & 0.4961633261 \\
\hline$\psi$ maior & 0.1482011376 & 0.3018021482 & 0.3699090469 & 0.5712656077 \\
\hline
\end{tabular}

Tabela 3.11: Proporção $\psi$ a ser vacinada aleatoriamente na população considerando uma vacina com $80 \%$ de eficácia contra cada sorotipo da dengue. Para cada cidade, obtemos um $\psi$ menor e maior, respectivamente relacionado, ao menor e maior $R_{0_{\text {efetivo }}}$, calculados em função da população de suscetiveis no momento em que a vacina é aplicada.

\begin{tabular}{|c|c|c|c|c|}
\hline \multicolumn{5}{|c|}{$\psi$ calculado para a população compartimenta por idades } \\
\hline Cidades & Aracaju - A & Brasília - B & Fortaleza - A & São Paulo - B \\
\hline pop. Total & 176945 & 1740922 & 777835 & 4109608 \\
\hline$R_{0}$ menor & 1.8141 & 1.9092 & 1.231 & 1.696 \\
\hline Pop $\mathbf{S}_{Z}(\mathbf{1 9 2})-R_{0}$ menor & 121351.073 & 1292228.82 & 475451.559 & 3056807.373 \\
\hline$R_{0}$ maior & 3.1764 & 2.7358 & 2.4835 & 2.3806 \\
\hline pop $\mathbf{S}_{Z}(\mathbf{1 9 2})-R_{0}$ maior & 86769.262 & 978296.93 & 377434.374 & 3604578.253 \\
\hline$R_{0_{\text {efetivo }}}$ menor & 1.2441322531 & 1.4171360136 & 0.7524486159 & 1.2615182043 \\
\hline$R_{0_{\text {efetivo }}}$ maior & 1.5576245942 & 1.5373605142 & 1.2050862559 & 2.0880480545 \\
\hline$\psi$ menor & 0.2452836631 & 0.3679392888 & - & 0.2591304305 \\
\hline$\psi$ maior & 0.447495979 & 0.4369181051 & 0.2127298511 & 0.6513547737 \\
\hline
\end{tabular}

Tabela 3.12: Proporção $\psi$ a ser vacinada no grupo etário com maior número de casos $(Z=A$ ou $B)$, considerando uma vacina com $80 \%$ de eficácia contra cada sorotipo da dengue. Para cada cidade, obtemos um $\psi$ menor e maior, respectivamente relacionado, ao menor e maior $R_{0_{\text {efetivo }}}$, calculados em função da população de suscetiveis no grupo etário $Z$ no momento em que a vacina é aplicada.

Os valores de $\psi$ obtidos representam a cobertura de vacinação em cada cidade que dever ser aplicada de uma só vez para reduzir a quantidade de infectados de forma que não se tenha mais surtos. Primeiro, vamos apresentar os resultados de aplicar a vacina continuamente em $2 \%$ e $5 \%$ dos suscetíveis soronegativos por ano, afim de analisar a evolução do processo de vacinação. Por fim apresentamos um exemplo em que comparamos os efeitos de aplicar a vacina continuamente e aplicar em uma grande proporção de uma só vez.

A Seção 3.4.1 contém os resultados de aplicar a vacina aleatória, cujas simulações são feitas com os modelos com múltiplos sorotipos e população total. Na Seção 3.4.2 temos os resultados da vacina direcionada para faixas etárias, neste caso a curva I contém o total de infectados das duas faixas etárias, novamente sem diferenciar por qual sorotipo. Até a semana 191 temos os dados e a curva I ajustada, considerando o total de infectados sem diferenciar sorotipo, de forma que a vacina é aplicada na semana 192 . 


\subsubsection{Vacinação aleatória na população}

Os resultados das simulações de vacinação aleatória com os dados de dengue de Aracaju, são apresentados na Figura 3.26. Os gráficos são semelhantes aos da Figura 3.18, com a diferença que neste caso a curva I representa o total de infectados com todos sorotipos e a vacina é aplicada a partir da semana 192. As simulações são considerando uma vacina com aplicação continua anual em $2 \%$ e $5 \%$ dos suscetíveis.

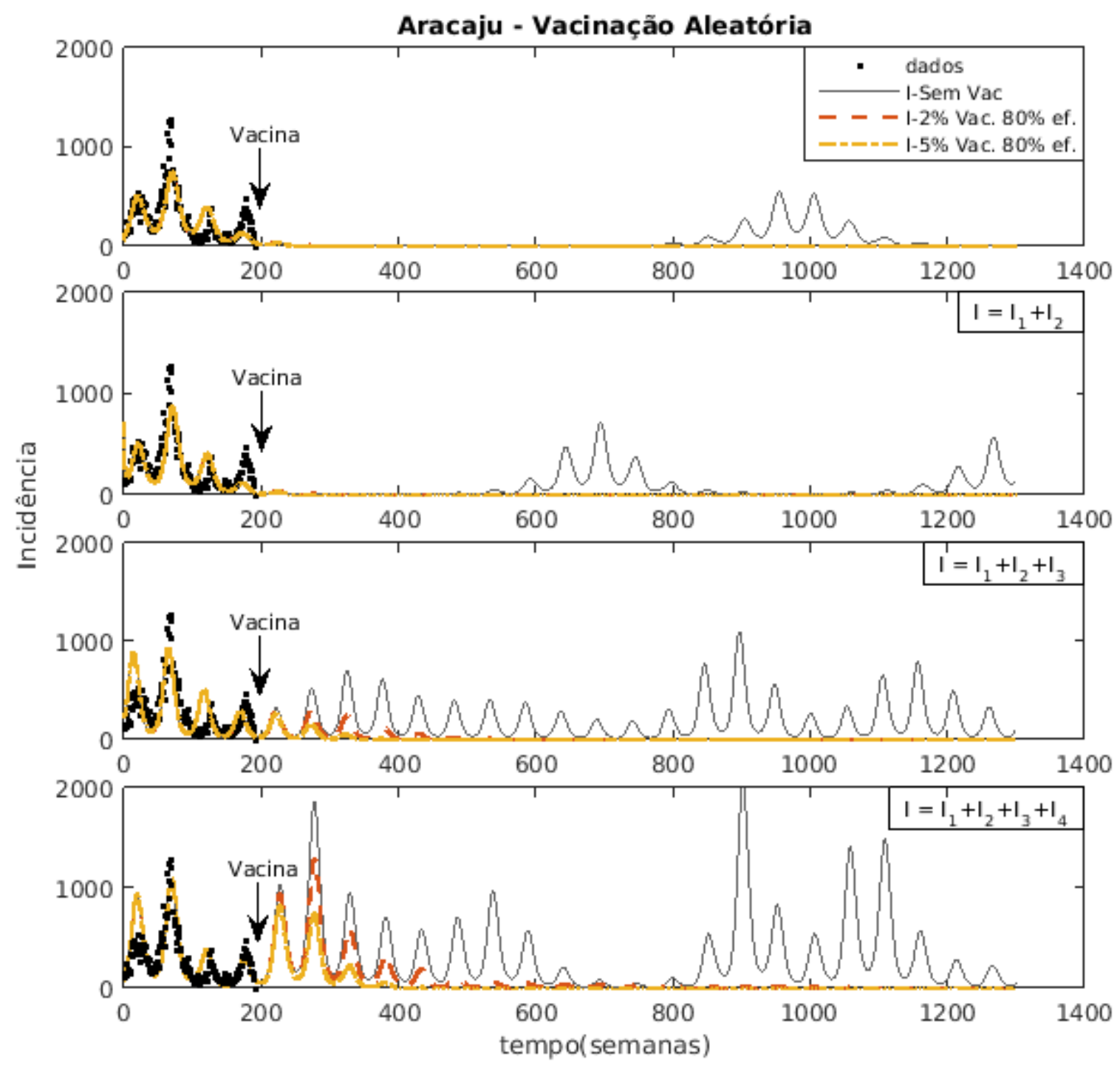

Figura 3.26: Vacinação aleatória na população nos modelos com múltiplos sorotipos e dados de Aracaju. A curva contínua (cinza) representa a curva de solução dos infectados sem aplicação da vacina com os modelos de 1 a 4 sorotipos, respectivamente, da primeira a quarta figura, de forma que nos modelos com mais de um sorotipo, a curva I contém a soma de todos os infectados. A vacina é implementada começando na semana 192, sendo aplicada em $2 \%$ (curva laranjada ${ }^{\prime}--^{\prime}$ ) e $5 \%$ (curva amarela ${ }^{\prime}-.^{\prime}$ ) dos suscetiveis. 
Os resultados das simulações de vacinação aleatória com os dados de dengue de Brasília, são apresentados na Figura 3.27. Novamente, os gráficos são semelhantes aos da Figura 3.19, sendo que a curva I representa o total de infectados com todos sorotipos, com a vacina sendo aplicada a partir da semana 192 em $2 \%$ e $5 \%$ dos suscetíveis por ano.

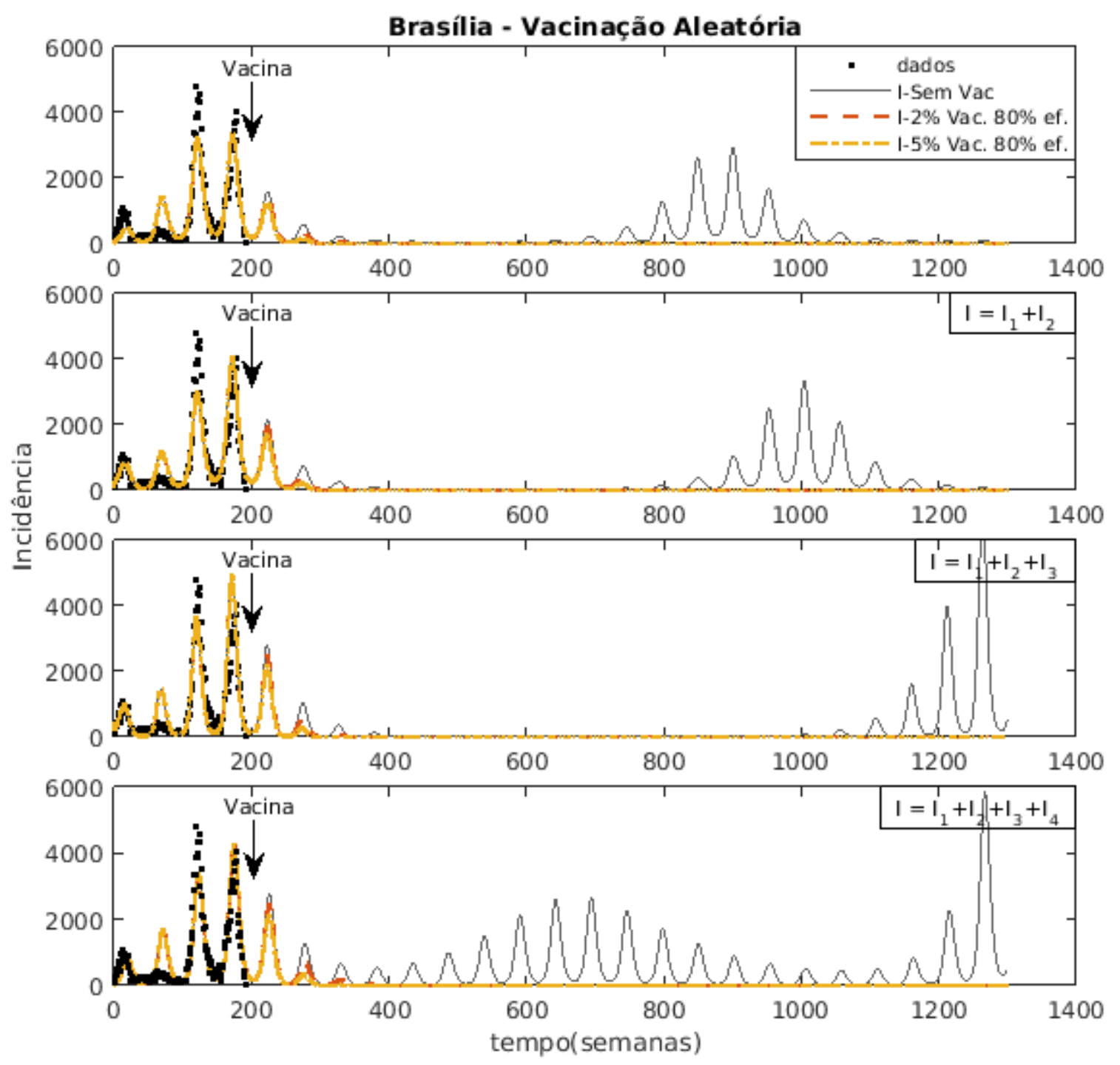

Figura 3.27: Vacinação aleatória na população nos modelos com múltiplos sorotipos e dados de Brasília. A curva contínua (cinza) representa a curva de solução dos infectados sem aplicação da vacina com os modelos de 1 a 4 sorotipos, respectivamente, da primeira a quarta figura, de forma que nos modelos com mais de um sorotipo, a curva I contém a soma de todos os infectados. A vacina é implementada começando na semana 192, sendo aplicada em $2 \%$ (curva laranjada ${ }^{-}--^{\prime}$ ) e $5 \%$ (curva amarela ${ }^{-}-.^{\prime}$ ) dos suscetíveis. 
Os resultados das simulações de vacinação aleatória com os dados de dengue de Fortaleza, são apresentados na Figura 3.28. Os gráficos são semelhantes aos da Figura 3.20, sendo que a curva I representa o total de infectados com todos sorotipos, e a vacina é aplicada a partir da semana 192 em $2 \%$ e $5 \%$ dos suscetíveis por ano.

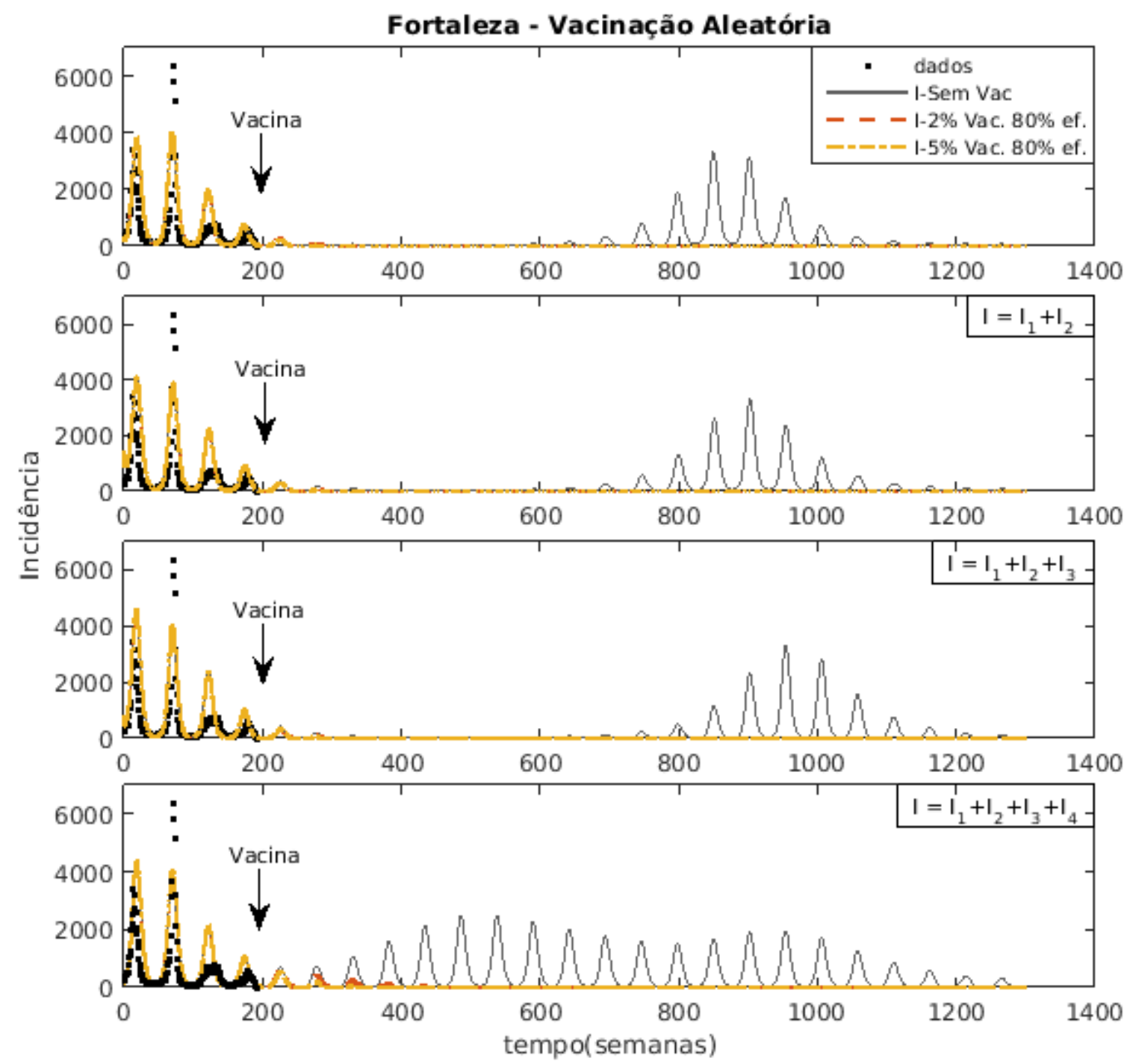

Figura 3.28: Vacinação aleatória na população nos modelos com múltiplos sorotipos e dados de Fortaleza. A curva contínua (cinza) representa a curva de solução dos infectados sem aplicação da vacina com os modelos de 1 a 4 sorotipos, respectivamente, da primeira a quarta figura, de forma que nos modelos com mais de um sorotipo, a curva I contém a soma de todos os infectados. A vacina é implementada começando na semana 192, sendo aplicada em $2 \%$ (curva laranjada ${ }^{\prime}--^{\prime}$ ) e $5 \%$ (curva amarela ${ }^{\prime}-._{-}^{\prime}$ ) dos suscetiveis. 
Os resultados das simulações de vacinação aleatória com os dados de dengue de São Paulo, são apresentados na Figura 3.29. Os gráficos são semelhantes aos da Figura 3.21, sendo que a curva I representa o total de infectados com todos sorotipos, com a vacina sendo aplicada a partir da semana 192 em $2 \%$ e $5 \%$ dos suscetíveis por ano.

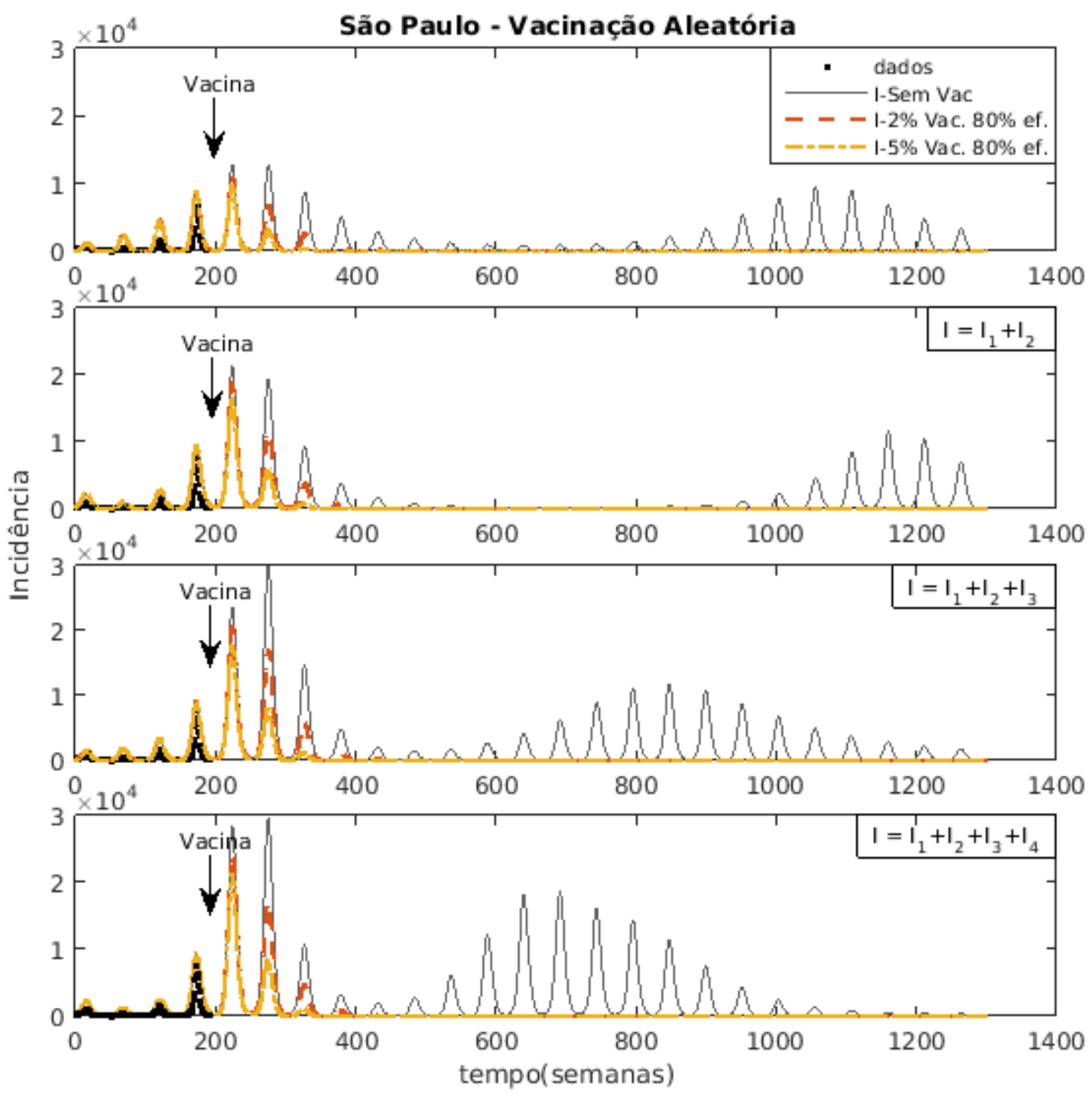

Figura 3.29: Vacinação aleatória na população nos modelos com múltiplos sorotipos e dados de São Paulo. A curva continua (cinza) representa a curva de solução dos infectados sem aplicação da vacina com os modelos de 1 a 4 sorotipos, respectivamente, da primeira a quarta figura, de forma que nos modelos com mais de um sorotipo, a curva I contém a soma de todos os infectados. A vacina é implementada começando na semana 192, sendo aplicada em $2 \%$ (curva laranjada ${ }^{\prime}--^{\prime}$ ) e $5 \%$ (curva amarela ${ }^{\prime}-._{-}^{\prime}$ ) dos suscetiveis. 


\subsubsection{Vacinação direcionada para faixas etárias}

De acordo com o estudo da Seção 1.3.1, para a cidade de Aracaju, o grupo etário que recebe a vacina é o grupo $\mathrm{A}$, correspondente a indivíduos na faixa etária de 0 à 19 anos. $\mathrm{O}$ grupo $\mathrm{B}$ consiste dos indivíduos com idade $\geq 20$ anos. Os resultados de aplicar a vacina continuamente a partir da semana 192 em $2 \%$ e $5 \%$ dos suscetíveis, são mostrados na Figura 3.30.

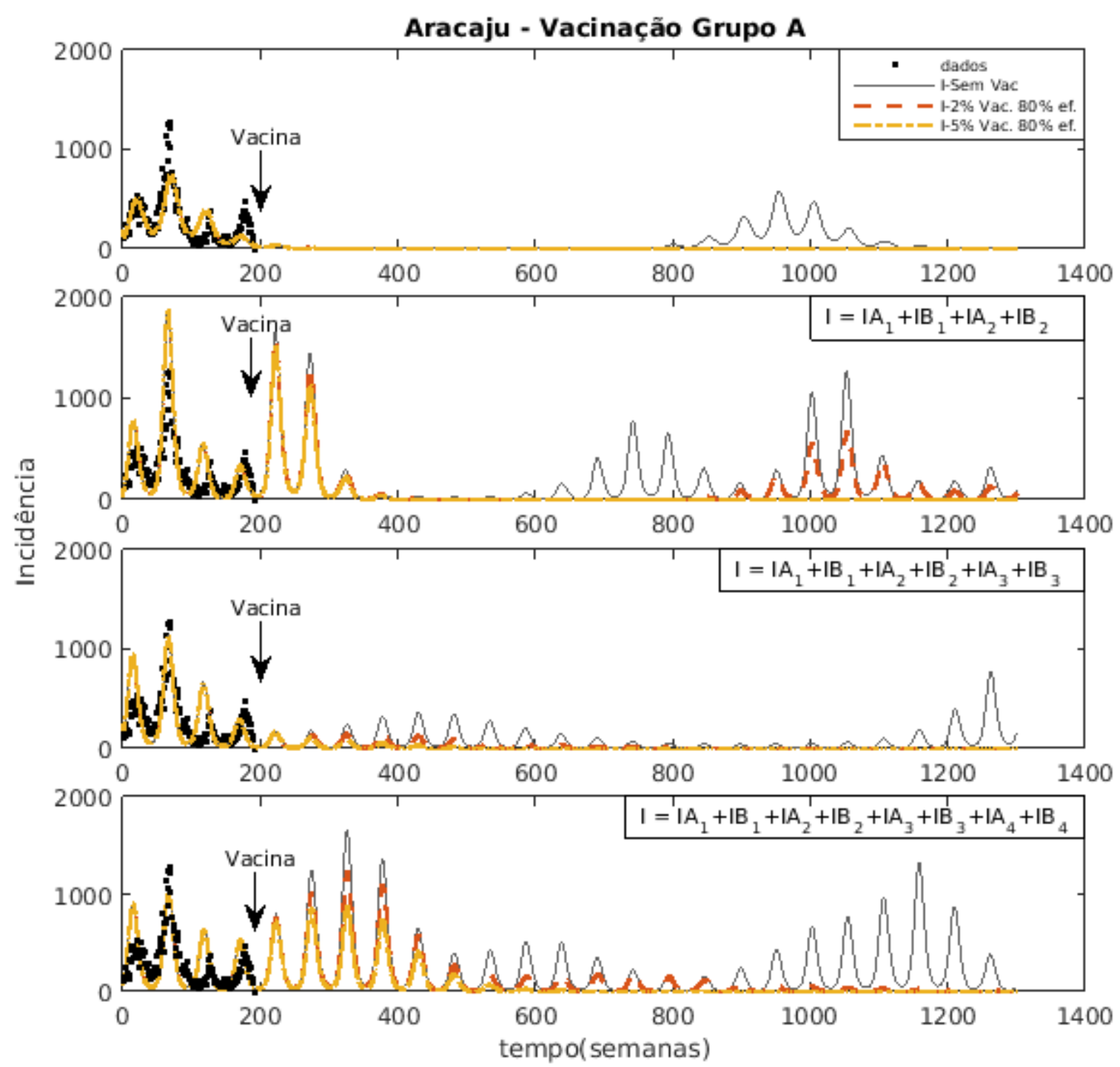

Figura 3.30: Vacinação direcionada para faixas etárias nos modelos com múltiplos sorotipos compartimentados e dados de Aracaju. A curva continua (cinza) representa a curva de solução dos infectados sem aplicação da vacina com os modelos de 1 a 4 sorotipos, respectivamente, da primeira a quarta figura, de forma que nos modelos com mais de um sorotipo, a curva I contém a soma de todos os infectados. A vacina é implementada começando na semana 192, sendo aplicada em $2 \%$ (curva laranjada ${ }^{-}-^{\prime}$ ) e 5\% (curva amarela' $\left.{ }^{\prime}-.^{\prime}\right)$ dos suscetiveis. 
Através do estudo dos dados de dengue da cidade de Brasília, Seção 1.3.1, temos na Figura 3.31, que o grupo etário que recebe a vacina é o grupo B, correspondente a indivíduos com idade maior ou igual a 20 anos, enquanto o grupo A é formado pela faixa etária de 0 à 19 anos. Os gráficos mostram os resultados de aplicar a vacina continuamente a partir da semana 192 em $2 \%$ e $5 \%$ dos suscetíveis.

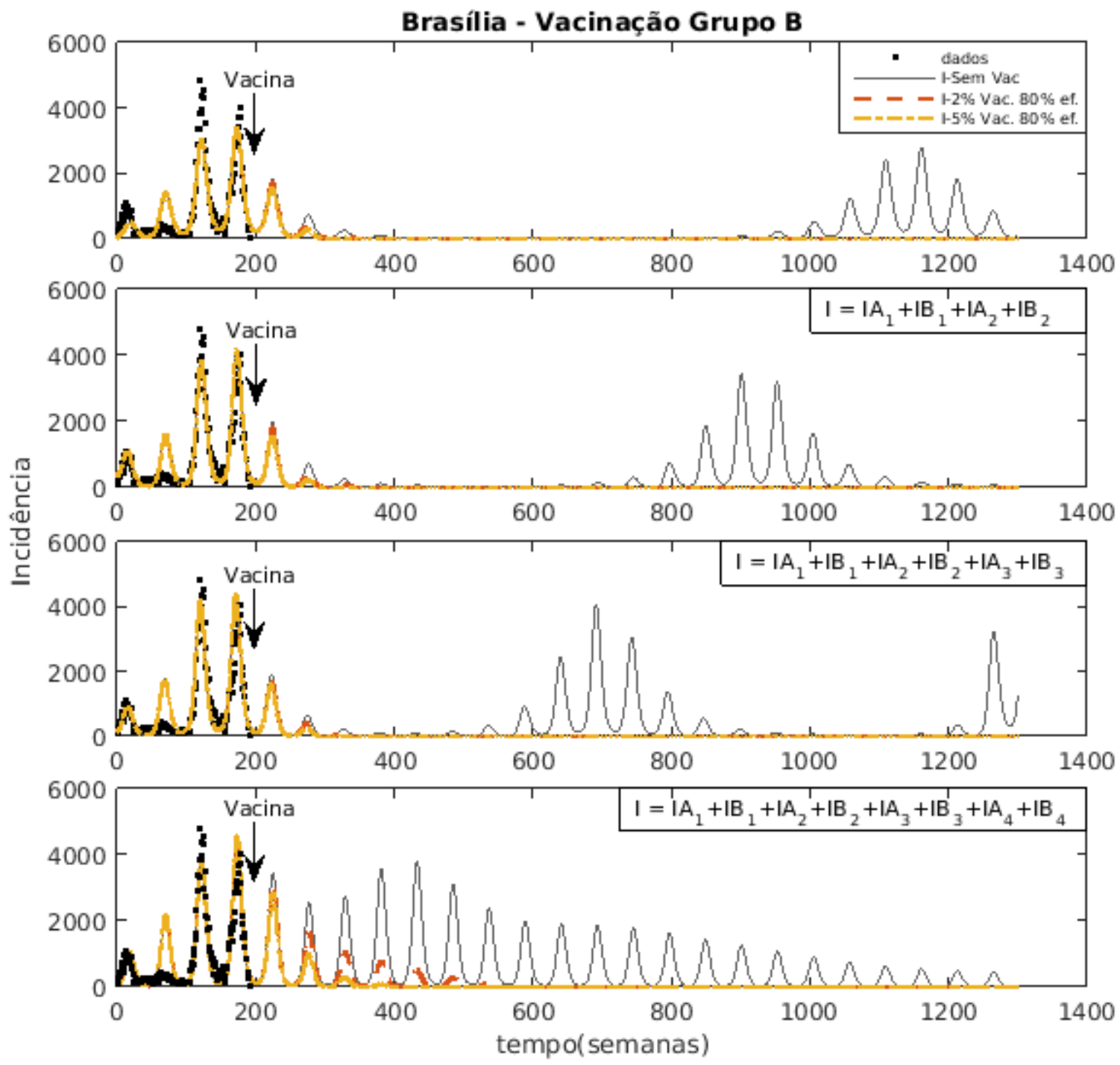

Figura 3.31: Vacinação direcionada para faixas etárias nos modelos com múltiplos sorotipos compartimentados e dados de Brasilia. A curva contínua (cinza) representa a curva de solução dos infectados sem aplicação da vacina com os modelos de 1 a 4 sorotipos, respectivamente, da primeira a quarta figura, de forma que nos modelos com mais de um sorotipo, a curva I contém a soma de todos os infectados. A vacina é implementada começando na semana 192, sendo aplicada em $2 \%$ (curva laranjada' $--^{\prime}$ ) e $5 \%$ (curva amarela $\left.{ }^{\prime}{ }_{-}-^{\prime}\right)$ dos suscetiveis. 
Para o caso de Fortaleza, o estudo dos dados (Seção 1.3.1), identificou que o grupo em maior risco é o grupo $\mathrm{A}$, correspondente a indivíduos na faixa etária de 0 à 19 anos. O grupo $\mathrm{B}$ consiste dos indivíduos com idade $\geq 20$ anos. Os resultados de aplicar a vacina continuamente a partir da semana 192 em $2 \%$ e $5 \%$ dos suscetíveis, são apresentados na Figura 3.32 .

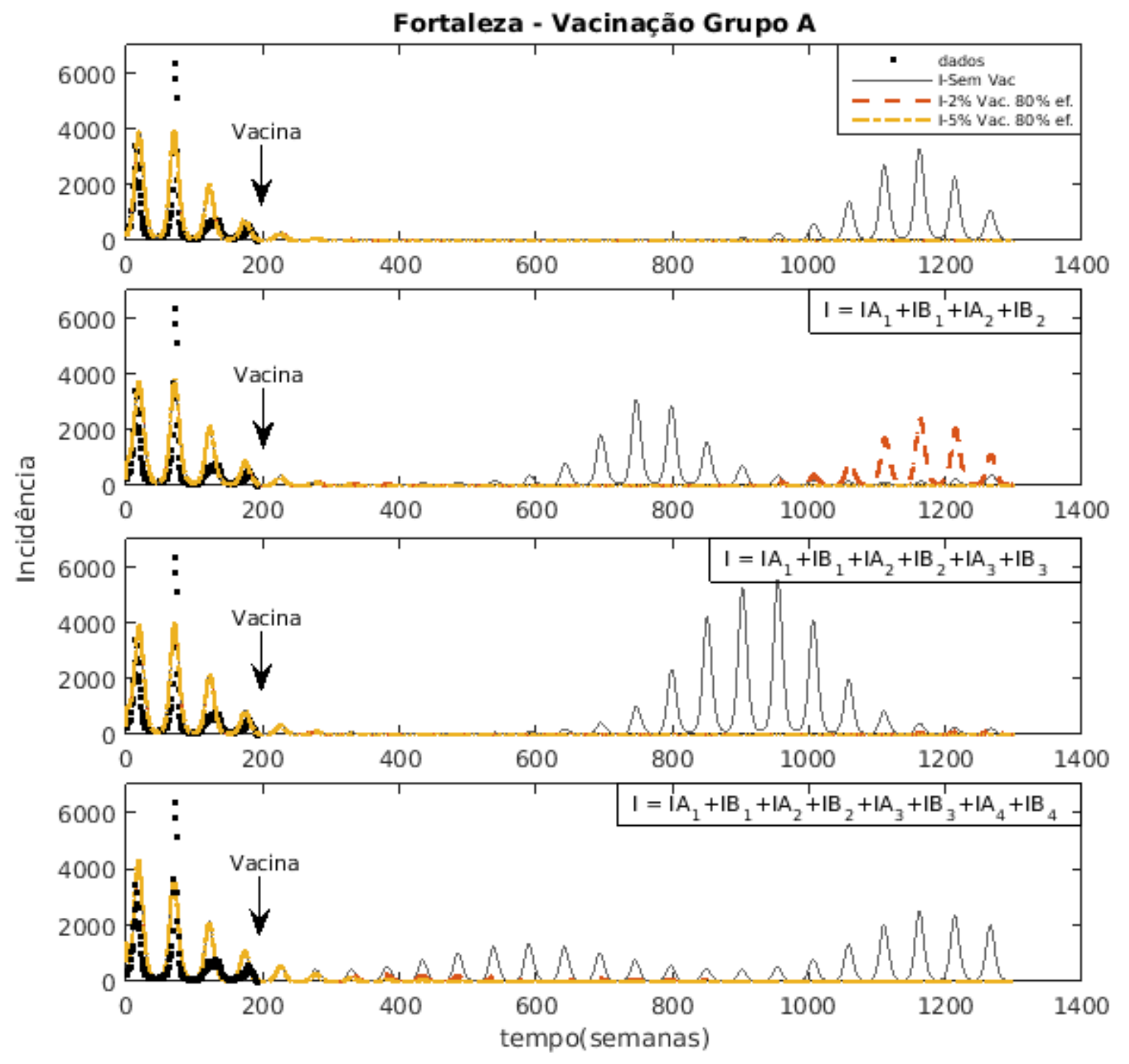

Figura 3.32: Vacinação direcionada para faixas etárias nos modelos com múltiplos sorotipos compartimentados e dados de Fortaleza. A curva continua (cinza) representa a curva de solução dos infectados sem aplicação da vacina com os modelos de 1 a 4 sorotipos, respectivamente, da primeira a quarta figura, de forma que nos modelos com mais de um sorotipo, a curva I contém a soma de todos os infectados. A vacina é implementada começando na semana 192, sendo aplicada em $2 \%$ (curva laranjada ${ }_{-}-^{\prime}$ ) e $5 \%$ (curva amarela'.$\left.--^{\prime}\right)$ dos suscetiveis . 
O estudo dos dados, segundo critérios da Seção 1.3.1, identificou que para a cidade de São Paulo, o grupo etário a receber a vacina é o grupo B, correspondente a indivíduos com idade maior ou igual a 40 anos, enquanto o grupo A é formado pela faixa etária de 0 à 39 anos. A Figura 3.33 contém os resultados de aplicar a vacina continuamente a partir da semana 192 em 2\% e $5 \%$ dos suscetíveis.

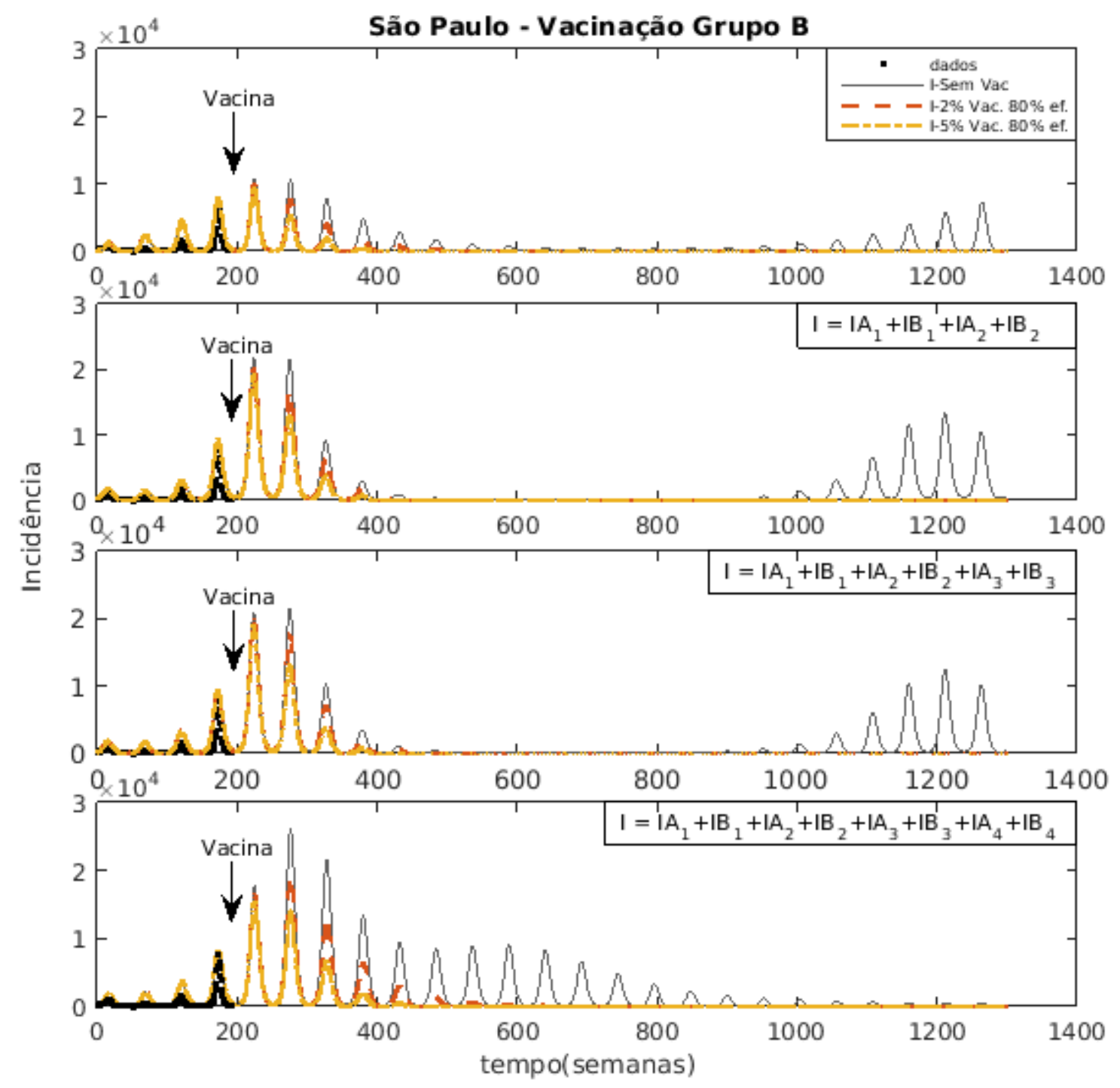

Figura 3.33: Vacinação direcionada para faixas etárias nos modelos com múltiplos sorotipos compartimentados e dados de São Paulo. A curva contínua (cinza) representa a curva de solução dos infectados sem aplicação da vacina com os modelos de 1 a 4 sorotipos, respectivamente, da primeira a quarta figura, de forma que nos modelos com mais de um sorotipo, a curva I contém a soma de todos os infectados. A vacina é implementada começando na semana 192, sendo aplicada em $2 \%$ (curva laranjada' $--^{\prime}$ ) e $5 \%$ (curva amarela $\left.{ }^{\prime}{ }_{-}-^{\prime}\right)$ dos suscetiveis. 


\subsubsection{Coberturas de vacinação}

Apresentamos aqui, a comparação de diferentes coberturas de vacinação para a cidade de São Paulo segundo as duas estratégias de vacinação: vacinação aleatória da população e vacinação direcionada para um grupo etário. No caso da segunda estratégia, o grupo etário a receber a vacina é o grupo B, correspondente a indivíduos com idade maior ou igual a 40 anos. A cidade de São Paulo foi escolhida por ser a cidade mais populosa dentre as estudadas e por apresentar os maiores valores de $\psi$ calculados para cobertura de vacinação. Neste caso, as proporções foram calculados em função da quantidade de suscetíveis na primeira semana $S(0)$, apresentados nas Tabelas 3.6 e 3.10 . Os resultados na Tabela 3.13, mostram que as proporções vacinadas afim de erradicar a infecção no caso de vacinação aleatória devem ser $50 \%$ e $57 \%$, respectivamente, aos valores de $R_{0_{\text {efetivo }}}$ menor e maior. Para o caso de vacinação direcionada, as proporções devem ser $17 \%$ e $62 \%$, respectivamente, ao $R_{0_{\text {efetivo }}}$ menor e $R_{0_{\text {efetivo }}}$ maior. A Figura 3.34 contém os resultados de diferentes coberturas de vacinação aplicadas continuamente até atingir aproximadamente os valores obtidos para $\psi$ e que resulte em eliminar a infecção.

\begin{tabular}{|c|c|c|c|c|c|c|c|c|c|}
\hline \multicolumn{10}{|c|}{$\psi$ calculado para população de São Paulo } \\
\hline Cidade & pop. Total & $\begin{array}{l}R_{0} \\
\text { menor }\end{array}$ & $\begin{array}{l}\text { Pop } \mathrm{S}(0)- \\
R_{0} \text { menor }\end{array}$ & $\begin{array}{l}R_{0} \\
\text { maior }\end{array}$ & $\begin{array}{l}\text { pop } \mathrm{S}(0)- \\
R_{0} \text { maior }\end{array}$ & $\begin{array}{l}R_{0_{\text {efetivo }}} \\
\text { menor }\end{array}$ & $\begin{array}{l}R_{0_{\text {efetivo }}} \\
\text { maior }\end{array}$ & $\psi$ menor & $\psi$ maior \\
\hline São Paulo & 11253503 & 2.13 & 8866072 & 2.93 & 7103603 & 1.68 & 1.85 & 0.50 & 0.57 \\
\hline São Paulo - B & 4109608 & 1.69 & 2805044 & 2.38 & 3434967 & 1.16 & 1.99 & 0.17 & 0.62 \\
\hline
\end{tabular}

Tabela 3.13: Proporção $\psi$ a ser vacinada aleatoriamente na população de São Paulo. Consideramos uma vacina com $80 \%$ de eficácia contra cada sorotipo da dengue e obtemos um $\psi$ menor e maior, respectivamente relacionado, ao menor e maior $R_{0_{\text {efetivo }}}$, calculados em função da população inicial de suscetíveis (S(0)).
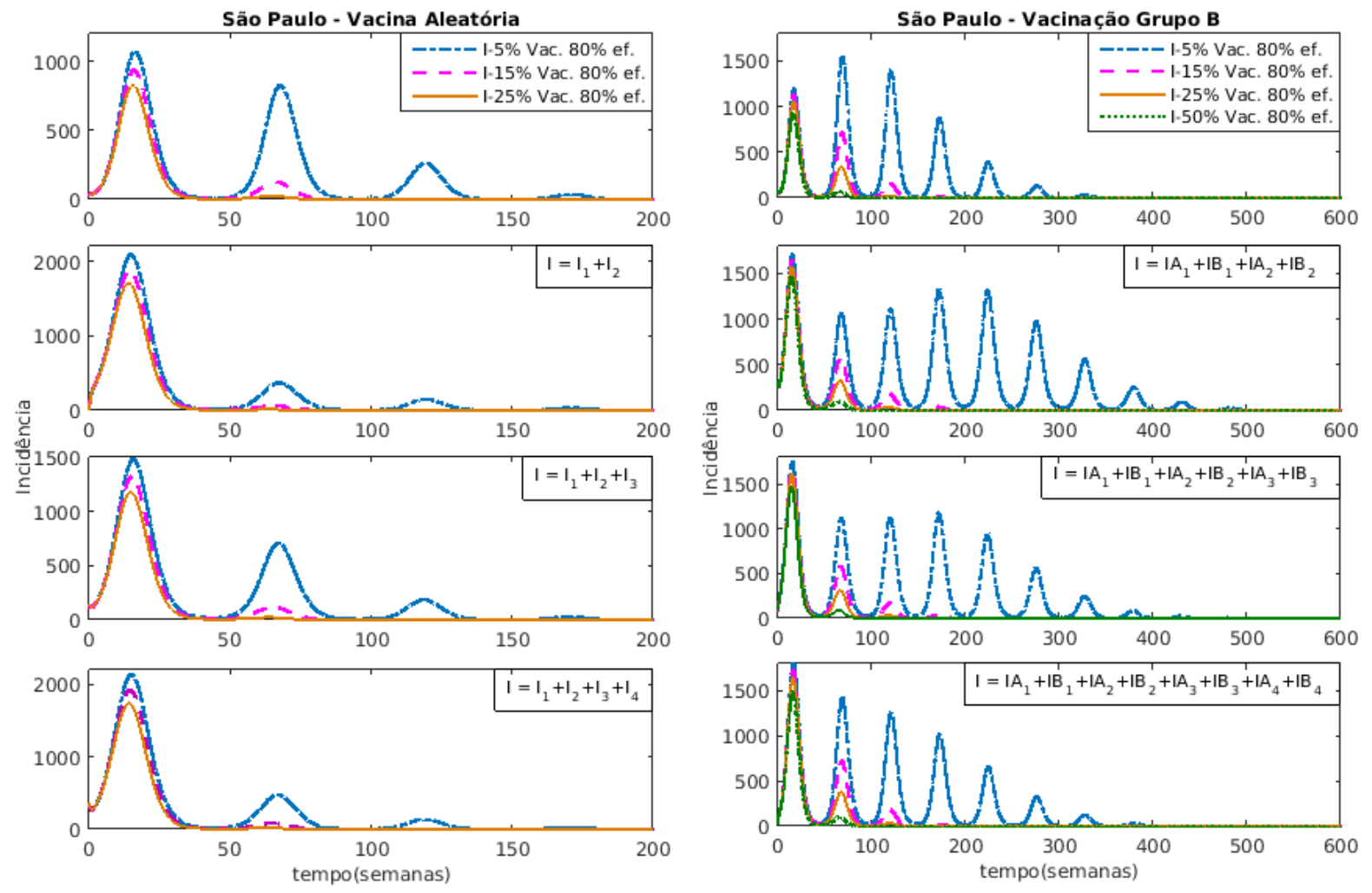

Figura 3.34: Comparação diferentes coberturas de vacinação na população aplicada para a cidade de São Paulo. A figura da esquerda contém os resultados de uma cobertura de vacinação anual aplicada em $5 \%$, $15 \%$ e $25 \%$ dos suscetiveis da população. Na figura da direita a vacinada é direcionada para os suscetiveis do grupo etário B, considerando cobertura anual de 5\%,15\%, $25 \%$ e $50 \%$. 


\section{Resultados da vacinação aleatória}

Como já foi observado, os parâmetros estimados no modelo com um sorotipo não capturaram surtos anuais, de forma que a aplicação da vacina reduz a quantidade de suscetíveis fazendo com que a infecção seja extinta. O mesmo ocorreu com os modelos de dois sorotipos nas séries de dados em que os parâmetros estimados não identificaram a coexistência de dois sorotipos. Para os modelos que acoplam a interação 3 ou 4 sorotipos, as oscilações ocorrem mais frequentemente e então a aplicação da vacina demora em torno de 3 ou 4 anos para reduzir a quantidade de suscetíveis de forma que não ocorram mais surtos, independentemente de aplicar a vacina continuamente em $2 \%$ e $5 \%$ dos suscetíveis.

\section{Resultados da vacinação direcionada para faixas etárias}

Os modelos compartimentados em duas faixas etárias apresentaram resultados mais significativos, como a vacina é direcionada para uma das faixas etárias, então a quantidade de vacinados é inferior quando aplicado no grupo com menor população, o que levaria um tempo maior para controlar a infecção considerando a mesma cobertura anual em $2 \%$ e $5 \%$ dos suscetíveis do respectivo grupo.

Neste caso, para os modelos com 2 sorotipos, os resultados mostram que para as cidades de Aracaju e Fortaleza, respectivamente, Figura 3.30 e Figura 3.32, não seria suficiente aplicar a vacina anualmente em $2 \%$ dos suscetíveis do grupo $\mathrm{A}$, correspondente a faixa etária de 0 à 19 anos, pois faria com que o número de casos voltasse a crescer depois de alguns anos. Isto pode ser devido ao modelo com 2 sorotipos ter um ciclo que se repete, fazendo com que se tenha, após um período, suscetíveis para algum dos sorotipos que ainda esteja em circulação. Porém os resultados foram bons com cobertura anual de vacinação de $5 \%$. Já para os modelos com 3 e 4 sorotipos a infecção foi extinta, mesmo demorando um tempo maior do que nos modelos com população total, pois demorou o tempo necessário para atingir a cobertura necessária na faixa etária.

Os resultados em geral, foram bastante favoráveis, pois apresentaram desfechos semelhantes para cidades dentro de um mesmo grupo etário de acordo com o agrupamento feito por meio de correlações na Seção 1.3.1. Por exemplo, Aracaju e Fortaleza, mesmo apresentando diferentes quantidades de notificações e terem projeções muito diferentes segundo conjunto de parâmetros estimados, obtiveram cenários pós-vacinação, equivalentes.

\section{Resultados da comparação de diferentes coberturas de vacinação}

É possível observar que os resultados são semelhantes em todos os modelos, diferindo apenas na intensidade da quantidade de infectados. Quando simulamos a aplicação de uma menor proporção de vacinados, os resultados mostram que seriam necessários 4 anos de vacinação contínua para eliminar a infecção no caso do modelo com população total e no máximo 9 anos no modelo compartimentado em duas faixas etárias. E em todos os casos quando se atinge a cobertura necessária de vacinação, então a infecção é eliminada em 1 ano. 


\section{Capítulo 4}

\section{Conclusões}

A dinâmica de transmissão da dengue vendo sendo amplamente discutida e modelada, especialmente após o desenvolvimento de vacinas e a capacidade destas em oferecer diferentes imunidades para os sorotipos existentes da doença. As características particulares da dengue fazem com que os modelos mais simples não descrevam a doença de forma realista e não apresentem bons resultados quando ajustados aos dados de incidência. Nosso trabalho teve o propósito de comparar o modelo de um sorotipo com modelos que descrevem a interação de dois, três e quatro sorotipos com a possibilidade de até quatro infecções sequenciais. Todos os modelos foram parametrizados com dados de notificação de dengue de cidades brasileiras.

Através do estudo dos dados epidemiológicos observamos que os surtos de dengue geralmente ocorrem uma vez por ano e que se repetem na mesma época do ano em cada local, demonstrando que as epidemias são sazonais. Mostramos que mesmo contendo poucos dados com identificação de sorotipos, que há alternância ao longo dos anos e coexistência de sorotipos em um mesmo surto. A dengue atinge todas as idades e geralmente as normalizações aplicadas não evidenciam faixas etárias em maior risco. Com a aplicação de uma normalização adequada, foi possível identificar que a dengue tem diferentes perfis etários no Brasil e que dentro de um mesmo estado, existem cidades com características totalmente diferentes. O coeficiente de correlação foi usado para fazer um agrupamento dessas cidades, de forma que analisamos por estados e para o grupo de cidades que estão recebendo a Fase III de testes da vacina produzida pelo Instituto Butantan.

O modelo básico que estudamos categoriza hospedeiros dentro de uma população como suscetíveis (S), infectados (I) e recuperados (R) e acoplado a estes consideramos os compartimentos dos vetores suscetíveis $(\mathrm{V})$ e infectados $\left(\mathrm{V}_{i}\right)$. Os modelos com múltiplos sorotipos foram expandidos a partir deste $\operatorname{SIRVV}_{i}$, considerando-se as seguintes hipóteses: a população é homogênea, assim inicialmente todos os indivíduos são igualmente suscetíveis à doença sendo soronegativos; as taxas de nascimento e mortes são iguais fazendo com que a população permaneça constante, e não inclui-se taxa de mortalidade pela doença; o período de infecciosidade é igual independente do sorotipo; em cada infecção o indivíduo passa por período de imunidade cruzada, implicando que terá imunidade temporária para os demais sorotipos e estará permanentemente imune para o sorotipo que já foi infectado, sendo que o período é o mesmo após cada infecção; os vetores só podem ser infectados uma vez e não se recuperam, supondo na dinâmica somente mosquitos fêmeas adultos capazes de transmitir a doença e incluindo uma forçante de sazonalidade em sua taxa de nascimento.

Na literatura, grande parte dos modelos consideram interação de dois sorotipos, pressupondo imunidade permanente após duas infecções sequenciais e a maioria trabalha com modelos simétricos. Também incluem a imunidade cruzada como um novo compartimento e o efeito ADE na segunda infecção, não considerando a transmissão vetor-hospedeiro. A grande vantagem dos nossos modelos com múltiplos sorotipos é que eles são assimétricos, isto é, com taxas de transmissão diferentes para cada sorotipo que são estimadas a partir dos dados de notificação de algumas cidades selecionadas, assim como os demais parâmetros. No modelo mais completo com coexistência de 4 sorotipos, consideramos que o indivíduo só adquire imunidade permanente após 4 infecções sequenciais. Aos modelos, incluímos a classes dos vacinados, e compartimentamos em duas faixas 
etárias, com o intuito de avaliar uma vacina tetravalente que apresenta eficácia diferente para os sorotipos, analisando-se duas estratégias de vacinação: vacinação aleatória na população e vacinação direcionada para faixas etárias. Os modelos estão adaptados de forma a simular aplicação da vacina tanto em soronegativos como em soropositivos ou em ambos.

Os resultados evidenciam que o modelo com coexistência de 4 sorotipos é o que melhor reproduz os dados de incidência de dengue e que é o mais adequado para analisar estratégias de vacinação com uma vacina tetravalente. Para a reprodução de surtos anuais e estimação de parâmetros, mostramos que é necessário a inclusão da forçante de sazonalidade na taxa de nascimento dos vetores. Porém, enfatizamos que os resultados dos ajustes e projeções dependem totalmente da qualidade dos dados. O adequado seria ter uma grande série de dados e que tenha surtos anuais mesmo que em diferentes intensidades. Os cenários com simulação de vacinação demonstram a superioridade da estratégia da vacina direcionada para faixas etárias, segundo os parâmetros estimados, e que as escolhas dos grupos etários devem ser definidas por município e não por um protocolo nacional. Como sequência deste estudo, aplicaremos a mesma metodologia para agrupar todos os municípios do Brasil.

Nosso modelo mais completo, que inclui os quatro sorotipo, infecção sequencial, vacinação tetravalente, sazonalidade na população de mosquitos e período de imunidade cruzada, foi construído de forma a permitir várias adaptações para diversos novos estudos. Diferentes estratégias de vacinação com combinação de diversos agrupamentos etários, por exemplo, podem ser incluídas, seguindo a construção proposta para as equações e consequente adaptação dos valores dos parâmetros. O modelos também podem ser usados para o estudo de diferentes doenças coexistindo em uma população, como dengue, Zika e Chikungunya, que possuem dinâmicas de transmissão semelhantes e são transmitidas por vetores. Assim como podem ser adaptados para se analisar dinâmicas que levam em conta a heterogeneidade na população. 


\section{Apêndice A}

\section{Teoria epidemiológica elementar}

Neste capítulo vamos discutir alguns modelos básicos existentes em epidemiologia matemática fundamentais para entender, prever e simular estratégias de controle de doenças infecciosas. A partir destes, modelos mais complexos são desenvolvidos, incluindo características particulares de cada doença. Também são apresentadas algumas definições e conceitos gerais.

\section{A.1 Modelagem matemática}

Um modelo matemático que descreve uma doença infecciosa deve levar em conta conceitos biológicos básicos da dinâmica da doença, além de fornecer informações sobre os parâmetros epidemiológicos, como a força de infecção $(\lambda)$ e o número básico de reprodução $\left(R_{0}\right)$ (Allen et al., 2008; Anderson et al., 1992; Brauer e Castillo-Chavez, 2001; Diekmann et al., 2009; Heesterbeek e Dietz, 1996; Keeling e Rohani, 2008; Krämer et al., 2010; Li et al., 2011; Ma e Xia, 2009; Sanches e Massad, 2016; van den Driessche e Watmough, 2002; van den Driessche, 2017; Vynnycky e White, 2010; Yang, 2001). A força de infecção determina a dimensão da propagação da doença, e o número básico de reprodução mede casos secundários que surgem de um indivíduo infeccioso. Ambos mostram o esforço que deve ser feito para evitar sua propagação.

Definição A.1 $\beta$ é a taxa de transmissão na qual dois indivíduos têm contato efetivo, isto seria $o$ contado de um suscetivel com um infeccioso. De forma que a força de infecção $\lambda=\beta I$, isto é, o risco de infecção é proporcional ao número de indivíduos infecciosos por unidade de tempo.

Nos modelos determinísticos, os indivíduos de uma população são divididos em classes ou compartimentos, os mais usados são os compartimentos dos suscetíveis (S), expostos (E), infectados/infecciosos (I) e removidos/recuperados (R) (Amaku et al., 2014; Anderson, 1982; Gumel e Lenhart, 2010; Hethcote, 1976; Keeling e Rohani, 2008; Kermack e McKendrick, 1927; Krämer et al., 2010; Martcheva, 2015). A transferência de uma classe para outra ocorre quando o indivíduo muda de estado, em outras palavras, isso seria o tempo de permanência em cada estado, por exemplo, um suscetível entra em contato com um infectado e então se torna infectado com uma certa probabilidade da transmissão ser bem sucedida.

Definição A.2 Um modelo deterministico descreve o que acontece em média em uma população e não incorpora efeitos do acaso. Enquanto o modelo estocástico permite que o número de indivíduos entre os compartimentos possa variar, devido as taxas, por exemplo, taxa na qual as pessoas são infectadas ou se recuperaram, variarem aleatoriamente. 


\section{A.1.1 Modelo sem demografia}

Modelos epidêmicos descrevem surtos que ocorreram no período de um ano ou menos enquanto modelos endêmicos são usados para entender uma doença que persiste em uma população por um longo tempo. Um modelo que não considera demografia só é útil quando se quer analisar um período curto de tempo (Keeling e Rohani, 2008). O modelo SIR sem demografia é representado na Figura A.1, (Kermack e McKendrick, 1927).

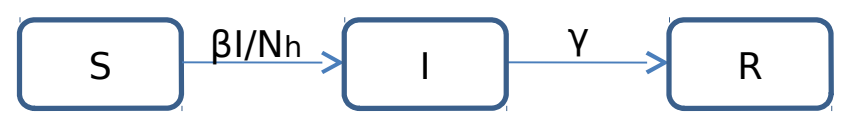

Figura A.1: Esquema do fluxo de individuos entre os compartimentos dos suscetiveis $S$, infectados I e recurados $R$ no modelo sem demografia. Cada compartimento representa uma população, e as flechas consideram a entrada e saída dos compartimentos de acordo a uma certa taxa.

Considera-se que $N_{h}$ é o tamanho da população de humanos, $\gamma$ é a constante que representa a taxa de recuperados, sendo o inverso do período infeccioso, e $\beta$ é a taxa de transmissão. A mudança do compartimento S para I indica que o indivíduo deixa de ser suscetível ao contrair a doença pelo contato efetivo a uma taxa $\beta$ com um infeccioso e também se torna infectado/infeccioso e após um intervalo de tempo será removido para o compartimento $\mathrm{R}$, o qual engloba indivíduos recuperados/removidos e que não transmitem mais a infecção. O fluxo entre estes compartimentos, são descritos por equações diferenciais ordinárias (EDOs), estruturadas por:

$$
\begin{aligned}
& \frac{d S}{d t}=-\beta I S / N_{h} \\
& \frac{d I}{d t}=\beta I S / N_{h}-\gamma I \\
& \frac{d R}{d t}=\gamma I
\end{aligned}
$$

com os valores iniciais $S(0) \geq 0, I(0) \geq 0, R(0) \geq 0$.

Da segunda equação do Sistema (A.1), se o valor inicial de suscetíveis $S(0)$ é menor do que $\frac{\gamma}{\beta} N_{h}$, então $d I / d t<0$ e a infecção não se propaga, resultado conhecido como valor limiar, já que a quantidade inicial de suscetíveis na população deve exceder este valor para que a infecção possa invadir (Kermack e McKendrick, 1927).

\section{A.1.2 Modelo com demografia}

O SIR com demografia é o modelo endêmico mais clássico. A maneira de introduzir demografia na dinâmica, é considerar o tempo médio natural de vida dos indivíduos como $1 / \mu_{h}$ anos, assim, a taxa na qual os indivíduos sofrem mortalidade é dada pelo inverso dessa expectativa de vida, $\mu_{h}$, devendo ser incluída em todos compartimentos. A Figura A.2 representa a dinâmica de interação entre os compartimentos do modelo SIR com demografia. 


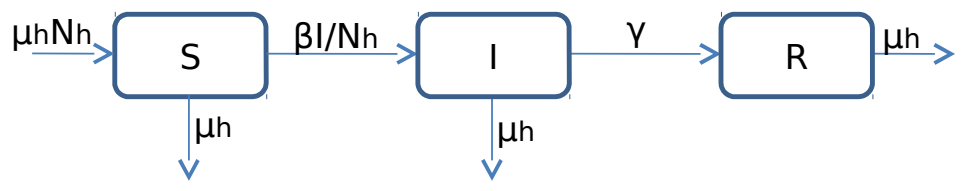

Figura A.2: Esquema do fluxo de individuos entre os compartimentos dos suscetiveis $S$, infectados I e recurados $R$ no modelo com demografia. Cada compartimento representa uma população, e as flechas consideram a entrada e saída dos compartimentos de acordo a uma certa taxa. Os nascimentos e mortes são dados pela mesma taxa, de forma que a população permanece constante.

Neste modelo o tamanho total da população $N_{h}$ permanece constante, ou seja, $\mu_{h}$ é a taxa de nascimentos e mortes naturais em qualquer classe (Hethcote, 2000; Keeling e Rohani, 2008; Kermack e McKendrick, 1927). O fluxo entre estes compartimentos, é descrito pelas equações diferenciais ordinárias (EDOs):

$$
\begin{aligned}
& \frac{d S}{d t}=\mu_{h} N_{h}-\beta I S / N_{h}-\mu_{h} S \\
& \frac{d I}{d t}=\beta I S / N_{h}-\gamma I-\mu_{h} I \\
& \frac{d R}{d t}=\gamma I-\mu_{h} R
\end{aligned}
$$

com os valores iniciais $S(0) \geq 0, I(0) \geq 0, R(0) \geq 0$ e tal que

$$
T=\left\{(S, I, R) \in \mathbb{R}_{+}^{3}: S+I+R \leq N_{h}\right\},
$$

pois interessa somente as soluções não-negativas desse problema de valor inicial que possui solução única para todo tempo positivo. O modelo é matematicamente e epidemiologicamente bem posto (Hethcote, 1976; Keeling e Rohani, 2008; Krämer et al., 2010; Rodrigues et al., 2012; Sotomayor, 1979).

Modelos mais realistas incluem também a idade como uma variável dependente e podem considerar compartimentos que melhor representam uma população, como fatores sociais que interferem diretamente em condições de saúde e saneamento na população, ou suscetíveis com diferentes graus de imunidade, suscetíveis separados por faixa etária, doentes crônicos, etc.

No caso de doenças transmitidas por vetor, como dengue, febre amarela, Malária, Zika e Chikungunyaetc, o modelo acopla a dinâmica dos mosquitos, podendo ser separados em larvas, mosquitos suscetíveis, infectados, outros (Amaku et al., 2014; Boccia et al., 2014; Burattini et al., 2008,?; de Moura Rodrigues et al., 2015; de Valdez et al., 2011; Dejnirattisai et al., 2016; Derouich et al., 2003; Esteva e Vargas, 1999; Thomé et al., 2010). Quanto mais compartimentos são incluídos, mais realista se torna o modelo, e consequentemente aumenta o nível de complexidade de suas soluções e a dificuldade de determinar valores para a grande quantidade de parâmetros de forma que reproduzam os dados de incidência (Cauchemez e Ferguson, 2008; Coelho et al., 2011; Ferguson et al., 1999b; He et al., 2009; Kao e Eisenberg, 2017; Keeling e Rohani, 2008; Krämer et al., 2010; Shrestha et al., 2011; White et al., 2007; Yang, 2001).

Definição A.3 Incidência se refere ao risco de contrair a doença, ou seja, a ocorrência de novos casos por unidade de tempo, enquanto prevalência indica quão disseminada a doença está, isto é, a proporção do número de casos na população em um determinado momento. 
Além disso, doenças que são consideradas fatais, não possuem o compartimento dos recuperados. Em geral, os modelos SIR são utilizados para descrever uma doença que confere imunidade contra reinfecção. Utiliza-se o SIS para descrever uma doença sem imunidade contra a reinfeç̧ão, para indicar que a passagem de indivíduos é da classe suscetível à classe infecciosa e depois de volta à classe suscetível. Normalmente, as doenças causadas por um vírus são de tipo SIR, enquanto as doenças causadas por bactéria são do tipo SIS (Brauer e Castillo-Chavez, 2001).

Quando modelamos doenças com altas taxas de mortalidade, como é o caso da Malária, não é adequado usar modelos com população constante (Esteva e Vargas, 1999). Em doenças que apresentam considerável risco de morte decorrente da infecção, a probabilidade de morte pela doença deve ser incluída no compartimento dos infectados .

Apesar de bastante simples, os modelo compartimentais SIR's e variações, não podem ser resolvidos explicitamente, mas podem ser usadas técnicas numéricas para fornecer uma solução aproximada da solução analítica. Além disso, podem ser analisados características qualitativas do sistema de equações (Hethcote, 1976, 2000; Keeling e Rohani, 2008; Krämer et al., 2010; Sotomayor, 1979).

\section{A.1.3 Modelo com vacinação}

Há duas maneiras de incluir vacinação em um modelo, a primeira consiste em vacinar recém nascidos, assim uma proporção $p$ de nascimentos já não entra na classe dos suscetíveis e vai para a classe dos vacinados. Outra abordagem é vacinar continuamente uma proporção aleatória de suscetíveis (Keeling e Rohani, 2008; Martcheva, 2015). A maior dificuldade no processo de vacinação é lidar com o fato de que é muito difícil produzir uma vacina $100 \%$ eficaz. A esperança é que a vacina forneça imunidade de longa duração à infecção e previna ambos a transmissão e os sintomas da doença (Anderson e May, 1985, 1982; Billings et al., 2008; d'Onofrio, 2002; Gomes et al., 2004, 2014; Keeling e Rohani, 2008; Liu et al., 2008; Maier et al., 2017; Massad et al., 1994; Rodrigues et al., 2013; Scherer e McLean, 2002; Yang, 2001).

Definição A.4 Eficácia da vacina é a proteção direta fornecida por vacinação contra infeç̧ão que exclui qualquer efeito indireto. Eficiência da vacina implica sobre a redução na incidência da infecção em uma população resultante da combinação direta e indireta da vacinação.

O modelo matemático mais simples usado para estudar a dinâmica de uma estratégia de vacinação é formulado com os quatro compartimentos: indivíduos suscetíveis (S), infecciosos (I), recuperados $(\mathrm{R})$ e acopla-se a estes o compartimento que vai receber os humanos vacinados $\left(\mathrm{H}_{V}\right)$ (Rodrigues et al., 2014). A dinâmica de transmissão em um modelo no qual se aplica vacina em recém-nascidos, é explicitada na Figura A.3. Tem-se que a proporção $p$ de recém-nascidos é vacinada e então movida para o compartimento dos vacinados $\mathrm{H}_{V}$.

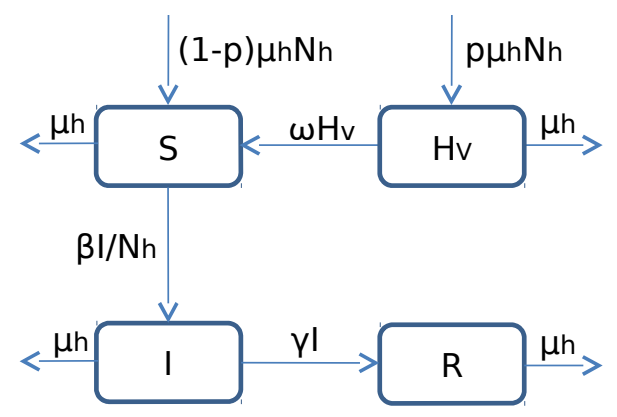

Figura A.3: Esquema do fluxo de indivíduos entre os compartimentos $S, H_{V}$, I e R. Uma proporção $p$ de recém-nascidos é vacinada, permanecendo imune por toda a vida ou pode sofrer uma perda de imunidade $\omega$ ao longo do tempo e voltar para o compartimento dos suscetiveis. 
Neste modelo considera-se que a taxa de nascimentos e mortes é $\left(\mu_{h}\right)$ de forma que a população se mantém constante de tamanho $N_{h}$ ao longo do tempo. Um indivíduo se torna infectado ao encontrar um infeccioso a uma taxa de infecção $\beta$ e se recupera a uma taxa $\gamma$ se tornando imune. $O$ modelo pode considerar uma vacina perfeita que confere imunidade por toda a vida, ou uma vacina que apresenta a perda de imunidade a uma taxa $\omega$ depois de alguns anos, que faz com que uma proporção dos vacinados volte a ser suscetível. O sistema de equações diferenciais que descreve esse modelo, denotado por $\mathrm{SH}_{V} \mathrm{IR}$, é dado por:

$$
\begin{aligned}
& \frac{d S}{d t}=(1-p) \mu_{h} N_{h}-\beta I S / N_{h}+\omega H_{v}-\mu_{h} S \\
& \frac{d H_{V}}{d t}=p \mu_{h} N_{h}-\omega H_{v}-\mu_{h} H_{V} \\
& \frac{d I}{d t}=\beta I S / N_{h}-\left(\gamma+\mu_{h}\right) I \\
& \frac{d R}{d t}=\gamma I-\mu_{h} R
\end{aligned}
$$

A segunda abordagem consiste em vacinar continuamente uma proporção aleatória $\psi_{S}$ de suscetíveis $\mathrm{S}$, e então movê-los para o compartimento dos vacinados $\mathrm{H}_{V}$, de forma que se a vacina não é $100 \%$ eficaz, então indivíduos vacinados podem contrair a infecção a uma taxa $\sigma$ (Figura A.4). Em todos os compartimentos considera-se a taxa de mortalidade natural dos humanos $\mu_{h}$.

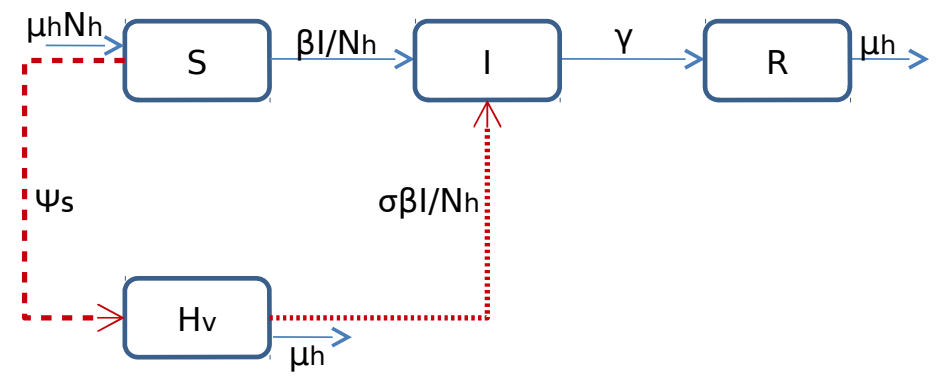

Figura A.4: Esquema do fluxo de indivíduos entre os compartimentos $S, I, R$ e $H_{V}$. Uma proporção aleatória $\psi_{S}$ da população é vacinada, então indivíduos vacinados podem contrair a infeç̧ão a uma taxa $\sigma$, em que $1-\sigma$ representa a eficácia da vacina.

O sistema de EDO's que descreve este modelo é dado por:

$$
\begin{aligned}
& \frac{d S}{d t}=\mu_{h} N_{h}-\beta I S / N_{h}-\psi_{S} S-\mu_{h} S \\
& \frac{d I}{d t}=\beta I S / N_{h}+\sigma \beta I H_{v} / N_{h}-\left(\gamma+\mu_{h}\right) I \\
& \frac{d R}{d t}=\gamma I-\mu_{h} R \\
& \frac{d H_{V}}{d t}=\psi_{S} S-\sigma \beta I H_{v} / N_{h}-\mu_{h} H_{V}
\end{aligned}
$$

com valores iniciais $S(0) \geq 0, I(0) \geq 0, R(0) \geq 0$ e $H_{V}(0) \geq 0$. E solução válida no domínio

$$
\Omega_{v}=\left\{\left(S, H_{V}, I, R\right) \in \mathbb{R}_{+}^{4}: S+I+R+H_{V} \leq N_{h}\right\} .
$$




\section{A.2 Número básico de reprodução e equilíbrios do sistema}

O $R_{0}$ é uma quantidade limiar, muito importante em epidemiologia matemática, que fornece um indicativo se a doença irá se propagar ou extinguir da população. (Allen et al., 2008; Anderson et al., 1992; Brauer e Castillo-Chavez, 2001; Ferguson et al., 1999b; Gumel e Lenhart, 2010; Heffernan et al., 2005; Krämer et al., 2010; Ma e Xia, 2009; Martcheva, 2015; Sanches e Massad, 2016; van den Driessche, 2017; Yang, 2001).

Definição A.5 $R_{0}$ é número médio de infecções secundárias causadas por um indivíduo infeccioso, durante seu período de infecciosidade, em uma população toda suscetível.

Definição A.6 $R_{0}$ em doenças de transmissão vetor-hospedeiro, pode ser definido como o número esperado de pessoas que irão se tornar infectadas por uma pessoa inicialmente infectada por um mosquito.

\section{A.2.1 Cálculo do $\mathbf{R}_{0}$}

Para um simples modelo SIR simples sem demografia, $R_{0}$ pode ser calculado de uma maneira intuitiva, pois é o produto da taxa per capita de infecção e o período médio de duração da infecção (Diekmann et al., 2009; Gumel e Lenhart, 2010; Keeling e Rohani, 2008). Assim, para o sistema de Equações A.1 tem-se a taxa per capita de infecção $=\beta S / N_{h}$, que se reduz a $\beta$ se a população é toda suscetível. Geralmente $R_{0}$ é tomado no contexto de população inteira suscetível, e a duração da infecção é $1 / \gamma$, de forma que obtemos:

$$
R_{0}=\frac{\beta}{\gamma} .
$$

Neste caso, $S(0)=N_{h}$ e se $R_{0}>1$ então o patógeno pode invadir a população.

Para estudar o contexto em que a população não é toda suscetível, define-se $R_{0_{\text {efetivo }}}$, que no caso desses modelos mais simples tem-se:

$$
R_{0_{\text {efetivo }}}=R_{0} \frac{S}{N_{h}} .
$$

Esta formulação vai ajudar a calcular o nível endêmico da doença na população, desde que no equilíbrio, $R_{0_{\text {efetivo }}}=1$. Então o nível de equilíbrio endêmico na população é $1 / R_{0}$. Esta formulação também ajuda no entendimento de herd imunidade. A proporção crítica da população que precisa ser imune é determinada considerando-se que $R_{0_{\text {efetivo }}}<1$ então precisamos que $S / N_{h}<1 / R_{0}$, isto é, que a proporção $1-1 / R_{0}$ da população seja imune e o restante pode ser suscetível que vai estar protegido. O tamanho de uma epidemia também aumenta conforme o limiar é excedido. Quanto maior a população de suscetíveis no começo da epidemia, menor ela será no final da epidemia. Dessa forma, a epidemia continua a aumentar enquanto a população suscetível é maior que o limiar crítico, mas quando esse ponto é alcançado então a epidemia começa a diminuir até terminar (Hethcote, 2000; Keeling e Rohani, 2008; Kermack e McKendrick, 1927; Krämer et al., 2010).

Dividindo a equação de S pela equação de R no modelo SIR sem demografia (Equação (A.1), obtemos:

$$
\begin{aligned}
\frac{d S}{d R} & =-\frac{\beta S}{\gamma N_{h}} \\
& =-R_{0} \frac{S}{N_{h}}
\end{aligned}
$$


e integrando em relação à $\mathrm{R}$, seque que:

$$
S(t)=S(0) e^{-R_{0} \frac{R(t)}{N_{h}}}
$$

Assim, supondo que o número inicial de recuperados $R(0)=0$, então conforme a epidemia se propaga, o número de suscetíveis diminui e o número de recuperados aumenta, porém como o termo $e^{-R_{0} \frac{R(t)}{N_{h}}}$ é sempre positivo, então $\mathrm{S}$ sempre permanece acima de 0 .

Para o modelo SIR (A.2), o valor de $R_{0}$ é dado pela taxa de transmissão $\beta$ multiplicada pelo período médio infeccioso com ajuste de mortes $1 /\left(\gamma+\mu_{h}\right)$ (Hethcote, 2000), ou simplesmente, a taxa de transmissão (o que entra) dividido pela taxa de transição (o que sai) do compartimento dos infecciosos;

$$
R_{0}=\frac{\beta}{\gamma+\mu_{h}}
$$

Podemos observar, pela segunda equação de (A.2), que se a variação dos infecciosos é maior que zero em uma população fechada com $R_{0}$ especificado, uma doença invade somente se a quantidade de suscetíveis é maior que o valor crítico $p_{c}=N_{h} / R_{0}$.

A Figura A.5 mostra como o aumento do $R_{0}$ faz com que se aumente a incidência de uma doença.

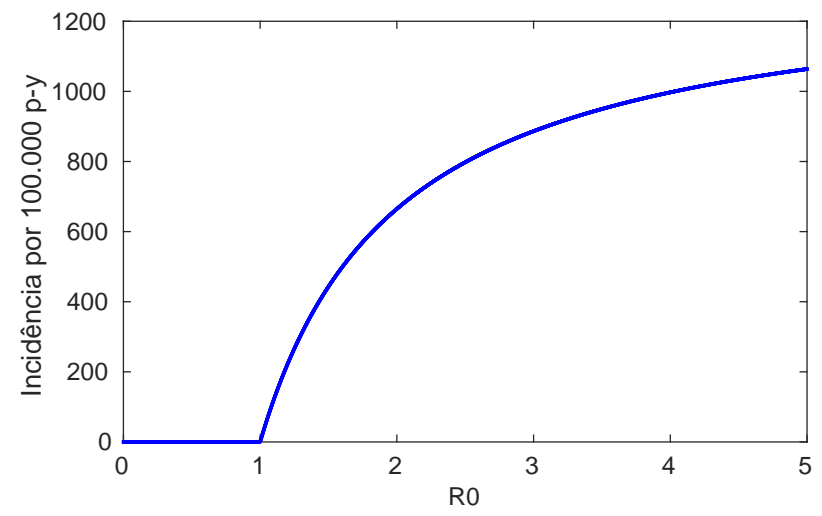

Figura A.5: Incidência em função do $R_{0}$ calculada com o modelo SIR com demografia.

\section{Método de próxima geração}

Uma forma de calcular o número básico de reprodução para sistemas mais complexos, fazendo uso do equilíbrio livre de doença, que será definido na próxima seção, é com a matriz de próxima geração, denotada por $K$. O método consiste em considerar somente a parte que contém entrada e saída de infectados no sistema de EDO's; calcular a Jacobiana desse sub-sistema no equilíbrio livre de doença, depois separar o sistema resultante em duas partes, uma parte contendo as transmissões $T$, ou seja, a produção de novos infecciosos, e a outra parte $\Sigma$ com a transição, descrevendo as trocas de estado (incluindo mortes e aquisição de imunidade). O último passo é calcular o raio espectral $(\rho)$ da matriz $K=-T \Sigma^{-1}$, o qual será o valor procurado do $R_{0}$ (Allen et al., 2008; Diekmann et al., 1990, 2009; van den Driessche e Watmough, 2002; van den Driessche, 2017). Esse processo é entendido como geração de indivíduos infectados, que em vez de processos de tempo real, considera-se os processos de geração associados, assim, a primeira geração consiste de indivíduos infectados inicialmente na população, a segunda geração consiste de todas infecções causadas por membros da primeira geração (Heesterbeek e Dietz, 1996). 
Como o valor do $R_{0}$ é baseado na linearização do sistema de EDOs em torno do equilíbrio livre de doença, precisamos fazer algumas suposições para garantir que o modelo é bem posto (Allen et al., 2008). Dado o sistema separado em termos de transmissão e transição, isto é, $x^{\prime}=T(x, y)+\Sigma(x, y)$, com $x \in \mathbb{R}^{n}$ e $y \in \mathbb{R}^{m}$, sendo as subpopulações de cada compartimento, respectivamente, $n$ compartimentos com doença e $m$ compartimentos sem infecciosos, supomos que os modelos epidemiológicos apresentados nesta tese satisfazem:

A1) $T(0, y)=0, \Sigma(0, y)=0, \forall y \geq 0$

Esta hipótese implica que o equilíbrio livre de doença de cada modelo (Seção A.2.2) é invariante.

A2) $T(x, y) \geq 0, \forall x$ e $y$ não negativos;

É um fato pois $T$ contém entradas de novas pessoas infectadas e que não pode ser um valor negativo.

A3) $\Sigma(x, y) \leq 0$ sempre que $x=0$;

Como $\Sigma$ é o compartimento com saída de infectados, então se não tivermos infectados, este terá um valor negativo.

A4) $\sum_{i=1}^{n} \Sigma(x, y) \geq 0, \forall x$ e $y$ não negativos;

Como esta soma representa a quantidade total de indivíduos que são removidos do compartimento dos infecciosos, temos que esse valor é sempre $\geq 0$.

A5) O equilíbrio livre de doença é único e é assintoticamente estável.

Todas as soluções com condições iniciais com 0 infectados permanecem próximas de $(0, y)$ quando $t \rightarrow \infty$.

Para exemplificar, aplicamos este método para o modelo (A.2) que só possui uma equação de infectados $d I / d t=\beta I S / N_{h}-\left(\gamma+\mu_{h}\right) I$. A matriz Jacobiana calculada no caso em que não se tem doença $\left(I=R=0\right.$ e $S=N_{h}$ ), só contém o termo $\beta-\gamma-\mu_{h}$ em que $\beta$ é o termo de transmissão e $-\left(\gamma+\mu_{h}\right)$ é o termo de transição, assim nosso subsistema de infecção será dado por apenas essa equação. Separando este em $T$ e $\Sigma$ e denotando por $x$, tem-se

$$
x^{\prime}=(T+\Sigma) x .
$$

em que

$$
x=I, \quad T=\beta, \quad \Sigma=-\left(\gamma+\mu_{h}\right) .
$$

Disto segue que

$$
R_{0}=\rho(K)=\rho\left(-T \Sigma^{-1}\right)=\rho\left(-\beta \times \frac{1}{-\left(\gamma+\mu_{h}\right)}\right)=\frac{\beta}{\left(\gamma+\mu_{h}\right)} .
$$

O número básico de reprodução $R_{0}$ para o modelo com estratégia de vacinação em recém nascidos (A.4), que denotaremos por $R_{0 p}$, é tal que (Scherer e McLean, 2002):

$$
R_{0 p}=(1-p) R_{0},
$$

indicando o número de casos secundários causados por um indivíduo infeccioso introduzido em uma população na qual uma proporção $p$ foi vacinada. Dessa forma, temos que a proporção crítica de vacinação que deve ser alcançada afim de erradicar a doença (quando $R_{0 p}=1$ ), é dada por

$$
p=1-\frac{1}{R_{0}} .
$$




\section{A.2.2 Estabilidade e equilíbrios do sistema}

Seja $\Delta$ um subconjunto aberto do $\mathbb{R}^{n}$. Um campo vetorial de classe $C^{k}$ em $\Delta$ é uma aplicação $F: \Delta \longrightarrow \mathbb{R}^{n}$ de classe $C^{k}, 1 \leq k \leq \infty$. Ao campo $F$ associamos a equação diferencial

$$
y^{\prime}=F(y) .
$$

As soluções de (A.14) são denominadas trajetórias ou curvas integrais de $F$.

Definição A.7 Um conjunto aberto $\Delta$, dotado da decomposição de órbitas de $F$, chama-se retrato de fase de F. A órbitas são orientadas no sentido das trajetórias do campo $F$; os pontos singulares são munidos da orientação trivial.

Definição A.8 Uma solução máxima de $y^{\prime}=F(y)$ é toda solução $\phi$ definida num intervalo $\mathcal{I}$, denominado intervalo máximo de $\phi$, tal que se $\psi$ é outra solução no intervalo $J$ com $J \supseteq \mathcal{I} e$ $\phi=\psi \mid \mathcal{I}$, então $\mathcal{I}=J$, ou seja, $\phi$ é máxima se não admite nenhuma outra extensão que também é solução de $y^{\prime}=F(y)$.

Teorema A.1 Se $\phi_{x}$ é uma solução máxima de $y^{\prime}=F(y)$ em $\mathcal{I}_{x}$ então:

a) $\phi_{x}$ é injetiva ou;

b) $\mathcal{I}_{x}=\mathbb{R}$ e $\phi_{x}$ é constante ou;

c) $\mathcal{I}_{x}=\mathbb{R}$ e $\phi_{x}$ é periódica;

Dem: (Ver (Sotomayor, 1979))

Se o modelo considera demografia então a doença pode persistir na população por um longo tempo. Isso pode ser observado através dos pontos de equilíbrio do sistema. O equilíbrio livre de doença é quando o patógeno sofre extinção e todos na população são suscetíveis. No equilíbrio endêmico obtemos que a população de suscetíveis é o inverso de $R_{0}$ ou seja, $S^{*}=\frac{\gamma+\mu_{h}}{\beta}$. Então encontra-se o valor de $I^{*}$ e de $R^{*}$. Pela análise de estabilidade, conclui-se que o equilíbrio endêmico é estável se $R_{0}>1$, caso contrário o equilíbrio livre de doença será estável (Diekmann et al., 2009; Keeling e Rohani, 2008).

Igualamos a zero as equações do sistema SIR dado em (A.2) e trabalhando com as variáveis que satisfazem esta equação, temos que equilíbrio livre de doença é o trivial, ocorre quando temos a população inteira de suscetíveis e nenhum infectado, ou seja $\left(S^{*}, I^{*}, R^{*}\right)=\left(N_{h}, 0,0\right)$. Para obter o equilíbrio endêmico, encontramos a solução não nula de

$$
\begin{aligned}
& \mu_{h} N_{h}-\beta I^{*} S^{*} / N_{h}-\mu_{h} S^{*}=0 \\
& \beta I^{*} S^{*} / N_{h}-\gamma I^{*}-\mu_{h} I^{*}=0 \\
& \gamma I^{*}-\mu_{h} R^{*}=0
\end{aligned}
$$

Da segunda equação do sistema acima, temos $I^{*}\left(\beta S^{*} / N_{h}-\left(\gamma+\mu_{h}\right)\right)=0$, isto implica que $I^{*}=0$ ou $S^{*}=N_{h}\left(\gamma+\mu_{h}\right) / \beta$, a primeira igualdade implica no equilíbrio livre de doença. Vamos analisar a segunda e denotá-la por $S^{*}=N_{h} / R_{0}$ (usando a equação (A.10)). Substituindo $S^{*}$ na primeira equação de (A.15), temos

$$
I^{*}=\frac{\mu_{h}}{\beta} N_{h}\left(R_{0}-1\right) .
$$


Como não podemos ter um número de infectados negativo, o equilíbrio só é biologicamente viável se $R_{0}>1$, o que condiz com a consideração de que a doença vai persistir na população, fato este caracterizado como análise de estabilidade de cada equilíbrio, assim se $R_{0}>1$ o equilíbrio endêmico é estável, caso contrário o equilíbrio livre de doença será estável (Keeling e Rohani, 2008).

Para encontrar o valor de $R^{*}$, usamos os fato de que $S^{*}+I^{*}+R^{*}=N_{h}$, então $R^{*}=N_{h}-S^{*}-I^{*}$. Portanto temos que o equilíbrio endêmico para o modelo SIR (A.2) é dado por:

$$
\left(S^{*}, I^{*}, R^{*}\right)=\left(\frac{N_{h}}{R_{0}}, \frac{\mu_{h}}{\beta} N_{h}\left(R_{0}-1\right), N_{h}-\frac{N_{h}}{R_{0}}-\frac{\mu_{h}}{\beta} N_{h}\left(R_{0}-1\right)\right) .
$$

Em modelos com mais compartimentos como o $\mathrm{SH}_{V} \mathrm{IR}$ e os modelos que consideram o compartimento dos vetores, o cálculo desses equilíbrios se torna mais complicado, nesses casos o mais fácil é utilizar métodos numéricos (Diekmann et al., 2009; Rodrigues et al., 2012). 


\section{Apêndice B}

\section{Resultados complementares}

Neste apêndice apresentamos os resultados de estimar parâmetros para duas cidades brasileiras utilizando a série de dados da $1^{\mathrm{a}}$ semana de 2008 à $35^{\mathrm{a}}$ semana de 2014 , isto é, um período de 347 semanas, aproximadamente 7 anos. Como foi mostrado na Figura 1.2, a maioria das cidades não notificaram surtos consecutivos nesse período. Escolhemos as cidades do Rio de Janeiro e Salvador que apresentam características bem diferentes na série de dados. Rio de Janeiro que não apresenta notificações nos anos de 2009 e 2010, com surtos nos anos seguintes com grandes quantidades de casos, e Salvador que apresenta surtos em quase todos os anos, mas com uma quantidade baixa de notificações (Figura 1.2). Para a estimação de parâmetros utilizamos os dados brutos sem normalização e os valores para os parâmetros globais dados nas Tabelas B.1 e B.2.

\begin{tabular}{c|c}
\hline Parâmetros & Valor(semanas) \\
\hline$\mu_{h}$ Nordeste & $7 /\left(71^{*} 365\right)$ \\
$\mu_{h}$ Sudeste & $7 /\left(75^{*} 365\right)$ \\
$\gamma$ & 1 \\
$\varphi$ & $7 / 180$ \\
$\mu_{m}$ & $7 / 10$ \\
\hline
\end{tabular}

Tabela B.1: Parâmetros globais que são mantidos fixos em todos os modelos. Consideramos as taxas de nascimento/mortalidade $\left(\mu_{h}\right)$, de recuperação $(\gamma)$ e de imunidade cruzada temporária $(\varphi)$ nos humanos e também a taxa de mortalidade dos vetores $\left(\mu_{m}\right)$ não são estimadas, mas sim consideradas fixas em todas séries temporais ajustadas aos modelos.

\begin{tabular}{c|c}
\hline Cidades & População Total \\
\hline Rio de Janeiro & 6320446 \\
Salvador & 2675656 \\
\hline
\end{tabular}

Tabela B.2: População total das cidades: Rio de Janeiro e Salvador, segundo o Censo demográfico de 2010, $I B G E$ (IBGE, 2017).

A seguir mostramos os resultados de ajustar os modelos aos dados das duas cidades escolhidas, e na sequência, a projeção e simulação de aplicar a vacina em uma proporção aleatória da população. Para a série de dados do Rio de Janeiro que possui um período de dois anos sem surtos, fica evidente que o modelo com 1 sorotipo não obteve um bom ajuste, enquanto os outros modelos com coexistência de mais de um sorotipo conseguiram captar melhor a dinâmica dos dados, mesmo assim não foram capazes de alcançar os picos, Figura B.1. No caso dos dados de Salvador, que possui surtos consecutivos nos 7 anos, os modelos obtiveram um resultado melhor, sendo que os modelos com 3 e 4 sorotipos foram capazes de se ajustar mais aos picos e não usou $100 \%$ do valor de I estimado, Figura B.2. 


\section{B.0.3 Resultados Rio de Janeiro}
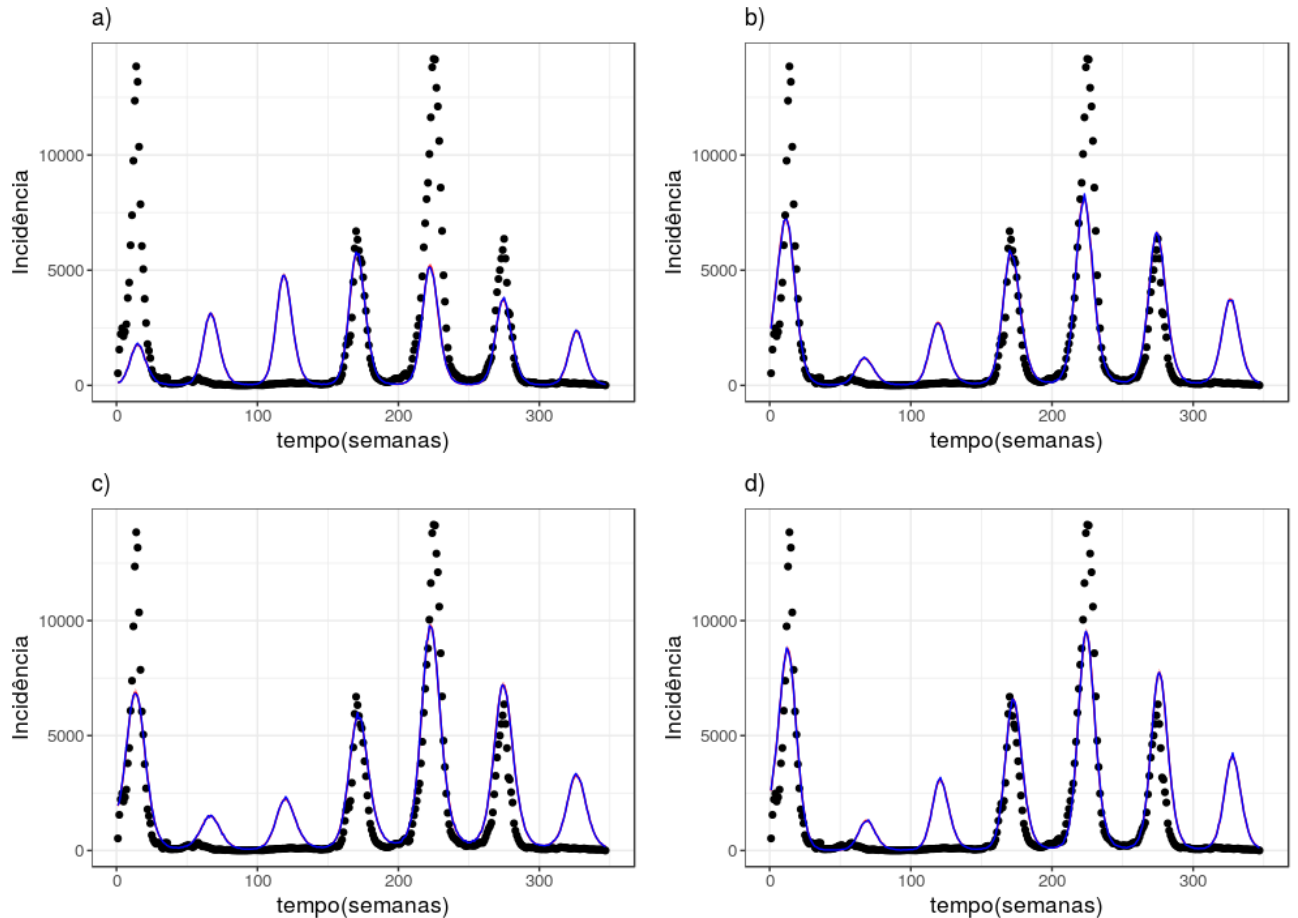

Figura B.1: Ajuste dos modelos aos dados de dengue da cidade do Rio de Janeiro. Notificações de dengue da $1^{a}$ semana de 2008 à $35^{a}$ semana 2014. Modelos: a) 1 sorotipo, b) 2 sorotipos, c) 3 sorotipos, b) 4 sorotipos. Os pontos em preto são os casos de dengue notificados por semana, a curva continua em azul representa uma estimativa amostrada dentro do intervalo de $95 \%$ de confiança.

\begin{tabular}{c|c|c|c|c}
\hline Rio de Janeiro & \multicolumn{4}{|c}{ Modelos } \\
\hline Parâmetros(semanas) & 1 Sorotipo & 2 Sorotipos & 3 Sorotipos & 4 Sorotipos \\
\hline$\beta_{1}, \Omega_{1}$ & $0.1503,8.5644$ & $0.1017,12.6948$ & $0.1233,10.4288$ & $0.5896,2.1807$ \\
$\beta_{2}, \Omega_{2}$ & - & $33.7665,0.029393$ & $1.8576,0.6112$ & $16.3570,0.05011$ \\
$\beta_{3}, \Omega_{3}$ & - & - & $0.7170,1.6432$ & $22.1898,0.04418$ \\
$\beta_{4}, \Omega_{4}$ & - & - & - & $10.5943,0.0784$ \\
$p$ & 0.9999 & 0.99 & 0.99 & 0.99 \\
$-\log$ Verossimilhança & 349567 & 227660 & 269029 & 265415 \\
\hline$\overline{R_{01}}$ & 2.4836 & 2.7325 & 2.5887 & 2.3226 \\
$\overline{R_{02}}$ & - & 2.1006 & 2.2857 & 1.5099 \\
$R_{03}$ & - & - & 2.3719 & 1.7709 \\
$R_{04}$ & - & - & - & 1.5004 \\
\hline$\alpha$ & 0.1184 & 0.09867 & 0.07991 & 0.1075058 \\
$\delta$ & 1.3501 & 1.3405 & 1.3260 & 1.163854 \\
$S(0)$ & 4818547 & 4011455 & 3883945 & 4777657 \\
$I_{1}(0)$ & 162.76 & 3.93 & 70.57 & 45.75 \\
$I_{2}(0)$ & - & 928.016 & 2443.13 & 208.09 \\
$I_{3}(0)$ & - & - & 127.35 & 12.32 \\
$I_{4}(0)$ & - & - & - & 990.09 \\
$V(0)$ & 8538718 & 9365012 & 8908773 & 7994197 \\
$V_{1}(0)$ & $5.9 \mathrm{e}-03$ & 1276.04 & $2.12 \mathrm{D}-04$ & 5.32 \\
$V_{2}(0)$ & - & 181.13 & 733.32 & 19.06 \\
$V_{3}(0)$ & - & - & 1.37 & 200.38 \\
$V_{4}(0)$ & - & - & - & 38.38 \\
\hline $\log$ Verossimilhança & 317502 & 150828 & 159415 & 155627 \\
\hline & & & & \\
\hline
\end{tabular}

Tabela B.3: Parâmetros encontrados para ajustar os casos de dengue notificados na cidade do Rio de Janeiro, da $1^{a}$ semana de 2008 à $35^{a}$ semana 2014, nos modelos de 1 a 4 sorotipos. Estimativa utilizando Minimos quadrados e verossimilhança. 


\section{B.0.4 Resultados Salvador}

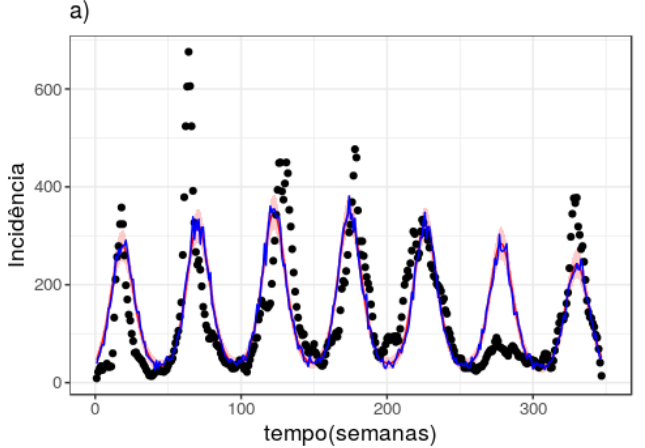

c)

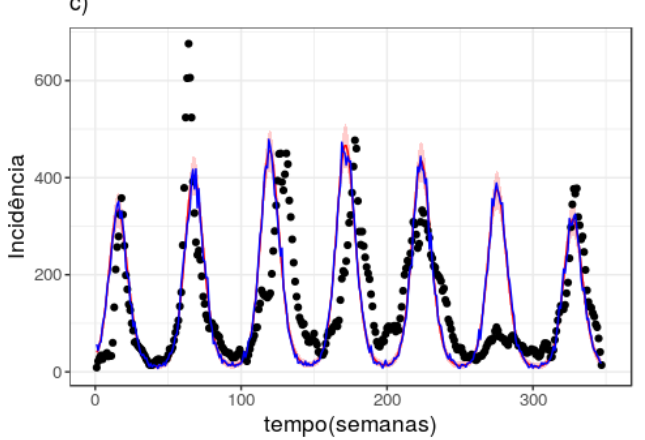

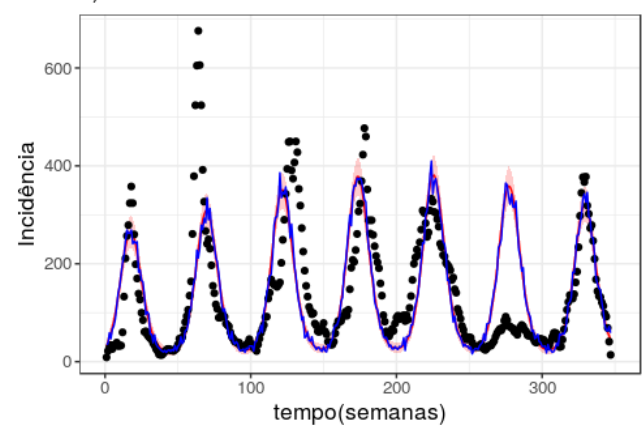

d)

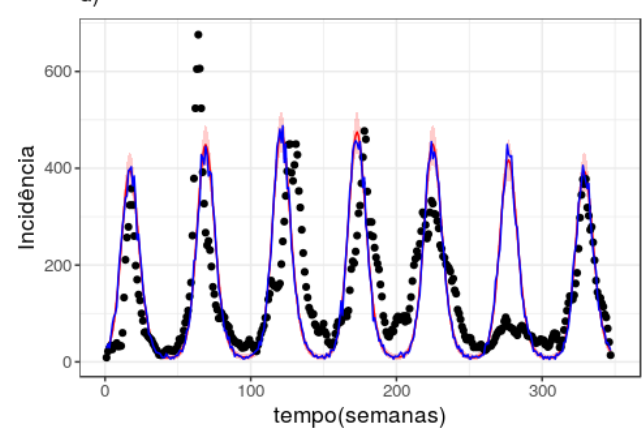

Figura B.2: Ajuste dos modelos aos dados de dengue da cidade de Salvador. Notificaçôes de dengue da $1^{a}$ semana de 2008 à $35^{a}$ semana 2014. Modelos: a) 1 sorotipo, b) 2 sorotipos, c) 3 sorotipos, b) 4 sorotipos. Os pontos em preto são os casos de dengue notificados por semana, a curva contínua em azul representa uma estimativa amostrada dentro do intervalo de $95 \%$ de confiança.

\begin{tabular}{c|c|c|c|c}
\hline Salvador & \multicolumn{4}{|c}{ Modelos } \\
\hline Parâmetros(semanas) & 1 Sorotipo & 2 Sorotipos & 3 Sorotipos & 4 Sorotipos \\
\hline$\beta_{1}, \Omega_{1}$ & $8.3263,0.1526$ & $10.890,0.1165$ & $3.8427,0.3248$ & $1.2851,0.9869$ \\
$\beta_{2}, \Omega_{2}$ & - & $1.3884,0.8979$ & $2.4763,0.5019$ & $1.0569,1.1871$ \\
$\beta_{3}, \Omega_{3}$ & - & - & $5.2051,0.2428$ & $1.5637,0.8053$ \\
$\beta_{4}, \Omega_{4}$ & - & - & - & $1.5063,0.8366$ \\
$p$ & 0.4135 & 0.41 & 0.41 & 0.41 \\
$-\log$ Verossimilhança & 14597 & 14682 & 15358 & 22980 \\
\hline$R_{01}$ & 1.9882 & 2.1628 & 2.0259 & 1.8253 \\
$R_{02}$ & - & 2.1252 & 2.0174 & 1.8057 \\
$R_{03}$ & - & - & 2.0513 & 1.8123 \\
$R_{04}$ & - & - & - & 1.8136 \\
\hline$\alpha$ & 0.05439 & 0.06692 & 0.08791 & 0.09884 \\
$\delta$ & 0.9569 & 1.0526 & 1.2744 & 1.0910 \\
$S_{(0)}$ & 1733060 & 1712434 & 2079690 & 2376785 \\
$I_{1}(0)$ & 54.89 & $2.05 \mathrm{e}-05$ & 1.99 & 0.205 \\
$I_{2}(0)$ & - & $1.93 \mathrm{e}-09$ & $8.42 \mathrm{e}-13$ & 14.80 \\
$I_{3}(0)$ & - & - & 145.46 & 46.20 \\
$I_{4}(0)$ & - & - & - & 0.0903 \\
$V(0)$ & 2931629 & 3193868 & 3041003 & 2696316 \\
$V_{1}(0)$ & 30.35 & 21.89 & $6.28 \mathrm{e}-07$ & 0.573 \\
$V_{2}(0)$ & - & $1.96 \mathrm{e}-07$ & 4.64 & 10.78 \\
$V_{3}(0)$ & - & - & 1.30 & 20.87 \\
$V_{4}(0)$ & - & - & 13900 & 0.132 \\
\hline $\log$ Verossimilhança & & & & 14796 \\
\hline
\end{tabular}

Tabela B.4: Parâmetros encontrados para ajustar os casos de dengue notificados na cidade de Salvador, da $1^{a}$ semana de 2008 à $35^{a}$ semana 2014, nos modelos de 1 a 4 sorotipos. Estimativa utilizando Minimos quadrados e verossimilhança. 


\section{B.0.5 Projeções e vacinação para Rio de Janeiro}

As projeções dos modelos com os parâmetros estimados dos dados do Rio de Janeiro, mostram que nenhum modelo conseguiu estimar surtos anuais, sendo que o modelo que melhor estimou coexistência foi o com 3 sorotipos. Concluímos que estes resultados se devem ao fato da série de dados ter um período de dois anos consecutivos sem notificações, sendo que teve na sequência três anos com surtos, e assim só foi possível estimar três taxas de transmissão diferentes. Portanto, o cenário de simulação de vacinação, não apresenta resultados significativos. A vacina neste caso é aplicada na semana 348. A Tabela B.5 contém os valores dos $\psi$ 's em função da quantidade de suscetíveis na semana 348 .

\begin{tabular}{|c|c|c|c|c|c|c|c|c|c|}
\hline \multicolumn{10}{|c|}{$\psi$ calculado para população do Rio de Janeiro } \\
\hline Cidade & pop. Total & $\begin{array}{l}R_{0} \\
\text { menor }\end{array}$ & $\begin{array}{l}\text { Pop } \mathrm{S}(348)- \\
R_{0} \text { menor }\end{array}$ & $\begin{array}{l}R_{0} \\
\text { maior }\end{array}$ & $\begin{array}{l}\text { pop } \mathrm{S}(348)- \\
R_{0} \text { maior }\end{array}$ & $\begin{array}{l}R_{0_{\text {efetivo }}} \\
\text { menor }\end{array}$ & $\begin{array}{l}R_{0_{\text {efetivo }}} \\
\text { maior }\end{array}$ & $\begin{array}{l}\psi R_{0}- \\
\text { menor }\end{array}$ & $\begin{array}{l}R_{0} \\
\text { - maior }\end{array}$ \\
\hline Rio de Janeiro & 6320446 & 1.50 & 4285413.822 & 2.73 & 3657951.311 & 1.02 & 1.58 & 0.02 & 0.46 \\
\hline
\end{tabular}

Tabela B.5: Proporção $\psi$ a ser vacinada aleatoriamente na população do Rio de Janeiro. Consideramos uma vacina com $80 \%$ de eficácia contra cada sorotipo da dengue e obtemos um $\psi$ menor e maior, respectivamente

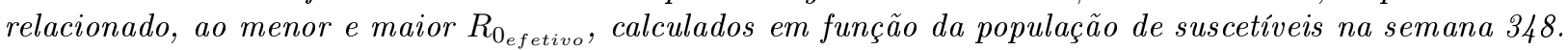
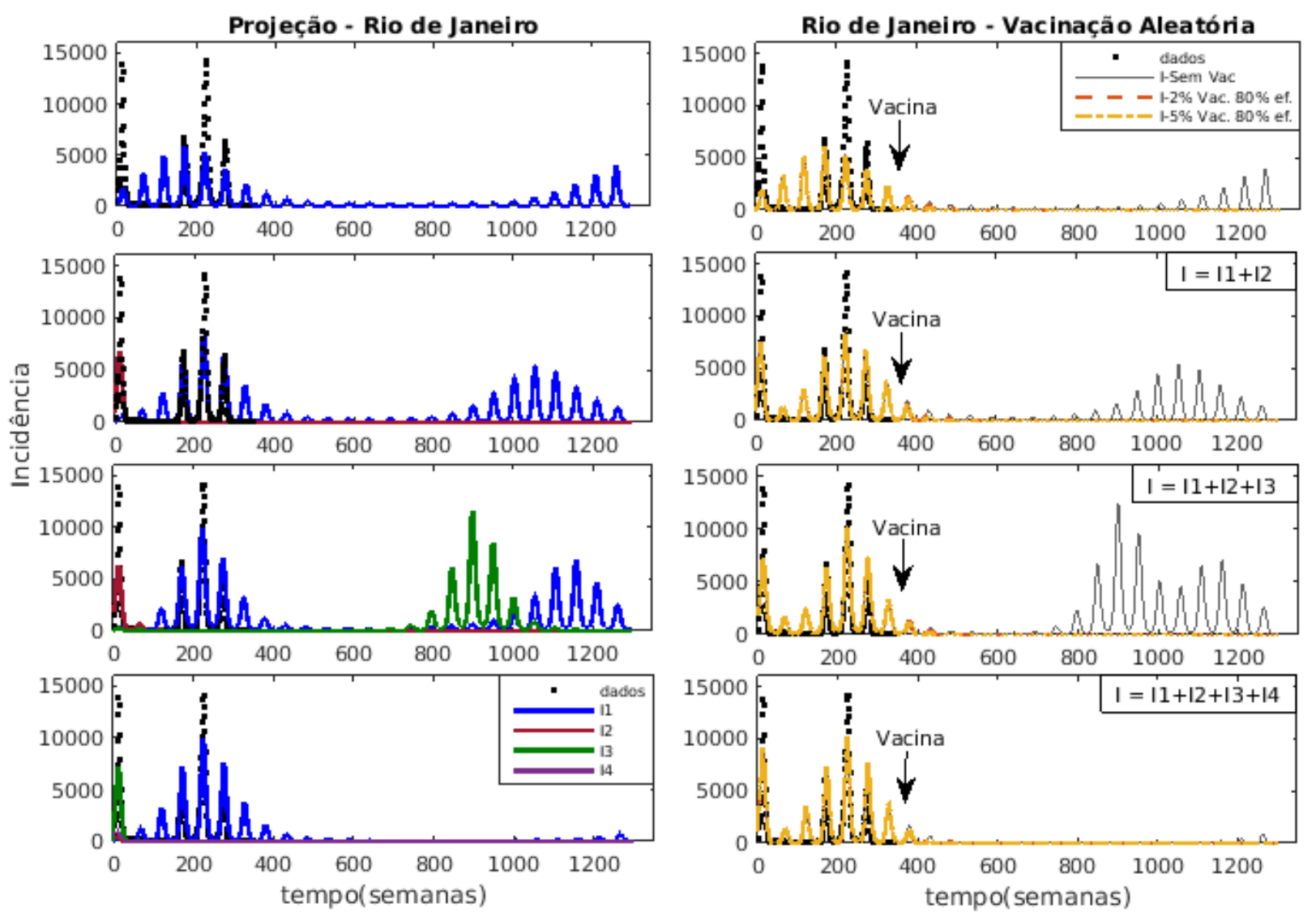

Figura B.3: Projeção dos modelos e simulação de vacinação aleatória na população com os parâmetros estimados dos dados de incidência de dengue do Rio de Janeiro. As soluções foram plotadas com os parâmetros dados na Tabela $B .3$ para um periodo de 25 anos $=1300$ semanas, em que as primeiras 347 semanas contém os dados. Nas figuras da esquerda tem-se os ajustes projetados para os modelos $n \times S I R V V_{i}, n=1,2,3,4$. As figuras da direita contêm o resultado de aplicar uma vacina que fornece $80 \%$ de eficácia contra cada sorotipo. A vacina é implementada na semana 348, sendo aplicada em 2\% (curva laranjada' $--^{\prime}$ ) e $5 \%$ (curva amarela ${ }^{\prime}-.^{\prime}$ ) dos suscetiveis por ano, tal que a curva I contém a soma de todos os infectados. 


\section{B.0.6 Projeções e vacinação para Salvador}

Para os dados de Salvador, a estimação de parâmetros obteve resultados bons para todos os modelos, sendo possível observar na Figura B.4 que até mesmo o modelo com 1 sorotipo, obteve surtos anuais, isto se deve ao fato que a série de dados apresenta uma característica interessante com surto em todos os anos do período, variando apenas em intensidade. Todos os modelos com dinâmica de múltiplos sorotipos, foram capazes de estimar a coexistência de sorotipos em um mesmo surto e a variação destes ao longo dos anos. Os cenários de vacinação, sugerem neste caso que a infecção seria eliminada em torno de 5 anos após vacinação contínua entre $2 \%$ e $5 \%$ da população. A Tabela B.6 contém os valores dos $\psi$ 's em função da quantidade de suscetíveis na semana 348 .

\begin{tabular}{|c|c|c|l|l|l|l|c|c|c|}
\hline \multicolumn{10}{|c|}{$\psi$ calculado para população de Salvador } \\
\hline Cidade & pop. Total & $\begin{array}{l}R_{0} \\
\text { menor }\end{array}$ & $\begin{array}{l}\text { Pop S(348) } \\
R_{0} \text { menor }\end{array}$ & $\begin{array}{l}R_{0} \\
\text { maior }\end{array}$ & $\begin{array}{l}\text { pop S(348) } \\
R_{0} \text { maior }\end{array}$ & $\begin{array}{l}R_{0_{\text {efetivo }}} \\
\text { menor }\end{array}$ & $\begin{array}{l}R_{0_{\text {efetivo }}} \\
\text { maior }\end{array}$ & $\begin{array}{l}\psi R_{0}- \\
\text { menor }\end{array}$ & $\begin{array}{l}\psi R_{0} \\
- \text { maior }\end{array}$ \\
\hline Salvador & 2675656 & 1.81 & 2278405.211 & 2.16 & 1681856.351 & 1.54 & 1.36 & 0.44 & 0.33 \\
\hline
\end{tabular}

Tabela B.6: Proporção $\psi$ a ser vacinada aleatoriamente na população de Salvador. Consideramos uma vacina com $80 \%$ de eficácia contra cada sorotipo da dengue e obtemos um $\psi$ menor e maior, respectivamente relacionado, ao menor e maior $R_{0_{\text {efetivo }}}$, calculados em função da população de suscetíveis na semana 348.
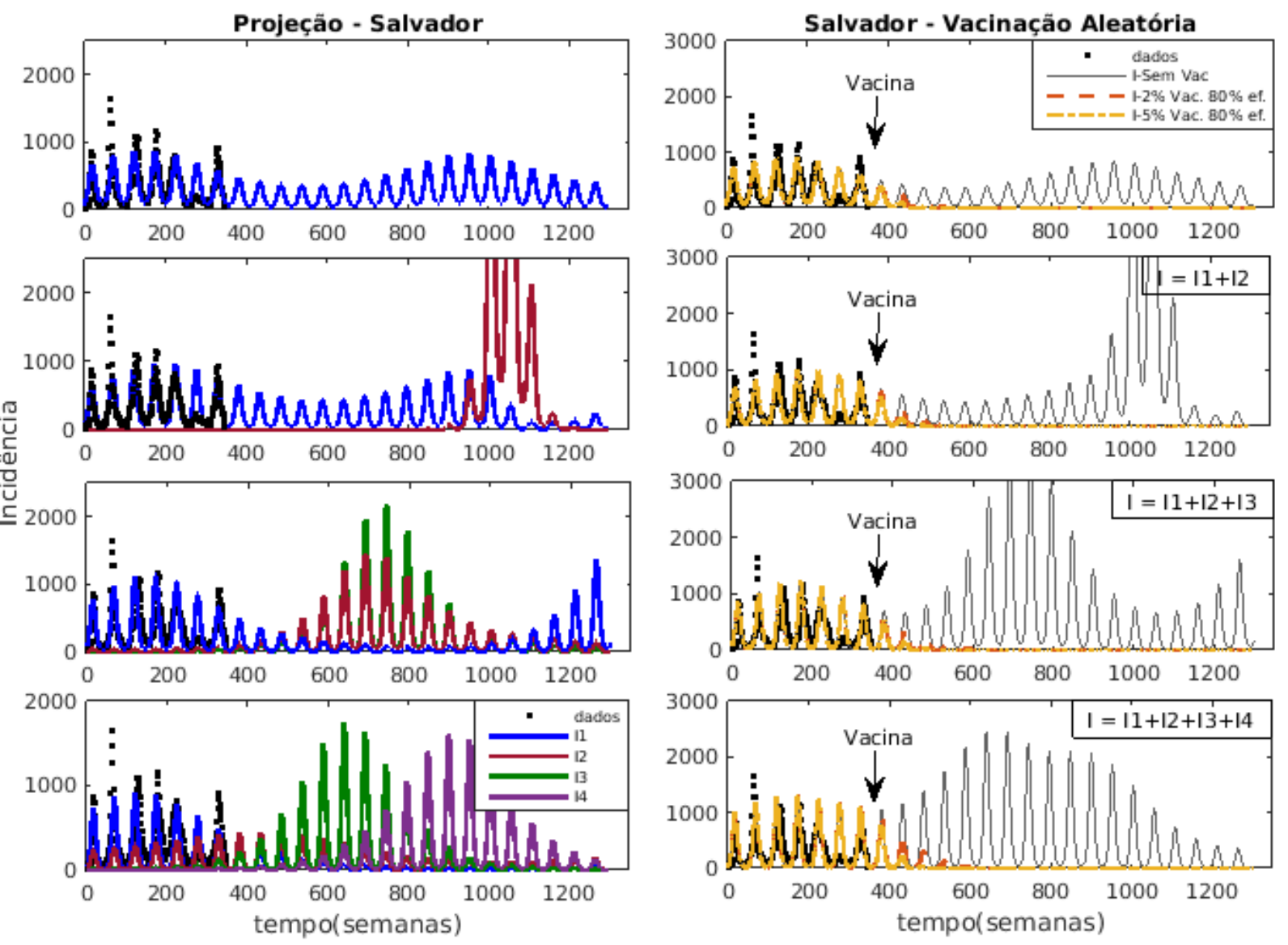

Figura B.4: Projeção dos modelos e simulação de vacinação aleatória na população com os parâmetros estimados dos dados de incidência de dengue de Salvador. As soluções foram plotadas com os parâmetros dados na Tabela B.4 para um período de 25 anos $=1300$ semanas, em que as primeiras 347 semanas contém os dados. Nas figuras da esquerda tem-se os ajustes projetados para os modelos $n \times S I R V V_{i}, n=1,2,3,4$. As figuras da direita contêm o resultado de aplicar uma vacina que fornece $80 \%$ de eficácia contra cada sorotipo. A vacina é implementada na semana 348, sendo aplicada em $2 \%$ (curva laranjada' $--^{\prime}$ ) e $5 \%$ (curva amarela' ${ }^{\prime} .-^{\prime}$ ) dos suscetiveis por ano, tal que a curva I contém a soma de todos os infectados. 
APÊNDICE B 


\section{Referências Bibliográficas}

Adams et al.(2006) B. Adams, E. C. Holmes, C. Zhang, M. P. Mammen, S. Nimmannitya, S. Kalayanarooj e M. Boots. Cross-protective immunity can account for the alternating epidemic pattern of dengue virus serotypes circulating in Bangkok. Proceedings of the National Academy of Sciences, 103(38):14234-14239. Citado na pág. xviii, xxi, 23

Águas et al.(2008) R. Águas, L. J. White, R. W. Snow e M. G. M. Gomes. Prospects for malaria eradication in sub-Saharan Africa. PloS one, 3(3):e1767. Citado na pág. xx, 40

Aguiar e Stollenwerk(2017) M. Aguiar e N. Stollenwerk. Mathematical models of dengue fever epidemiology: multi-strain dynamics, immunological aspects associated to disease severity and vaccines. Communication in Biomathematical Sciences, 1(1):1-12. Citado na pág. xxii, 19, 23

Aguiar et al.(2011) M. Aguiar, S. Ballesteros, B. W. Kooi e N. Stollenwerk. The role of seasonality and import in a minimalistic multi-strain dengue model capturing differences between primary and secondary infections: complex dynamics and its implications for data analysis. Journal of theoretical biology, 289:181-196. Citado na pág. xxi, xxii, 19, 23, 27, 45, 52

Aguiar et al.(2013) M. Aguiar, B. W. Kooi, F. Rocha, P. Ghaffari e N. Stollenwerk. How much complexity is needed to describe the fluctuations observed in dengue hemorrhagic fever incidence data? Ecological Complexity, 16:31-40. Citado na pág. xxii, 19

Aguiar et al.(2016) M. Aguiar, N. Stollenwerk e S. B. Halstead. The impact of the newly licensed dengue vaccine in endemic countries. PLoS neglected tropical diseases, 10(12):e0005179. Citado na pág. xxi, xxii, 19, 23, 27, 30

Allen et al.(2008) L. J. S. Allen, F. Brauer, P. van den Driessche e J. Wu. Mathematical epidemiology, volume 1945. Springer. Citado na pág. 22, 34, 36, 83, 88, 89, 90

Amaku et al.(2014) M. Amaku, F. A. B. Coutinho, S. M. Raimundo, L. F. Lopez, M. N. Burattini e E. Massad. A comparative analysis of the relative efficacy of vector-control strategies against dengue fever. Bulletin of mathematical biology, 76(3):697-717. Citado na pág. xx, 83, 85

Amaku et al.(2016) M. Amaku, F. Azevedo, M. N. Burattini, G. E. Coelho, F. A. B. Coutinho, D. Greenhalgh, L. F. Lopez, R. S. Motitsuki, A. Wilder-Smith e E. Massad. Magnitude and frequency variations of vector-borne infection outbreaks using the Ross-Macdonald model: explaining and predicting outbreaks of dengue fever. Epidemiology $\mathcal{E}$ Infection, 144(16):3435-3450. Citado na pág. xx, 1, 18, 19, 22

Anderson et al.(1999) E. Anderson, Z. Bai, C. Bischof, S. Blackford, J. Demmel, J. Dongarra, J. Du Croz, A. Greenbaum, S. Hammarling, A. McKenney e D. Sorensen. LAPACK Users' Guide. Society for Industrial and Applied Mathematics, Philadelphia PA, third edição. Citado na pág. 47

Anderson e May(1985) R. M. Anderson e R. M. May. Age-related changes in the rate of disease transmission: implications for the design of vaccination programmes. Epidemiology 63 Infection, 94(3):365-436. Citado na pág. xx, 27, 33, 86 
Anderson et al.(1992) R. M. Anderson, R. M. May e B. Anderson. Infectious diseases of humans: dynamics and control, volume 28. Wiley Online Library. Citado na pág. xix, xx, 22, 83, 88

Anderson(1982) Roy M. Anderson. Directly transmitted viral and bacterial infections of man. Em Population dynamics of infectious diseases: theory and applications. Chapman and Hall. Citado na pág. xix, $\mathrm{xx}, 52,83$

Anderson e May(1982) Roy M. Anderson e Robert M. May. Directly transmitted infections diseases: control by vaccination. Science, 215(4536):1053-1060. Citado na pág. xx, 27, 33, 86

Andraud et al.(2012) M. Andraud, N. Hens, C. Marais e P. Beutels. Dynamic epidemiological models for dengue transmission: a systematic review of structural approaches. PloS one, 7(11): e49085. Citado na pág. xx, 22, 52

Barmak et al.(2011) D. H. Barmak, C. O. Dorso, M. Otero e H. G. Solari. Dengue epidemics and human mobility. Physical Review E, 84(1):011901. Citado na pág. xx, 18

Bhatt et al.(2013) S. Bhatt, P. W. Gething, O. J. Brady, J. P. Messina, A. W. Farlow, C. L. Moyes, J. M. Drake, J. S. Brownstein, A. G. Hoen, O. Sankoh et al. The global distribution and burden of dengue. Nature, 496(7446):504. Citado na pág. xvii, xviii, 43

Billings et al.(2007) L. Billings, I. B. Schwartz, L. B. Shaw, M. McCrary, D. S. Burke e D. A. T. Cummings. Instabilities in multiserotype disease models with antibody-dependent enhancement. Journal of theoretical biology, 246(1):18-27. Citado na pág. xxi, 23, 34, 38

Billings et al.(2008) L. Billings, A. Fiorillo e I. B. Schwartz. Vaccinations in disease models with antibody-dependent enhancement. Mathematical biosciences, 211(2):265-281. Citado na pág. xxi, $27,34,38,86$

Bliman et al.(2015) P. A. Bliman, M. S. Aronna, F. C. Coelho e M. A. H. B. Da Silva. Ensuring successful introduction of wolbachia in natural populations of Aedes aegypti by means of feedback control. Journal of mathematical biology, páginas 1-32. Citado na pág. xviii, xx

Boccia et al.(2014) T. M. Q. R. Boccia, M. N. Burattini, F. A. B. Coutinho e E. Massad. Will people change their vector-control practices in the presence of an imperfect dengue vaccine? Epidemiology and infection, 142(03):625-633. Citado na pág. xviii, xxi, 52, 85

Brauer e Castillo-Chavez(2001) F. Brauer e C. Castillo-Chavez. Mathematical models in population biology and epidemiology, volume 40. Springer. Citado na pág. xix, $\mathrm{xx}, 1,18,22,39,83,86$, 88

Burattini et al.(2008) M. N. Burattini, M. Chen, A. Chow, F. A. B. Coutinho, K. T. Goh, L. F. Lopez, S. Ma e E. Massad. Modelling the control strategies against dengue in Singapore. Epidemiology E3 Infection, 136(3):309-319. Citado na pág. xx, 85

Casella e Berger(2002) G. Casella e R. L. Berger. Statistical inference, volume 2. Duxbury Pacific Grove, CA. Citado na pág. 12, 40, 41, 42

Cauchemez e Ferguson(2008) S. Cauchemez e N. M. Ferguson. Likelihood-based estimation of continuous-time epidemic models from time-series data: application to measles transmission in London. Journal of the Royal Society Interface, 5(25):885-897. Citado na pág. 40, 85

Chikaki e Ishikawa(2009) E. Chikaki e H. Ishikawa. A dengue transmission model in Thailand considering sequential infections with all four serotypes. The Journal of Infection in Developing Countries, 3(09):711-722. Citado na pág. xxi, xxii, 19

Clayton et al.(1993) D. Clayton, M. Hills e A. Pickles. Statistical models in epidemiology, volume 161. Oxford university press Oxford. Citado na pág. 40, 41 
Coelho e Carvalho(2015) F. C. Coelho e L. Max De Carvalho. Estimating the attack ratio of dengue epidemics under time-varying force of infection using aggregated notification data. Scientific reports, 5:18455. Citado na pág. 1, 6, 40

Coelho et al.(2011) F. C. Coelho, C. T. Codeço e M. G. M. Gomes. A Bayesian framework for parameter estimation in dynamical models. PloS one, 6(5):e19616. Citado na pág. 1, 40, 85

Coudeville e Garnett(2012) L. Coudeville e G. P. Garnett. Transmission dynamics of the four dengue serotypes in Southern Vietnam and the potential impact of vaccination. PloS one, 7(12): e51244. Citado na pág. xxi, xxii, 19

Cummings et al.(2005) D. A. T. Cummings, I. B. Schwartz, L. Billings, L. B. Shaw e D. S. Burke. Dynamic effects of antibody-dependent enhancement on the fitness of viruses. Proceedings of the National Academy of Sciences of the United States of America, 102(42):15259-15264. Citado na pág. xviii, xxi

de Castro Medeiros et al.(2011) L. C. de Castro Medeiros, C. A. R. Castilho, C. Braga, W. V. de Souza, L. Regis e A. M. V. Monteiro. Modeling the dynamic transmission of dengue fever: investigating disease persistence. PLOS neglected tropical diseases, 5(1):e942. Citado na pág. $\mathrm{xx}, 18$

de Moura Rodrigues et al.(2015) M. de Moura Rodrigues, G. R. A. M. Marques, L. L. N. Serpa, M. de Brito Arduino, J. C. Voltolini, G. L. Barbosa, V. R. Andrade e de V. L. C. Lima. Density of Aedes aegypti and Aedes albopictus and its association with number of residents and meteorological variables in the home environment of dengue endemic area, São Paulo, Brazil. Parasites $\mathfrak{E}$ vectors, 8(1):115. Citado na pág. xvii, $\mathrm{xx}, 85$

de Valdez et al.(2011) M. R. Wise de Valdez, D. Nimmo, J. Betz, Hong-Fei Gong, A. A. James, L. Alphey e W. C. Black. Genetic elimination of dengue vector mosquitoes. Proceedings of the National Academy of Sciences, 108(12):4772-4775. Citado na pág. xviii, xx, 85

Dejnirattisai et al.(2016) W. Dejnirattisai, P. Supasa, W. Wongwiwat, A. Rouvinski, G. BarbaSpaeth, T. Duangchinda, A. Sakuntabhai, Van-M. Cao-Lormeau, P. Malasit, F. A. Rey et al. Dengue virus sero-cross-reactivity drives antibody-dependent enhancement of infection with zika virus. Nature immunology, 17(9):1102. Citado na pág. xvii, xxi, 85

Derouich et al.(2003) M. Derouich, A. Boutayeb e E. H. Twizell. A model of dengue fever. BioMedical Engineering OnLine, 2(1):4. Citado na pág. 22, 36, 85

Diekmann et al.(1990) O. Diekmann, J. A. P. Heesterbeek e J. A. J. Metz. On the definition and the computation of the basic reproduction ratio $\mathrm{r} 0$ in models for infectious diseases in heterogeneous populations. Journal of mathematical biology, 28(4):365-382. Citado na pág. 33, 34, 89

Diekmann et al.(2009) O. Diekmann, J. A. P. Heesterbeek e M. G. Roberts. The construction of next-generation matrices for compartmental epidemic models. Journal of the Royal Society Interface, página rsif20090386. Citado na pág. 83, 88, 89, 91, 92

d'Onofrio(2002) Alberto d'Onofrio. Stability properties of pulse vaccination strategy in SEIR epidemic model. Mathematical biosciences, 179(1):57-72. Citado na pág. xx, 86

dos Santos et al.(2018) B. C. dos Santos, L. M. Sartori, C. Peixoto, J. S. Bevilacqua e S. M. Oliva. Prospective study about the influence of human mobility in dengue transmission in the state of Rio de Janeiro. Em Modeling, Dynamics, Optimization and Bioeconomics III: DGS IV, Madrid, Spain, June 2016, and Bioeconomy VIII, Berkeley, USA, April 2015-Selected Contributions IV, páginas 419-427. Springer. Citado na pág. xx, 1, 18

Esteva e Vargas(1998) L. Esteva e C. Vargas. Analysis of a dengue disease transmission model. Mathematical biosciences, 150(2):131-151. Citado na pág. xxii, 22, 27, 36, 38, 39, 40 
Esteva e Vargas(1999) L. Esteva e C. Vargas. A model for dengue disease with variable human population. Journal of mathematical biology, 38(3):220-240. Citado na pág. 22, 36, 38, 85, 86

Esteva e Vargas(2003) L. Esteva e C. Vargas. Coexistence of different serotypes of dengue virus. Journal of Mathematical Biology, 46(1):31-47. Citado na pág. xxi, 19, 27, 36, 38

Fares et al.(2015) R. C. G. Fares, K. P. R. Souza, G. Añez e M. Rios. Epidemiological scenario of dengue in Brazil. BioMed research international, 2015. Citado na pág. xviii, 1

Ferguson et al.(1999a) N. Ferguson, R. Anderson e S. Gupta. The effect of antibody-dependent enhancement on the transmission dynamics and persistence of multiple-strain pathogens. Proceedings of the National Academy of Sciences, 96(2):790-794. Citado na pág. xviii, xxi

Ferguson et al.(1999b) N. M. Ferguson, C. A. Donnelly e R. M. Anderson. Transmission dynamics and epidemiology of dengue: insights from age-stratified sero-prevalence surveys. Philosophical Transactions of the Royal Society of London B: Biological Sciences, 354(1384):757-768. Citado na pág. xxi, $33,85,88$

Ferguson et al.(2016) N. M. Ferguson, I. Rodríguez-Barraquer, I. Dorigatti, L. Mier y TeranRomero, D. J. Laydon e D. A. T. Cummings. Benefits and risks of the Sanofi-Pasteur dengue vaccine: Modeling optimal deployment. Science, 353(6303):1033-1036. Citado na pág. xix, xxi, 1, 15,27

Fried et al.(2010) J. R. Fried, R. V. Gibbons, S. Kalayanarooj, S. J. Thomas, A. Srikiatkhachorn, In-Kyu Yoon, R. G. Jarman, S. Green, A. L. Rothman e D. A. T. Cummings. Serotype-specific differences in the risk of dengue hemorrhagic fever: an analysis of data collected in Bangkok, Thailand from 1994 to 2006. PLoS neglected tropical diseases, 4(3):e617. Citado na pág. xviii, xxi

Gibbons et al.(2007) R. V. Gibbons, S. Kalanarooj, R. G. Jarman, A. Nisalak, D. W. Vaughn, T. P. Endy, M. P. Mammen Jr e A. Srikiatkhachorn. Analysis of repeat hospital admissions for dengue to estimate the frequency of third or fourth dengue infections resulting in admissions and dengue hemorrhagic fever, and serotype sequences. The American journal of tropical medicine and hygiene, 77(5):910-913. Citado na pág. xviii, 1

Gjini et al.(2016) E. Gjini, C. Valente, R. Sa-Leao e M. G. M. Gomes. How direct competition shapes coexistence and vaccine effects in multi-strain pathogen systems. Journal of theoretical biology, 388:50-60. Citado na pág. xviii, xxi, 40

Gomes et al.(2004) M. G. M. Gomes, L. J. White e G. F. Medley. Infection, reinfection, and vaccination under suboptimal immune protection: epidemiological perspectives. Journal of Theoretical Biology, 228(4):539-549. Citado na pág. xxi, 27, 86

Gomes et al.(2014) M. G. M. Gomes, M. Lipsitch, A. R. Wargo, G. Kurath, C. Rebelo, G. F. Medley e A. Coutinho. A missing dimension in measures of vaccination impacts. PLoS pathogens, 10(3):e1003849. Citado na pág. xxi, 27, 86

Gubler et al.(2014) D. J. Gubler, E. E. Ooi, S. Vasudevan e J. Farrar. Dengue and dengue hemorrhagic fever. CABI. Citado na pág. xvii, xviii, 27

Gumel e Lenhart(2010) A. B. Gumel e S. Lenhart. Modeling paradigms and analysis of disease transmission models, volume 75. American Mathematical Soc. Citado na pág. xx, 33, 83, 88

Hartley et al.(2002) L. M. Hartley, C. A. Donnelly e G. P. Garnett. The seasonal pattern of dengue in endemic areas: mathematical models of mechanisms. Transactions of the royal society of tropical medicine and hygiene, 96(4):387-397. Citado na pág. xxi, 27, 45 
He et al.(2009) D. He, E. L. Ionides e A. A. King. Plug-and-play inference for disease dynamics: measles in large and small populations as a case study. Journal of the Royal Society Interface. Citado na pág. 40,85

Heesterbeek e Dietz(1996) J. A. P. Heesterbeek e K. Dietz. The concept of ro in epidemic theory. Statistica Neerlandica, 50(1):89-110. Citado na pág. 33, 83, 89

Heffernan et al.(2005) J. M. Heffernan, R. J. Smith e L. M. Wahl. Perspectives on the basic reproductive ratio. Journal of the Royal Society Interface, 2(4):281-293. Citado na pág. 33, 88

Hethcote(1976) Herbert W. Hethcote. Qualitative analyses of communicable disease models. Mathematical Biosciences, 28(3):335-356. Citado na pág. 39, 83, 85, 86

Hethcote(2000) Herbert W. Hethcote. The mathematics of infectious diseases. SIAM review, 42 (4):599-653. Citado na pág. xvii, $\mathrm{xx}, 85,86,88,89$

IBGE(2017) IBGE. Instituto Brasileiro de Geografia e Estatística, sinopse do censo demográfico, 2010. https://censo2010.ibge.gov.br/sinopse/index.php?dados=8, 2017. Último acesso em 09/10/2017. Citado na pág. $1,2,3,4,52,53,93$

Kao e Eisenberg(2017) Yu-Han Kao e M. C. Eisenberg. Practical unidentifiability of a simple vector-borne disease model: implications for parameter estimation and intervention assessment. bioRxiv, página 164079. Citado na pág. xxi, 40, 85

Keeling e Rohani(2008) M. J. Keeling e P. Rohani. Modeling infectious diseases in humans and animals. Princeton University Press. Citado na pág. xvii, xix, xx, 22, 23, 27, 34, 40, 52, 83, 84, 85, $86,88,91,92$

Kermack e McKendrick(1927) W. O. Kermack e A. G. McKendrick. A contribution to the mathematical theory of epidemics. Part I. Em Proceedings of the Royal Society of London A: Mathematical, Physical and Engineering Sciences, volume 115, páginas 700-721. The Royal Society. Citado na pág. xx, $22,83,84,85,88$

King et al.(2016) A. A. King, D. Nguyen e E. L. Ionides. Statistical inference for partially observed Markov processes via the R package pomp. Journal of Statistical Software, 69(12):1-43. doi: $10.18637 /$ jss.v069.i12. Citado na pág. xxii, 19, 40, 42, 45

King et al.(2017) A. A. King, E. L. Ionides, C. M. Bretó, S. P. Ellner, M. J. Ferrari, B. E. Kendall, M. Lavine, D. Nguyen, D. C. Reuman, H. Wearing e S. N. Wood. pomp: Statistical Inference for Partially Observed Markov Processes, 2017. URL http://kingaa.github.io/pomp. R package, version 1.12. Citado na pág. xxii, $19,40,42,45$

King et al.(2018) J. G. King, C. Souto-Maior, L. M. Sartori, R. Maciel de Freitas e M. G. M. Gomes. Variation in wolbachia effects on aedes mosquitoes as a determinant of invasiveness and vectorial capacity. Nature Communications, 9(1). Citado na pág. xviii, xx

Kooi et al.(2014) B. W. Kooi, M. Aguiar e N. Stollenwerk. Analysis of an asymmetric two-strain dengue model. Mathematical biosciences, 248:128-139. Citado na pág. xxi, 19, 23, 38, 40

Krämer et al.(2010) A. Krämer, M. Kretzschmar e K. Krickeberg. Modern Infectious Disease Epidemiology. Statistics for Biology and Health. Springer New York. Citado na pág. xvii, xix, xx, $1,18,22,23,27,33,83,85,86,88$

Li et al.(2011) Jing Li, D. Blakeley e R. J. Smith. The failure of $\mathrm{R}_{0}$. Computational and mathematical methods in medicine, 2011. Citado na pág. 33, 83

Liu et al.(2008) X. Liu, Y. Takeuchi e S. Iwami. SVIR epidemic models with vaccination strategies. Journal of Theoretical Biology, 253(1):1-11. Citado na pág. xxi, 27, 86 
Liu-Helmersson et al.(2016) J. Liu-Helmersson, M. Quam, A. Wilder-Smith, H. Stenlund, K. Ebi, E. Massad e J. Rocklöv. Climate change and Aedes vectors: 21st century projections for dengue transmission in Europe. EBioMedicine, 7:267-277. Citado na pág. xvii, xx, 18

Ma e Xia(2009) S. Ma e Y. Xia. Mathematical understanding of infectious disease dynamics, volume 16. World Scientific. Citado na pág. xvii, 83, 88

Maier et al.(2017) S. B. Maier, X. Huang, E. Massad, M. Amaku, M. N. Burattini e D. Greenhalgh. Analysis of the optimal vaccination age for dengue in brazil with a tetravalent dengue vaccine. Mathematical biosciences, 294:15-32. Citado na pág. xxi, 27, 86

Martcheva(2015) Maia Martcheva. An introduction to mathematical epidemiology, volume 61. Springer. Citado na pág. xvii, xxi, 22, $83,86,88$

Massad et al.(1994) E. Massad, M. N. Burattini, R. S. De A. Neto, Hyun Mo Yang, F. A. B. Coutinho e D. M. T. Zanetta. A model-based design of a vaccination strategy against rubella in a non-immunized community of São Paulo state, Brazil. Epidemiology $\mathscr{E}$ Infection, 112(3): 579-594. Citado na pág. xxi, 27, 86

Massad et al.(2008) E. Massad, S. Ma, M. Chen, C. J. Struchiner, N. Stollenwerk e M. Aguiar. Scale-free network of a dengue epidemic. Applied Mathematics and Computation, 195(2):376-381. Citado na pág. xx, 18

Ministério da Saúde(2016) Ministério da Saúde. Dengue: Diagnóstico e Manejo clínico - Adulto e criança. MINISTÉRIO DA SAÚDE, 2016. Citado na pág. xviii, 1, 4, 8

Ministério da Saúde/SVS(2017) Ministério da Saúde/SVS. DATASUS - Sistema de Informação de Agravos de Notificação - Sinan Net. http://tabnet.datasus.gov.br/cgi/deftohtm.exe?idb2012/ d0203.def, 2017. Último acesso em 02/11/2017. Citado na pág. 1, 4

Nagao e Koelle(2008) Y. Nagao e K. Koelle. Decreases in dengue transmission may act to increase the incidence of dengue hemorrhagic fever. Proceedings of the National Academy of Sciences, 105 (6):2238-2243. Citado na pág. xvii, xviii, xxi

Nisalak et al.(2003) A. Nisalak, T. P. Endy, S. Nimmannitya, S. Kalayanarooj, U. Thisayakorn, R. M. Scott, D. S. Burke, C. H. Hoke, B. L. Innis e D. W. Vaughn. Serotype-specific dengue virus circulation and dengue disease in Bangkok, Thailand from 1973 to 1999. The American journal of tropical medicine and hygiene, 68(2):191-202. Citado na pág. xvii, xxi

Nunes et al.(2015) M. R. T. Nunes, N. R. Faria, J. M. de Vasconcelos, N. Golding, M. U. G. Kraemer, L. F. de Oliveira, R. do S. da Silva Azevedo, D. E. A. da Silva, E. V. P. da Silva, S. P. da Silva et al. Emergence and potential for spread of chikungunya virus in brazil. BMC medicine, 13(1):102. Citado na pág. xvii, xx

Precioso et al.(2015) A. R. Precioso, R. Palacios, B. Thomé, G. Mondini, P. Braga e J. Kalil. Clinical evaluation strategies for a live attenuated tetravalent dengue vaccine. Vaccine, 33(50): 7121-7125. Citado na pág. xviii, xix, xxi, xxii, 1, 6, 15, 19, 27, 69

Recker et al.(2009) M. Recker, K. B. Blyuss, C. P. Simmons, T. Tinh Hien, B. Wills, J. Farrar e S. Gupta. Immunological serotype interactions and their effect on the epidemiological pattern of dengue. Proceedings of the Royal Society of London B: Biological Sciences, páginas rspb-2009. Citado na pág. xviii, xxi

Reich et al.(2013) N. G. Reich, S. Shrestha, A. A. King, P. Rohani, J. Lessler, S. Kalayanarooj, In-Kyu Yoon, R. V. Gibbons, D. S. Burke e D. A. T. Cummings. Interactions between serotypes of dengue highlight epidemiological impact of cross-immunity. Journal of The Royal Society Interface, 10(86):20130414. Citado na pág. xxi, 19, 23 
Rodrigues et al.(2012) H. S. Rodrigues, M. T. T. Monteiro, D. F. M. Torres e A. Zinober. Dengue disease, basic reproduction number and control. International Journal of Computer Mathematics, 89(3):334-346. Citado na pág. xx, 23, 27, 85, 92

Rodrigues et al.(2013) H. S. Rodrigues, M. T. T. Monteiro e D. F. M. Torres. Dengue in Cape Verde: vector control and vaccination. Mathematical Population Studies, 20(4):208-223. Citado na pág. $\mathrm{xx}, 27,52,86$

Rodrigues et al.(2014) H. S. Rodrigues, M. T. T. Monteiro e D. F. M. Torres. Vaccination models and optimal control strategies to dengue. Mathematical biosciences, 247:1-12. Citado na pág. xxi, 27,86

Rodriguez-Barraquer et al.(2011) I. Rodriguez-Barraquer, M. T. Cordeiro, C. Braga, W. V. de Souza, E. T. Marques e D. A. T. Cummings. From re-emergence to hyperendemicity: the natural history of the dengue epidemic in Brazil. PLoS neglected tropical diseases, 5(1):e935. Citado na pág. xviii, $\mathrm{xx}$

Ross(1911) Ronald Ross. The prevention of malaria. John Murray; London. Citado na pág. xvii, xix

Sanches e Massad(2016) R. P. Sanches e E. Massad. A comparative analysis of three different methods for the estimation of the basic reproduction number of dengue. Infectious Disease Modelling, 1(1):88-100. Citado na pág. 33, 83, 88

Sartori(2014) Larissa M. Sartori. Métodos para resolução de EDOs stiff resultantes de modelos químicos atmosféricos. Dissertação de Mestrado, Instituto de Matemática e Estatística, Universidade de São Paulo, Brasil. Citado na pág. xxii, 40, 45

Scherer e McLean(2002) A. Scherer e A. McLean. Mathematical models of vaccination. British Medical Bulletin, 62(1):187-199. Citado na pág. xix, xxi, 86, 90

Schwartz et al.(2005) I. B. Schwartz, L. B. Shaw, D. A. T. Cummings, L. Billings, M. McCrary e D. S. Burke. Chaotic desynchronization of multistrain diseases. Physical Review E, 72(6):066201. Citado na pág. xviii, xxi

Shrestha et al.(2011) S. Shrestha, A. A. King e P. Rohani. Statistical inference for multi-pathogen systems. PLoS computational biology, 7(8):e1002135. Citado na pág. 40, 85

Sotomayor(1979) Jorge Sotomayor. Lições de equaçôes diferenciais ordinárias, volume 11. Instituto de Matemática Pura e Aplicada, CNPq. Citado na pág. 22, 23, 27, 33, 39, 40, 85, 86, 91

Souto-Maior et al.(2015) C. Souto-Maior, J. S. Lopes, E. Gjini, C. J. Struchiner, L. Teixeira e M. G. M. Gomes. Heterogeneity in symbiotic effects facilitates wolbachia establishment in insect populations. Theoretical ecology, 8(1):53-65. Citado na pág. xviii, xx

Souto-Maior(2017) Caetano Souto-Maior. Model-based inferences in host-pathogen-symbiont interactions. Implications for the design of experimental and observational studies. Tese de Doutorado, Instituto de Tecnologia Química e Biológica António Xavier, Universidade Nova de Lisboa. Citado na pág. $\mathrm{xx}, \mathrm{xxii}, 19,23$

Stocks et al.(2017) T. Stocks, T. Britton e M. Höhle. pomp-Astic inference for epidemic models: Simple vs. complex. bioRxiv, página 125880. Citado na pág. 40, 42

Teixeira et al.(2013) M. G. Teixeira, J. B. Siqueira Jr, Germano L. C. Ferreira, L. Bricks e G. Joint. Epidemiological trends of dengue disease in Brazil (2000-2010): a systematic literature search and analysis. PLoS neglected tropical diseases, 7(12):e2520. Citado na pág. xvii, xviii, 6, 27

Thomé et al.(2010) R. C. A. Thomé, H. Mo Yang e L. Esteva. Optimal control of Aedes aegypti mosquitoes by the sterile insect technique and insecticide. Mathematical Biosciences, 223(1): 12-23. Citado na pág. xx, 85 
Torresi et al.(2017) J. Torresi, G. Ebert e M. Pellegrini. Vaccines licensed and in clinical trials for the prevention of dengue. Human vaccines \& immunotherapeutics, 13(5):1059-1072. Citado na pág. xix, 15,27

van den Driessche e Watmough(2002) P. van den Driessche e J. Watmough. Reproduction numbers and sub-threshold endemic equilibria for compartmental models of disease transmission. Mathematical biosciences, 180(1-2):29-48. Citado na pág. 33, 34, 83, 89

van den Driessche(2017) Pauline van den Driessche. Reproduction numbers of infectious disease models. Infectious Disease Modelling, 2(3):288-303. Citado na pág. 33, 83, 88, 89

Villela et al.(2017) D. A. M. Villela, L. S. Bastos, L. M. De Carvalho, O. G. Cruz, M. F. C. Gomes, B. Durovni, M. C. Lemos, V. Saraceni, F. C. Coelho e C. T. Codeço. Zika in Rio de Janeiro: Assessment of basic reproduction number and comparison with dengue outbreaks. Epidemiology ES Infection, 145(8):1649-1657. Citado na pág. xvii, xxi, 33

Vynnycky e White(2010) E. Vynnycky e R. White. An introduction to infectious disease modelling. Oxford University Press. Citado na pág. 1, 19, 22, 83

Wang et al.(2017) L. Wang, H. Zhao, S. M. Oliva e H. Zhu. Modeling the transmission and control of Zika in Brazil. Scientific reports, 7(1):7721. Citado na pág. xvii, xx

Wearing e Rohani(2006) H. J. Wearing e P. Rohani. Ecological and immunological determinants of dengue epidemics. Proceedings of the National Academy of Sciences, 103(31):11802-11807. Citado na pág. xviii, xxi

Werren(1997) John H. Werren. Biology of wolbachia. Annual review of entomology, 42(1):587609. Citado na pág. xviii, $\mathrm{xx}$

White et al.(2007) L. J. White, J. N. Mandl, M. G. M. Gomes, A. T. Bodley-Tickell, P. A. Cane, P. Perez-Brena, J. C. Aguilar, M. M. Siqueira, S. A. Portes, S. M. Straliotto et al. Understanding the transmission dynamics of respiratory syncytial virus using multiple time series and nested models. Mathematical biosciences, 209(1):222-239. Citado na pág. xx, 40, 85

Wikramaratna et al.(2010) P. S. Wikramaratna, C. P. Simmons, S. Gupta e M. Recker. The effects of tertiary and quaternary infections on the epidemiology of dengue. PloS one, 5(8):e12347. Citado na pág. xxii, 19

Wilder-Smith e Massad(2016) A. Wilder-Smith e E. Massad. Age specific differences in efficacy and safety for the cyd-tetravalent dengue vaccine. Expert review of vaccines, 15(4):437-441. Citado na pág. xix, xxi, 27

World Health Organization(2017) World Health Organization. World health statistics 2017: monitoring health for the SDGs, sustainable development goals, 2017. Citado na pág. xvii

World Health Organization et al.(2009) World Health Organization, Special Programme for Research, Training in Tropical Diseases, Department of Control of Neglected Tropical Diseases, Epidemic e Pandemic Alert. Dengue: guidelines for diagnosis, treatment, prevention and control. World Health Organization. Citado na pág. xviii, xix, xx, 1, 18, 27

Yang(2001) Hyun Mo Yang. Epidemiologia Matemática: Estudo dos efeitos da vacinação em doenças de transmissão direta. Editora da UNICAMP. Citado na pág. $\mathrm{xx}, 83,85,86,88$ 